The functional role of B cells and their secreted antibodies in transplantation and cancer 
(C) Thomas H.P.M. Habets, Maastricht, the Netherlands 2017.

All rights reserved. No part of this book may be reproduced, stored in a retrieval system of any nature, or transmitted in any form or by any means (electronic, mechanical, photocopying, recording or otherwise) without prior written permission of the author, or when appropriate, by the publishers of the publications.

ISBN: $\quad$ 978-90-8559-270-9

Cover art: Thomas H.P.M. Habets

Layout: $\quad$ Thomas H.P.M. Habets, Wouter F.C.J. Habets

Figures: $\quad$ Thomas H.P.M. Habets

Production: Optima Grafische Communicatie, Rotterdam, the Netherlands 


\title{
The functional role of B cells and their secreted antibodies
}

\author{
in transplantation and cancer
}

\section{DISSERTATION}

\author{
to obtain the degree of Doctor at Maastricht University, \\ on the authority of the Rector Magnificus, Prof. dr. Rianne M. Letschert, \\ in accordance with the decision of the Board of Deans, \\ to be defended in public
} on Wednesday March 22 ${ }^{\text {nd }}, 2017$ at 10:00 hours by 


\section{Supervisors}

Prof. dr. G.M.J. Bos

Prof. dr. M.G.J. Tilanus

\section{Co-supervisor}

Dr. J. Vanderlocht

\section{Assessment Committee}

Prof. dr. M.H.V. de Baets (Chairman)

Prof. dr. N. Hellings, Hasselt University, Hasselt, Belgium

Prof. dr. B.W.W. Kramer

Prof. dr. K.M.L. Leunissen

Dr. H. Otten, Utrecht University, Utrecht 
'A man who dares to waste one hour of time has not discovered the value of life.' (Charles Darwin) 



\section{TABLE OF CONTENTS}

Chapter 1 General introduction 9

Chapter 2 The development of Rhesus-D (RhD) antibodies after RhD 65 incompatible kidney transplantation in a setting of reduced immunosuppression

Chapter 3 The prevalence of antibodies against the HLA-DRB3 protein in kidney transplantation and the correlation with HLA expression

Chapter 4 The dynamics of serum free light chain (sFLC) immunoglobulin (Ig) 107 normalization after kidney transplantation

Chapter 5 Fractionated radiotherapy with $3 \times 8$ Gy induces systemic antitumour responses and abscopal tumour inhibition without modulating the humoral anti-tumour response

Chapter 6 The JAK1 and JAK2 inhibitor ruxolitinib inhibits the activation and 163 proliferation of polyclonally stimulated peripheral B cells

Chapter 7 Serum free light chain immunoglobulins (sFLC Igs) do not modulate the activation and proliferation of polyclonally stimulated $B$ cells and T cells

Chapter 8 General discussion

Chapter 9 Summary

Samenvatting

Chapter 10 Valorisation

Appendix A List of abbreviations

B Acknowledgements (Dankwoord)

C List of publications

D Curriculum vitae

E Notes 


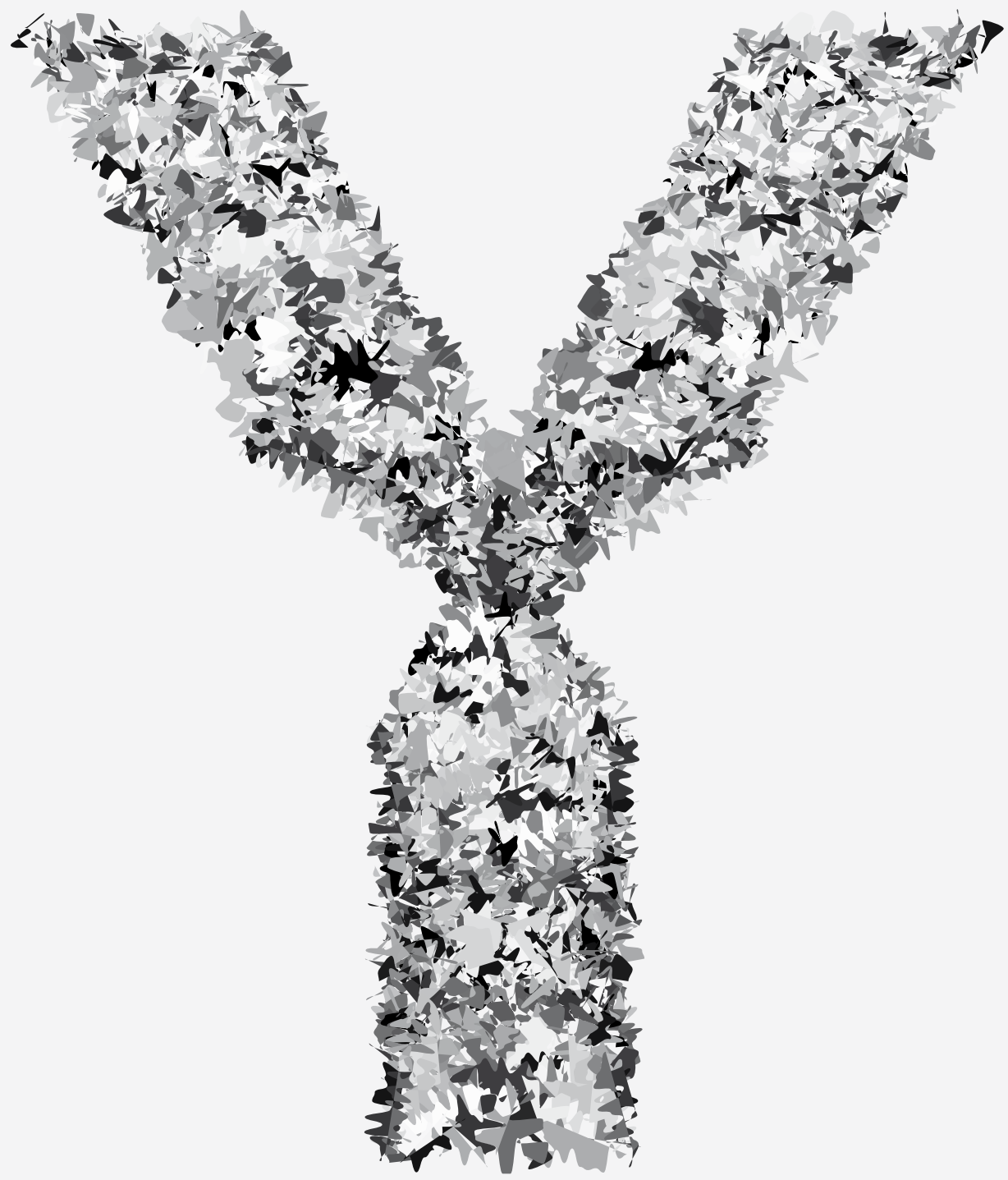




\section{CHAPTER}

\section{General introduction}

B cells and antibodies in general

Renewed interest in B cells and antibodies

B cells and antibodies in blood diseases

B cells and antibodies in organ transplantation

Scope of the thesis 



\section{B CELLS AND ANTIBODIES IN GENERAL}

\section{History of B cells}

B cells, also named B (bursal or bone marrow-derived) lymphocytes are a population of cells expressing clonally diverse immunoglobulin (Ig) receptors on the cell surface, which are able to recognize specific antigenic epitopes ${ }^{1}$. Only the landmark findings will be described in this paragraph. In 1890, the first clear functional identification of cells that we now classify as B cells came with the discovery of circulating antitoxins (e.g. Igs or antibodies) to diphtheria and tetanus ${ }^{2}$. Nevertheless, the real launching point for the discovery of cells that produce antibodies started after the identification of serum gammaglobulin in $1938^{3}$. Ten years later, plasma cells or terminally differentiated B cells were suggested to be a source of antibody production ${ }^{4}$. In the 1950s', Niels Jerne ${ }^{5}$ and Macfarlane Burnet ${ }^{6}$ proposed their competing interpretations of antibody formation: the 'natural selection' theory and 'clonal selection' theory. Shortly thereafter, experimental evidence supported the 'clonal selection' theory based on examining single cells ${ }^{7}$. In the early 1960s, Gerald Edelman and Rodney Porter reported the chemical structure of the antibody molecule and gamma-globulin ${ }^{8,9}$. Though, in the mid-1960s and early 1970s, the identity and characterization of B cells was further determined by animal models, clinical examination of patients with immune deficiencies, and technology to clarify the expression of cell surface molecules. For example, in chickens, the cells that were responsible for antibody production were discovered in the bursa of Fabricius 10,11. Furthermore, murine transplantation models revealed that cells derived from the bone marrow facilitated antibody responses ${ }^{12,13}$. Furthermore, membrane-bound Ig expression (e.g. B cell receptor), complement component receptors, and Fc receptors could be used to distinguish normal and leukemic B cells ${ }^{14,15}$. In the 1980s, Susumu Tonegawa described the combination rearrangement of the $\mathrm{V}$ (variable), D (diversity), and J (joining) gene segments in the $\mathrm{H}$ (heavy) chain locus and the $\mathrm{V}$ and $\mathrm{J}$ gene segments in the $\mathrm{L}$ (light) chain locus ${ }^{16}$. Importantly, David Baltimore et al. discovered the recombination-activating gene 1 (RAG1) and $R A G 2$, which encode enzymes crucial for $\bigvee(D) J$ recombination ${ }^{17,18}$. A decade later Honjo et al. showed that class switch recombination (CSR; first revealed in the chicken) and somatic hypermutation (SHM) were mediated by an enzyme called activation-induced cytidine deaminase (AID) ${ }^{19,20}$. In the last 25 years, approximately ten specific B cell surface markers have been identified using monoclonal antibodies (mAbs). The first specific molecule for $B$ cells was named B1 described in 1980 by Nadler et al., which is now classified as CD20 (cluster 


\section{Chapter 1}

of differentiation) ${ }^{21}$. At present, many complexities in B cell development, various subsets, and functions are unfolded. Although these studies resulted in a significant understanding of $B$ cells, there is much more to learn about the biology, regulation, and functions of B cells and their secreted products in health and disease.

\section{Development of B cells}

The human B cell development has been significantly studied and the process of functional rearrangement of the Ig loci is fundamental ${ }^{22}$. The B cells arise initially from the fetal liver and then from hematopoietic stem cells (HSCs) in the adult bone marrow. The HSCs first differentiate in multipotent progenitor cells (MPP), and subsequently in common lymphoid progenitor cells (CLP) ${ }^{23}$. The initial steps of B cell lineage commitment comprise of gene rearrangements at the $\mathrm{Ig} \mathrm{H}$ and $\mathrm{L}$ chain loci and the expression of 'key' transcription factors such as Pax5 (and E2A) ${ }^{24,25}$. The combinatorial rearrangement of the $V, D$, and $J$ segments in the $\mathrm{H}$ chain locus and the $\mathrm{V}$ and $\mathrm{J}$ segments in the $\mathrm{L}$ chain loci generates a diverse repertoire of functional $V D J_{H}$ and $\mathrm{VJ}_{L^{\prime}}$, which encode the $\mathrm{B}$ cell receptor $(\mathrm{BCR})^{26,27}$. The $R A G 1-2$ genes are responsible for the initial stages of DNA strand breakage in the BCR rearrangement.

The B cells can be separated in B1 (immature) and B2 (mature) lineage cells, which have individual but also overlapping roles in humoral immunity ${ }^{28,29}$. The B1 population, which originates from fetal liver and bone marrow cells, is mainly found in peritoneal and pleural cavities, but is also observed in the spleen. The B1 cells are capable of self-renewal and produce low-affinity natural antibody (IgM) independent of T cell help to provide innate immunity ${ }^{28-31}$. On the other hand, the majority of B cells are B2 cells, which originates from the bone marrow, and develop (mature) further in the periphery (spleen and lymph nodes). These B2 cells are T cell dependent and generate high affinity antibodies (IgG) to provide adaptive immunity $22,32,33$.

Importantly, the B cell identity is characterized by the expression of a functional BCR, however B1 cells display a restricted VDJ rearrangement (particularly VJ $\left.{ }_{H}\right)^{34-37}$. In contrast, the bone marrow-derived B2 cells experience sequential steps of VDJ recombination: (1) pro-B cells comprising of stages pre-pro B cells (germline Ig loci) followed by pro-B cells (D-J $J_{H}$ and $V_{H}-D J_{H}$ rearrangement); (2) pre-B cells comprising of stages large pre- $B$ cells $\left(V_{H} D J_{H}\right.$ pairs a surrogate light chain $\lambda 5$-Vpre-B) followed by small pre-B cells (Pre-BCR surface expression, critical for further B cell differentiation); (3) immature bone marrow-derived B cells (L chain rearrangement to form a complete $B C R)^{17,33,38-40}$. To ensure correct $B$ cell development, the 
$B$ cells undergo positive selection through antigen-independent signaling via the pre-BCR and BCR. In case the (pre)-BCR do not bind to their ligand, the development will discontinue. Afterwards, the BCR is subjected to self-antigens defined as negative selection. When the BCR shows a strong binding to self-antigens, these B cells undergo clonal deletion, receptor editing, anergy, or ignorance ${ }^{1,41}$. The negative selection process (only $10 \%$ passes) provides a state of central tolerance, in which $B$ cells do not react with self-antigens ${ }^{42,43}$.

After reaching the immature B2 stage, these B2 cells will leave the bone marrow and enter the circulation as transitional (TR) B cells, which are further divided in T1, T2, and T3 subsets ${ }^{44-46}$. These TR cells are found in the blood and spleen, and are the last stage before these cells (only $30 \%$ passes due to tonic BCR signaling) develop into mature follicular B cells (recirculation in blood and secondary lymphoid organs) or marginal zone B subsets (home to marginal zone of the spleen) ${ }^{47,48}$. Once further differentiated they are considered mature $B$ cells, or naïve B cells.

\section{Activation and function of B cells}

The BCR ligation initiates downstream signaling pathways to activate the B cell. Though, the specific humoral immune response that is mounted is affected by the type of antigen, the $B$ cell subset, the avidity of BCR crosslinking, and intracellular interactions. Generally, a proper $B$ cell response requires BCR ligation (signal 1) and subsequent activation and differentiation via other cells and/or molecules (signal 2) ${ }^{49}$. There are two humoral responses based on the second signal: (1) thymus-dependent (TD) responses, in which antigen presenting $B$ cells are supported by CD4+ (helper) T cells; or (2) thymus-independent (TI) responses, in which B cells are supported by self-expressing innate receptors such as Toll-like receptors (TLRs), or through a powerful BCR crosslinking. In these two responses, especially (follicular) B2 cells are major contributors to TD responses, while B1 or B2 cells (marginal zone) are contributors to $\mathrm{TI}$ responses. In addition, the TI responses are short and display IgM production, whereas the TD responses are prolonged and show CSR of IgG isotypes (increased antibody affinity). Both responses generate long-lived memory B cells and plasma cells, however TD responses are significantly more robust 22 .

TI responses are initiated within days, with substantial numbers of plasma cells in splenic extrafollicular regions ${ }^{50,51}$. The produced antibodies are mainly IgM with low affinity for antigen. After 2 to 3 weeks most of these plasma cells die, however some differentiate into long-lived plasma cells and memory B cells ${ }^{52,53}$. In addition, a fraction of the B1 cells are 


\section{Chapter 1}

constantly activated and produce natural polyreactive antibodies of the $\lg M$ and IgA isotype. These antibodies bind to pathogens and commensals, but also to self-components such as cellular debris ${ }^{31,54}$. The B1 cells are suggested to be 'innate-like' due to their limited $1 g_{H}-\lg _{L}$ variable regions and their ability to serve as barrier and maintain house-keeping functions.

In the first days, TD responses show also substantial numbers of plasma cells (splenic extrafollicular regions) that produce low affinity $\operatorname{lgM}$ antibodies. However, after a few days germinal centers (GCS) arise, which are clusters of proliferating $B$ cells that are located at the borders of B cell follicles and T cell zones in the spleen and lymph nodes ${ }^{55,56}$. In these GCs, the TD response further evolves by means of antigen affinity maturation and the formation of long-lived memory B cells and plasma cells. The development of GCs needs several signals of activated CD4+ T cells and antigen presenting B cells. In general, key signals include HLA class II restricted presentation by B cells, co-stimulation via CD40-CD40L, and cytokine IL-21 57. The interactions induce transcriptional programing of GC B cells mainly via $B C L-6$. As a consequence, the enzyme AID is activated, which makes point mutations in the Ig $\mathrm{V}$ regions. This process is called SHM and results in the generation of diverse variants of GC B cells with an altered antigen affinity and specificity ${ }^{20,58,59}$. After selective competition and survival, only variants with a high antigen affinity are preserved. In addition, AID also mediates CSR with the aim to generate Ig isotypes with higher affinity such as IgG (upon CSR e.g. IgM switches to an $\lg \mathrm{G}$ isotype) ${ }^{20,60}$. Current models suggest that $\mathrm{GC}$ light zones contain antigen competition and CD4+ T cell survival factors, while proliferation and SHM occurs in GC dark zones ${ }^{57}$.

Humoral responses, especially TD responses are able to generate long-lived memory B cells and plasma cells. The long-lived plasma cells can persist for a lifetime in an organism, however the precise mechanism of their longevity remains an area for further research. The commitment of mature B cells to plasma cells (terminally differentiated B cells) requires the expression of B lymphocyte induced maturation protein 1 (Blimp1). Blimp1 reduces the gene expression of mature $B$ cells, and starts the transcriptional programing of plasma cells by repression of $B C L-6$ and Pax5 and by upregulation of $X b p 1^{61-64}$. These long-lived plasma cells migrate to the bone marrow where they generate stable and high levels of antibodies throughout the lifetime of the host ${ }^{65,66}$. In contrast, the clonal expansion of antigen-specific memory B cells occurs long after the immunological encounter. These cells are generated in GCs, but studies reported also GC-independent memory B cell generation ${ }^{67}$. Importantly, these memory $B$ cells are less dependent on (CD4+) T cells for their reactivation and remain in the host at increased levels ${ }^{68}$. In addition, these $B$ cells can rapidly divide (enter the cell 
cycle), since they have a reduced BCR threshold ${ }^{69,70}$.

\section{Antibody structure}

Antibodies also called Igs are heterodimeric proteins that consist of two heavy $(H)$ chains and two light $(L)$ chains, where the $L$ chains can consist of either a kappa $(K)$ or lambda $(\lambda)$ isotype ${ }^{71,72}$ (Figure 1). During Ig synthesis, B cells and plasma cells demonstrate 10 to $40 \%$ overproduction of $\mathrm{L}_{\text {chains }}{ }^{73}$. In contrast, the $\mathrm{H}$ chains are not overproduced since these will e.g. accumulate in Russel bodies (intracellular inclusions filled with Ig aggregates) of plasma cells, which may result in apoptosis ${ }^{74}$. When the overproduced $L$ chains are secreted in the serum, these are defined as serum free light chain immunoglobulins (sFLC Igs). The k sFLC Igs are monomeric and $\pm 25 \mathrm{kDa}$, and $\lambda$ sFLC Igs are mainly dimeric and $\pm 50 \mathrm{kDa}{ }^{75,76}$.

With regard to a complete antibody, each component chain has one variable $(V)$ and one or more constant $(C)$ domains that are connected via a disulphide bridge between two conserved cysteine residues ${ }^{77}$. The $\mathrm{L}$ chains $( \pm 25 \mathrm{kDa}$ ) have one $\mathrm{C}$ domain, whereas $\mathrm{H}$ chains contain either three or four of these domains. The $\mathrm{H}$ chains with three $\mathrm{C}$ domains contain a spacer hinge region between the first $\left(C_{H} 1\right)$ and second $\left(C_{H} 2\right)$ domain $( \pm 55 \mathrm{kDa})$. Altogether, the complete antibody (e.g. IgG) has a molecular mass of $\pm 150 \mathrm{kDa}$.

The Fab (fragment antigen-binding) region consists of one entire $L$ chain and the $V_{H}$ and $C_{H} 1$ region of the $H$ chain. The Fab region can be further divided in variable $V_{L}$ and $V_{H}$ domains and constant $C_{L}$ and $C_{H} 1$ domains. The $V_{L}$ and $V_{H}$ domains are created by a complex sequence of gene rearrangements. To this end, both the $H$ and $L$ chains are encoded by a different multigene family, and each $V$ and $C$ domain is encoded by independent $V(D) J$ gene segments for the $V_{H}(V D J)$ and $V_{L}(V J$, no $D)$, and individual exons for the $C$ domains ${ }^{27,78}$. The initiation of $\mathrm{V}(D) \mathrm{J}$ rearrangement requires the $R A G 1 / 2$ genes encoding enzymes that are only expressed in developing lymphocytes (e.g. B cells) ${ }^{79}$. Importantly, the $V$ domains consist of three complementarity-determining regions (CDRs) and four framework regions. The three CDRs of the $\mathrm{H}$ chain pair with the three CDRs of the $\mathrm{L}$ chain which form the antigen binding site. In this way, the antigen binding site is a product of $V(D) J$ rearrangements resulting in a large diversity. After exposure to antigen, the $\mathrm{V}$ domain genes of GC B cells are subjected to somatic hypermutation (SHM) with support of CD4+ T cells. This mechanism allows antibody affinity maturation in response to repeated exposure to antigen ${ }^{80}$.

The Fc (fragment crystallizable) region consists of the $\mathrm{C}_{\mathrm{H}} 2$ and $\mathrm{C}_{\mathrm{H}} 3$ (or $\mathrm{C}_{\mathrm{H}} 4$, only IgM, $\operatorname{lgE}$ ) and is essential for various effector functions such as Fc receptor (FcR) and complement 


\section{Chapter 1}

binding. Immune cells such as NK cells with FcRs bind to the $\mathrm{C}_{H} 3$ region and complement $\mathrm{C} 1 \mathrm{q}$ binds to the $\mathrm{C}_{\mathrm{H}} 2$ region of the antibody ${ }^{81,82}$. There are five $\mathrm{C}$ domain classes of the $\mathrm{H}$ chain, stated as $\lg M(\lg \mu), \lg G(\lg \gamma), \lg A(\lg \alpha), \lg D(\lg \delta)$, and $\lg E(\lg \varepsilon)$. The $\mathrm{C}$ domains of the $\mathrm{H}$ chains (Fc region) can alter while maintaining their antigen specificity (Fab region is not changed). The switching of these $\mathrm{C}$ domains is called class switch recombination (CSR) and occurs after e.g. cytokine release of T cells ${ }^{83}$. In this way, the specific biological properties of an antibody can change upon CSR (e.g. IgM can switch into IgG after T cell-help). The enzyme activationinduced cytidine deaminase (AID) plays a crucial role in facilitating both SHM and CSR ${ }^{79,84}$.
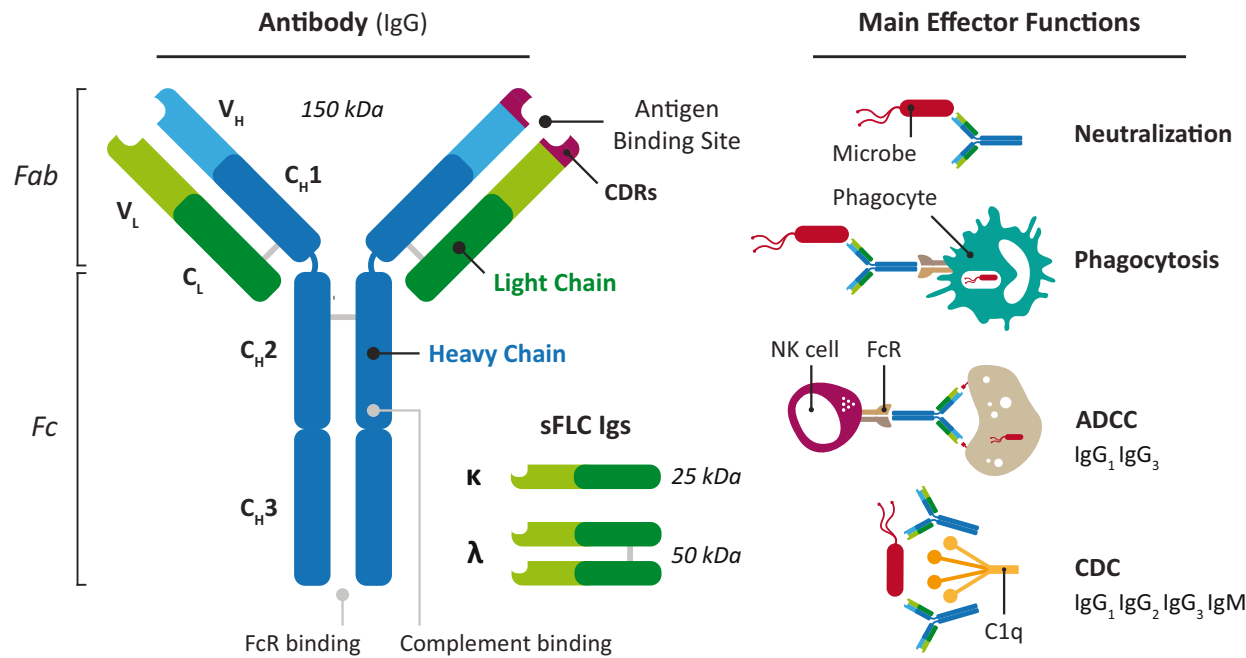

Figure 1: Schematic representation of the antibody (Ig) structure and their main effector functions. An antibody (e.g. IgG $\pm 150 \mathrm{kDa}$ ) consists of two heavy $(\mathrm{H})$ chains and two light $(\mathrm{L})$ chains. Each $\mathrm{H}$ chain has three constant (C) domains $\left(C_{H} 1-3\right)$ and one variable $(V)$ domain $\left(V_{H}\right)$. And each light chain has one $C$ domain $\left(C_{L}\right)$ and one $V$ domain $\left(V_{L}\right)$. The $V_{H}$ and $V_{L}$ contain $V(D) J$ gene segments containing the CDRs, which form the antigen binding site. The Fab region consists of one entire $L$ chain and the $V_{H}$ and $C_{H} 1$ domain. And the Fc region consists of $C_{H} 2$ (complement) and $C_{H} 3$ (FcR binding). L chains that are secreted in serum are called sFLC Igs and are either kappa ( $\mathrm{k} ; \pm 25 \mathrm{kDa}$ ) or lambda ( $\lambda$; $\pm 50 \mathrm{kDa}$ ). The main effector functions of Igs include neutralization and opsonization followed by phagocytosis (e.g. macrophages), ADCC (e.g. NK cells using their FcR), and CDC (C1q followed by the complement cascade).

\section{Antibody isotypes and effector functions}

In humans, antibodies are divided in five isotypes (IgM, IgG, $\lg A, \lg D$, and $\lg E$ ) based on the $\mathrm{H}$ chains and these Ig isotypes differ in biological function, functional location, and ability to deal with antigens. Moreover, $\lg G$ can be divided in four subclasses $\lg G_{1}, \operatorname{lgG}_{2}, \operatorname{lgG}_{3}, \operatorname{lgG}_{4} 85,86$, and $\lg A$ can be divided in two subclasses $\lg \mathrm{A}_{1}$ and $\lg \mathrm{A}_{2}{ }^{87}$. In mice, only the $\lg \mathrm{G}$ subclasses are different: $\lg _{1}, \lg G_{2 a^{\prime}} \lg G_{2 b^{\prime}}, \operatorname{lgG}_{2 c^{\prime}}$ and $\lg G_{3}$. The main effector functions of antibodies (Igs) 
are neutralization, opsonization and phagocytosis of microbes, antibody-dependent cellular cytotoxicity (ADCC) via e.g. NK cells, and complement-dependent cytotoxicity (CDC) via C1q activation (Figure 1). However, specific therapeutic antibodies can also block and/or activate receptors (signaling), target cells to deliver immunocytokines, small molecules, toxins and/ or radionuclides.

IgM $( \pm 970 \mathrm{kDa})$. IgM is the first Ig that is expressed on the cell surface of B cells. Naïve B cells express monomeric IgM, which is associated with CD79a and CD79b for proper cell signaling. This complex of $\operatorname{IgM}$ and $\operatorname{CD} 79(\mathrm{a}, \mathrm{b})$ is called the $\mathrm{B}$ cell receptor (BCR) and crucial for $B$ cell survival ${ }^{88-90}$. After antigenic recognition and maturation, multimeric (pentameric) IgM is secreted ${ }^{91}$. These IgM antibodies have a low affinity, but high avidity by means of multiple interactions of the pentameric structure with antigens. Due to this property, IgM neutralizes antigens, which are removed via e.g. complement (C1q) fixation ${ }^{92,93}$. These IgM antibodies also called natural antibodies are associated with a primary immune response or are a first line of defence against antigens, since IgM is early expressed in B cell development and the $V_{H}$ and $V_{L}$ regions are not subjected to substantial SHM ${ }^{71,94,95}$. In this way, the IgM antibodies are more polyreactive than other isotypes resulting in a rapid response to multiple antigens.

IgG $( \pm 150 \mathrm{kDa})$. IgG is the most frequent Ig isotype ( $\pm 10-20 \%$ of plasma protein) that is found in the human body ${ }^{86}$. Based on the $\mathrm{H}$ chain regions $\mathrm{C}_{\mathrm{H}} 1$ and $\mathrm{C}_{\mathrm{H}} 3$ and functional differences, 4 subclasses ( $\left(g G_{1}, \operatorname{lgG}_{2}, \operatorname{lgG}_{3}, \lg _{4}\right)$ were identified. The $\lg G$ subclasses have the longest serum half-life of all Ig isotypes and their rank was determined based on the serum level in healthy individuals $\left(\lg G_{1}>\lg G_{2}>\lg G_{3}>\lg G_{4}\right)$. ${ }^{85}$. The $\lg G$ subclasses have various biological activities such as complement activation after neutralization and opsonization of pathogens. To this end, only $\lg _{4}$ is not ably to fix complement component $\mathrm{C} 1 \mathrm{q}$, whereas the other $\lg \mathrm{G}$ subclasses fix $\mathrm{C} 1 \mathrm{q}$ to $\mathrm{C}_{H} 2$, but differ in their strength to activate the complement cascade $\left(\lg G_{3}>\lg G_{1}>\mid g G_{2}\right)$ 96. The activation of complement via these antibodies is defined as CDC.

The $\mathrm{C}_{\mathrm{H}} 3$ region of the IgG subclasses is important for FcyR (class I, II, and III) binding. $\operatorname{lgG}_{1}$ and $\operatorname{lgG}_{3}$ bind to all FcyR classes, while $\operatorname{lgG}_{4}$ only binds to FcyRII and FcyRIII, and IgG only to FcyRII ${ }^{97,98}$. Notably, $\operatorname{lgG}_{4}$ and $\lg G_{2}$ display significant weaker binding as compared to $\lg _{1}{ }^{86}$. The binding of FcyRs is a key function of IgG antibodies, since this initiates ADCC ${ }^{99}$. Immune cells such as NK cells, macrophages, and DCs express different levels of these FcyRs and bind to antibody-coated antigen, which results in eradication of these antigens ${ }^{100,101 .}$ 


\section{Chapter 1}

The IgG subclasses are mainly present during the secondary antibody response, as B cells that produce primary IgM antibodies will undergo CSR with the help of T cells. There is also skewing in the $\lg G$ subclass that is induced, since $\lg G_{1}$ and $\lg G_{3}$ are generally associated with protein antigens, whereas $\operatorname{lgG}_{2}$ and $\operatorname{lgG}_{4}$ are associated with polysaccharide antigens ${ }^{71}$. The $\lg G$ subclasses in mice $\left(\lg G_{1}, \operatorname{lgG}_{2 a^{\prime}} \lg G_{2 b^{\prime}}, \lg G_{2 c^{\prime}} \lg G_{3}\right)$ display different effector functions as compared to humans. The murine $\lg G$ subclasses $\lg _{2 a}$ and $\operatorname{lgG}_{2 b}$ are potent in both $A D C C$ and $C D C$, whereas $\lg _{3}$ is potent in $A D C C$ but less effective in $C D C$, and $\lg _{1}$ does not display ADCC but low CDC. When translating the murine (mu) effector functions to the human (hu) IgG subclasses, these can be summarized as follows: hu $\operatorname{lgG}_{1}$ vs. mu $\lg _{2 a}$ (complement and bind protein antigens), hu $\operatorname{lgG}_{3}$ vs. $\mathrm{mu}_{\lg } \mathrm{g}_{2 \mathrm{~b}}$ (complement and bind protein antigens), hu $\operatorname{lgG}_{4}$ vs. $m u \operatorname{lgG}_{1}$ (bind carbohydrate antigens).

IgA $( \pm 160 \mathrm{kDa})$. The IgA levels are higher than IgM, but significantly lower than IgG. Though, the IgA levels are considerable higher at mucosal surfaces and secretions such as saliva and breast milk as compared to $\operatorname{lgG}{ }^{102}$. IgA is monomeric in serum, but $\lg A$ at the mucosa called secretory $\lg A(s \lg A)$ is dimeric. The two subclasses of $\lg A\left(\lg A_{1}\right.$ and $\left.\lg A_{2}\right)$ differ mainly in their hinge regions ${ }^{103}$. IgA has an elongated hinge region increasing the sensitivity for bacterial proteases ${ }^{104,105}$. IgA antibodies are important for the protection of mucosal surfaces from bacteria, viruses, and toxins via neutralization, opsonization, and complement activation ${ }^{87}$.

IgD $( \pm 180 \mathrm{kDa})$. IgD antibodies are present at very low levels in the serum (short serum halflife). The exact function of IgD antibodies is unclear, since there is no data of participation in antibody effector mechanisms ${ }^{106,107}$. However, IgD that is expressed on the surface of B cells is comparable to $\lg \mathrm{M}$, where $\operatorname{IgD}$ is associated with CD79a and CD79b for cell signaling. IgD is expressed on B cells that leave the bone marrow (TR B cells) and re-populate in secondary lymphoid organs (mature B cells) ${ }^{108}$. These IgD+ B cells co-express IgM and both participate in BCR signaling ${ }^{109,110 .}$

IgE ( $\pm 190 \mathrm{kDa}$ ). IgE antibodies show the lowest serum level (shortest half-life). These potent antibodies are associated with allergic and hypersensitivity reactions, and parasitic worm infections ${ }^{111-113}$. IgE has an exceptionally high affinity for the FcERIs, which are expressed on specific immune cells such as mast cells, basophils, and eosinophils ${ }^{114-116}$. Furthermore, IgE antibodies can upregulate the FcعRI expression on these particular cells ${ }^{117}$. In addition to the 
binding of a complete IgE antibody, also sFLC Igs (IgE) are able to bind and activate mast cells followed by their degranulation ${ }^{118}$.

\section{RENEWED INTEREST IN B CELLS AND ANTIBODIES}

Since 1890, research has been conducted to clarify the role of B cells and antibodies in the immune system of healthy and diseased individuals. Most discoveries and characterizations of B cells and their secreted products occurred from the mid-1960s till the 1990s. Nowadays, there is a renewed interest in B cells and their antibodies, since antibody-based therapy has become one of the most important strategies to treat cancer patients. In addition, the role of tumour-infiltrating B cells (TIB) remains controversial, and the identification of regulatory $B$ cells (Bregs) in cancer, autoimmunity, and inflammation may assist to improve treatment strategies. Furthermore, conventional therapies such as radiotherapy and chemotherapy are combined with novel immunotherapeutic approaches to enhance the patient's own immune system to overcome cancer.

\section{Antibody therapy}

To date, the clinical potential of monoclonal antibodies has grown significantly with over 50 antibodies approved for human therapy and every year novel antibodies are evaluated in clinical trials (Phase III) for many diseases such as cancer, autoimmunity, inflammation, and organ transplantation ${ }^{119,120}$. The hybridoma technology that was established in 1975 made it possible to produce large amount of monoclonal antibodies in mice targeting specific cell surface antigens ${ }^{121}$. Nevertheless, these antibodies from mouse origin were immunogenic in humans, had a short half-life, and were not able to induce suitable human immune effector functions ${ }^{122,123}$. Subsequent advances in antibody engineering made it possible to generate chimeric and humanized monoclonal antibodies (mid-1980s, antibodies of rodent origin) ${ }^{124}$. Nowadays, most monoclonal antibodies that enter clinical trials are of human origin, which are derived from large phage display libraries (expression of human antibody fragments) ${ }^{120}$. Although, these human monoclonal antibodies are usually complete IgG antibodies, various other approaches for antibody construction have been evaluated such as bispecifics, loaded nanoparticles, and single-chain variable fragments. The antibodies can recognize glycolipids, glycoproteins, carbohydrates, growth signals, and hematopoietic- or angiogenic antigens ${ }^{125}$. In cancer, monoclonal antibodies such as rituximab (anti-CD20) ${ }^{126,127}$, trastuzumab 


\section{Chapter 1}

(anti-HER2) ${ }^{128,129}$, and cetuximab (anti-EGFR) ${ }^{130,131}$ target tumour-associated antigens that are mostly overexpressed on tumour cells. The antibodies (dependent on the Ig isotype) are able to induce immune-mediated tumour cell killing via several mechanisms including ADCC, CDC, neutralization, opsonization, and/or phagocytosis ${ }^{123}$. Additionally, these antibodies can inhibit important enzymes, block or stimulate receptors, deliver immunocytokines, toxins, or radioisotopes, or can be used for tumour imaging purposes ${ }^{125}$. Currently, there is increased interest in a different group of monoclonal antibodies called immune checkpoint inhibitors, which block inhibitory signals including CTLA-4 (cytotoxic T-lymphocyte-associated protein 4) 132 expressed on T cells (ipilimumab ${ }^{133}$ ), and PD-L1 (programmed death-ligand 1 ) expressed on tumour cells and tumour-infiltrating DCs and macrophages ${ }^{134}$. The blockade of CTLA-4 on T cells and PD-L1 on tumour cells removes inhibitory signals, thereby maintaining proper T cell activity to kill tumour cells.

In autoimmunity and inflammation, the first therapeutic antibody for inflammation in Crohn's disease was infliximab (anti-TNF) in $1998^{135}$. In the last decade second generation human(ized) TNF antibodies were developed such as etanercept, adalimumab, certolizumab, and golimumab ${ }^{136}$. These TNF antibodies are the most successful class of drugs approved for the treatment of inflammatory diseases such as Crohn's disease, ulcerative colitis, plaque psoriasis, and rheumatoid arthritis ${ }^{122}$. Notably, there are many other antibodies approved or in clinical development that target a wide range of molecules that are involved in different autoimmune- or inflammatory diseases. Importantly, these antibodies show similar effector functions as compared to antibodies used in cancer.

\section{B cells as therapeutic application}

\section{Tumour-infiltrating B cells}

The pro- and anti-inflammatory effects of B cells and antibodies remains controversial in the field of cancer. Although it is not yet feasible to predict in what way B cells affect immunity in a certain tumour, in many human cancers the presence of tumour-infiltrating B cells (TIBS) is correlated with an increased patients' survival ${ }^{137}$. There is less attention for TIBs, since it has been shown that the absolute number of $B$ cells is significantly lower as compared to $T$ cells among the tumour-infiltrating cells ${ }^{138-140}$. To date, the infiltration or the presence of $B$ cells in tumours and/or lymph node metastases is correlated with an improved prognosis in ovarian cancer, colorectal cancer, breast cancer, head and neck cancer, melanoma, and 
other cancers ${ }^{141-145}$. The infiltrated B cells were often colocalised with $T$ cells, probably due to presence of IFN- $\gamma$ in the microenvironment, which can attract $B$ cells via upregulation of CXCR3 (CXC chemokine receptor 3) or VCAM-1 (vascular cell adhesion protein 1) ${ }^{146,147}$. This is supported by a clinical study showing that the prognosis of ovarian cancer improved when both $B$ cells and T cells infiltrated the tumour as compared to T cells only ${ }^{142}$. Furthermore, intratumoural injections of IL-12 (stimulation of IFN- $\gamma$ ) resulted in Th1 associated antibodies $\left(\operatorname{lgG}_{1}\right)^{148}$. The presence of $T$ cells and $B$ cells frequently resemble the organisation of tertiary lymphoid structures, which reflects a location of the anti-tumour immune response. This is consistent with the observation that B cell infiltrates show CSR and SHM, which indicate that these $B$ cells have been maturated and selected to recognize tumour-specific antigens ${ }^{142,149}$. In short, the functional properties of TIBs can be summarized as follows: (1) B cells infiltrate many human tumours, where they produce anti-tumour antibodies (undergo CSR and SHM); (2) TIBs produce several pro- and anti-inflammatory cytokines; (3) TIBs present their tumour antigens to T cells; (4) TIBs induce tertiary lymphoid structures, immune responses; (5) TIBS may promote angiogenesis and tumour promotion; (6) TIBs obtain a regulatory phenotype, also defined as regulatory $B$ cells ${ }^{137}$.

In recent years, a new subset of B cells was identified as regulatory B cells (Breg) and these are major players in the pathogenesis of autoimmune diseases and cancer. The term 'regulatory B cell' was first introduced in 2006, and their effector functions were similar to regulatory $T$ cells (Treg) that produce immunosuppressive cytokines such as IL-10 and TGF- $\beta$, and express inhibitory molecules ${ }^{150,151}$. The first data originated from murine autoimmune models (experimental autoimmune encephalomyelitis (EAE)) where Bregs produce cytokine IL-10 ${ }^{152-154}$. A role of B cells (Bregs) in cancer was established in murine tumour models, which demonstrated decreased tumour growth in case of B cell deficient or B cell depleted mice ${ }^{155,156}$. In subsequent research, these B cells showed to inhibit the anti-tumour effects of T cells and may stimulate CD4+ T cells to convert in Tregs ${ }^{157-160}$. It is suggested that signals from the tumour environment stimulate Breg generation and in turn these Bregs promote tumour growth via their interactions with Tregs, myeloid-derived suppressor cells (MDSC), tumour-associated macrophages (TAM), natural killer (NK) cells, effector T cells, and tumour cells ${ }^{161}$. The tumour-supporting Bregs utilize their suppressive effects via the secretion of immunosuppressive cytokines IL-10 and TGF- $\beta$, but also directly interact with cells via cell death markers (e.g. Fas-L) or co-inhibitory molecules (e.g. PD-L1) ${ }^{161,162}$. These Bregs are able to directly polarize T helper (Th) cells towards Th2 cells and Tregs thereby inhibiting Th1 and 


\section{Chapter 1}

Th17 cells. Additionally, they stimulate anti-inflammatory TAMs (M2) and indirectly inhibit CD8+ T cells and NK cells via MDSCs, TAMs, Th2 cells, and Tregs ${ }^{161,163 .}$

To date, there is a controversy, since several studies suggest that TIBs are protective 164-166, while others indicate that Bregs are increased in patients with solid tumours, which is associated with increased aggressiveness and inferior patients' outcome ${ }^{167-171}$. In lymphoid malignancies, the anti-tumour immune responses are suppressed by malignant B cells that 'perform' as Bregs via the expression of suppressive ligands ${ }^{172-174}$. Notably, Bregs have been identified in various types of solid cancer including colorectal, ovarian, breast, gastric, lung, bladder, hepatocellular, pancreatic, and oesophageal carcinoma ${ }^{161}$.

The Breg population is extensively studied in mouse models for various autoimmune diseases including rheumatic arthritis (RA), autoimmune diabetes, EAE, and systemic lupus erythematous (SLE). Nevertheless, there is limited evidence about the specific role of human Bregs in these autoimmune diseases and cancer. Although, B cells (Bregs) can be depleted via a monoclonal antibody against CD20 (rituximab), there is limited efficacy of this method (opposing results) in several models ${ }^{175-178}$. Additionally, some clinical studies using rituximab did not show a pronounced clinical benefit in renal cell carcinoma, colorectal carcinoma, and melanoma ${ }^{179,180}$. Notably, depletion of B cells can disturb the balance in the overall immune response. Therefore, existing immunotherapies that target $B$ cells in these diseases require further investigation.

\section{Antibodies}

There are a few studies showing a correlation between the serum antibody distribution and patients' survival. In melanoma, an accumulation of $\lg _{4}+B$ cells was correlated with local IL-10 production, but there was no difference in patients' survival. These melanoma patients showed a relative increase of total $\operatorname{lgG}_{4}$ (not tumour-specific) in the serum, which correlated with a decreased survival. In addition, this study indicated a tendency towards a correlation between $\lg G_{1}$ in the serum and increased survival. The $\lg G_{1}$-dependent killing of tumour cells via monocytes was inhibited by $\operatorname{lgG}_{4}$ in vitro ${ }^{181}$. Furthermore, it was shown that patients with metastatic melanoma or advance disease had increased levels of total $\operatorname{lgG}_{4}$ in the serum as compared to the primary disease ${ }^{182}$. In patients with pancreatic cancer, increased levels of serum IgE were observed and in vitro experiments demonstrated ADCC against pancreatic tumour cells ${ }^{183}$. The increased level of serum IgE was associated with an increased survival of patients with glioma ${ }^{184}$. In another study, poor outcomes were associated with increased 
levels of serum $\operatorname{lgG}_{4}$. The mechanism was suggested to be $\operatorname{lgG}_{4}$ that inhibited IgE-dependent pro-inflammatory functions mediated via FcRs ${ }^{185}$.

In contrast, there are many reports that identified tumour-specific antibodies in the serum of patients with cancer, however only a limited number of studies tried to correlate tumour-specific antibody responses with patients' survival ${ }^{186}$. To this end, the serum level of MUC1-specific antibodies (mucin 1 glycoprotein; tumour cells show a different glycosylation) serves as a prognostic marker of increased survival in patients with pancreatic cancer ${ }^{187}$. Conversely, there was no association found between the antibody response against a panel of tumour antigens and the prognosis in patients with melanoma. Remarkably, only a few patients with a detectable serum antibody against a fraction of individual tumour antigens demonstrated a worst prognosis ${ }^{188}$. Additionally, patients who had complete resection of colorectal carcinoma showed a correlation between tumour-specific antibodies and a worst prognosis ${ }^{189}$. At present, more studies are evaluating antibodies to use as prognostic factor in patients with cancer. These studies indicate that tumour-specific antibodies may exhibit diverse roles in anti-tumour immunity. The antibody isotype, affinity, antigen expression on tumour cells, and the phase of tumour progression, are factors that influence the antibody efficiency in cancer. In addition, the concentration and isotype of tumour-specific antibodies may reflect a $\mathrm{CD} 4+\mathrm{T}$ cell response. It remains controversial whether antibodies stimulate or inhibit specific phases of tumour progression.

\section{Combination therapy}

Currently, the combination of standard (also called conventional) cancer treatments such as surgery, chemotherapy and radiotherapy (RT) with immunotherapy (IT) have shown to be more beneficial for the treatment of solid tumours as compared to when each treatment is applied individually ${ }^{137,190}$. There is increasing evidence that this multimodal approach results in an effective modulation of anti-tumour immunity, but the precise combination strategies and the percentage of complete responses in cancer patients are still far from optimal and require further improvement. The main goal of IT is to boost and restore the immune system of the patient to specifically attack and destroy the tumour. Ideally, conventional treatments but also small molecule inhibitors can be effective immune stimulators via the promotion of immunogenic tumour cell death (ICD), and the release of tumour-associated antigens (TAA) and damage associated molecular patterns (DAMP). The subsequent administration of IT can reinforce the tumour-specific immune response that is induced via the standard treatments 


\section{Chapter 1}

with the aim to ultimately generate a complete response ${ }^{191}$.

\section{Radiotherapy}

$\mathrm{RT}$ is one of the most regularly used conventional treatment for many cancer types in which tumour cells are locally eradicated with either curative or palliative intent. Although RT can be immunosuppressive, many studies demonstrated the potential immunomodulatory role of radiation. To this end, radiation-induced tumour cell death results in the release of danger signals that stimulate tumour-specific immune responses. These danger signals (e.g. DAMPs) promote phagocytosis by APCs such as immature DCs and macrophages ${ }^{192}$. Critical DAMPs are intracellular proteins including calreticulin, heat-shock proteins, and high-mobility group box 1 (HMGB1) ${ }^{193-195}$. In this way, RT generates an inflammatory microenvironment full with necrotic and apoptotic cells, DAMPs, TAAs, cytokines, and chemokines ${ }^{192}$. These DAMPs and TAAs are taken up by immature DCs, which in response maturate, migrate, and present their antigens in the context of HLA (class I-II) molecules to naïve T cells in adjacent lymph nodes. The activated T cells, but also B cells (and their secreted antibodies) migrate to the tumour site to eradicate tumour cells via T cell-mediated killing (granzymes, perforin, and Fas-L) and antibody-mediated killing (e.g. CDC and ADCC) ${ }^{196-200}$. Furthermore, tumour irradiation also stimulates the upregulation of certain proteins such as MHC-I, Fas, co-stimulatory molecule B7.1, lymphocyte function-associated antigen 3 (LFA-3), and intercellular adhesion molecule 1 (ICAM-1) 201-204. These MHC-I proteins directly present their antigens to CD8+ T cells and increased binding of T cells to adhesion molecules further promote killing of the tumour cells 202,205,206. The activated CD8+ T cells express Fas-ligand, which upon binding with Fas induces apoptosis of tumour cells ${ }^{207,208}$. In another study, 21 out of 23 irradiated human carcinoma cell lines showed an upregulation of immunomodulatory molecules (e.g. Fas, ICAM-1, MHC-I) and these irradiated cells showed increased killing as compared to non-irradiated cells ${ }^{208}$.

Radiation-induced bystander effects of non-irradiated cells are generally detrimental for treatment outcome, however some exhibit biological properties that are beneficial such as the abscopal effect (first described by R.J. Mole in 1953) ${ }^{209-211}$. In this infrequent observed phenomenon tumours (mostly metastases) outside the field of primary irradiation regressed or even disappeared ${ }^{212,213}$. RT has been shown to induce abscopal effects in several types of cancer such as melanoma, lung carcinoma, renal cell carcinoma, hepatocellular carcinoma, and lymphoma ${ }^{214-225}$. The precise biological mechanism that underlies this effect remains elusive, but it is most likely a systemic immune system activation as a result of ICD of the 
irradiated tumour. In addition, the eradication of irradiated tumour cells and 'distant' nonirradiated metastases is suggested to be mediated primarily via DC-induced activation of T cells ${ }^{226,227}$. Although, this phenomenon is uncommon, it indicates that the immune system harbours powerful pathways for the control of metastatic tumours and may reveal targets for therapeutic intervention.

\section{Immunotherapy}

Currently, there are many clinical trials that combine RT with IT to boost the anti-tumour immune response initiated by irradiation. There are four immunotherapeutic approaches ${ }^{228}$ : (1) The stimulation of cross-priming (DC) to tumour-specific T cells via the administration of DC growth factors (e.g. GM-CSF and Flt3-L), intratumoural injection of autologous DCs, DC activation via TLR agonists (TLR2, TLR3, TLR7, and TLR9), and vaccines with tumour-specific antigens (e.g. CEA) ${ }^{190,229}$; (2) The improvement of immune effector functions of T cells via cytokines (IL-2), stimulating co-stimulation of T cells (co-stimulatory molecules including the $B 7 / C D 28$ and the TNF/TNFR family), and immune checkpoint blockade to reinforce $T$ cell effector function while blocking inhibitory signals (CTLA-4 and PD-1) ${ }^{230}$; (3) Neutralization of immunosuppressive factors of the tumour microenvironment (inhibition MDSCs, Tregs); (4) Adoptive immune cell therapy (e.g. T cells) ${ }^{231}$. Altogether, these approaches demonstrate an increase in anti-tumour responses and future directions may combine multiple strategies to further improve IT with the main goal to harness patients' innate ability to eliminate evasive tumour cells ${ }^{232}$.

\section{Chemotherapy and small molecule inhibitors}

Other cancer therapies consist of chemotherapy or small molecule inhibitors combined with IT. Conventional chemotherapy such as (platinum) alkylating agents, anthracyclines, texanes, and antimetabolites eliminates tumour cells via direct cytotoxicity, but some of these agents can also change the expression of MHC-I, ICAM-I, and TAAs on tumour cells, making them more prone for immune-mediated killing ${ }^{233-235}$. These agents also induce ICD ${ }^{236}$, modulate Tregs ${ }^{237,238}$, and interact with vaccines to boost the effector function of immune cells against TAAs ${ }^{239}$. So far, many preclinical studies showed a benefit of combining chemotherapy with IT by means of vaccines to generate an effective anti-tumour immunity, and some of these combination treatments are now clinically used 236,240,241.

The use of small molecule inhibitors for cancer treatment has grown significantly 


\section{Chapter 1}

in the last decade ${ }^{242}$. These molecules target specific proteins such as receptors and growth factors ${ }^{243}$. The benefit of small molecule inhibitors such as Bcl-2 inhibitors (induce apoptosis ${ }^{244}$ ) and tyrosine kinase inhibitors (interfere with proliferation and survival ${ }^{242}$ ), is that they modulate specific cellular pathways that are vital for tumour biology. Therefore, combining these molecules with IT is a promising approach to enhance anti-tumour immunity.

\section{B CELLS AND ANTIBODIES IN BLOOD DISEASES}

\section{B cell malignancies}

Hematopoietic and lymphoid malignancies are tumours affecting the bone marrow, blood, and lymphatic system that are sorted in three classes: leukemias (30\%), lymphomas (56\%), and myelomas (14\%). Malignancies restricted to B cells are entitled B cell malignancies and represent a diverse collection of diseases including non-Hodgkin's lymphomas (85\%), some leukemias (2\%), and myelomas (13\%) ${ }^{245}$. Importantly, during the continuous process of B cell differentiation and maturation, the involved genes are prone to become changed, which can lead to malignant transformation. The transformations can occur during distinct stages of $B$ cell development as shown in Figure $2^{246}$. When the genetic alterations (e.g. mutations in CCND1, MAF, FGFR3 or IRF4) occur in plasma cells (terminally differentiated B cells), this can result in the development of Multiple Myeloma (MM) or Kahler's disease (Figure 2) ${ }^{247}$.

\section{Multiple Myeloma}

MM is characterized by: (1) clonal expansion of neoplastic plasma cells in the bone marrow; (2) presence of monoclonal protein in the blood and/or urine; (3) organ dysfunction such as kidney failure. $\mathrm{MM}$ accounts for $\pm 1 \%$ of all neoplastic diseases and 10 to $15 \%$ of hematologic malignancies. The percentage of MM patients that decease is 15 to $20 \%$ from hematologic malignancies and $2 \%$ of all deaths from cancer ${ }^{248}$. The annual incidence is 5.6 cases per 100.000 individuals in Western countries and the median age of diagnosis is \pm 70 years. In addition, $\pm 37 \%$ of the patients is $<65$ years, $\pm 26 \%$ between 65 years and 74 years, and $\pm 37 \%>75$ years 249,250 . The underlying pathophysiology of MM arises due to genetic changes during the terminal differentiation of B cells in plasma cells (Figure 2). In about 50\%, MM patients show a chromosomal translocation of an oncogene into the Ig $\mathrm{H}$ chain gene located on chromosome $14{ }^{251}$. The translocation results in overexpression of the oncogene and uncontrolled cell proliferation. Furthermore, a subset of MM patients shows trisomies of 
several chromosomes $(3,5,7,9,11,15,19$, and 21$)$, which also contribute to abnormal cell growth ${ }^{248,252}$. During the development of MM, more genetic (e.g. mutations of RAS) and epigenetic events occur that ultimately lead to the expansion of malignant plasma cells ${ }^{253}$. Besides the abnormalities in plasma cells, MM cells are dependent on other cells that are present in the bone marrow such as osteoblasts, fibroblasts, osteoclasts, stromal cells, and lymphocytes. One of the most characteristic feature of $\mathrm{MM}$ is the occurrence of osteolysis (active reabsorption of bone) due to a misbalance in osteoblast and osteoclast activity ${ }^{249}$.

The International Myeloma Working Group defined specific diagnostic criteria for

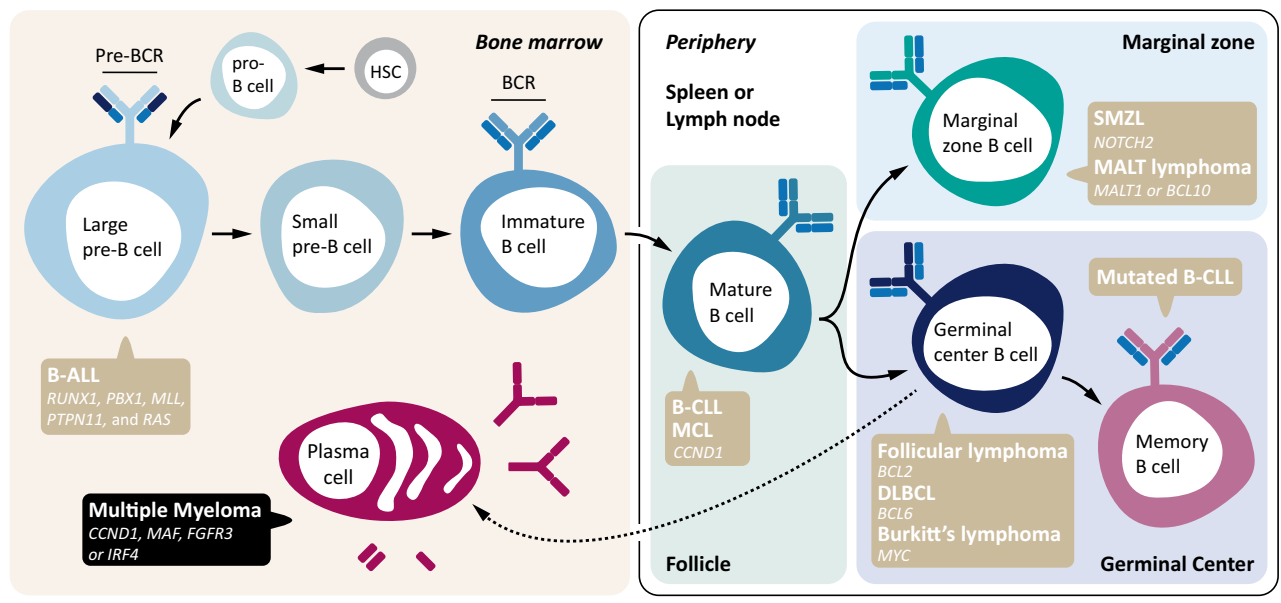

Figure 2: B cell malignancies develop at distinct stages of B cell differentiation. B cell malignancies often show chromosomal translocations, genetic mutations, and aberrations such as hyperploidy and aneuploidy. Pre-B cell: $B$ cell acute lymphocytic leukemia (B-ALL) involves $B C R-A B L 1$ translocation and mutations in $R U N X 1, P B X 1, M L L$, PTPN11, and RAS. Mature B cell: B cell chronic lymphocytic leukemia (B-CLL) and mantle cell lymphoma (MCL) involve mutations in CCND1. Marginal zone B cell: splenic marginal zone lymphoma (SMZL) and mucosa-associated lymphoid tissue (MALT) lymphoma involve mutations in NOTCH2, and MALT1 or BCL10. Germinal center B cell: follicular lymphoma, diffuse large B cell lymphoma (DLBCL), and Burkitt's lymphoma involve mutations in $B C L 2$, $B C L 6$, or MYC. Memory B cell: mutated B-CLL. Plasma cell (migration to the bone marrow): multiple myeloma (MM) involves mutations in CCND1, MAF, FGFR3, or IRF4.

three classes of myeloma: symptomatic myeloma, asymptomatic myeloma, and monoclonal gammopathy of undetermined significance (MGUS) ${ }^{254}$. Symptomatic myeloma patients have monoclonal plasma cells in the bone marrow (>10\%), monoclonal protein in serum or urine (>30 g/L), symptoms of myeloma associated organ or tissue impairment including anaemia, hypercalcaemia, renal insufficiency, or osteoporosis. Asymptomatic myeloma patients have monoclonal plasma cells in the bone marrow (>10\%) and monoclonal protein (>30 g/L), but 


\section{Chapter 1}

do not show myeloma associated organ or tissue impairment. And MGUS patients show low levels of monoclonal plasma cells in the bone marrow $(<10 \%)$ and monoclonal protein $(<30$ $\mathrm{g} / \mathrm{L}$ ), and do not show myeloma associated organ or tissue impairment. In most cases plasma cells produce monoclonal IgG or IgA antibodies (also called paraprotein), though the amount is dependent on the myeloma diagnosis. Notably, plasma cells in both myeloma and MGUS patients also produce monoclonal FLC Igs, in the urine called Bence Jones proteins ${ }^{25,256}$. Only $\pm 20 \%$ of myeloma patients produce only FLC Igs in the serum and urine, and in addition $\pm 2 \%$ show neither the production of FLC Igs nor paraproteins and are called non-secretors ${ }^{248}$. The sFLC Igs are filtrated through the glomeruli of the nephrons (kidney) and actively reabsorbed in the proximal tubules. Oversaturation of this reabsorption due to high levels of monoclonal sFLC Igs lead to cast formation in the distal tubules. This subsequently results in obstruction, inflammation, and acute kidney injury. Around $90 \%$ of the renal impairment in patients with myeloma is caused by this cast nephropathy ${ }^{257}$.

Patients with MGUS and asymptomatic myeloma are not treated, but patients with symptomatic myeloma are treated with a combination of chemotherapy such as alkylating drugs cyclophosphamide and melphalan (interfere with DNA synthesis and subsequently the ability for cells to divide). Besides the alkylating drugs, corticosteroids are administrated as a general treatment for myeloma. Although myeloma is relatively treatable, it is not curable, therefore the effort is pointed towards improving patient survival and quality of life. In the last decade, new drugs such as bortezomib, thalidomide, and lenalidomide became available that had an anti-myeloma effect and demonstrated an improved survival of patients ${ }^{258-260}$. Bortezomib and carfilzomib are proteasome inhibitors that interfere with several important pathways in myeloma cells including NF-K $\beta$ signaling, angiogenesis, and cytokine signaling ${ }^{261}$. Thalidomide and lenalidomide are molecules targeting angiogenesis, thereby disrupting the environment and tumour growth ${ }^{262}$. Notably, the treatment regimen is dependent on age and comorbidity of these MM patients. Patients (generally $<65$ years) who are fit enough undergo high dose chemotherapy followed by autologous stem cell transplantation (SCT). In this procedure, the initial induction therapy should preserve the hematopoietic stem cells (HSCS) that these can be collected and frozen. After intensive melphalan and/or combination treatments with new drugs (e.g. bortezomib, lenalidomide), these 'frozen' HSCs are placed back into the patient via autologous SCT ${ }^{248,249}$. 


\section{Hematopoietic stem cell transplantation}

In 1959, Thomas et al. showed that a patient with leukemia who was treated with total-body irradiation followed by infusion of bone marrow from her identical twin, had a remission of three months ${ }^{263}$. Subsequently, the first allogeneic (from another individual) hematopoietic stem cell transplantations (HSCT) became available in the 1960s, after the identification and typing of HLA molecules. In addition to allogeneic HSCT, patients can also receive their own HSCs, which is defined as autologous HSCT ${ }^{264}$. Currently, autologous HSCT is used in patients with hematological malignancies (e.g. MM) receiving high dose chemotherapy as treatment. Since non-malignant HSCs are relatively sensitive for this treatment, these are collected in advance and subsequently 'transplanted' back after chemotherapy. In contrast, allogeneic HSCT is used in patients that exhibit acquired or congenital failure of the bone marrow cells (e.g. acute myeloid leukemia (AML), Non-Hodgkin's lymphoma). In these patients, HSCs of the patient are first eradicated and then replaced with HLA matched donor HSCs, usually to stimulate the strong beneficial graft-versus-tumour or graft-versus-leukemia (GVL) effect of these allogeneic cells (e.g. NK cells) against the hematologic malignancy ${ }^{265,266}$. Nevertheless, in just $30 \%$ of the cases a 'fully' HLA matched donor is found ${ }^{267}$. To this end, the ideal donor in allogeneic HSCT is a HLA identical sibling, though in a large percentage such a sibling is not available, therefore these patients are matched with unrelated donors (MUD) ${ }^{268}$. To date, the patient and donor are matched for the HLA-A,HLA-B, HLA-C, HLA-DRB1, and HLA-DQ1 loci, and having a 10 out of 10 match displays the best transplant outcome. Clinical studies showed that a single or multiple mismatches of especially the HLA-A and HLA-B loci resulted in significant worst transplant outcome ${ }^{269-272}$. These HLA mismatches of the patient and donor can lead to the development of graft-versus-host disease (GVHD), in which donor cells (lymphocytes) attack healthy cells of the patient ${ }^{273}$. When the patient is rejecting the graft (donor HSCs) this is called host-versus-graft (HVG) reactivity. In addition, the patients that undergo allogeneic HSCT show an increased susceptibility for opportunistic infections as a result of the gradual or incomplete reconstitution of the donor's HSCs (immune system). To this end, CD8+ T cells and B cells recover in months, while CD4+ T cells recover slow, even up to several years ${ }^{274,275}$.

\section{Graft-versus-host disease}

The major complication of allogenic HSCT is the development of GVHD. The onset of GVHD is more severe and frequent when HLA mismatched grafts are used (major mismatch), though 


\section{Chapter 1}

GVHD can also occur (up to 60\%) when patient and donor are fully HLA matched but have a minor mismatch ${ }^{264}$. Furthermore, GVHD can be divided in acute GVHD (mainly occurring in the first 100 days after HSCT) or chronic GVHD (usually occurring after day 100 of the HSCT). The key symptoms of acute GVHD are related to the skin (exanthema), gastrointestinal tract (enteritis), and liver (cholestatic hepatitis). The pathophysiology of acute GVHD is initiated by donor T cells that respond to alloantigen presented via the HLA molecules on patient's APCS ${ }^{276}$. In contrast, chronic GVHD is a chronic inflammatory disease that is characterized by sclerosis and multi-organ involvement (e.g. skin, mouth, liver, eyes, and nails). The most important risk factor for chronic GVHD is acute GVHD, and chronic GVHD is currently the leading cause of long-term morbidity and mortality after HSCT. Although donor T cells play a crucial role in chronic GVHD, research indicated that donor B cells also contribute to the pathophysiology and characteristics of this disease ${ }^{277-279}$. Nevertheless, the exact biological role of these B cells and their secreted antibodies in chronic GVHD and their interactions with T cells remains elusive. Currently, it is suggested that there is a failure in peripheral $B$ cell tolerance in patients with chronic GHVD and an increased antigen to BCR sensitivity is associated with poor recovery of naïve B cells and increased B cell survival. In addition, a malfunction in the recovery of Bregs may also play a role in the abnormal $B$ cell homeostasis after HSCT 280.

The first line treatment for both acute and chronic GVHD are corticosteroids such as methylprednisolone. Second or greater line therapy include mycophenolate mofetil (MMF), extracorporeal photochemotherapy (ECP), sirolimus (rapamycin), and rituximab (targeting $B$ cells and is more beneficial in chronic GVHD). Despite this relatively long list of various types of medication, the mortality that is associated with GVHD remains high. Currently, there are novel therapies in development targeting cytokines, antibody production, B cells, and T cells in both acute and chronic GVHD ${ }^{281}$. One of the emerging drugs is ruxolitinib, which inhibits both Janus associated kinases (JAK) 1 and JAK2 ${ }^{282}$. In a limited number of cases, ruxolitinib showed a clinical response thereby reducing the biological and clinical signs of both acute and chronic GVHD ${ }^{283}$. The mechanism of action is suggested to be an inhibition of T cells and DCs, but a potential biological effect on B cells, which play a role in the pathophysiology of chronic GVHD remains elusive. 


\section{B CELLS AND ANTIBODIES IN ORGAN TRANSPLANTATION}

\section{Recipient and donor matching}

In organ transplantation, the central focus is to prevent complications such as transplant rejection, where the recipient's immune system targets the transplanted organ, which can lead to transplant failure and removal of the organ. To prevent transplant rejection, many studies have shown that the survival of transplanted grafts is significantly increased when the recipients and organ donors are matched for human leukocyte antigens (HLA) and ABO blood group antigens, besides the administration of immunosuppressive medication.

\section{HLA molecules in transplantation}

\section{HLA loci and molecule structure}

The human variant of the Major Histocompatibility Complex (MHC) is defined as HLA, and is essential in presenting exogenous and endogenous peptides to the immune system. In the 1950s, the first HLA loci were identified as HLA-A and HLA-B followed by HLA-C (HLA class I genes) ${ }^{284}$. Subsequently, a second class of HLA loci was discovered and defined as HLA-DR (D-Related) followed by HLA class II loci HLA-DQ and HLA-DP (HLA class II genes) ${ }^{285-287}$. The HLA genes are the most polymorphic loci of the human genome located on the short arm of chromosome 6 (6p21.3) and are divided in three classes (HLA class I, II, III) (Figure 3).

The HLA class I genes are divided in classical highly polymorphic genes $H L A-A, H L A-B$, and $H L A-C$ and less polymorphic non-classical genes $H L A-E, H L A-F$, and $H L A-G{ }^{288}$. These HLA class I molecules are expressed on most nucleated cells, although the level of expression is dependent on the tissue ${ }^{285}$. HLA class I molecules consist of three extracellular domains ( $\alpha 1$, $\alpha 2, \alpha 3)$ encoded by exon 2, 3 and 4, which together form a single extracellular $\alpha$ chain. The $\alpha 1$ and $\alpha 2$ domains show the highest degree of polymorphism, since these form the peptide binding groove responsible for presenting peptides to $T$ cells. The other extracellular domain $\alpha 3$ is non-covalently coupled to beta2-microglobulin ( $\beta 2-M)$, which is necessary for surface expression and peptide groove stability. The molecule is anchored in the cell membrane via a transmembrane domain (exon 5) and has a short cytoplasmic tail (exon 6-8). A complete HLA class I molecule has a molecular mass of $\pm 43 \mathrm{kDa}{ }^{285,289}$. Importantly, these molecules present mostly peptides ( 8 to 16 residues) derived from intracellular proteins such as e.g. viruses. The peptide-loaded HLA class I molecule presents this to the T cell receptor (TCR) of 


\section{Chapter 1}

CD8+ T cells, which results in T cell activation, and the elimination of the cell presenting the foreign peptide ${ }^{290}$. In addition, these HLA class I molecules can act as ligands for activating or inhibiting receptors present on natural killer (NK) cells. Importantly, NK cell activation is determined by a balance of activating and inhibitory signals. HLA interaction with activating receptors is important for antiviral NK reactivity, and interaction of inhibitory receptors such as Killer-cell Immunoglobulin-like Receptors (KIRs) and CD94/NKG2A (ligand HLA-E) provides an inhibitory signal that protects healthy cells from being eradicated by NK cells. Therefore, cells that do not have HLA class I molecules become sensitive for NK cell killing ${ }^{291,292}$. In case of virally infected or malignant cells, HLA class I molecules are often downregulated on the cell surface to escape from $T$ cell killing.

The HLA class // genes are divided in classical genes HLA-DR, HLA-DQ, and HLA-DP that are involved in peptide presentation, and non-classical genes HLA-DM and HLA-DO that play a crucial role in the regulation of the classical genes ${ }^{285}$. These HLA class II molecules are mainly expressed on antigen-presenting cells (APCs) such as macrophages, B cells, and DCs, but also on activated T cells, and thymic epithelial cells. HLA class II molecules consist of two non-covalently coupled protein chains, one $\alpha$ chain of $\pm 34 \mathrm{kDa}$ and one $\beta$ chain of $\pm 29 \mathrm{kDa}$ encoded by the $A$ and $B$ gene, respectively (e.g. HLA-DRA, HLA-DRB). The extracellular part consists of two domains of the $\alpha(\alpha 1$ and $\alpha 2)$ and $\beta$ ( $\beta 1$ and $\beta 2$ ) chain that are encoded by exon 2 and 3 . The $\alpha 1$ and $\beta 1$ domains form the peptide binding groove, and especially the $\beta 1$ domain exhibits the highest degree of polymorphism. With regard to the HLA-DRB1 gene, 1929 alleles are determined as compared to the alternative HLA-DRB genes HLA-DRB3, HLADRB4, and HLA-DRB5 (e.g. HLA-DRB3 has 121 alleles) ${ }^{293}$. The $\alpha 2$ and $\beta 2$ domains are the backbone and important for co-receptor binding (e.g. CD4). The $\alpha$ and $\beta$ chains are anchored in the cell membrane via a transmembrane domain and have a short cytoplasmic tail (exon 4-6) ${ }^{285,294}$. A complete HLA class II molecule ( $\alpha$ and $\beta$ ) has a molecular mass of $\pm 63 \mathrm{kDa}$. Importantly, these molecules present peptides (up to 30 residues) derived from exogenous proteins such as e.g. bacteria. The peptide-loaded HLA class II molecule presents this to the TCR of CD4+ T cells, which results in T cell activation and polarization in T helper (Th) cell subsets such as Th1, Th2, and Th17 ${ }^{295}$. These Thelper cells initiate effector functions such as the production of antibodies and stimulation of CD8+ T cells, NK cells or macrophages ${ }^{296}$.

The HLA class III genes encode for a large variety of non-HLA genes that are involved in the immune system including proteins for the complement system, heat-shock proteins, and cytokines (TNF- $\alpha)^{297,298}$. 


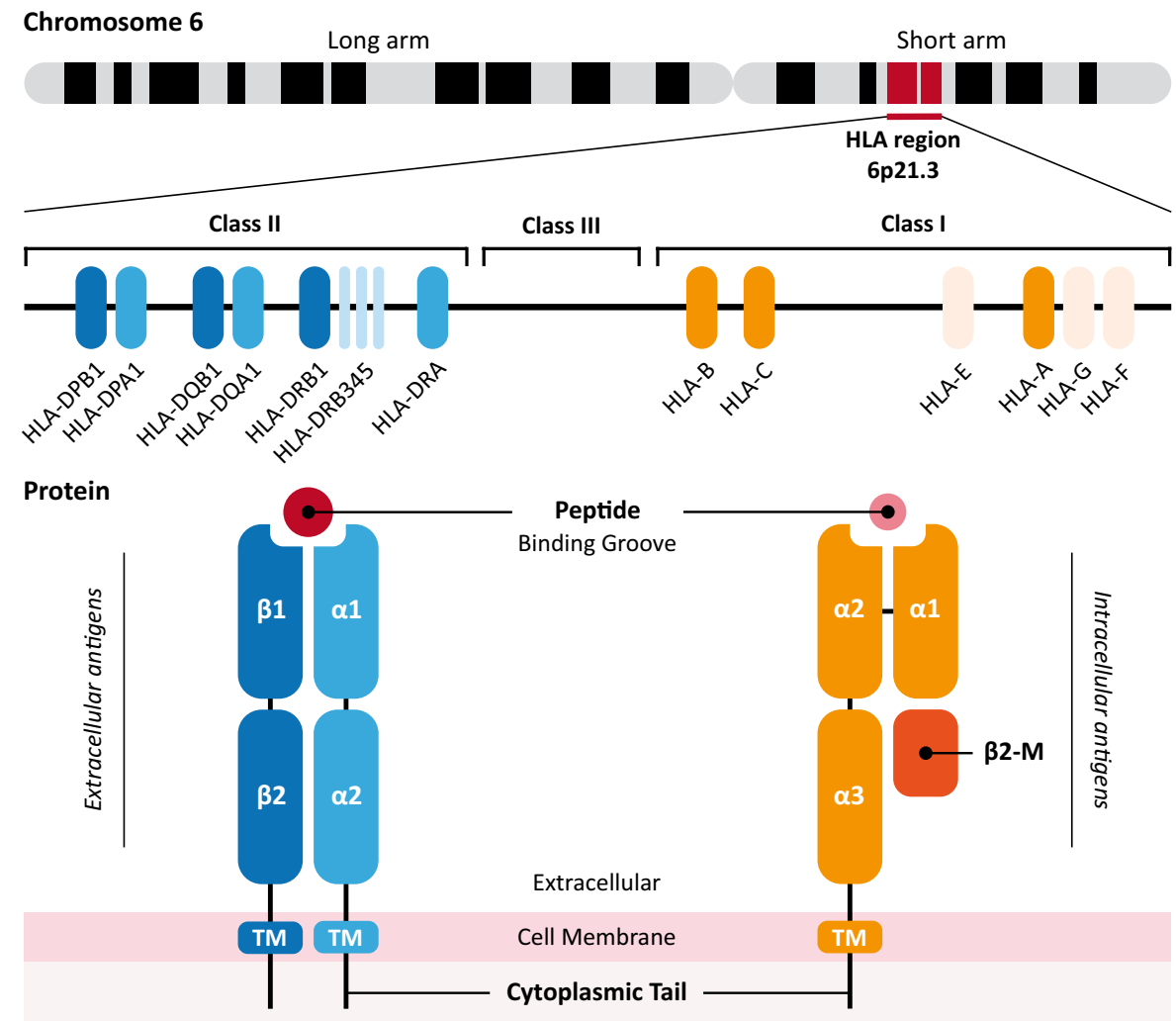

Figure 3: The position of the HLA loci on chromosome 6 and the protein structure of HLA class I and II molecules. The polymorphic HLA genes are located on the short arm of chromosome 6 (6p21.3) and they are categorized into three major classes: HLA class I, II, and III. The HLA class I genes contain classical genes: HLA- $A,-B$, and $-C$ and nonclassical genes: $H L A-E,-F$, and $-G$. The HLA class II genes comprise of $H L A-D R$, $-D Q$, and $-D P$, each consisting of an a and $\beta$ chain. The HLA class III genes encode for proteins of the complement system, heat-shock proteins, cytokines. The HLA class I proteins have three $\alpha$ domains, and $\alpha 3$ is linked to $\beta 2-\mathrm{M}$. The class I molecules are present on almost all nucleated cells and present mainly intracellular antigens derived from e.g. viruses. The HLA class II proteins have two $\alpha$ domains and two $\beta$ domains. The class II molecules are present on APCs such as macrophages, B cells, and DCs and present extracellular antigens derived from e.g. bacteria.

\section{HLA in transplantation}

In healthy individuals, the innate and adaptive immune system protects the body for foreign pathogens via the highly polymorphic HLA molecules that present a wide-ranging diversity of pathogen-derived peptides. This polymorphic nature of HLA enables humans to deal with a broad variety of pathogens that are encountered during life. The presented peptides can be derived from foreign proteins (e.g. viruses and bacteria) or from endogenous proteins (e.g. self-peptides). The self-peptides are important for the education of immune cells to prevent 


\section{Chapter 1}

auto-reactivity such as the positive and negative T cell selection in the thymus ${ }^{299}$. However, in certain individuals the central and peripheral tolerance are not in balance anymore, which can lead to the development of autoimmune diseases such as systemic lupus erythematosus (SLE) and rheumatoid arthritis (RA) ${ }^{300,301 .}$

Although the highly polymorphic nature of HLA is an extremely enhanced system to protect the body from invaders, it creates problems when organs or tissues are transplanted from donors to recipients. In (kidney) transplantation, the recognition of foreign (donor) HLA molecules by the recipient's immune system creates a barrier for successful graft outcome 302,303. These foreign HLA antigens that are present on the donor cells are the trigger for a powerful immune response in the recipient, which may cause graft rejection ${ }^{304}$. The donor HLA antigens can be presented via two pathways: Intact donor HLA antigens are presented by donor APCs to recipient T cells (direct pathway) or donor HLA antigens that are shed from the graft are processed into peptides and presented by recipient APCs to T cells (indirect pathway) ${ }^{305}$. The subsequent immunogenic events result in activation and clonal expansion of alloreactive T cells, B cells, and the synthesis of HLA antibodies. Notably, the development of HLA antibodies does not occur naturally, only after contact with foreign HLA antigens. The immunological events, which stimulate HLA antibody formation in recipients are pregnancy, blood transfusion, and previous transplantation ${ }^{306-308}$. Approximately $25 \%$ of the pregnant women develop antibodies against paternal HLA antigens present on fetal cells that enter the maternal blood circulation ${ }^{309,310}$. The frequency of HLA antibodies rises with the number of pregnancies. HLA antibodies recognize a specific part of the HLA molecule, which is called epitope or determinant ${ }^{311}$. In addition, there are so-called 'public' epitopes, which means that these epitopes are shared among HLA alleles, and 'private' epitopes that are specific for an allele ${ }^{312-314}$. Furthermore, the HLA antigens retain several epitopes, which are recognized by specific antibodies.

To prevent alloreactive responses in transplantation, the recipient and kidney donor are matched for HLA molecules, besides the administration of immunosuppressive drugs to the recipient. The degree of HLA matching between recipient and donor has a great impact on graft outcome, since zero HLA mismatches has shown to be superior on graft outcome as compared to one or more ${ }^{315-318}$. It has been shown that HLA-DR mismatches display a strong effect in the first five months after transplantation (associated with increased risk of acute rejection), whereas mismatches of HLA-A and HLA-B are associated with late graft loss ${ }^{319}$. In general, the recipient and donor are matched for HLA compatibility based on the number of 
mismatched HLA-A, HLA-B, and HLA-DR antigens of the donor. In our transplant center, the minimal matching criteria consist of $1 B$ and $1 D R / 2 D R$ matches between recipient and donor. However, in living donation, the HLA matching is less, because of the excellent quality of the donor kidney, and the recipients are transplanted before having dialysis (pre-emptive) ${ }^{320-322}$. Still, improved matching in living donors extends the graft outcome.

\section{Blood group antigens in transplantation}

\section{Blood group systems}

To date, there are 33 blood group systems that represent over 300 antigens, which are listed by the International Society of Blood Transfusion ${ }^{323,324}$. These antigens can be proteins in which polymorphisms are located in the variation of amino acid sequence (e.g. Rhesus, Kell), glycoproteins or glycolipids (e.g. ABO). Currently, the ABO blood group system is the most important in the field of transplantation and transfusion. Already in 1900, Karl Landsteiner discovered the $A B O$ system and subsequent research identified (4) $A, B$, and $O(H)$ antigens (carbohydrate structures) ${ }^{325,326}$. There are four main ABO blood group types: $A, B, A B, O$, and a rare Bombay type. The Landsteiner's Law indicated that an individual without $A B O$ antigens (RBCs) will always have the corresponding antibodies (which form early in life). In short, blood group A (no B antigen) has B antibodies, and blood group B (no A antigen) has A antibodies. Blood group $O$ (no $A$ and $B$ antigens) has $A$ and $B$ antibodies, and blood group $A B$ ( $A$ and $B$ antigens) has no $A$ and $B$ antibodies ${ }^{327}$. In early days, it became clear that donation of blood, organs, and/or tissues between two individuals who have incompatible ABO blood groups would result in (hyper)acute rejection. To date, the ABO blood group system exceeds the significance of the HLA system, since $A B O$ antigens are not only expressed on RBCs, but also on a wide variety of human tissues such as platelets, endothelial, and epithelial cells. However, most importantly, every individual contains antibodies against the ABO antigens that are absence in the individual's own body, which usually induces a (hyper)acute rejection of the transplanted graft ${ }^{328-331}$.

The second most important blood group system is Rhesus (Rh), in which RhD (D-antigen) is the most immunogenic ${ }^{332,333}$. Although ABO antigens are present on RBCs, they are also expressed on a wide variety of human tissues such as most epithelial and endothelial cells. In contrast, RhD antigens are only expressed on RBCs. Therefore, RhD antigens are not considered as 'transplant antigens' for the allocation of solid organ transplantation. 


\section{RhD antibodies}

The Rh blood group system is the most polymorphic blood group in humans, which contains more than 45 independent antigens ${ }^{333,334}$. The conventional antigens are encoded by $R H D$ and RHCE, however multiple gene conversion events created hybrid genes. In these hybrid genes, regions of RhD are combined with RhCE or the conversion generates many different Rh antigens. To this end, two genes RHD and RHCE located on chromosome 1 encode for the Rh proteins RhD and RhCE that are expressed on the surface of RBCs (Figure 4). RhD carries the $\mathrm{D}$ antigens, and RhCE carries the CE antigens in different combinations (ce, Ce, cE, and CE) ${ }^{335}$. There is a large difference in the amount of amino acids in the variants, which also explains why exposure to RhD can result in a strong immune response in an RhD- individual. In addition, RBCs also express a Rh protein called RhAG (Rh-associated glycoprotein) ${ }^{336}$.

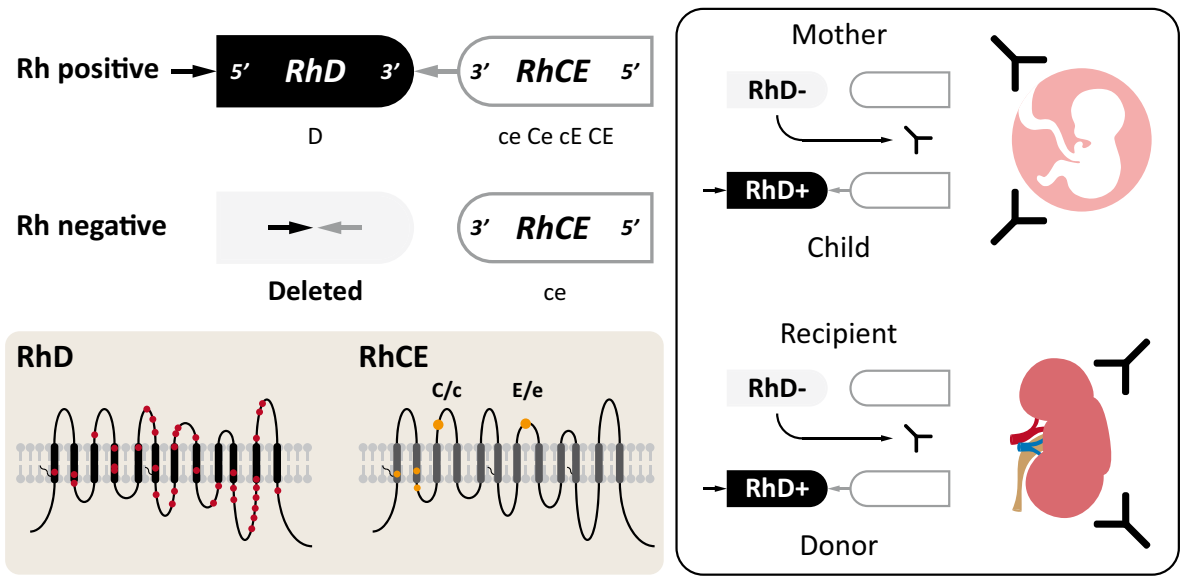

Figure 4: The $R \boldsymbol{h} D$ and $R \boldsymbol{h C E}$ locus, protein structure, and RhD antibodies in pregnancy and kidney transplantation. (Upper left) Schematic representation of the $R h D$ and $R h C E$ locus. The $R h D$ and $R h C E$ genes have opposite orientation (3' facing each other). Rh-individuals display a complete deletion of the RhD gene ${ }^{337}$. (Lower left) The RhD and RhCE proteins in the RBC membrane (12 transmembrane domains predicted). The circles represent amino acid positions that differ between RhD and RhCE. In case of RhCE, the amino acid changes for the C/c and E/e polymorphisms are shown. (Upper right) In pregnancy, RhD- women who have a RhD+ fetus are at risk to develop RhD antibodies that can result in HDFN. (Lower right) In transplantation, RhD- kidney recipients who have RhD incompatible kidney transplantation are at risk to develop RhD antibodies against the transplanted RhD+ donor graft.

Regarding RhD, RhD- (D negative) is more prevalent in the Caucasian population (15$17 \%)$ as compared to African (3-5\%) or Asian populations $(<0.1 \%)^{338}$. The higher incidence of RhD- in Caucasian persons of European descent is thought to be a result of a deletion of the RHD gene ${ }^{337,339}$ (Figure 4). In pregnancy, RhD- women who have a RhD+ fetus are at risk 
to develop RhD antibodies resulting in hemolytic disease of the fetus and newborn (HDFN). Maternal RhD antibodies (IgG) cross the placenta and bind to fetal RhD+RBCs, which result in their eradication, and causing anemia. It has been shown that $8.2 \%$ of RhD- women with a $\mathrm{RhD}+$ fetus are at risk to develop long persisting RhD antibodies, and this risk is significantly higher in a subsequent pregnancy (17\%) ${ }^{340,341}$. Before anti-RhD prophylaxis, RhD antibodies lead to the destruction of RBCs in the fetus, which caused fetal brain damage (high levels of bilirubin) and even death. Nowadays, the synthesis of maternal RhD antibodies is prevented by administration of anti-RhD prophylaxis and the RhD immunization rate has been reduced to 0.1 to $0.3 \%{ }^{342}$. The mechanism of action is thought to be antigen blocking and inhibition of the immune response by negative feedback in the spleen. With regard to transplantation, it has been shown that RhD- kidney transplant recipients developed RhD antibodies after receiving $\mathrm{RhD}$ incompatible kidney transplantation. Notably, these observations are limited to a few case reports from the 1970s and 1980s and only one clinical study from $1996^{343-345}$.

\section{Biomarkers in transplantation}

The term biological (bio)marker is defined as a measurable objective indicator of a biological or medical state that is observed from outside the patient. This biomarker can be measured accurately and reproducibly to evaluate biological, pathogenic or pharmacologic processes. Preferably, this biomarker should be the fundamental player of the pathophysiology of the disease, be stable, related to disease activity and severity, predict disease progression, and sensitive for treatment to determine the drug efficacy. Currently, creatinine is the 'golden' standard to assess kidney function, donor HLA-specific antibodies (DSA) are used to monitor transplant recipients before and after kidney transplantation, and antibody fragments such as SFLC Igs are proposed to use as biomarker for B cell activity and adaptive immune system activation, but may also reflect kidney function.

\section{Markers for kidney function}

At present, chronic kidney disease (CKD) is a significant health problem in various Western countries. CKD is defined as a reduction in kidney function with a glomerular filtration rate (GFR) under $60 \mathrm{~mL} / \mathrm{min}$ per $1.73 \mathrm{~m}^{2}$ and/or damage to the kidney(s) for 3 months and more ${ }^{346}$. It is essential to diagnose, monitor, and evaluate treatment in CKD using markers that assess kidney function. The ideal marker for kidney function is the GFR, which is the volume filtered through the glomerulus in the Bowman's capsule per unit of time. In addition, these 


\section{Chapter 1}

GFR values are associated with age, sex, and body surface (120 and $130 \mathrm{~mL} / \mathrm{min}$ per $1.73 \mathrm{~m}^{2}$ in young men and women, respectively) ${ }^{347,348}$. However, measuring the GFR (mGFR) is time consuming and therefore the GFR is usually estimated (eGFR) using endogenous filtration markers such as serum creatinine ( $\mathrm{SCr}$ ) and cystatin C (CysC). SCr (creatine degradation) has a molecular weight of $0.113 \mathrm{kDa}$ and is freely filtrated through the glomerulus ${ }^{349}$. It is not reabsorbed or metabolized, however a major downside is that a fraction of $\mathrm{SCr}$ in the urine is excreted by proximal tubular cells ${ }^{346,350}$. Furthermore, other factors influencing the eGFR based on SCr include variation in creatinine production as a result of dietary intake, muscle mass fluctuations, and differences in tubular secretion and excretion ${ }^{351-353}$. Since 1957 many (>20) equations were developed to determine the eGFR. To date, the most used equation in routine practice is the modification of diet in renal disease (MDRD) ${ }^{354,355}$. Although the MDRD equation is very accurate for patients with CKD, there is an underestimated GFR for healthy individuals (false positive diagnosis of CKD). To overcome the imprecision of SCr based eGFR equations, $\mathrm{SCr}$ is combined with $\mathrm{CysC}$ to improve the eGFR ${ }^{356}$. Besides $\mathrm{SCr}$ and $\mathrm{CysC}$, other endogenous markers are proposed to evaluate kidney function such as beta2-microglobulin $(\beta 2-M)$ and blood urea nitrogen (BUN) ${ }^{357,358}$. $\beta 2-M(11.8 \mathrm{kDa})$ is present on all nucleated cells in the body (fragment of an HLA class I molecule) ${ }^{359,360}$. It is freely filtrated through the glomerulus and completely reabsorbed in the proximal tubule ${ }^{361}$. The $\beta 2-\mathrm{M}$ levels are increased in CKD, but also in malignancies, infections, and autoimmune diseases ${ }^{362,363}$. Several studies showed that $\beta 2-\mathrm{M}$ is a good endogenous marker for GFR (suggested to be superior than CysC) and that the $\beta 2-\mathrm{M}$ level increases prior to $\mathrm{SCr}$ in case of GFR decline ${ }^{364,365}$.

In addition to biomarkers to evaluate kidney function, also biomarkers to determine kidney damage and particular acute kidney injury (AKI) are important for kidneys' outcome. To this end, albuminuria a condition in which an abnormal quantity of albumin is detected in the urine is known to precede a decline in eGFR. Although albuminuria is a good biomarker, the elevation of albumin in the urine may occur after the kidney damage, or is not observed in other types of kidney damage (e.g. tubulointerstitial disease) ${ }^{366}$. This has led to the search for more sensitive and specific biomarkers that are able to diagnose (A)KI in patients with CKD. There are many encouraging biomarkers for (A)KI including kidney injury molecule 1 (KIM-1) 367-369, fibroblast growth factor 23 (FGF-23) 370,371, neutrophil gelatinase-associated lipocalin $(\mathrm{NGAL}){ }^{372-374}$, and apolipoprotein A-IV (ApoA-IV) ${ }^{375}$. Of these biomarkers, KIM-1 represents a very hopeful marker for the future, however larger studies are required before KIM-1 can be applied in routine clinical practice. 
In the last decades, SCr has been the 'golden' standard to assess kidney function and diagnose CKD. Various eGFR equations are developed, and besides the routinely used MDRD equation, a superior eGFR equation that combines $\mathrm{SCr}$ and $\mathrm{CySC}$ is recommended to use in specific conditions. However, there is still area for improvement by means of the sensitivity and specificity of biomarkers to determine the eGFR, but also for an early diagnosis of CKD. Therefore, ongoing studies are examining and validating numerous promising biomarkers to assess kidney function and/or AKI.

\section{Donor HLA-specific antibodies}

In kidney transplantation, the presence of pre-transplant antibodies against HLA, and more precisely those antigens that are expressed on the allograft (donor HLA-specific antibodies :DSA) is associated with (hyper)acute antibody-mediated rejection (AMR) ${ }^{376-378}$. In addition, the development of de novo (new) DSA in kidney transplant recipients after transplantation is often an indication for the start of AMR ${ }^{379}$. Therefore, many clinical studies support the significance of DSA monitoring for a risk assessment in kidney transplant recipients before and after transplantation ${ }^{380,381}$. In the last decades, new techniques for the detection of DSA were introduced such as the solid phase assay (SPA), in which HLA antigens are attached to a solid phase matrice. These SPAs were developed to be more advanced (improved sensitivity and specificity) as compared to the 'golden' standard CDC antibody assay ${ }^{377,382}$. In this CDC assay, donor lymphocytes are incubated with sera from the transplant recipient to observe complement-mediated killing of the donor lymphocytes. Although the CDC assays are costeffective and correlated significantly with graft outcome, these assays also showed a limited sensitivity and specificity. The SPA platforms can range from ELISAs to the more sensitive flow cytometry-based microspheres such as multiplex-bead arrays using Luminex technology 383,384. There are three types of resolution in SPA assays: (1) screening assay: HLA antigens isolated from multiple cells coated on solid-phase matrices (ELISA or Luminex) to e.g. answer yes or no for the presence of HLA class I or II antibodies; (2) phenotype beads: these are also called 'cell-like' beads and contain six HLA class I and II antigens (mostly two alleles of each HLA locus) to resemble a similar expression ratio that is observed on the cell surface ${ }^{385}$; (3) single antigen (SA) beads: these color-coded beads contain multiple copies of a single HLA allele on the surface and can be distinguished based on a unique dye to dye ratio. In this way, a Luminex (L)SA assay may contain up to 100 beads that are each conjugated with a single HLA antigen. The HLA antibodies in the sera of transplant recipients will bind to their specific 


\section{Chapter 1}

HLA target (bead) and these will be detected by emission of fluorescence ${ }^{386,387}$.

The combination of immunological research, novel clinical data, and the improved sensitivity and specificity of these SPAs has led to the improvement of the interpretation of DSA in recipients before and after transplantation ${ }^{388}$. A detailed and exact overview of the patient's antibody repertoire makes it feasible to determine the frequency of incompatible donors by means of calculating the panel reactive antibody (cPRA) levels ${ }^{389}$. In other words, this allows to match for graft donors who do not have the HLA alleles where these DSA bind too. Furthermore, the information of DSA before transplantation can be used to define a desensitization regime based on the type and strength of the DSA present in the transplant recipient ${ }^{390,391}$. The examination of DSA after transplantation allows early detection of these antibodies, which makes it possible to provide and evaluate rejection treatment ${ }^{380,392}$.

\section{Antibodies in graft rejection}

\section{Graft rejection}

The main problem in kidney transplantation is rejection of the graft. Before transplantation, detrimental systemic effects of the donor (severity depends on donor origin) or reperfusion injury can treat the graft. Warm and cold ischemia due to reperfusion injury can up-regulate the expression of HLA antigens and toll-like receptors (TLRs) and can trigger the release of numerous chemokines, proinflammatory cytokines, damage-associated molecular patterns (DAMPs), and adhesion molecules inside the kidney graft ${ }^{393,394}$. The increased expression of HLA antigens and TLRs provides a robust signal to the immune system and increases cellular infiltration in the graft, and these mechanisms play a crucial role in the risk of graft rejection 302,395 . Notably, the risk of graft rejection increases in case of HLA and ABO incompatibility.

The increase in SCr points towards graft rejection, however subclinical rejection may be apparent only on biopsy of the kidney graft ${ }^{396}$. Furthermore, the histologic evaluation of the biopsy determines the prognosis and the treatment options ${ }^{397}$. Graft rejection is divided in hyperacute (within minutes, mainly caused by pre-sensitization to the donor tissue), acute (within days or weeks, T cell and/or antibody alloreactivity), and chronic (months to years, alloreactive $T$ cells and/or antibodies) ${ }^{393}$. In addition, graft rejection can also be determined based on pathophysiological changes (e.g. antibody-endothelial), severity (degree of injury and inflammation assessed by histologic evaluation, and graded via the Banff schema ${ }^{398,399}$ ), presence or absence of graft (kidney) dysfunction, response to treatment, and involvement 
of immunological mechanisms (innate or adaptive immune response). The most detrimental response, the adaptive immune response can be divided in T cell-mediated and/or antibodymediated rejection (AMR).

\section{Antibody-mediated rejection (AMR)}

Alloantibodies or DSA are the major obstacle to short- and long-term graft survival. The main targets of AMR are HLA molecules (class I and/or II) and ABO blood group antigens, but also minor histocompatibility antigens may be target of AMR such as the endothelial-cell surface alloantigen MICA (MHC-class I polypeptide-related sequence A) ${ }^{338,400-402}$. In general, (CD4+) T cell help is required to initiate the alloantibody response. The immunological cascade starts with donor DCs that present their antigens to recipient T cells (the direct pathway), or after reprocessing these antigens by DCs of the recipient (the indirect pathway). Activated T cells provide help by means of cytokines and co-stimulatory factors to naïve B cells (or B cells that present their own antigens) to stimulate the formation of B cell memory, CSR, and antibody affinity maturation (SHM) ${ }^{392}$. Subsequently, the $B$ cell response promotes the generation of long-lived plasma cells, which migrate (home) to the bone marrow. These long-lived plasma cells produce antibodies (e.g. DSA) forever, without T cell help ${ }^{403}$.

AMR can be divided in acute (aAMR) or chronic (CAMR). aAMR can appear any time after the transplantation (within days to years). Four criteria define aAMR: evidence of acute graft dysfunction, histological signs such as neutrophils in capillaries or acute tubular injury, immunopathology evidence such as complement $4 d$ (C4d) deposits (most reliable marker for aAMR), and serological confirmation of DSA at the time of biopsy ${ }^{404-406}$. In CAMR, circulating DSA are usually present months to years before graft dysfunction and the features of cAMR include chronic allograft glomerulopathy and arteriopathy, deposition of C4d in peritubular capillaries and/or glomeruli (is correlated with DSA) ${ }^{407-409}$. There are four theoretical stages in the development of cAMR (the time between the stages can range from days to months or years): (1) de novo donor-reactive antibodies (most likely DSA); (2) complement activation (C4d deposition) and antibody reactivity within the graft; (3) in addition to C4d, there are pathological differences (graft biopsy), but graft function is normal; (4) this includes stage 1 , 2,3 , and there is graft dysfunction (clinical evidence of chronic rejection) ${ }^{392,404}$. Additionally, in pre-sensitized transplant recipients circulating DSA can cause hyperacute rejection.

Activation of the complement cascade via DSA is fundamental for the pathogenesis of (hyper)acute rejection ${ }^{410}$. Circulating DSA bind to HLA molecules that are expressed on 


\section{Chapter 1}

the surface of endothelial cells within the graft. The complement component $\mathrm{C} 1 \mathrm{q}$ is able to bind to $\lg G_{1}, \lg G_{2}$, and $\lg G_{3}(\lg M)$, which initiates the complete complement cascade (C2 to C9). After subsequent activation of complement components C2, C3, and C4; C5b starts the formation of the membrane attack complex (MAC) consisting of C5b, C6, C7, C8, and C9. The MAC creates a pore in the cell membrane, which causes endothelial cell lysis ${ }^{392}$. However, antibodies can also lyse endothelial cells of the graft via complement-independent pathways such as ADCC. Antibodies (DSA) bind to HLA molecules within the graft and certain immune cells such as NK cells and macrophages that express FcRs are able to bind to the Fc part of these DSA ( $\operatorname{lgG}_{1}$ and $\left.\lg G_{3}\right)$. Subsequently, these immune cells become activated (e.g. NK cell degranulation) and cause lysis of the endothelial cells in the graft ${ }^{411}$. Notably, DSA can also act as agonist and induce proliferation of the endothelial cells via upregulation of fibroblast growth factor receptors (FGFR) and resistance to apoptosis via BCL-XL and BCL-2 ${ }^{392}$. These antibody-mediated mechanisms lead to the destruction of the kidney graft, inducing graft dysfunction and rejection.

\section{Antibody fragments (sFLC Igs)}

The numerous observations of increased (s)FLC Igs in various autoimmune and inflammatory diseases resulted in the suggestion that (s)FLC Igs may be a biomarker for B cell activity and adaptive immune system activation. The interest in FLC Igs started with the observation that increased polyclonal FLC Igs concentrations were measured in various biological fluids such as the blood, cerebrospinal fluid, synovial fluid, and bronchoalveolar lavage. These patients suffered from autoimmune and inflammatory diseases including rheumatoid arthritis ${ }^{412}$, Sjögren's syndrome ${ }^{413}$, systemic lupus erythematosus (SLE) ${ }^{414}$, asthma ${ }^{415}$, rhinitis ${ }^{416}$, atopic dermatitis ${ }^{417}$, food allergy, chronic obstructive pulmonary disease (COPD) ${ }^{418}$, inflammatory bowel disease (IBD) ${ }^{419}$, idiopathic pulmonary fibrosis ${ }^{420}$, and multiple sclerosis ${ }^{421}$. Although, many of these diseases demonstrated an increased level of polyclonal (s)FLC Igs, only in SLE a number of criteria for biomarker validation are made. To date, the polyclonal (s)FLC Igs in these autoimmune and inflammatory diseases are not evaluated in routine clinical practice. Importantly, however, the prognostic value of measuring monoclonal $\mathrm{k}$ and/or $\lambda$ (s)FLC Igs in plasma cell malignancies such as MM and related disorders is well acknowledged and used in clinical examination (guidelines) ${ }^{422,423}$.

In general, the kidneys are responsible for the clearance and proteolysis of sFLC Igs. The $\mathrm{k}( \pm 25 \mathrm{kDa})$ and $\lambda( \pm 50 \mathrm{kDa}) \mathrm{sFLC}$ Igs are filtrated through the glomeruli of the nephrons 
(cortex). However, the exact glomerular clearance remains unknown, but it is suggested that the clearance for $\mathrm{K}$ SFLC Igs is $40 \%$ per hour and for $\lambda$ sFLC Igs is $20 \%$ per hour based on their size and cationic charge ${ }^{424,425}$. Individuals with normal kidney function show a $\mathrm{k}$ sFLC Ig halflife of 2-4 hours and a $\lambda$ sFLC Ig half-life of 3-6 hours ${ }^{426,427}$. Notably, the serum ratio is not a representation of $\mathrm{sFLC}$ Ig production, but reflects the difference in clearance of $\mathrm{K}$ and $\lambda \mathrm{sFLC}$ Igs, with a $\mathrm{k} / \lambda$ ratio of $0.26-1.65$ throughout all age groups ${ }^{428}$. After filtration through the glomerulus, the sFLC Igs are rapidly absorbed via two saturable scavenger receptors called megalin and cubilin, which are present on the proximal tubular epithelial cells (PTECs) in the proximal tubules (outer medulla) ${ }^{426,429}$. The internalization is constant and not influenced by the isoelectric point ${ }^{430}$. After endocytosis via clathrin-coated pits in the PTECs, the endocytic vesicles traffic and enter the lysosomal pathway ${ }^{429,431,432}$. These sFLC Igs are subsequently converted to amino acids and recycled in the body for new protein synthesis ${ }^{75}$. In general, almost all sFLC Igs are reabsorbed (>99\%) and less than 1-10 mg/day (1\%) are excreted in the urine $^{425,433}$ (Figure $\mathbf{5}$ left).

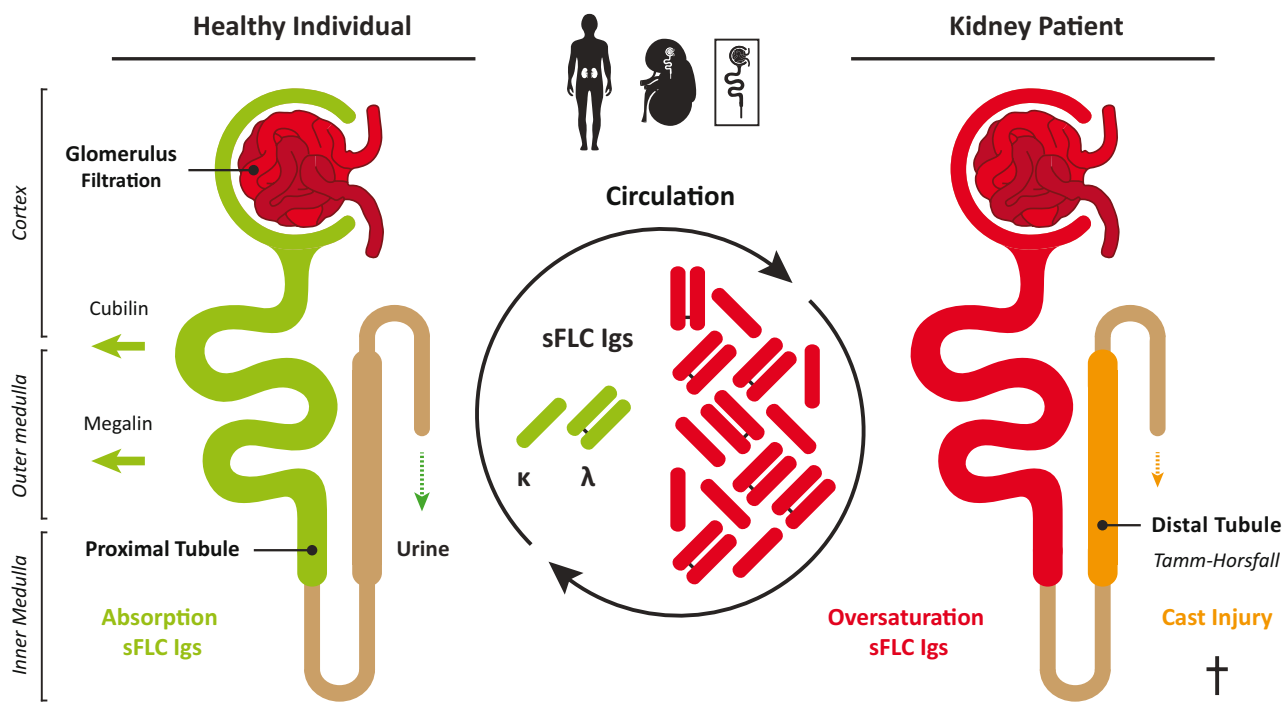

Figure 5: Schematic representation of the SFLC Ig metabolism in nephrons of healthy individuals and kidney patients. (Left) In healthy individuals, the SFLC Igs are filtrated through the glomerulus of the nephron (the nephrons are located in the kidneys). The filtrated SFLC Igs are almost completely ( $>99 \%)$ internalized by the scavenger receptors cubilin and megalin. Only a small fraction $(<1 \%)$ is released in the urine, and the sFLC Ig levels remain within the reference levels. (Right) In kidney patients, direct and indirect consequences of various diseases result in elevated SFLC Ig levels. The receptor-mediated uptake in the proximal tubule is oversaturated, which results in an accumulation of sFLC Igs in the distal tubule. These sFLC Igs bind to Tamm-Horsfall proteins, which leads to cast injury, and ultimately the nephrons dysfunction and die (cast nephropathy). 


\section{Chapter 1}

In contrast, patients with autoimmune- and inflammatory diseases, malignancies, and diseases that indirectly damage the kidneys (e.g. hypertension) show increased SFLC Ig levels. The receptor-mediated absorption (megalin and cubilin) of sFLC Igs is oversaturated in the proximal tubules and increased SFLC Igs are excreted in the urine during an early stage of CKD ${ }^{73}$. The progression of CKD is accompanied with a further increase of sFLC Ig levels ${ }^{434}$. These sFLC Igs bind to a specific epitope on the Tamm-Horsfall (uromodulin) proteins and form thick casts in the distal tubules of the nephrons ${ }^{435,436}$. At this moment, the excretion of sFLC Igs in the urine decreases and rises in the blood. Importantly, the reticulo-endothelial system of the liver becomes the main route of sFLC Ig clearance, and the serum half-life rises up to $32 \mathrm{~h}$ or more ${ }^{437}$. Furthermore, the thick casts in the distal tubules induce inflammatory processes and ultimately the nephrons dysfunction and die ${ }^{75}$ (Figure 5 right).

Since the kidneys play a major role in the proper clearance of sFLC Igs, it has been suggested that $\mathrm{k}$ and $\lambda \mathrm{sFLC}$ Ig levels may be a biomarker for kidney function in patients with CKD. Besides monitoring the sFLC Igs in patients with CKD, also evaluating the sFLC Ig levels after kidney transplantation may be indicative for proper graft function, however at present such data about SFLC Ig levels in the field of kidney transplantation remains elusive.

Although, (s)FLC Igs are always overproduced (10-40\%) by B cells and plasma cells in normal Ig synthesis, there is limited information about the biological role of these (s)FLC Igs. Only a few studies reported that (s)FLC Igs are able to prevent neutrophil apoptosis, induce mast cell degranulation, and inhibit viral replication ${ }^{118,438,439}$. Furthermore, these (s) FLC Igs bind to a variety of cell membranes of different cell lines, but also to PBMCs including monocytes, B cells, and T cells ${ }^{440}$. Notably, a study showed that these (s)FLC Igs are able to bind directly to antigens suggesting their potential role in initiating antigen-specific immune responses ${ }^{441}$. To date, these findings point towards a biological role of (s)FLC Igs, though understanding of the specific functions of (s)FLC Igs on e.g. B cell and T cell function is an important area for further research. 


\section{SCOPE OF THE THESIS}

The main aim of this thesis was to investigate the functional role of B cells and their secreted antibodies in transplantation and cancer. We explored to what extent B cells are activated to produce antibodies when patients are exposed to foreign antigens in (kidney) transplantation, whether their secreted antibodies can be used as biomarker after (kidney) transplantation or cancer treatment, and to what extent B cell function can be influenced in the field of cancer. The chapters are schematically represented in Figure 6.

\section{The exposure to foreign antigens activates $B$ cells}

In chapter 2, we assessed the development of RhD antibodies in kidney transplant recipients who received $\mathrm{RhD}$ incompatible transplantation in a setting of reduced immunosuppression and in absence of anti-RhD prophylaxis.

In chapter 3, we investigated the prevalence and reactivity patterns of HLA-DRB3 antibodies in kidney transplantation and the correlation with HLA expression and graft outcome.

\section{The usage of $B$ cells and their secreted antibodies as biomarker}

In chapter 4, we studied the dynamics of sFLC Ig normalization after kidney transplantation in different graft donors and the correlation with markers for kidney function (SCr, MDRD, and $\beta 2-M)$ and HLA antibody levels.

In chapter 5, we evaluated the therapeutic effect of fractionated RT alone or combined with DC stimulation (Flt3-L) on a pre-existing humoral anti-tumour response in an animal model to investigate the abscopal effect.

\section{The stimulation or inhibition of $B$ cells and their effector functions}

In chapter 6, we investigated the effect of JAK1/2 inhibitor ruxolitinib on the activation and proliferation of B cells.

In chapter 7, we assessed the effect of purified (unconjugated) SFLC Igs or high sFLC Ig levels in sera from MM and CKD patients on the activation and proliferation of $B$ cells and T cells.

This thesis concludes with a general discussion in chapter $\mathbf{8}$, which elucidates the impact of our findings and recommends future research perspectives in the context of B cell biology in transplantation and cancer. 


\section{Chapter 1}

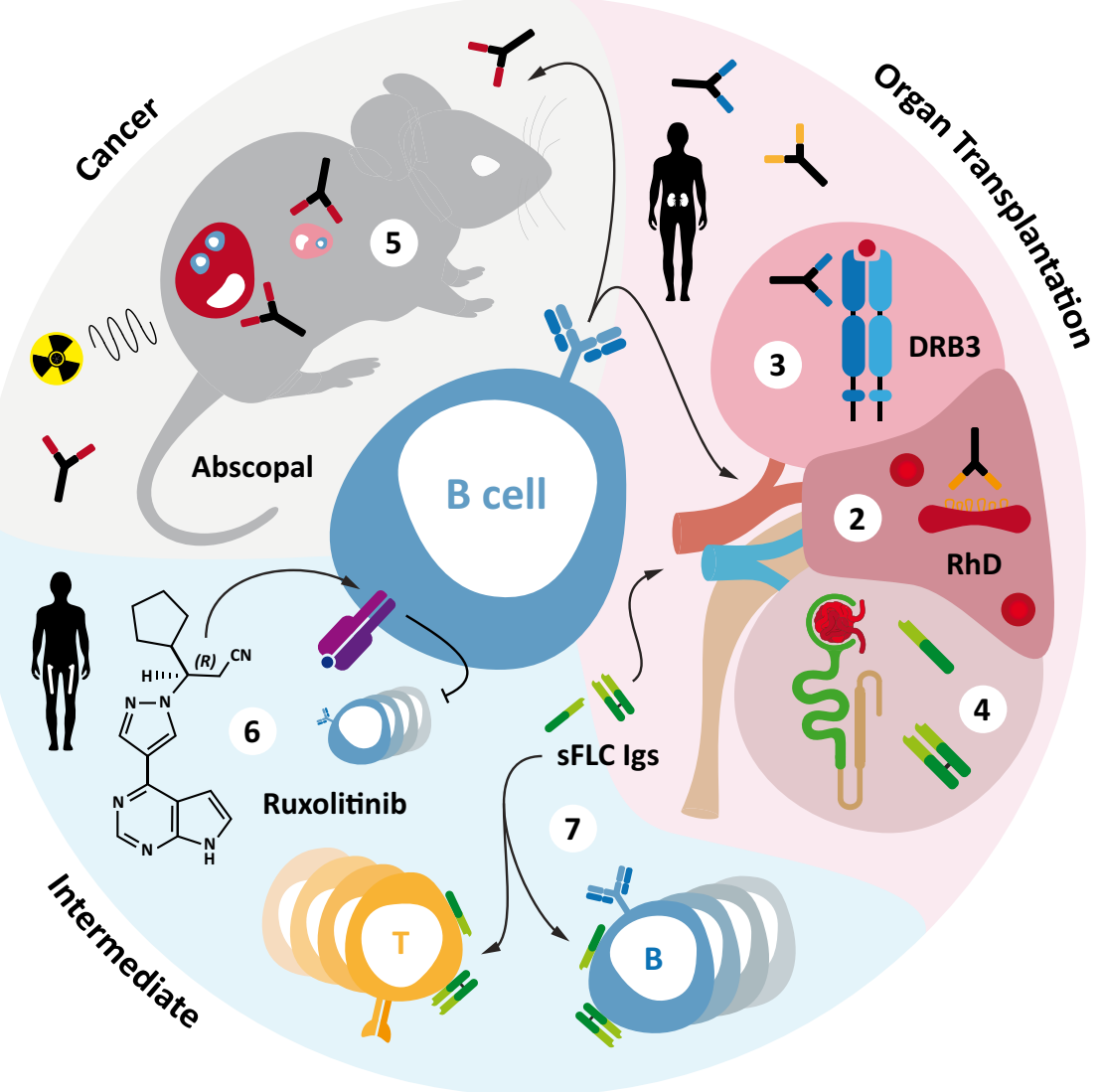

Figure 6: Schematic outline of the thesis. The general aim of the studies presented in this thesis was to explore the role of B cells and their secreted antibodies in transplantation and cancer. In chapter 2, we examined the development of RhD antibodies in transplant recipients who had RhD incompatible kidney transplantation. In chapter 3, we describe the prevalence and reactivity patterns of antibodies against HLA-DRB3 in kidney transplantation and the correlation with HLA expression. In chapter 4, we assessed the dynamics of $\mathrm{k}$ and $\lambda \mathrm{sFLC}$ Ig normalization after kidney transplantation. In chapter 5, we studied whether stimulation of DCs with growth factor Flt3-L alone or combined with fractionated RT modulates a pre-existing humoral anti-tumour response in a mouse model to investigate the abscopal effect. Chapter 6 describes the inhibitory effect of JAK1/2 inhibitor ruxolitinib on the activation and proliferation of peripheral B cells. In chapter 7, we studied the effect of sFLC Igs on the activation and proliferation of polyclonally stimulated B cells and T cells. 


\section{REFERENCES}

1. LeBien TW, Tedder TF. B lymphocytes: how they develop and function. Blood. 2008;112(5):1570-1580.

2. Behring E, Kitasato S. Ueber das Zustandekommen der Diphtherie-Immunitat und der Tetanus-Immunitat bei Thieren. Deutsche medizinsche Wochenschrift. 1890;16:1113-1114.

3. Tiselius A, Kabat EA. Electrophoresis of Immune Serum. Science. 1938;87(2262):416-417.

4. Fagraeus A. The plasma cellular reaction and its relation to the formation of antibodies in vitro. J Immunol. 1948;58(1):1-13.

5. Jerne NK. The Natural-Selection Theory of Antibody Formation. Proc Natl Acad Sci U S A. 1955;41(11):849-857.

6. Burnet FM. A modification of Jerne's theory of antibody production using the concept of clonal selection. Aust J Sci. 1957;20:67-69.

7. Nossal GJ, Lederberg J. Antibody production by single cells. Nature. 1958;181(4620):1419-1420.

8. Porter RR. Chemical Structure of Gamma-Globulin and Antibodies. Br Med Bull. 1963;19:197-201.

9. Edelman GM, Gally JA. A Model for the 7s Antibody Molecule. Proc Natl Acad Sci U S A. 1964;51:846-853.

10. Cooper MD, Peterson RD, Good RA. Delineation of the Thymic and Bursal Lymphoid Systems in the Chicken. Nature. 1965;205:143-146.

11. Cooper MD, Raymond DA, Peterson RD, South MA, Good RA. The functions of the thymus system and the bursa system in the chicken. J Exp Med. 1966;123(1):75-102.

12. Miller JF, Mitchell GF. Cell to cell interaction in the immune response. I. Hemolysin-forming cells in neonatally thymectomized mice reconstituted with thymus/thoracic duct lymphocytes. J Exp Med. 1968;128(4):801-820.

13. Mitchell GF, Miller JF. Cell to cell interaction in the immune response. II. The source of hemolysin-forming cells in radiated mice given bone marrow and thymus/thoracic duct lymphocytes. J Exp Med. 1968;128(4):821-837.

14. Coombs RR, Feinstein A, Wilson AB. Immunoglobulin determinants on the surface of human lymphocytes. Lancet. 1969;2(7631):1157-1160.

15. Froland S, Natvig JB, Berdal P. Surface-bound immunoglobulin as a marker of B lymphocytes in man. Nat New Biol. 1971;234(51):251-252.

16. Brack C, Hirama M, Lenhard-Schuller R, Tonegawa S. A complete immunoglobulin gene is created by somatic recombination. Cell. 1978;15(1):1-14.

17. Oettinger MA, Schatz DG, Gorka C, Baltimore D. RAG-1 and RAG-2, adjacent genes that synergistically activate V(D)J recombination. Science. 1990;248(4962):1517-1523.

18. Schatz DG, Baltimore D. The V(D)J recombination activating gene, RAG-1. Cell. 1989;59(6):1035-1048.

19. Kincade PW, Lawton AR, Bockman DE, Cooper MD. Suppression of immunoglobulin $G$ synthesis as a result of antibody-mediated suppression of immunoglobulin $\mathrm{M}$ synthesis in chickens. Proc Natl Acad Sci U S A. 1970;67(4):1918-1925.

20. Muramatsu M, Kinoshita K, Fagarasan S, Yamada S, Shinkai Y, Honjo T. Class switch recombination and hypermutation require activation-induced cytidine deaminase (AID), a potential RNA editing enzyme. Cell. 2000;102(5):553-563.

21. Stashenko P, Nadler LM, Hardy R, Schlossman SF. Characterization of a human B lymphocyte-specific antigen. J Immunol. 1980;125(4):1678-1685.

22. Naradikian MS, Scholz JL, Oropallo MA, Cancro MP. Understanding B cell biology. Vol. Drugs Targeting B-Cells in Autoimmune Diseases: Springer; 2014.

23. Kondo M. Lymphoid and myeloid lineage commitment in multipotent hematopoietic progenitors. Immunol Rev. 2010;238(1):37-46.

24. Nutt SL, Kee BL. The transcriptional regulation of B cell lineage commitment. Immunity. 2007;26(6):715-725.

25. Cobaleda C, Jochum W, Busslinger M. Conversion of mature B cells into $T$ cells by dedifferentiation to uncommitted progenitors. Nature. 2007;449(7161):473-477.

26. Alt FW, Yancopoulos GD, Blackwell TK, et al. Ordered rearrangement of immunoglobulin heavy chain variable region segments. EMBO J. 1984;3(6):1209-1219.

27. Tonegawa S. Somatic generation of antibody diversity. Nature. 1983;302(5909):575-581. 


\section{Chapter 1}

28. Ghosn EE, Sadate-Ngatchou P, Yang Y, Herzenberg LA, Herzenberg LA. Distinct progenitors for B-1 and B-2 cells are present in adult mouse spleen. Proc Natl Acad Sci U S A. 2011;108(7):2879-2884.

29. Montecino-Rodriguez E, Dorshkind K. B-1 B cell development in the fetus/adult. Immunity. 2012;36(1):13-21.

30. Herzenberg LA. B-1 cells: the lineage question revisited. Immunol Rev. 2000;175:9-22.

31. Griffin DO, Holodick NE, Rothstein TL. Human B1 cells in umbilical cord and adult peripheral blood express the novel phenotype CD20+CD27+ CD43+ CD70. J Exp Med. 2011;208(1):67-80.

32. Melchers F, Strasser A, Bauer SR, Kudo A, Thalmann P, Rolink A. Cellular stages and molecular steps of murine B-cell development. Cold Spring Harb Symp Quant Biol. 1989;54 Pt 1:183-189.

33. Hardy RR. B cell ontogeny and B cell subsets. Curr Opin Immunol. 1989;2(2):189-198.

34. Pennell CA, Mercolino TJ, Grdina TA, Arnold LW, Haughton G, Clarke SH. Biased immunoglobulin variable region gene expression by Ly-1 B cells due to clonal selection. Eur J Immunol. 1989;19(7):1289-1295.

35. Pennell CA, Sheehan KM, Brodeur PH, Clarke SH. Organization and expression of VH gene families preferentially expressed by Ly-1+ (CD5) B cells. Eur J Immunol. 1989;19(11):2115-2121.

36. Seidl KJ, Wilshire JA, MacKenzie JD, Kantor AB, Herzenberg LA, Herzenberg LA. Predominant VH genes expressed in innate antibodies are associated with distinctive antigen-binding sites. Proc Natl Acad Sci U S A. 1999;96(5):2262-2267.

37. Kantor AB, Merrill CE, Herzenberg LA, Hillson JL. An unbiased analysis of V(H)-D-J(H) sequences from B-1a, B-1b, and conventional B cells. J Immunol. 1997;158(3):1175-1186.

38. Pillai S, Baltimore D. Formation of disulphide-linked mu 2 omega 2 tetramers in pre-B cells by the $18 \mathrm{~K}$ omegaimmunoglobulin light chain. Nature. 1987;329(6135):172-174.

39. Kitamura D, Kudo A, Schaal S, Muller W, Melchers F, Rajewsky K. A critical role of lambda 5 protein in B cell development. Cell. 1992;69(5):823-831.

40. Hardy RR, Li YS, Allman D, Asano M, Gui M, Hayakawa K. B-cell commitment, development and selection. Immunol Rev. 2000;175:23-32.

41. Martensson IL, Almqvist N, Grimsholm O, Bernardi Al. The pre-B cell receptor checkpoint. FEBS Lett. 2010;584(12):2572-2579.

42. Allman DM, Ferguson SE, Lentz VM, Cancro MP. Peripheral B cell maturation. II. Heat-stable antigen(hi) splenic B cells are an immature developmental intermediate in the production of long-lived marrow-derived B cells. J Immunol. 1993;151(9):4431-4444.

43. Forster I, Rajewsky K. The bulk of the peripheral B-cell pool in mice is stable and not rapidly renewed from the bone marrow. Proc Natl Acad Sci U S A. 1990;87(12):4781-4784.

44. Allman D, Lindsley RC, DeMuth W, Rudd K, Shinton SA, Hardy RR. Resolution of three nonproliferative immature splenic B cell subsets reveals multiple selection points during peripheral B cell maturation. J Immunol. 2001;167(12):6834-6840.

45. Carsetti R, Kohler G, Lamers MC. Transitional B cells are the target of negative selection in the B cell compartment. J Exp Med. 1995;181(6):2129-2140.

46. Loder F, Mutschler B, Ray RJ, et al. B cell development in the spleen takes place in discrete steps and is determined by the quality of B cell receptor-derived signals. J Exp Med. 1999;190(1):75-89.

47. Pillai S, Cariappa A. The follicular versus marginal zone B lymphocyte cell fate decision. Nat Rev Immunol. 2009;9(11):767-777.

48. Pillai S, Cariappa A, Moran ST. Marginal zone B cells. Annu Rev Immunol. 2005;23:161-196.

49. Bretscher P, Cohn M. A theory of self-nonself discrimination. Science. 1970;169(3950):1042-1049.

50. Tarlinton DM. Evolution in miniature: selection, survival and distribution of antigen reactive cells in the germinal centre. Immunol Cell Biol. 2008;86(2):133-138.

51. Gourley TS, Wherry EJ, Masopust D, Ahmed R. Generation and maintenance of immunological memory. Semin Immunol. 2004;16(5):323-333.

52. Bortnick A, Chernova I, Quinn WJ, 3rd, Mugnier M, Cancro MP, Allman D. Long-lived bone marrow plasma cells are induced early in response to $\mathrm{T}$ cell-independent or $\mathrm{T}$ cell-dependent antigens. J Immunol. 2012;188(11):5389-5396.

53. Obukhanych TV, Nussenzweig MC. T-independent type II immune responses generate memory B cells. J Exp 
Med. 2006;203(2):305-310.

54. Haas KM, Poe JC, Steeber DA, Tedder TF. B-1a and B-1b cells exhibit distinct developmental requirements and have unique functional roles in innate and adaptive immunity to S. pneumoniae. Immunity. 2005;23(1):7-18.

55. Nieuwenhuis P, Opstelten D. Functional anatomy of germinal centers. Am J Anat. 1984;170(3):421-435.

56. Jacob J, Kassir R, Kelsoe G. In situ studies of the primary immune response to (4-hydroxy-3-nitrophenyl)acetyl. I. The architecture and dynamics of responding cell populations. J Exp Med. 1991;173(5):1165-1175.

57. Victora GD, Nussenzweig MC. Germinal centers. Annu Rev Immunol. 2012;30:429-457.

58. Allman D, Jain A, Dent A, et al. BCL-6 expression during B-cell activation. Blood. 1996;87(12):5257-5268.

59. Pavri R, Gazumyan A, Jankovic M, et al. Activation-induced cytidine deaminase targets DNA at sites of RNA polymerase II stalling by interaction with Spt5. Cell. 2010;143(1):122-133.

60. Zotos D, Tarlinton DM. Determining germinal centre B cell fate. Trends Immunol. 2012;33(6):281-288.

61. Shaffer AL, Lin KI, Kuo TC, et al. Blimp-1 orchestrates plasma cell differentiation by extinguishing the mature $B$ cell gene expression program. Immunity. 2002;17(1):51-62.

62. Angelin-Duclos C, Cattoretti G, Lin KI, Calame K. Commitment of B lymphocytes to a plasma cell fate is associated with Blimp-1 expression in vivo. J Immunol. 2000;165(10):5462-5471.

63. Martins G, Calame K. Regulation and functions of Blimp-1 in T and B Iymphocytes. Annu Rev Immunol. 2008;26:133-169.

64. Reimold AM, Iwakoshi NN, Manis J, et al. Plasma cell differentiation requires the transcription factor XBP-1. Nature. 2001;412(6844):300-307.

65. Schittek B, Rajewsky K. Maintenance of B-cell memory by long-lived cells generated from proliferating precursors. Nature. 1990;346(6286):749-751.

66. Manz RA, Thiel A, Radbruch A. Lifetime of plasma cells in the bone marrow. Nature. 1997;388(6638):133-134.

67. Crotty S, Felgner P, Davies H, Glidewell J, Villarreal L, Ahmed R. Cutting edge: long-term B cell memory in humans after smallpox vaccination. J Immunol. 2003;171(10):4969-4973.

68. Maruyama M, Lam KP, Rajewsky K. Memory B-cell persistence is independent of persisting immunizing antigen. Nature. 2000;407(6804):636-642.

69. Gagro A, Toellner KM, Grafton G, et al. Naive and memory B cells respond differentially to T-dependent signaling but display an equal potential for differentiation toward the centroblast-restricted CD77/globotriaosylceramide phenotype. Eur J Immunol. 2003;33(7):1889-1898.

70. Good KL, Avery DT, Tangye SG. Resting human memory B cells are intrinsically programmed for enhanced survival and responsiveness to diverse stimuli compared to naive B cells. J Immunol. 2009;182(2):890-901.

71. Schroeder HW, Jr., Cavacini L. Structure and function of immunoglobulins. J Allergy Clin Immunol. 2010;125(2 Suppl 2):S41-52.

72. Edelman GM, Gall WE, Waxdal MJ, Konigsberg WH. The covalent structure of a human gamma G-immunoglobulin. I. Isolation and characterization of the whole molecule, the polypeptide chains, and the tryptic fragments. Biochemistry. 1968;7(5):1950-1958.

73. Bradwell AR. Serum Free Light Chain Analysis. Birmingham: The Binding Site Ltd.; 2010.

74. Corcos D, Osborn MJ, Matheson LS, et al. Immunoglobulin aggregation leading to Russell body formation is prevented by the antibody light chain. Blood. 2010;115(2):282-288.

75. Basnayake K, Stringer SJ, Hutchison CA, Cockwell P. The biology of immunoglobulin free light chains and kidney injury. Kidney Int. 2011;79(12):1289-1301.

76. Day ED. The light chains of immunoglobulins. Day ED. Advanced Immunochemistry. New York: Wiley; 1990.

77. Williams AF, Barclay AN. The immunoglobulin superfamily--domains for cell surface recognition. Annu Rev Immunol. 1988;6:381-405.

78. Leder P. The genetics of antibody diversity. Sci Am. 1982;246(5):102-115.

79. Dudley DD, Chaudhuri J, Bassing CH, Alt FW. Mechanism and control of V(D)J recombination versus class switch recombination: similarities and differences. Adv Immunol. 2005;86:43-112.

80. Peled JU, Kuang FL, Iglesias-Ussel MD, et al. The biochemistry of somatic hypermutation. Annu Rev Immunol. 2008;26:481-511.

81. Nimmerjahn F, Gordan S, Lux A. FcgammaR dependent mechanisms of cytotoxic, agonistic, and neutralizing 


\section{Chapter 1}

antibody activities. Trends Immunol. 2015;36(6):325-336.

82. Beurskens FJ, van Schaarenburg RA, Trouw LA. C1q, antibodies and anti-C1q autoantibodies. Mol Immunol. 2015;68(1):6-13.

83. Stavnezer J, Guikema JE, Schrader CE. Mechanism and regulation of class switch recombination. Annu Rev Immunol. 2008;26:261-292.

84. Neuberger MS. Antibody diversification by somatic mutation: from Burnet onwards. Immunol Cell Biol. 2008;86(2):124-132.

85. Schur PH. IgG subclasses. A historical perspective. Monogr Allergy. 1988;23:1-11.

86. Vidarsson G, Dekkers G, Rispens T. IgG subclasses and allotypes: from structure to effector functions. Front Immunol. 2014;5:520.

87. Woof JM, Russell MW. Structure and function relationships in IgA. Mucosal Immunol. 2011;4(6):590-597.

88. Fuentes-Panana EM, Monroe JG. Basal B-cell receptor signaling in B lymphocytes: mechanisms of regulation and role in positive selection, differentiation, and peripheral survival. Immunol Rev. 2004;197:26-40.

89. Hombach J, Tsubata T, Leclercq L, Stappert H, Reth M. Molecular components of the B-cell antigen receptor complex of the IgM class. Nature. 1990;343(6260):760-762.

90. Reth M. Antigen receptors on B lymphocytes. Annu Rev Immunol. 1992;10:97-121.

91. Bendtzen K, Hansen MB, Ross C, Svenson M. High-avidity autoantibodies to cytokines. Immunol Today. 1998;19(5):209-211.

92. Czajkowsky DM, Shao Z. The human IgM pentamer is a mushroom-shaped molecule with a flexural bias. Proc Natl Acad Sci U S A. 2009;106(35):14960-14965.

93. Manson JJ, Mauri C, Ehrenstein MR. Natural serum IgM maintains immunological homeostasis and prevents autoimmunity. Springer Semin Immunopathol. 2005;26(4):425-432.

94. Ehrenstein MR, Notley CA. The importance of natural IgM: scavenger, protector and regulator. Nat Rev Immunol. 2010;10(11):778-786.

95. Casali P, Schettino EW. Structure and function of natural antibodies. Microbiol Immunol. 1996;210:167-179.

96. Bindon $\mathrm{Cl}$, Hale $\mathrm{G}$, Bruggemann $\mathrm{M}$, Waldmann $\mathrm{H}$. Human monoclonal IgG isotypes differ in complement activating function at the level of C4 as well as C1q. J Exp Med. 1988;168(1):127-142.

97. Bruhns P. Properties of mouse and human IgG receptors and their contribution to disease models. Blood. 2012;119(24):5640-5649.

98. Bruhns P, lannascoli B, England $P$, et al. Specificity and affinity of human Fcgamma receptors and their polymorphic variants for human IgG subclasses. Blood. 2009;113(16):3716-3725.

99. Seidel UJ, Schlegel P, Lang P. Natural killer cell mediated antibody-dependent cellular cytotoxicity in tumor immunotherapy with therapeutic antibodies. Front Immunol. 2013;4:76.

100. Guilliams M, Bruhns P, Saeys Y, Hammad H, Lambrecht BN. The function of Fcgamma receptors in dendritic cells and macrophages. Nat Rev Immunol. 2014;14(2):94-108.

101. Gillis C, Gouel-Cheron A, Jonsson F, Bruhns P. Contribution of Human FcgammaRs to Disease with Evidence from Human Polymorphisms and Transgenic Animal Studies. Front Immunol. 2014;5:254.

102. Woof JM, Mestecky J. Mucosal immunoglobulins. Immunol Rev. 2005;206:64-82.

103. Kawamura S, Saitou N, Ueda S. Concerted evolution of the primate immunoglobulin alpha-gene through gene conversion. J Biol Chem. 1992;267(11):7359-7367.

104. Mattu TS, Pleass RJ, Willis AC, et al. The glycosylation and structure of human serum IgA1, Fab, and Fc regions and the role of N-glycosylation on Fcalpha receptor interactions. J Biol Chem. 1998;273(4):2260-2272.

105. Herr AB, Ballister ER, Bjorkman PJ. Insights into IgA-mediated immune responses from the crystal structures of human FcalphaRI and its complex with IgA1-Fc. Nature. 2003;423(6940):614-620.

106. Rowe DS, Fahey JL. A New Class of Human Immunoglobulins. II. Serum Igd. J Exp Med. 1965;121:185-199.

107. Rowe DS, Fahey JL. A New Class of Human Immunoglobulins. I. A Unique Myeloma Protein. J Exp Med. 1965;121:171-184.

108. Chen K, Cerutti A. The function and regulation of immunoglobulin D. Curr Opin Immunol. 2011;23(3):345-352.

109. Finkelman FD, van Boxel JA, Asofsky R, Paul WE. Cell membrane IgD: demonstration of IgD on human lymphocytes by enzyme-catalyzed iodination and comparison with cell surface Ig of mouse, guinea pig, and 
rabbit. J Immunol. 1976;116(4):1173-1181.

110. Ruddick JH, Leslie GA. Structure and biologic functions of human IgD. XI. Identification and ontogeny of a rat Iymphocyte immunoglobulin having antigenic crossreactivity human IgD. J Immunol. 1977;118(3):1025-1031.

111. Finkelman FD, Vercelli D. Advances in asthma, allergy mechanisms, and genetics in 2006. J Allergy Clin Immunol. 2007;120(3):544-550.

112. Stanworth DR. The discovery of IgE. Allergy. 1993;48(2):67-71.

113. Thornton CA, Holloway JA, Popplewell EJ, Shute JK, Boughton J, Warner JO. Fetal exposure to intact immunoglobulin E occurs via the gastrointestinal tract. Clin Exp Allergy. 2003;33(3):306-311.

114. Gould HJ, Sutton BJ, Beavil AJ, et al. The biology of IGE and the basis of allergic disease. Annu Rev Immunol. 2003;21:579-628.

115. Kinet JP. The high-affinity IgE receptor (Fc epsilon RI): from physiology to pathology. Annu Rev Immunol. 1999;17:931-972.

116. Kraft S, Kinet JP. New developments in FcepsilonRI regulation, function and inhibition. Nat Rev Immunol. 2007;7(5):365-378.

117. Gould HJ, Sutton BJ. IgE in allergy and asthma today. Nat Rev Immunol. 2008;8(3):205-217.

118. Redegeld FA, van der Heijden MW, Kool M, et al. Immunoglobulin-free light chains elicit immediate hypersensitivity-like responses. Nat Med. 2002;8(7):694-701.

119. Reichert JM. Antibodies to watch in 2016. MAbs. 2016;8(2):197-204.

120. Frenzel A, Schirrmann T, Hust M. Phage display-derived human antibodies in clinical development and therapy. MAbs. 2016:0.

121. Kohler G, Milstein C. Continuous cultures of fused cells secreting antibody of predefined specificity. Nature. 1975;256(5517):495-497.

122. Chan AC, Carter PJ. Therapeutic antibodies for autoimmunity and inflammation. Nat Rev Immunol. 2010;10(5):301-316.

123. Weiner LM, Surana R, Wang S. Monoclonal antibodies: versatile platforms for cancer immunotherapy. Nat Rev Immunol. 2010;10(5):317-327.

124. Almagro JC, Fransson J. Humanization of antibodies. Front Biosci. 2008;13:1619-1633.

125. Scott AM, Wolchok JD, Old LJ. Antibody therapy of cancer. Nat Rev Cancer. 2012;12(4):278-287.

126. Coiffier B, Lepage E, Briere J, et al. CHOP chemotherapy plus rituximab compared with CHOP alone in elderly patients with diffuse large-B-cell lymphoma. N Engl J Med. 2002;346(4):235-242.

127. McLaughlin P, Grillo-Lopez AJ, Link BK, et al. Rituximab chimeric anti-CD20 monoclonal antibody therapy for relapsed indolent lymphoma: half of patients respond to a four-dose treatment program. J Clin Oncol. 1998;16(8):2825-2833.

128. Slamon DJ, Leyland-Jones B, Shak S, et al. Use of chemotherapy plus a monoclonal antibody against HER2 for metastatic breast cancer that overexpresses HER2. N Engl J Med. 2001;344(11):783-792.

129. Vogel CL, Cobleigh MA, Tripathy $D$, et al. Efficacy and safety of trastuzumab as a single agent in first-line treatment of HER2-overexpressing metastatic breast cancer. J Clin Oncol. 2002;20(3):719-726.

130. Cunningham D, Humblet $Y$, Siena $S$, et al. Cetuximab monotherapy and cetuximab plus irinotecan in irinotecanrefractory metastatic colorectal cancer. N EngI J Med. 2004;351(4):337-345.

131. Van Cutsem E, Kohne $\mathrm{CH}$, Hitre $\mathrm{E}$, et al. Cetuximab and chemotherapy as initial treatment for metastatic colorectal cancer. N Engl J Med. 2009;360(14):1408-1417.

132. Leach DR, Krummel MF, Allison JP. Enhancement of antitumor immunity by CTLA-4 blockade. Science. 1996;271(5256):1734-1736.

133. Hodi FS, O'Day SJ, McDermott DF, et al. Improved survival with ipilimumab in patients with metastatic melanoma. N Engl J Med. 2010;363(8):711-723.

134. Han X. Anti-PD-1/PD-L1 therapy of human cancer: past, present, future. J Clin Invest. 2015;125(9):3384-3391.

135. Targan SR, Hanauer SB, van Deventer SJ, et al. A short-term study of chimeric monoclonal antibody cA2 to tumor necrosis factor alpha for Crohn's disease. Crohn's Disease cA2 Study Group. N Engl J Med. 1997;337(15):10291035.

136. Tracey D, Klareskog L, Sasso EH, Salfeld JG, Tak PP. Tumor necrosis factor antagonist mechanisms of action: a 


\section{Chapter 1}

comprehensive review. Pharmacol Ther. 2008;117(2):244-279.

137. Silina K, Rulle U, Kalnina Z, Line A. Manipulation of tumour-infiltrating B cells and tertiary lymphoid structures: a novel anti-cancer treatment avenue? Cancer Immunol Immunother. 2014;63(7):643-662.

138. Balch CM, Riley LB, Bae YJ, et al. Patterns of human tumor-infiltrating lymphocytes in 120 human cancers. Arch Surg. 1990;125(2):200-205.

139. Bindea G, Mlecnik B, Tosolini M, et al. Spatiotemporal dynamics of intratumoral immune cells reveal the immune landscape in human cancer. Immunity. 2013;39(4):782-795.

140. Schoorl R, Riviere AB, Borne AE, Feltkamp-Vroom TM. Identification of T and B lymphocytes in human breast cancer with immunohistochemical techniques. Am J Pathol. 1976;84(3):529-544.

141. Ladanyi A, Kiss J, Mohos A, et al. Prognostic impact of B-cell density in cutaneous melanoma. Cancer Immunol Immunother. 2011;60(12):1729-1738.

142. Nielsen JS, Sahota RA, Milne K, et al. CD20+ tumor-infiltrating lymphocytes have an atypical CD27- memory phenotype and together with CD8+ T cells promote favorable prognosis in ovarian cancer. Clin Cancer Res. 2012;18(12):3281-3292.

143. Pretscher D, Distel LV, Grabenbauer GG, Wittlinger M, Buettner M, Niedobitek G. Distribution of immune cells in head and neck cancer: CD8+ T-cells and CD20+ B-cells in metastatic lymph nodes are associated with favourable outcome in patients with oro- and hypopharyngeal carcinoma. BMC Cancer. 2009;9:292.

144. Richards CH, Flegg KM, Roxburgh CS, et al. The relationships between cellular components of the peritumoural inflammatory response, clinicopathological characteristics and survival in patients with primary operable colorectal cancer. Br J Cancer. 2012;106(12):2010-2015.

145. Schmidt M, Hellwig B, Hammad S, et al. A comprehensive analysis of human gene expression profiles identifies stromal immunoglobulin kappa $\mathrm{C}$ as a compatible prognostic marker in human solid tumors. Clin Cancer Res. 2012;18(9):2695-2703.

146. Schenkel JM, Fraser KA, Beura LK, Pauken KE, Vezys V, Masopust D. T cell memory. Resident memory CD8 T cells trigger protective innate and adaptive immune responses. Science. 2014;346(6205):98-101.

147. Serre K, Cunningham AF, Coughlan RE, et al. CD8 T cells induce T-bet-dependent migration toward CXCR3 ligands by differentiated $B$ cells produced during responses to alumprotein vaccines. Blood. 2012;120(23):4552-4559.

148. van Herpen CM, van der Voort R, van der Laak JA, et al. Intratumoral rhIL-12 administration in head and neck squamous cell carcinoma patients induces B cell activation. Int J Cancer. 2008;123(10):2354-2361.

149. Cipponi A, Mercier M, Seremet T, et al. Neogenesis of lymphoid structures and antibody responses occur in human melanoma metastases. Cancer Res. 2012;72(16):3997-4007.

150. Lundy SK. Killer B lymphocytes: the evidence and the potential. Inflamm Res. 2009;58(7):345-357.

151. Mizoguchi A, Bhan AK. A case for regulatory B cells. J Immunol. 2006;176(2):705-710.

152. Fillatreau S, Sweenie CH, McGeachy MJ, Gray D, Anderton SM. B cells regulate autoimmunity by provision of IL-10. Nat Immunol. 2002;3(10):944-950.

153. Wolf SD, Dittel BN, Hardardottir F, Janeway CA, Jr. Experimental autoimmune encephalomyelitis induction in genetically B cell-deficient mice. J Exp Med. 1996;184(6):2271-2278.

154. Mizoguchi A, Mizoguchi E, Takedatsu H, Blumberg RS, Bhan AK. Chronic intestinal inflammatory condition generates IL-10-producing regulatory $B$ cell subset characterized by CD1d upregulation. Immunity. 2002;16(2):219-230.

155. Brodt P, Gordon J. Anti-tumor immunity in B lymphocyte-deprived mice. I. Immunity to a chemically induced tumor. J Immunol. 1978;121(1):359-362.

156. Monach PA, Schreiber H, Rowley DA. CD4+ and B lymphocytes in transplantation immunity. II. Augmented rejection of tumor allografts by mice lacking B cells. Transplantation. 1993;55(6):1356-1361.

157. Olkhanud PB, Damdinsuren B, Bodogai $M$, et al. Tumor-evoked regulatory B cells promote breast cancer metastasis by converting resting CD4(+) T cells to T-regulatory cells. Cancer Res. 2011;71(10):3505-3515.

158. Qin Z, Richter G, Schuler T, Ibe S, Cao X, Blankenstein T. B cells inhibit induction of T cell-dependent tumor immunity. Nat Med. 1998;4(5):627-630.

159. Shah S, Divekar AA, Hilchey SP, et al. Increased rejection of primary tumors in mice lacking B cells: inhibition of anti-tumor CTL and TH1 cytokine responses by B cells. Int J Cancer. 2005;117(4):574-586. 
160. Tadmor T, Zhang Y, Cho HM, Podack ER, Rosenblatt JD. The absence of B lymphocytes reduces the number and function of T-regulatory cells and enhances the anti-tumor response in a murine tumor model. Cancer Immunol Immunother. 2011;60(5):609-619.

161. Schwartz M, Zhang Y, Rosenblatt JD. B cell regulation of the anti-tumor response and role in carcinogenesis. J Immunother Cancer. 2016;4:40.

162. Zhang Y, Rosenblatt JD. Regulatory B cells in anti-tumor immunity. Int Immunol. 2015;27(10):521-530.

163. Mauri C, Ehrenstein MR. The 'short' history of regulatory B cells. Trends Immunol. 2008;29(1):34-40.

164. Berntsson J, Nodin B, Eberhard J, Micke P, Jirstrom K. Prognostic impact of tumour-infiltrating B cells and plasma cells in colorectal cancer. Int J Cancer. 2016;139(5):1129-1139.

165. Kroeger DR, Milne K, Nelson BH. Tumor-Infiltrating Plasma Cells Are Associated with Tertiary Lymphoid Structures, Cytolytic T-Cell Responses, and Superior Prognosis in Ovarian Cancer. Clin Cancer Res. 2016;22(12):3005-3015.

166. Lundgren S, Berntsson J, Nodin B, Micke P, Jirstrom K. Prognostic impact of tumour-associated B cells and plasma cells in epithelial ovarian cancer. J Ovarian Res. 2016;9:21.

167. Ou Z, Wang $Y$, Liu L, et al. Tumor microenvironment B cells increase bladder cancer metastasis via modulation of the IL-8/androgen receptor (AR)/MMPs signals. Oncotarget. 2015;6(28):26065-26078.

168. Shao Y, Lo CM, Ling CC, et al. Regulatory B cells accelerate hepatocellular carcinoma progression via CD40/ CD154 signaling pathway. Cancer Lett. 2014;355(2):264-272.

169. Shimabukuro-Vornhagen A, Schlosser HA, Gryschok L, et al. Characterization of tumor-associated B-cell subsets in patients with colorectal cancer. Oncotarget. 2014;5(13):4651-4664.

170. Wei X, Jin Y, Tian Y, et al. Regulatory B cells contribute to the impaired antitumor immunity in ovarian cancer patients. Tumour Biol. 2016;37(5):6581-6588.

171. Woo JR, Liss MA, Muldong MT, et al. Tumor infiltrating B-cells are increased in prostate cancer tissue. J Transl Med. 2014;12:30.

172. Ansell SM, Lesokhin AM, Borrello I, et al. PD-1 blockade with nivolumab in relapsed or refractory Hodgkin's lymphoma. N Engl J Med. 2015;372(4):311-319.

173. Armand P, Nagler A, Weller EA, et al. Disabling immune tolerance by programmed death-1 blockade with pidilizumab after autologous hematopoietic stem-cell transplantation for diffuse large B-cell lymphoma: results of an international phase II trial. J Clin Oncol. 2013;31(33):4199-4206.

174. Westin JR, Chu F, Zhang M, et al. Safety and activity of PD1 blockade by pidilizumab in combination with rituximab in patients with relapsed follicular lymphoma: a single group, open-label, phase 2 trial. Lancet Oncol. 2014;15(1):69-77.

175. Affara NI, Ruffell B, Medler TR, et al. B cells regulate macrophage phenotype and response to chemotherapy in squamous carcinomas. Cancer Cell. 2014;25(6):809-821.

176. Bodogai M, Wejksza K, et al. Anti-CD20 antibody promotes cancer escape via enrichment of tumor-evoked regulatory B cells expressing low levels of CD20 and CD137L. Cancer Res. 2013;73(7):2127-2138.

177. Lee KE, Spata M, Bayne LJ, et al. Hif1a Deletion Reveals Pro-Neoplastic Function of B Cells in Pancreatic Neoplasia. Cancer Discov. 2016;6(3):256-269.

178. Zhang Y, Morgan R, Podack ER, Rosenblatt J. B cell regulation of anti-tumor immune response. Immunol Res. 2013;57(1-3):115-124.

179. Aklilu M, Stadler WM, Markiewicz M, et al. Depletion of normal B cells with rituximab as an adjunct to IL-2 therapy for renal cell carcinoma and melanoma. Ann Oncol. 2004;15(7):1109-1114.

180. Barbera-Guillem E, Nelson MB, Barr B, et al. B lymphocyte pathology in human colorectal cancer. Experimental and clinical therapeutic effects of partial B cell depletion. Cancer Immunol Immunother. 2000;48(10):541-549.

181. Karagiannis P, Gilbert AE, Josephs $\mathrm{DH}$, et al. IgG4 subclass antibodies impair antitumor immunity in melanoma. J Clin Invest. 2013;123(4):1457-1474.

182. Daveau M, Pavie-Fischer J, Rivat L, et al. IgG4 subclass in malignant melanoma. J Natl Cancer Inst. 1977;58(2):189-192.

183. Fu SL, Pierre J, Smith-Norowitz TA, et al. Immunoglobulin E antibodies from pancreatic cancer patients mediate antibody-dependent cell-mediated cytotoxicity against pancreatic cancer cells. Clin Exp Immunol. 


\section{Chapter 1}

2008;153(3):401-409.

184. Wrensch M, Wiencke JK, Wiemels J, et al. Serum IgE, tumor epidermal growth factor receptor expression, and inherited polymorphisms associated with glioma survival. Cancer Res. 2006;66(8):4531-4541.

185. van Neerven RJ, Wikborg T, Lund G, et al. Blocking antibodies induced by specific allergy vaccination prevent the activation of CD4+ T cells by inhibiting serum-lgE-facilitated allergen presentation. J Immunol. 1999;163(5):2944-2952.

186. Reuschenbach $M$, von Knebel Doeberitz $M$, Wentzensen N. A systematic review of humoral immune responses against tumor antigens. Cancer Immunol Immunother. 2009;58(10):1535-1544.

187. Hamanaka Y, Suehiro Y, Fukui M, Shikichi K, Imai K, Hinoda Y. Circulating anti-MUC1 IgG antibodies as a favorable prognostic factor for pancreatic cancer. Int J Cancer. 2003;103(1):97-100.

188. Zornig I, Halama N, Lorenzo Bermejo J, et al. Prognostic significance of spontaneous antibody responses against tumor-associated antigens in malignant melanoma patients. Int J Cancer. 2015;136(1):138-151.

189. Yamaguchi T, Takii Y, Maruyama S. Usefulness of serum p53 antibody measurement in colorectal cancer: an examination of 1384 primary colorectal cancer patients. Surg Today. 2014;44(8):1529-1535.

190. Hodge JW, Ardiani A, Farsaci B, Gameiro SR. The tipping point for combination therapy: cancer vaccines with radiation, chemotherapy, or targeted small molecule inhibitors. Semin Oncol. 2012;39(3):323-339.

191. Melero I, Berman DM, Aznar MA, Korman AJ, Perez Gracia JL, Haanen J. Evolving synergistic combinations of targeted immunotherapies to combat cancer. Nat Rev Cancer. 2015;15(8):457-472.

192. Barker HE, Paget JT, Khan AA, Harrington KJ. The tumour microenvironment after radiotherapy: mechanisms of resistance and recurrence. Nat Rev Cancer. 2015;15(7):409-425.

193. Bianchi ME, Beltrame M, Paonessa G. Specific recognition of cruciform DNA by nuclear protein HMG1. Science. 1989;243(4894 Pt 1):1056-1059.

194. Krysko DV, Garg AD, Kaczmarek A, Krysko O, Agostinis P, Vandenabeele P. Immunogenic cell death and DAMPs in cancer therapy. Nat Rev Cancer. 2012;12(12):860-875.

195. Krysko O, Love Aaes T, Bachert C, Vandenabeele P, Krysko DV. Many faces of DAMPs in cancer therapy. Cell Death Dis. 2013;4:e631.

196. Formenti SC, Demaria S. Combining radiotherapy and cancer immunotherapy: a paradigm shift. J Natl Cancer Inst. 2013;105(4):256-265.

197. Golden EB, Apetoh L. Radiotherapy and Immunogenic Cell Death. Semin Radiat Oncol. 2015;25(1):11-17.

198. Kono K, Mimura K, Kiessling R. Immunogenic tumor cell death induced by chemoradiotherapy: molecular mechanisms and a clinical translation. Cell Death Dis. 2013;4:e688.

199. Tesniere A, Apetoh L, Ghiringhelli F, et al. Immunogenic cancer cell death: a key-lock paradigm. Curr Opin Immunol. 2008;20(5):504-511.

200. Vatner RE, Cooper BT, Vanpouille-Box C, Demaria S, Formenti SC. Combinations of immunotherapy and radiation in cancer therapy. Front Oncol. 2014;4:325.

201. Chakraborty M, Abrams SI, Camphausen K, et al. Irradiation of tumor cells up-regulates Fas and enhances CTL Iytic activity and CTL adoptive immunotherapy. J Immunol. 2003;170(12):6338-6347.

202. Reits EA, Hodge JW, Herberts CA, et al. Radiation modulates the peptide repertoire, enhances MHC class I expression, and induces successful antitumor immunotherapy. J Exp Med. 2006;203(5):1259-1271.

203. Sheard MA. lonizing radiation as a response-enhancing agent for CD95-mediated apoptosis. Int J Cancer. 2001;96(4):213-220.

204. Vereecque R, Buffenoir G, Gonzalez R, et al. gamma-ray irradiation induces B7.1 expression in myeloid leukaemic cells. Br J Haematol. 2000;108(4):825-831.

205. Baluna RG, Eng TY, Thomas CR. Adhesion molecules in radiotherapy. Radiat Res. 2006;166(6):819-831.

206. Zamai L, Rana R, Mazzotti G, Centurione L, Vitale M. Lymphocyte binding to K562 cells: effect of target cell irradiation and correlation with ICAM-1 and LFA-3 expression. Eur J Histochem. 1994;38 Suppl 1:53-60.

207. Chakraborty M, Abrams SI, Coleman CN, Camphausen K, Schlom J, Hodge JW. External beam radiation of tumors alters phenotype of tumor cells to render them susceptible to vaccine-mediated T-cell killing. Cancer Res. 2004;64(12):4328-4337.

208. Garnett CT, Palena C, Chakraborty M, Tsang KY, Schlom J, Hodge JW. Sublethal irradiation of human tumor cells 
modulates phenotype resulting in enhanced killing by cytotoxic T lymphocytes. Cancer Res. 2004;64(21):79857994.

209. Demaria S, Formenti SC. Radiation as an immunological adjuvant: current evidence on dose and fractionation. Front Oncol. 2012;2:153.

210. Formenti SC, Demaria S. Systemic effects of local radiotherapy. Lancet Oncol. 2009;10(7):718-726.

211. Liauw SL, Connell PP, Weichselbaum RR. New paradigms and future challenges in radiation oncology: an update of biological targets and technology. Sci Transl Med. 2013;5(173):173sr172.

212. Kaminski JM, Shinohara E, Summers JB, Niermann KJ, Morimoto A, Brousal J. The controversial abscopal effect. Cancer Treat Rev. 2005;31(3):159-172.

213. Mole RH. Whole body irradiation; radiobiology or medicine? Br J Radiol. 1953;26(305):234-241.

214. Abuodeh Y, Venkat P, Kim S. Systematic review of case reports on the abscopal effect. Curr Probl Cancer. 2015.

215. Bramhall RJ, Mahady K, Peach AH. Spontaneous regression of metastatic melanoma - clinical evidence of the abscopal effect. Eur J Surg Oncol. 2014;40(1):34-41.

216. Golden EB, Demaria S, Schiff PB, Chachoua A, Formenti SC. An abscopal response to radiation and ipilimumab in a patient with metastatic non-small cell lung cancer. Cancer Immunol Res. 2013;1(6):365-372.

217. Grimaldi AM, Simeone E, Giannarelli D, et al. Abscopal effects of radiotherapy on advanced melanoma patients who progressed after ipilimumab immunotherapy. Oncoimmunology. 2014;3:e28780.

218. Lakshmanagowda PB, Viswanath L, Thimmaiah N, Dasappa L, Supe SS, Kallur P. Abscopal effect in a patient with chronic lymphocytic leukemia during radiation therapy: a case report. Cases J. 2009;2:204.

219. Ohba K, Omagari K, Nakamura T, et al. Abscopal regression of hepatocellular carcinoma after radiotherapy for bone metastasis. Gut. 1998;43(4):575-577.

220. Okuma K, Yamashita H, Niibe Y, Hayakawa K, Nakagawa K. Abscopal effect of radiation on lung metastases of hepatocellular carcinoma: a case report. J Med Case Rep. 2011;5:111.

221. Postow MA, Callahan MK, Barker CA, et al. Immunologic correlates of the abscopal effect in a patient with melanoma. N Engl J Med. 2012;366(10):925-931.

222. Siva S, Macmanus MP, Martin RF, Martin OA. Abscopal effects of radiation therapy: A clinical review for the radiobiologist. Cancer Lett. 2013.

223. Stamell EF, Wolchok JD, Gnjatic S, Lee NY, Brownell I. The abscopal effect associated with a systemic antimelanoma immune response. Int J Radiat Oncol Biol Phys. 2013;85(2):293-295.

224. Sullivan RJ, Lawrence DP, Wargo JA, Oh KS, Gonzalez RG, Piris A. Case records of the Massachusetts General Hospital. Case 21-2013. A 68-year-old man with metastatic melanoma. N Engl J Med. 2013;369(2):173-183.

225. Wersall PJ, Blomgren H, Pisa P, Lax I, Kalkner KM, Svedman C. Regression of non-irradiated metastases after extracranial stereotactic radiotherapy in metastatic renal cell carcinoma. Acta Oncol. 2006;45(4):493-497.

226. Demaria S, Ng B, Devitt ML, et al. Ionizing radiation inhibition of distant untreated tumors (abscopal effect) is immune mediated. Int J Radiat Oncol Biol Phys. 2004;58(3):862-870.

227. Dewan MZ, Kawashima N, et al. Fractionated but not single-dose radiotherapy induces an immune-mediated abscopal effect when combined with anti-CTLA-4 antibody. Clin Cancer Res. 2009;15(17):5379-5388.

228. Smyth MJ, Ngiow SF, Ribas A, Teng MW. Combination cancer immunotherapies tailored to the tumour microenvironment. Nat Rev Clin Oncol. 2016;13(3):143-158.

229. Palucka K, Banchereau J. Cancer immunotherapy via dendritic cells. Nat Rev Cancer. 2012;12(4):265-277.

230. Pardoll DM. The blockade of immune checkpoints in cancer immunotherapy. Nat Cancer. 2012;12(4):252-264.

231. Restifo NP, Dudley ME, Rosenberg SA. Adoptive immunotherapy for cancer: harnessing the T cell response. Nat Rev Immunol. 2012;12(4):269-281.

232. Khalil DN, Smith EL, Brentjens RJ, Wolchok JD. The future of cancer treatment: immunomodulation, CARs and combination immunotherapy. Nat Rev Clin Oncol. 2016;13(5):273-290.

233. Gelbard A, Garnett CT, Abrams SI, et al. Combination chemotherapy and radiation of human squamous cell carcinoma of the head and neck augments CTL-mediated lysis. Clin Cancer Res. 2006;12(6):1897-1905.

234. Kaneno R, Shurin GV, Kaneno FM, Naiditch H, Luo J, Shurin MR. Chemotherapeutic agents in low noncytotoxic concentrations increase immunogenicity of human colon cancer cells. Cell Oncol (Dordr). 2011;34(2):97-106.

235. Ramakrishnan R, Assudani D, Nagaraj S, et al. Chemotherapy enhances tumor cell susceptibility to CTL- 


\section{Chapter 1}

mediated killing during cancer immunotherapy in mice. J Clin Invest. 2010;120(4):1111-1124.

236. Zitvogel L, Kepp O, Kroemer G. Immune parameters affecting the efficacy of chemotherapeutic regimens. Nat Rev Clin Oncol. 2011;8(3):151-160.

237. Leao IC, Ganesan P, Armstrong TD, Jaffee EM. Effective depletion of regulatory $T$ cells allows the recruitment of mesothelin-specific CD8 T cells to the antitumor immune response against a mesothelin-expressing mouse pancreatic adenocarcinoma. Clin TransI Sci. 2008;1(3):228-239.

238. Lutsiak ME, Semnani RT, De Pascalis R, Kashmiri SV, Schlom J, Sabzevari H. Inhibition of CD4(+)25+ T regulatory cell function implicated in enhanced immune response by low-dose cyclophosphamide. Blood. 2005;105(7):2862-2868.

239. Garnett CT, Hodge JW. Combination of docetaxel and recombinant vaccine enhances T-cell responses and antitumor activity: effects of docetaxel on immune enhancement. Clin Cancer Res. 2008;14(11):3536-3544.

240. Ramakrishnan R, Gabrilovich DI. Mechanism of synergistic effect of chemotherapy and immunotherapy of cancer. Cancer Immunol Immunother. 2011;60(3):419-423.

241. Stein WD, Gulley JL, Schlom J, et al. Tumor regression and growth rates determined in five intramural $\mathrm{NCl}$ prostate cancer trials: the growth rate constant as an indicator of therapeutic efficacy. Clin Cancer Res. 2011;17(4):907-917.

242. Zhang J, Gray NS. Targeting cancer with small molecule kinase inhibitors. Nat Rev Cancer. 2009;9(1):28-39.

243. Arkin MR, Wells JA. Small-molecule inhibitors of protein-protein interactions: progressing towards the dream. Nat Rev Drug Discov. 2004;3(4):301-317.

244. Kang $\mathrm{MH}$, Reynolds $\mathrm{CP}$. Bcl-2 inhibitors: targeting mitochondrial apoptotic pathways in cancer therapy. Clin Cancer Res. 2009;15(4):1126-1132.

245. Altekruse SF, Kosary CL, Krapcho M. SEER cancer statistics review, 1975-2007. Bethesda, MD: National Cancer Institute. 2007.

246. Rickert RC. New insights into pre-BCR and BCR signalling with relevance to B cell malignancies. Nat Rev Immunol. 2013;13(8):578-591.

247. Prideaux SM, Conway O'Brien E, Chevassut TJ. The genetic architecture of multiple myeloma. Adv Hematol. 2014;2014:864058.

248. Smith D, Yong K. Multiple myeloma. BMJ. 2013;346:f3863.

249. Palumbo A, Anderson K. Multiple myeloma. N Engl J Med. 2011;364(11):1046-1060.

250. Bird JM, Owen RG, D'Sa S, et al. Guidelines for the diagnosis and management of multiple myeloma 2011. Br J Haematol. 2011;154(1):32-75.

251. Corre J, Munshi N, Avet-Loiseau H. Genetics of multiple myeloma: another heterogeneity level? Blood. 2015;125(12):1870-1876.

252. Avet-Loiseau H, Attal M, Moreau P, et al. Genetic abnormalities and survival in multiple myeloma: the experience of the Intergroupe Francophone du Myelome. Blood. 2007;109(8):3489-3495.

253. Bochtler T, Hegenbart U, Cremer FW, et al. Evaluation of the cytogenetic aberration pattern in amyloid light chain amyloidosis as compared with monoclonal gammopathy of undetermined significance reveals common pathways of karyotypic instability. Blood. 2008;111(9):4700-4705.

254. Palumbo A, Sezer O, Kyle R, et al. International Myeloma Working Group guidelines for the management of multiple myeloma patients ineligible for standard high-dose chemotherapy with autologous stem cell transplantation. Leukemia. 2009;23(10):1716-1730.

255. Jones HB. Papers on Chemical Pathology, Lecture III. Lancet. 1847;II:88-92.

256. Jones $\mathrm{HB}$. On the new substance occurring in the urine of a patient with mollities ossium. Philosophical Transactions of the Royal Society of London. 1848;Series B: Biological Sciences(138):55-62.

257. Leung N, Nasr SH. Myeloma-related kidney disease. Adv Chronic Kidney Dis. 2014;21(1):36-47.

258. Rajkumar SV, Jacobus S, Callander NS, et al. Lenalidomide plus high-dose dexamethasone versus lenalidomide plus low-dose dexamethasone as initial therapy for newly diagnosed multiple myeloma: an open-label randomised controlled trial. Lancet Oncol. 2010;11(1):29-37.

259. Rajkumar SV, Rosinol L, Hussein M, et al. Multicenter, randomized, double-blind, placebo-controlled study of thalidomide plus dexamethasone compared with dexamethasone as initial therapy for newly diagnosed 
multiple myeloma. J Clin Oncol. 2008;26(13):2171-2177.

260. San Miguel JF, Schlag R, Khuageva NK, et al. Bortezomib plus melphalan and prednisone for initial treatment of multiple myeloma. N Engl J Med. 2008;359(9):906-917.

261. Chen D, Frezza M, Schmitt S, Kanwar J, Dou QP. Bortezomib as the first proteasome inhibitor anticancer drug: current status and future perspectives. Curr Cancer Drug Targets. 2011;11(3):239-253.

262. Chen N, Zhou S, Palmisano M. Clinical Pharmacokinetics and Pharmacodynamics of Lenalidomide. Clin Pharmacokinet. 2016.

263. Thomas ED, Lochte HL, Jr., Cannon JH, Sahler OD, Ferrebee JW. Supralethal whole body irradiation and isologous marrow transplantation in man. J Clin Invest. 1959;38:1709-1716.

264. Passweg JR, Halter J, Bucher C, et al. Hematopoietic stem cell transplantation: a review and recommendations for follow-up care for the general practitioner. Swiss Med Wkly. 2012;142:w13696.

265. Copelan EA. Hematopoietic stem-cell transplantation. N Engl J Med. 2006;354(17):1813-1826.

266. Gyurkocza B, Rezvani A, Storb RF. Allogeneic hematopoietic cell transplantation: the state of the art. Expert Rev Hematol. 2010;3(3):285-299.

267. Oevermann L, Lang P, Feuchtinger T, et al. Immune reconstitution and strategies for rebuilding the immune system after haploidentical stem cell transplantation. Ann N Y Acad Sci. 2012;1266:161-170.

268. Tiercy JM. Unrelated hematopoietic stem cell donor matching probability and search algorithm. Bone Marrow Res. 2012;2012:695018.

269. Petersdorf EW. HLA matching in hematopoietic cell transplantation. Curr Immunol. 2008;20(5):588-593.

270. Petersdorf EW, Anasetti C, Martin PJ, et al. Limits of HLA mismatching in unrelated hematopoietic cell transplantation. Blood. 2004;104(9):2976-2980.

271. Lee SJ, Klein J, Haagenson M, et al. High-resolution donor-recipient HLA matching contributes to the success of unrelated donor marrow transplantation. Blood. 2007;110(13):4576-4583.

272. Furst D, Muller C, Vucinic $V$, et al. High-resolution HLA matching in hematopoietic stem cell transplantation: a retrospective collaborative analysis. Blood. 2013;122(18):3220-3229.

273. Anasetti C, Storb R, et al. Effect of HLA incompatibility on graft-versus-host disease, relapse, and survival after marrow transplantation for patients with leukemia or lymphoma. Hum Immunol. 1990;29(2):79-91.

274. Bosch M, Khan FM, Storek J. Immune reconstitution after hematopoietic cell transplantation. Curr Opin Hematol. 2012;19(4):324-335.

275. Sahin U, Toprak SK, Atilla PA, Atilla E, Demirer T. An overview of infectious complications after allogeneic hematopoietic stem cell transplantation. J Infect Chemother. 2016;22(8):505-514.

276. Teshima T, Reddy P, Zeiser R. Acute Graft-versus-Host Disease: Novel Biological Insights. Biol Blood Marrow Transplant. 2016;22(1):11-16.

277. Socie G, Ritz J. Current issues in chronic graft-versus-host disease. Blood. 2014;124(3):374-384.

278. Young JS, Chen Y, et al. Donor B cells in transplants augment clonal expansion and survival of pathogenic CD4+ T cells that mediate autoimmune-like chronic graft-versus-host disease. J Immunol. 2012;189(1):222-233.

279. Flynn R, Du J, Veenstra RG, et al. Increased T follicular helper cells and germinal center B cells are required for cGVHD and bronchiolitis obliterans. Blood. 2014;123(25):3988-3998.

280. Sarantopoulos S, Ritz J. Aberrant B-cell homeostasis in chronic GVHD. Blood. 2015;125(11):1703-1707.

281. Kekre N, Antin JH. Emerging drugs for graft-versus-host disease. Expert Opin Drugs. 2016;21(2):209-218.

282. Quintas-Cardama A, Vaddi K, Liu P, et al. Preclinical characterization of the selective JAK1/2 inhibitor INCB018424: therapeutic implications for the treatment of myeloproliferative neoplasms. Blood. 2010;115(15):3109-3117.

283. Zeiser R, Burchert A, Lengerke $C$, et al. Ruxolitinib in corticosteroid-refractory graft-versus-host disease after allogeneic stem cell transplantation: a multicenter survey. Leukemia. 2015;29(10):2062-2068.

284. Klein J. Fifty years ago Peter A. Gorer discovered the H-2 complex. Immunogenetics. 1986;24(6):331-338.

285. Klein J, Sato A. The HLA system. First of two parts. N Engl J Med. 2000;343(10):702-709.

286. Bodmer WF. The HLA system: structure and function. J Clin Pathol. 1987;40(9):948-958.

287. Tait BD. The ever-expanding list of HLA alleles: changing HLA nomenclature and its relevance to clinical transplantation. Transplant Rev (Orlando). 2011;25(1):1-8.

288. Koller BH, Geraghty DE, DeMars R, Duvick L, Rich SS, Orr HT. Chromosomal organization of the human major 


\section{Chapter 1}

histocompatibility complex class I gene family. J Exp Med. 1989;169(2):469-480.

289. Kostyu DD, Hannick LI, Traweek JL, Ghanayem M, Heilpern D, Dawson DV. HLA class I polymorphism: structure and function and still questions. Hum Immunol. 1997;57(1):1-18.

290. Parham P, Ohta T. Biology of antigen presentation of MHC class I molecules. Science. 1996;272(5258):67-74.

291. Vivier E, Ugolini S, Blaise D, Chabannon C, Brossay L. Targeting natural killer cells and natural killer T cells in cancer. Nat Rev Immunol. 2012;12(4):239-252.

292. Manser AR, Weinhold S, Uhrberg M. Human KIR repertoires: shaped by genetic diversity and evolution. Immunol Rev. 2015;267(1):178-196.

293. Robinson J, Halliwell JA, Hayhurst JD, Flicek P, Parham P, Marsh SG. The IPD and IMGT/HLA database: allele variant databases. Nucleic Acids Res. 2015;43(Database issue):D423-431.

294. Roche PA, Furuta K. The ins and outs of MHC class II-mediated antigen processing and presentation. Nat Rev Immunol. 2015;15(4):203-216.

295. Trombetta ES, Mellman I. Cell biology of antigen processing in vitro and in vivo. Annu Rev Immunol. 2005;23:975-1028.

296. Luckheeram RV, Zhou R, Verma AD, Xia B. CD4(+)T cells: differentiation and functions. Clin Dev Immunol. 2012;2012:925135.

297. Xie T, Rowen L, Aguado B, et al. Analysis of the gene-dense major histocompatibility complex class III region and its comparison to mouse. Genome Res. 2003;13(12):2621-2636.

298. Horton R, Rand V, et al. Gene map of the extended human MHC. Nat Rev Genet. 2004;5(12):889-899.

299. Klein L, Kyewski B, Allen PM, Hogquist KA. Positive and negative selection of the T cell repertoire: what thymocytes see (and don't see). Nat Rev Immunol. 2014;14(6):377-391.

300. Klein J, Sato A. The HLA system. Second of two parts. N Engl J Med. 2000;343(11):782-786.

301. Ghodke Y, Joshi K, Chopra A, Patwardhan B. HLA and disease. Eur J Epidemiol. 2005;20(6):475-488.

302. Kim IK, Bedi DS, Denecke C, Ge X, Tullius SG. Impact of innate and adaptive immunity on rejection and tolerance. Transplantation. 2008;86(7):889-894.

303. LaRosa DF, Rahman AH, Turka LA. The innate immune system in allograft rejection and tolerance. J Immunol. 2007;178(12):7503-7509.

304. Afzali B, Lechler RI, Hernandez-Fuentes MP. Allorecognition and the alloresponse: clinical implications. Tissue Antigens. 2007;69(6):545-556.

305. Sayegh $\mathrm{MH}$. Why do we reject a graft? Role of indirect allorecognition in graft rejection. Kidney Int. 1999;56(5):1967-1979.

306. Scornik JC, Ireland JE, Howard RJ, Fennell RS, 3rd, Pfaff WW. Role of regular and leukocyte-free blood transfusions in the generation of broad sensitization. Transplantation. 1984;38(6):594-598.

307. Thick M, Verbi V, Kennedy L, Welsh K. Sensitization following kidney graft failure and blood transfusion. Transplantation. 1984;37(5):525-526.

308. Van Rood JJ, Eernisse JG, Van Leeuwen A. Leucocyte antibodies in sera from pregnant women. Nature. 1958;181(4625):1735-1736.

309. Bouma GJ, van Caubergh P, van Bree SP, et al. Pregnancy can induce priming of cytotoxic T lymphocytes specific for paternal HLA antigens that is associated with antibody formation. Transplantation. 1996;62(5):672-678.

310. Rebibou JM, Chabod J, Alcalay D, et al. Flow cytometric evaluation of pregnancy-induced anti-HLA immunization and blood transfusion-induced reactivation. Transplantation. 2002;74(4):537-540.

311. Lee PC, Lee PH, Shaw CK, et al. HLA epitopes for kidney allocation. Transplant Proc. 1998;30(7):3496-3497.

312. McKenna RM, Lee KR, Gough JC, et al. Matching for private or public HLA epitopes reduces acute rejection episodes and improves two-year renal allograft function. Transplantation. 1998;66(1):38-43.

313. Piazza A, Poggi E, Ozzella G, et al. Public epitope specificity of HLA class I antibodies induced by a failed kidney transplant: alloantibody characterization by flow cytometry. Transplantation. 2006;81(9):1298-1305.

314. Rodey GE, Fuller TC. Public epitopes and the antigenic structure of the HLA molecules. Crit Rev Immunol. $1987 ; 7(3): 229-267$.

315. Opelz G, Dohler B. Effect of human leukocyte antigen compatibility on kidney graft survival: comparative analysis of two decades. Transplantation. 2007;84(2):137-143. 
316. Opelz G, Wujciak T, Dohler B. Is HLA matching worth the effort? Collaborative Transplant Study. Transplant Proc. 1999;31(1-2):717-720.

317. Opelz G, Wujciak T, Mytilineos J, Scherer S. Revisiting HLA matching for kidney transplantation. Transplant Proc. 1993;25(1 Pt 1):173-175.

318. Takemoto S, Port FK, Claas FH, Duquesnoy RJ. HLA matching for kidney transplantation. Hum Immunol. 2004;65(12):1489-1505.

319. Thorogood J, Persijn GG, Schreuder GM, et al. The effect of HLA matching on kidney graft survival in separate posttransplantation intervals. Transplantation. 1990;50(1):146-150.

320. Opelz G. Impact of HLA compatibility on survival of kidney transplants from unrelated live donors. Transplantation. 1997;64(10):1473-1475.

321. Opelz G. HLA compatibility and kidney grafts from unrelated live donors. Collaborative Transplant Study. Transplant Proc. 1998;30(3):704-705.

322. Terasaki PI, Cecka JM, Gjertson DW, Takemoto S. High survival rates of kidney transplants from spousal and living unrelated donors. N Engl J Med. 1995;333(6):333-336.

323. Logdberg L, Reid ME, Lamont RE, Zelinski T. Human blood group genes 2004: chromosomal locations and cloning strategies. Transfus Med Rev. 2005;19(1):45-57.

324. Logdberg L, Reid ME, Zelinski T. Human blood group genes 2010: chromosomal locations and cloning strategies revisited. Transfus Med Rev. 2011;25(1):36-46.

325. Owen R. Karl Landsteiner and the first human marker locus. Genetics. 2000;155(3):995-998.

326. Landsteiner K. Ueber Agglutinationserscheinungen nor-malen menschlichen Blutes. Wien Klin Wochschr 1901;14:1132-1134.

327. Springer GF, Tegtmeyer H. Apparent violation of "Landsteiner's law". Klin Wochenschr. 1974;52(6):295-297.

328. Toki D, Ishida H, Setoguchi K, et al. Acute antibody-mediated rejection in living ABO-incompatible kidney transplantation: long-term impact and risk factors. Am J Transplant. 2009;9(3):567-577.

329. Ishida H, Miyamoto $\mathrm{N}$, Shirakawa $\mathrm{H}$, et al. Evaluation of immunosuppressive regimens in ABO-incompatible living kidney transplantation--single center analysis. Am J Transplant. 2007;7(4):825-831.

330. Tanabe K, Takahashi K, Sonda K, et al. Clinicopathological analysis of rejection episodes in ABO-incompatible kidney transplantation. Transplant Proc. 1996;28(3):1447-1448.

331. Toma H, Tanabe K, Tokumoto T. Long-term outcome of ABO-incompatible renal transplantation. Urol Clin North Am. 2001;28(4):769-780.

332. Westhoff $\mathrm{CM}$. The Rh blood group system in review: a new face for the next decade. Transfusion. 2004;44(11):1663-1673.

333. Westhoff CM. The structure and function of the Rh antigen complex. Semin Hematol. 2007;44(1):42-50.

334. Daniels G. A century of human blood groups. Wien Klin Wochenschr. 2001;113(20-21):781-786.

335. Avent ND, Reid ME. The Rh blood group system: a review. Blood. 2000;95(2):375-387.

336. Scott ML. The complexities of the Rh system. Vox Sang. 2004;87 Suppl1:58-62.

337. Wagner FF, Flegel WA. RHD gene deletion occurred in the Rhesus box. Blood. 2000;95(12):3662-3668.

338. Race RR, Sanger R. Blood groups in man. Oxford, England: Blackwell; 1975.

339. Colin Y, Cherif-Zahar B, Le Van Kim C, Raynal V, Van Huffel V, Cartron JP. Genetic basis of the RhD-positive and RhD-negative blood group polymorphism as determined by Southern analysis. Blood. 1991;78(10):2747-2752.

340. Woodrow JC. Rh immunisation and its prevention. Ser Haematol. 1970;3(3):1-151.

341. Mollison PL, Contreras M, et al. Blood Transfusion in Clinical Medicine. Oxford: Blackwell Science; 1997.

342. Engelfriet CP, Reesink HW, Judd WJ, et al. Current status of immunoprophylaxis with anti-D immunoglobin. Vox Sang. 2003;85(4):328-337.

343. Kenwright MG, Sangster JM, Sachs JA. Development of RhD antibodies after kidney transplantation. Br Med J. 1976;2(6028):151-152.

344. Murray S, Dewar PJ, Dinning G. Development of RhD antibodies after kidney transplantation. $\mathrm{Br}$ Med J. 1976;2(6035):585-586.

345. Quan VA, Kemp LJ, Payne A, Andrews PA, Sacks SH. Rhesus immunization after renal transplantation. Transplantation. 1996;61(1):149-150. 


\section{Chapter 1}

346. Stevens LA, Coresh J, Greene T, Levey AS. Assessing kidney function--measured and estimated glomerular filtration rate. N Engl J Med. 2006;354(23):2473-2483.

347. Wesson L. Physiology of the human kidney. New York: Grune \& Stratton; 1969.

348. Smith H. Comparative physiology of the kidney. In: Smith H, ed. The kidney: structure and function in health and disease. Vol. 520-74. New York: Oxford University Press; 1951.

349. Colls PC. Notes on Creatinine. J Physiol. 1896;20(2-3):107-111.

350. Shemesh O, Golbetz H, Kriss JP, Myers BD. Limitations of creatinine as a filtration marker in glomerulopathic patients. Kidney Int. 1985;28(5):830-838.

351. Levey AS, Coresh J. GFR estimation: from physiology to public health. Am J Kidney Dis. 2014;63(5):820-834

352. Branten AJ, Vervoort G, Wetzels JF. Serum creatinine is a poor marker of GFR in nephrotic syndrome. Nephrol Dial Transplant. 2005;20(4):707-711.

353. Preiss DJ, Godber IM, Lamb EJ, Dalton RN, Gunn IR. The influence of a cooked-meat meal on estimated glomerular filtration rate. Ann Clin Biochem. 2007;44(Pt 1):35-42.

354. Levey AS, Greene T, et al. Expressing the Modification of Diet in Renal Disease Study equation for estimating glomerular filtration rate with standardized serum creatinine values. Clin Chem. 2007;53(4):766-772.

355. Levey AS, Bosch JP, Lewis JB, Greene T, Rogers N, Roth D. A more accurate method to estimate glomerular filtration rate from serum creatinine: a new prediction equation. Modification of Diet in Renal Disease Study Group. Ann Intern Med. 1999;130(6):461-470.

356. Inker LA, Schmid $\mathrm{CH}$, Tighiouart $\mathrm{H}$, et al. Estimating glomerular filtration rate from serum creatinine and cystatin C. N Engl J Med. 2012;367(1):20-29.

357. Lopez-Giacoman S, Madero M. Biomarkers in chronic kidney disease, from kidney function to kidney damage. World J Nephrol. 2015;4(1):57-73.

358. Schardijn GH, Statius van Eps LW. Beta 2-microglobulin: its significance in the evaluation of renal function. Kidney Int. 1987;32(5):635-641.

359. Berggard I, Bearn AG. Isolation and properties of a low molecular weight beta-2-globulin occurring in human biological fluids. J Biol Chem. 1968;243(15):4095-4103.

360. Cresswell P, Springer T, Strominger JL, Turner MJ, Grey HM, Kubo RT. Immunological identity of the small subunit of HL-A antigens and beta2-microglobulin and its turnover on the cell membrane. Proc Natl Acad Sci U S A. 1974;71(5):2123-2127.

361. Mistry CD, O'Donoghue DJ, Nelson S, Gokal R, Ballardie FW. Kinetic and clinical studies of beta 2-microglobulin in continuous ambulatory peritoneal dialysis: influence of renal and enhanced peritoneal clearances using glucose polymer. Nephrol Dial Transplant. 1990;5(7):513-519.

362. Karlsson FA, Wibell L, Evrin PE. beta 2-Microglobulin in clinical medicine. Scand J Clin Lab Invest Suppl. 1980;154:27-37.

363. Mavlight GM, Stuckey SE, Cabanillas FF, et al. Diagnosis of leukemia or lymphoma in the central nervous system by beta 2-microglobulin determination. N Engl J Med. 1980;303(13):718-722.

364. Bianchi C, Donadio C, Tramonti G, Consani C, Lorusso P, Rossi G. Reappraisal of serum beta2-microglobulin as marker of GFR. Ren Fail. 2001;23(3-4):419-429.

365. Donadio C, Ardini M, Giordani R. Cystatin C, beta 2-microglobulin, and retinol-binding protein as indicators of glomerular filtration rate: comparison with plasma creatinine. J Pharm Biomed Anal. 2001;24(5-6):835-842.

366. KDIGO. KDIGO 2012 Clinical Practice Guideline for the Evaluation and Management of Chronic Kidney Disease. Kidney Int Supplements. 2013;3(1).

367. Bhavsar NA, Kottgen A, Coresh J, Astor BC. Neutrophil gelatinase-associated lipocalin (NGAL) and kidney injury molecule 1 (KIM-1) as predictors of incident CKD stage 3: the Atherosclerosis Risk in Communities (ARIC) Study. Am J Kidney Dis. 2012;60(2):233-240.

368. Peters HP, Meijer E, et al. High urinary excretion of kidney injury molecule-1 is an independent predictor of end-stage renal disease in patients with IgA nephropathy. Nephrol Dial Transplant. 2011;26(11):3581-3588.

369. Ichimura T, Bonventre JV, Bailly V, et al. Kidney injury molecule-1 (KIM-1), a putative epithelial cell adhesion molecule containing a novel immunoglobulin domain, is up-regulated in renal cells after injury. J Biol Chem. 1998;273(7):4135-4142. 
370. Nakano C, Hamano T, Fujii N, et al. Combined use of vitamin D status and FGF23 for risk stratification of renal outcome. Clin J Am Soc Nephrol. 2012;7(5):810-819.

371. Fliser D, Kollerits B, Neyer U, et al. Fibroblast growth factor 23 (FGF23) predicts progression of chronic kidney disease: the Mild to Moderate Kidney Disease (MMKD) Study. J Am Soc Nephrol. 2007;18(9):2600-2608.

372. Smith ER, Lee D, Cai MM, et al. Urinary neutrophil gelatinase-associated lipocalin may aid prediction of renal decline in patients with non-proteinuric Stages 3 and 4 chronic kidney disease (CKD). Nephrol Dial Transplant. 2013;28(6):1569-1579.

373. Bolignano D, Coppolino G, et al. Neutrophil gelatinase-associated lipocalin (NGAL) and progression of chronic kidney disease. Clin J Am Soc Nephrol. 2009;4(2):337-344.

374. Mishra J, Ma Q, Prada A, et al. Identification of neutrophil gelatinase-associated lipocalin as a novel early urinary biomarker for ischemic renal injury. J Am Soc Nephrol. 2003;14(10):2534-2543.

375. Boes E, Fliser D, Ritz E, et al. Apolipoprotein A-IV predicts progression of chronic kidney disease: the mild to moderate kidney disease study. J Am Soc Nephrol. 2006;17(2):528-536.

376. Kissmeyer-Nielsen F, Olsen S, Petersen VP, Fjeldborg O. Hyperacute rejection of kidney allografts, associated with pre-existing humoral antibodies against donor cells. Lancet. 1966;2(7465):662-665.

377. Patel R, Terasaki PI. Significance of the positive crossmatch test in kidney transplantation. N Engl J Med. 1969;280(14):735-739.

378. Colvin RB. Antibody-mediated renal allograft rejection: diagnosis and pathogenesis. J Am Soc Nephrol. 2007;18(4):1046-1056.

379. Wiebe C, Gibson IW, Blydt-Hansen TD, et al. Evolution and clinical pathologic correlations of de novo donorspecific HLA antibody post kidney transplant. Am J Transplant. 2012;12(5):1157-1167.

380. Loupy A, Hill GS, Jordan SC. The impact of donor-specific anti-HLA antibodies on late kidney allograft failure. Nat Rev Nephrol. 2012;8(6):348-357.

381. Otten HG, Verhaar MC, Hene RJ, van Zuilen AD. Pretransplant donor-specific HLA class-I and -II antibodies are associated with an increased risk for kidney graft failure. Am J Transplant. 2012;12(6):1618-1623.

382. Taylor CJ, Chapman JR, Ting A, Morris PJ. Characterization of lymphocytotoxic antibodies causing a positive crossmatch in renal transplantation. Relationship to primary and regraft outcome. Transplantation. 1989;48(6):953-958.

383. Konvalinka A, Tinckam K. Utility of HLA Antibody Testing in Kidney Transplantation. I Am Soc Nephrol. 2015;26(7):1489-1502.

384. Haarberg KM, Tambur AR. Detection of donor-specific antibodies in kidney transplantation. Br Med Bull. 2014;110(1):23-34.

385. Zachary AA, Leffell MS. Detecting and monitoring human leukocyte antigen-specific antibodies. Hum Immunol. 2008;69(10):591-604.

386. Zachary AA, Vega RM, Lucas DP, Leffell MS. HLA antibody detection and characterization by solid phase immunoassays: methods and pitfalls. Methods Mol Biol. 2012;882:289-308.

387. Gebel HM, Liwski RS, Bray RA. Technical aspects of HLA antibody testing. Curr Opin Organ Transplant. 2013;18(4):455-462.

388. Tait BD, Susal C, Gebel HM, et al. Consensus guidelines on the testing and clinical management issues associated with HLA and non-HLA antibodies in transplantation. Transplantation. 2013;95(1):19-47.

389. Cecka JM, Kucheryavaya AY, Reinsmoen NL, Leffell MS. Calculated PRA: initial results show benefits for sensitized patients and a reduction in positive crossmatches. Am J Transplant. 2011;11(4):719-724.

390. Montgomery RA, Lonze BE, King KE, et al. Desensitization in HLA-incompatible kidney recipients and survival. N Engl J Med. 2011;365(4):318-326.

391. Stegall MD, Gloor J, Winters JL, Moore SB, Degoey S. A comparison of plasmapheresis versus high-dose IVIG desensitization in renal allograft recipients with high levels of donor specific alloantibody. Am J Transplant. 2006;6(2):346-351.

392. Colvin RB, Smith RN. Antibody-mediated organ-allograft rejection. Nat Rev Immunol. 2005;5(10):807-817.

393. Nankivell BJ, Alexander SI. Rejection of the kidney allograft. N Engl J Med. 2010;363(15):1451-1462.

394. Braza F, Brouard S, Chadban S, Goldstein DR. Role of TLRs and DAMPs in allograft inflammation and transplant 


\section{Chapter 1}

outcomes. Nat Rev Nephrol. 2016;12(5):281-290.

395. Briscoe DM, Alexander SI, Lichtman AH. Interactions between T lymphocytes and endothelial cells in allograft rejection. Curr Opin Immunol. 1998;10(5):525-531.

396. Nankivell BJ, Borrows RJ, Fung CL, O'Connell PJ, Allen RD, Chapman JR. The natural history of chronic allograft nephropathy. N Engl J Med. 2003;349(24):2326-2333.

397. Halloran PF. Immunosuppressive drugs for kidney transplantation. N Engl J Med. 2004;351(26):2715-2729.

398. Sis B, Mengel M, Haas M, et al. Banff '09 meeting report: antibody mediated graft deterioration and implementation of Banff working groups. Am J Transplant. 2010;10(3):464-471.

399. Solez K, Colvin RB, Racusen LC, et al. Banff 07 classification of renal allograft pathology: updates and future directions. Am J Transplant. 2008;8(4):753-760.

400. Erlich HA, Opelz G, Hansen J. HLA DNA typing and transplantation. Immunity. 2001;14(4):347-356.

401. Sumitran-Holgersson S, Wilczek HE, Holgersson J, Soderstrom K. Identification of the nonclassical HLA molecules, mica, as targets for humoral immunity associated with irreversible rejection of kidney allografts. Transplantation. 2002;74(2):268-277.

402. Mizutani K, Terasaki P, Rosen A, et al. Serial ten-year follow-up of HLA and MICA antibody production prior to kidney graft failure. Am J Transplant. 2005;5(9):2265-2272.

403. Shapiro-Shelef M, Calame K. Regulation of plasma-cell development. Nat Rev Immunol. 2005;5(3):230-242.

404. Takemoto SK, Zeevi A, Feng S, et al. National conference to assess antibody-mediated rejection in solid organ transplantation. Am J Transplant. 2004;4(7):1033-1041.

405. Racusen LC, Colvin RB, Solez K, et al. Antibody-mediated rejection criteria - an addition to the Banff 97 classification of renal allograft rejection. Am J Transplant. 2003;3(6):708-714.

406. Haas M, Sis B, Racusen LC, et al. Banff 2013 meeting report: inclusion of c4d-negative antibody-mediated rejection and antibody-associated arterial lesions. Am J Transplant. 2014;14(2):272-283.

407. Mauiyyedi S, Pelle PD, Saidman S, et al. Chronic humoral rejection: identification of antibody-mediated chronic renal allograft rejection by C4d deposits in peritubular capillaries. J Am Soc Nephrol. 2001;12(3):574-582.

408. Regele $\mathrm{H}$, Bohmig GA, Habicht A, et al. Capillary deposition of complement split product C4d in renal allografts is associated with basement membrane injury in peritubular and glomerular capillaries: a contribution of humoral immunity to chronic allograft rejection. J Am Soc Nephrol. 2002;13(9):2371-2380.

409. Sijpkens YW, Joosten SA, Wong MC, et al. Immunologic risk factors and glomerular C4d deposits in chronic transplant glomerulopathy. Kidney Int. 2004;65(6):2409-2418.

410. Auchincloss H, Jr., Sachs DH. Xenogeneic transplantation. Annu Rev Immunol. 1998;16:433-470.

411. Wang W, Erbe AK, Hank JA, Morris ZS, Sondel PM. NK Cell-Mediated Antibody-Dependent Cellular Cytotoxicity in Cancer Immunotherapy. Front Immunol. 2015;6:368.

412. Kormelink TG, Tekstra J, Thurlings RM, et al. Decrease in immunoglobulin free light chains in patients with rheumatoid arthritis upon rituximab (anti-CD20) treatment correlates with decrease in disease activity. Ann Rheum Dis. 2010;69(12):2137-2144.

413. Moutsopoulos HM, Steinberg AD, Fauci AS, Lane HC, Papadopoulos NM. High incidence of free monoclonal lambda light chains in the sera of patients with Sjogren's syndrome. J Immunol. 1983;130(6):2663-2665.

414. Aggarwal R, Sequeira W, Kokebie R, et al. Serum free light chains as biomarkers for systemic lupus erythematosus disease activity. Arthritis Care Res (Hoboken). 2011;63(6):891-898.

415. Kraneveld $A D$, Kool $M$, van Houwelingen $A H$, et al. Elicitation of allergic asthma by immunoglobulin free light chains. Proc Natl Acad Sci U S A. 2005;102(5):1578-1583.

416. Groot Kormelink T, Calus L, De Ruyck N, et al. Local free light chain expression is increased in chronic rhinosinusitis with nasal polyps. Allergy. 2012;67(9):1165-1172.

417. Schouten B, van Esch BC, van Thuijl AO, et al. Contribution of IgE and immunoglobulin free light chain in the allergic reaction to cow's milk proteins. J Allergy Clin Immunol. 2010;125(6):1308-1314.

418. Braber S, Blokhuis BR, et al. An association between neutrophils and immunoglobulin free light chains in the pathogenesis of chronic obstructive pulmonary disease. Am J Respir Crit Care Med. 2012;185(8):817-824.

419. Rijnierse A, Redegeld FA, Blokhuis BR, et al. Ig-free light chains play a crucial role in murine mast cell-dependent colitis and are associated with human inflammatory bowel diseases. J Immunol. 2010;185(1):653-659. 
420. Groot Kormelink T, Pardo A, Knipping K, et al. Immunoglobulin free light chains are increased in hypersensitivity pneumonitis and idiopathic pulmonary fibrosis. PLoS One. 2011;6(9):e25392.

421. Krakauer M, Schaldemose Nielsen H, Jensen J, Sellebjerg F. Intrathecal synthesis of free immunoglobulin light chains in multiple sclerosis. Acta Neurol Scand. 1998;98(3):161-165.

422. Ludwig H, Miguel JS, Dimopoulos MA, et al. International Myeloma Working Group recommendations for global myeloma care. Leukemia. 2014;28(5):981-992.

423. Rajkumar SV, Dimopoulos MA, Palumbo A, et al. International Myeloma Working Group updated criteria for the diagnosis of multiple myeloma. Lancet Oncol. 2014;15(12):e538-548.

424. Camargo MJ, Sumpio BE, Maack T. Kinetics of renal catabolism of absorbed proteins: influence of lysosomal pH. Contrib Nephrol. 1984;42:19-29.

425. Maack T, Johnson V, Kau ST, Figueiredo J, Sigulem D. Renal filtration, transport, and metabolism of lowmolecular-weight proteins: a review. Kidney Int. 1979;16(3):251-270.

426. Wochner RD, Strober W, Waldmann TA. The role of the kidney in the catabolism of Bence Jones proteins and immunoglobulin fragments. J Exp Med. 1967;126(2):207-221.

427. Solomon A, Waldmann TA, Fahey JL, McFarlane AS. Metabolism of Bence Jones Proteins. J Clin Invest. 1964;43:103-117.

428. Katzmann JA, Clark RJ, Abraham RS, et al. Serum reference intervals and diagnostic ranges for free kappa and free lambda immunoglobulin light chains: relative sensitivity for detection of monoclonal light chains. Clin Chem. 2002;48(9):1437-1444.

429. Nielsen R, Christensen El, Birn H. Megalin and cubilin in proximal tubule protein reabsorption: from experimental models to human disease. Kidney Int. 2016;89(1):58-67.

430. Dreisbach AW, Batuman V. Low-molecular-weight protein competition for binding sites on renal brush border membranes. Ren Physiol Biochem. 1994;17(6):287-293.

431. Klassen RB, Allen PL, Batuman V, Crenshaw K, Hammond TG. Light chains are a ligand for megalin. J Appl Physiol (1985). 2005;98(1):257-263.

432. Batuman V, Verroust PJ, Navar GL, et al. Myeloma light chains are ligands for cubilin (gp280). Am J Physiol. 1998;275(2 Pt 2):F246-254.

433. Clyne DH, Pollak VE. Renal handling and pathophysiology of Bence Jones proteins. Nephrol. 1981;24:78-87.

434. Desjardins $L$, Liabeuf $S$, Lenglet $A$, et al. Association between free light chain levels, and disease progression and mortality in chronic kidney disease. Toxins (Basel). 2013;5(11):2058-2073.

435. Hutchison CA, Batuman V, Behrens J, et al. The pathogenesis and diagnosis of acute kidney injury in multiple myeloma. Nat Rev Nephrol. 2012;8(1):43-51.

436. Sanders PW, Herrera GA, Kirk KA, Old CW, Galla JH. Spectrum of glomerular and tubulointerstitial renal lesions associated with monotypical immunoglobulin light chain deposition. Lab Invest. 1991;64(4):527-537.

437. Miettinen TA, Kekki M. Effect of impaired hepatic and renal function on Bence Jones protein catabolism in human subjects. Clin Chim Acta. 1967;18:395-407.

438. Cohen G, Rudnicki M, Deicher R, Horl WH. Immunoglobulin light chains modulate polymorphonuclear leucocyte apoptosis. Eur J Clin Invest. 2003;33(8):669-676.

439. Matsumori A, Shimada M, Jie X, Higuchi H, Groot Kormelink T, Redegeld FA. Effects of free immunoglobulin light chains on viral myocarditis. Circ Res. 2010;106(9):1533-1540.

440. Hutchinson AT, Jones DR, Raison RL. The ability to interact with cell membranes suggests possible biological roles for free light chain. Immunol Lett. 2012;142(1-2):75-77.

441. Thio M, Groot Kormelink T, Fischer MJ, Blokhuis BR, Nijkamp FP, Redegeld FA. Antigen binding characteristics of immunoglobulin free light chains: crosslinking by antigen is essential to induce allergic inflammation. PLoS One. 2012;7(7):e40986. 


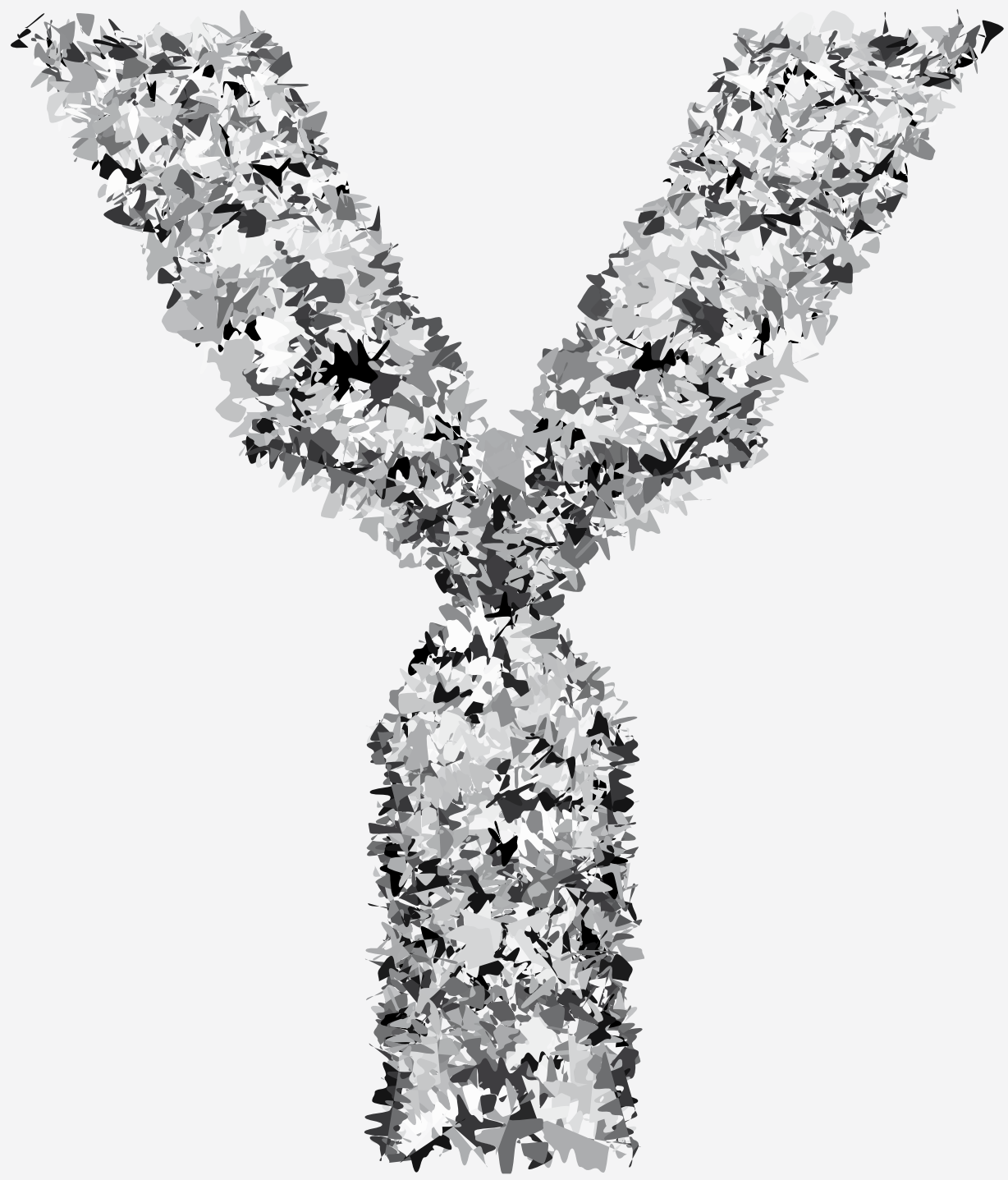




\section{CHAPTER

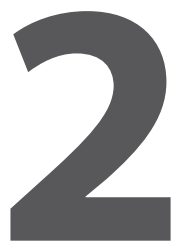

\section{The development of Rhesus-D (RhD) antibodies after RhD incompatible kidney transplantation in a setting of reduced immunosuppression}

Thomas H.P.M. Habets ${ }^{1,2}$, Joris Vanderlocht ${ }^{1}$, Ron J.M.H.E. Straat ${ }^{3}$, Tim C. van Smaalen ${ }^{4}$, Gerard M.J. Bos $^{2,5}$, Erik A. Beckers ${ }^{2}$, Maarten H.L. Christiaans ${ }^{6}$, Yvonne M.C. Henskens ${ }^{3}$

\footnotetext{
1 Tissue Typing Laboratory, Department of Transplantation Immunology, MUMC+, Maastricht

2 Division of Hematology, Department of Internal Medicine, MUMC+, Maastricht

3 Central Diagnostic Laboratory, Cluster for Hemostasis and Transfusion, MUMC+, Maastricht

4 Department of Surgery, MUMC+, Maastricht

5 CiMaas BV, Maastricht

6 Division of Nephrology, Department of Internal Medicine, MUMC+, Maastricht
} 


\section{Chapter 2}

\section{ABSTRACT}

Background: RhD antigens are not taken into account in the allocation of solid organs. Female transplant recipients with RhD antibodies as a consequence of RhD incompatible kidney transplantation may develop hemolytic disease of the fetus and newborn in future pregnancies. We examined RhD antibody development in transplant recipients who received RhD incompatible kidney transplantation in absence of RhD prophylaxis and in a setting of reduced immunosuppression.

Study design: From 1993 until 2015, 1355 kidney patients were transplanted in our center of which 156 were RhD- who received a RhD+ donor graft. The sera were tested 3 months after transplantation for irregular antibodies using a 3-cell screening and an identification panel. In case of RhD antibody positivity, also a serum 1 month before transplantation was tested.

Results: In 7 out of 156 transplant recipients (4.5\%) we demonstrated irregular erythrocyte antibodies after transplantation, which were further identified as 5 (3.2\%) recipients with RhD antibodies. In the 5 recipients, we found only 1 (0.6\%) recipient without RhD antibodies before transplantation.

Conclusion: Although the risk of RhD antibody development is considerably lower after RhD incompatible kidney transplantation as compared to a RhD mismatched pregnancy, anti-RhD prophylaxis may be advisable when transplant recipients want to have a future pregnancy. 


\section{INTRODUCTION}

For many patients that suffer from end stage renal disease (ESRD) kidney transplantation is the treatment of choice, which results in an increased quality of life and patient survival. At present, ESRD patients and graft donors are matched for two major antigen systems, the human leukocyte antigens (HLA) and ABO blood group antigens that are both present on endothelial cells, to prevent the development of donor-specific HLA antibodies, hyperacute rejection, and inferior graft outcome ${ }^{1,2}$. In contrast, the second most immunogenic red blood cell (RBC) antigen Rhesus-D (RhD) is not expressed on endothelium of the kidneys and as a consequence these antigens are not considered in kidney transplantation. These RhD antigens are only present on RBCs; and RhD antibodies are formed when a RhD- individual receives blood cells from a $\mathrm{RhD}+$ individual. As little as $0.5 \mathrm{~mL}$ of blood has been shown to be sufficient to induce a primary RhD antibody production ${ }^{3}$. Furthermore, these formed RhD antibodies may persist for many years in the blood circulation ${ }^{4}$.

It has been shown that RhD incompatible kidney transplantation can result in RhD antibody formation and these antibodies may have clinical implications in case of a future pregnancy ${ }^{5}$. In those patients, a RhD+ fetus is at risk to develop hemolytic disease of the fetus and newborn (HDFN), which can result in perinatal mortality and morbidity ${ }^{6}$. During pregnancy, anti-RhD prophylaxis is given to RhD- females that prevents antibody formation in RhD- females who are exposed to RhD+ fetal cells ${ }^{7}$. Without anti-RhD prophylaxis, $8.2 \%$ of these RhD- women who carry a RhD+ fetus develop RhD antibodies 6 months after delivery, and this percentage increases to $17 \%$ after a subsequent pregnancy ${ }^{8,9}$. In the last decades, there is an increase in the number of kidney transplant recipients having a pregnancy, and the development of $\mathrm{RhD}$ antibodies after RhD incompatible kidney transplantation may be a risk factor for complications during future pregnancies ${ }^{10}$. In literature, case reports from the 1970s and 1980s showed the development of RhD antibodies after kidney transplantation. However, only one clinical study from 1996 focussed on RhD immunization in a cohort of 42 RhD- transplant recipients who had RhD+ kidney transplantation ${ }^{11-13}$. In this study by Quan et al., 2 out of 42 (5\%) RhD- kidney transplant recipients developed RhD antibodies for the first time after RhD incompatible kidney transplantation while receiving immunosuppressive medication (cyclosporin, prednisolone, and azathioprine) ${ }^{5}$.

In the last decades, major advances in the immunosuppressive conditioning of organ recipients and the procedure of organ preservation were made. It has become clear 


\section{Chapter 2}

that immunosuppressive medication is particularly capable of improving short-term outcome in kidney transplantation by reducing acute rejection episodes. Besides adverse effects such as decreased immune competence, long-term treatment is accompanied with various adverse side effects such as malignancy and cardiovascular complications. In contrast to most other transplant centers that combine different drugs at decreased dose while keeping their suppressive potential, our transplant center uses tacrolimus as maintenance monotherapy 14. Furthermore, most recipients in our center did not receive induction therapy with ATG (anti-thymocyte globulin) or anti-IL-2 receptor blockers before transplantation. In the 1990s and early 2000s, transplant recipients received diverse combinations of immunosuppressive drugs after transplantation such as corticosteroids, azathioprine, cyclosporin, sirolimus, and everolimus. However, in recent years, transplant recipients received primarily triple therapy comprising of tacrolimus (calcineurin inhibitor), mycophenolic acid (MMF), and prednisolone (withdrawn after two days). After two days, tacrolimus and MMF are administered as duotherapy for 3 months, and thereafter tacrolimus is given as monotherapy.

In this study, we determined the prevalence and development of RhD antibodies in recipients who received $\mathrm{RhD}$ incompatible kidney transplantation in the absence of anti-RhD prophylaxis and in a transplant setting of reduced immunosuppressive medication.

\section{MATERIALS AND METHODS}

\section{RhD negative kidney patients}

We screened a total of 1355 kidney transplant recipients of the Maastricht University Medical Center (the Netherlands) who had kidney transplantation in the time-period from 1993 until 2015. Both living and all types of deceased donors were included. Of these 1355 recipients, we identified 156 RhD- kidney patients who received RhD incompatible kidney transplantation. We retrospectively collected frozen serum samples of these $156 \mathrm{RhD}$ - patients, which were tested all at once for the presence of irregular antibodies 3 months after transplantation. In case of RhD antibody identification also the sera 1 month before transplantation were tested.

Since we included RhD- patients in the time-period from 1993 until 2015, the kidney patients received diverse combinations of immunosuppressive drugs after RhD incompatible kidney transplantation, which are shown in Table 1. Notably, most of these recipients $(n=76)$ received reduced immunosuppression denoted as triple therapy (regimen 4 ) in recent years. 
Table 1: The different drug combinations administered to $156 \mathrm{RhD}$ - transplant recipients in the time-period from 1993 until 2015. Induction therapy was only administered to a limited number of transplant recipients. The immunosuppressive drugs after kidney transplantation are represented as therapy 1, 2, and 3. MMF, mycophenolic acid. IL-2R MoAb, a monoclonal antibody against the IL-2 receptor.

\begin{tabular}{llllll}
\hline Regimen & $\boldsymbol{n}$ & Induction & Therapy (1) & Therapy (2) & Therapy (3) \\
\hline $\mathbf{1}$ & 14 & Corticosteroids & Tacrolimus & \\
$\mathbf{2}$ & 10 & Corticosteroids & Cyclosporin & \\
$\mathbf{3}$ & 1 & Tacrolimus & Sirolimus & \\
$\mathbf{4}$ & 76 & Corticosteroids & MMF & Tacrolimus \\
$\mathbf{5}$ & 36 & Corticosteroids & Tacrolimus & Sirolimus \\
$\mathbf{6}$ & 4 & & Corticosteroids & Azathioprine & Cyclosporin \\
$\mathbf{7}$ & 4 & & Corticosteroids & Azathioprine & Tacrolimus \\
$\mathbf{8}$ & 2 & & Corticosteroids & Tacrolimus & Other \\
$\mathbf{9}$ & 4 & IL-2R MoAb & Corticosteroids & MMF & Tacrolimus \\
$\mathbf{1 0}$ & 3 & IL-2R MoAb & Corticosteroids & MMF & Sirolimus \\
$\mathbf{1 1}$ & 2 & IL-2R MoAb & Corticosteroids & Everolimus & Tacrolimus \\
\hline & & & & & \\
\hline
\end{tabular}

\section{Measurement of RhD antibodies in serum}

The serum samples were examined with a 3-cell screening (ID-DiaCell I-II-III, Biorad, Swiss) and a 11-cell identification panel in the $\mathrm{IH}-1000$ analyzer using the manufacturers' protocol (Biorad, Swiss). To prevent (reduce) variation in detection, the ID-DiaCell I-II-III screening (Lot. 45184.08.x) and the identification panel (Lot. 45161.66.x) were from the same batch. In short, the sera were screened for irregular antibodies and in case of positivity the antibodies were further identified by means of an identification panel. In case of a positive RhD identification the serum samples before kidney transplantation (max. 1 month) were also tested. When such a serum sample before kidney transplantation was negative for RhD antibodies, other immunizing events such as transfusions of blood and/or thrombocytes that occurred in the period around the kidney transplantation were excluded.

\section{RESULTS}

In order to determine both the prevalence and development of RhD antibodies in kidney transplant recipients who received RhD incompatible kidney transplantation, we screened a total of 1355 kidney transplant recipients in our transplant cohort in the time-period from 


\section{Chapter 2}

1993 until 2015. As shown in Figure 1, we identified 156 RhD- recipients who received a $\mathrm{RhD}+$ donor graft. In order to determine to what extent $\mathrm{RhD}$ incompatible transplantation is able to induce RhD antibodies in a setting of reduced immunosuppression, we analysed the sera of these 156 RhD- kidney transplant recipients 3 months after transplantation using the 3-cell screening panel (ID-DiaCell I-II-III) and the IH-1000 analyzer. This time point of 3 months was selected, since in case of RhD immunization, a strong and robust antibody response is observed after immunization and RhD antibodies subsequently persist for a very long time in the blood circulation ${ }^{4}$.

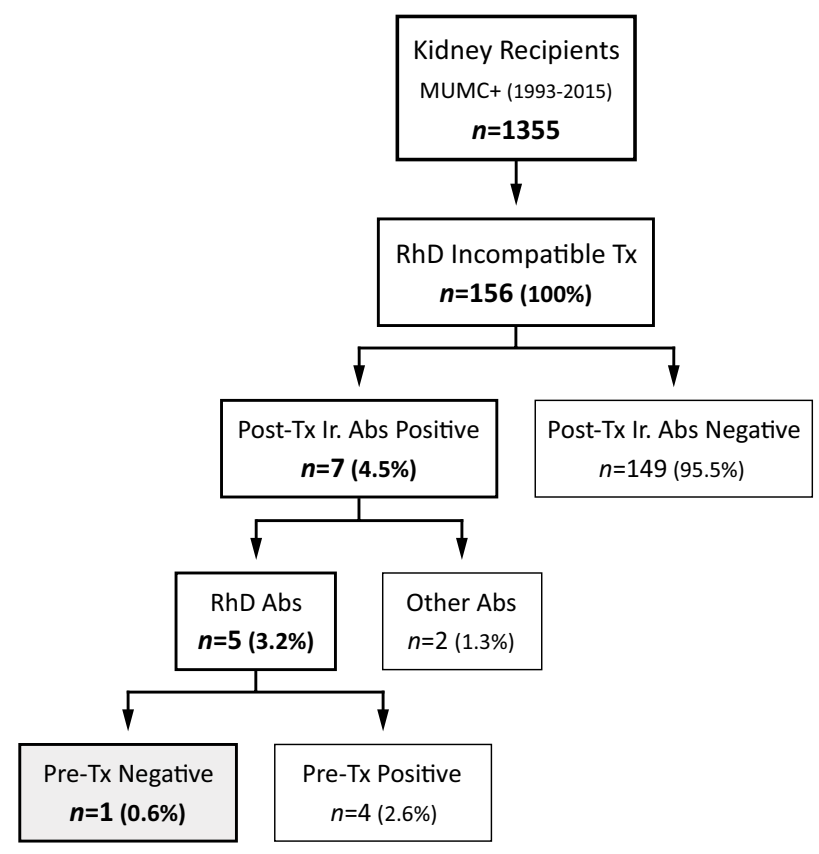

Figure 1: Schematic representation of the prevalence and development of $\mathrm{RhD}$ antibodies in transplant recipients who received RhD incompatible kidney transplantation. A total of 1355 kidney patients were transplanted at MUMC+ in the time-period from 1993 until 2015. Of these 1355 patients, we found 156 RhDrecipients who received a RhD+ kidney graft. In 7 (4.5\%) RhD- recipients irregular antibodies were detected and antibody identification showed that 5 (3.2\%) RhDrecipients had RhD antibodies. Only 1 (0.6\%) RhD- recipient was negative for RhD antibodies before transplantation. Pre Tx, before transplantation. Post Tx, after transplantation. Ir. Abs, irregular antibodies.

We observed that 7 out of 156 (4.5\%) recipients displayed the presence of irregular antibodies, whereas 149 out of 156 (95.5\%) recipients were negative for these antibodies. The 7 sera with irregular antibodies were further specified using an identification panel, and 5 out of 156 (3.2\%) recipients displayed RhD antibodies. In 1 of these 5 recipients, we found also Jk (Kidd) antibodies. In contrast, 2 (1.3\%) recipients without RhD antibodies displayed the presence of $K$ (Kell) antibodies or showed a reactivity with an undetermined specificity.

To determine whether RhD incompatible kidney transplantation was the source of $\mathrm{RhD}$ immunisation, we analysed the serum of these $5 \mathrm{RhD}$ - recipients with RhD antibodies 1 
month before kidney transplantation. We observed only 1 serum that was negative for RhD antibodies before kidney transplantation. This female RhD- recipient showed no history of prior immunization from RhD+ blood transfusions or pregnancies. The remaining 4 sera were positive for RhD antibodies ( 1 serum was also positive for $\mathrm{Jk}^{\mathrm{a}}$ ) before transplantation. With respect to reduced immunosuppression, these $5 \mathrm{RhD}$ - recipients had different combinations of drugs after kidney transplantation. The female RhD- recipient (1 out of 5) without RhD antibodies before transplantation received regimen 4 after kidney transplantation (Table 1).

In conclusion, we showed that only 1 out of 156 (0.6\%) RhD- recipients who received RhD incompatible kidney transplantation developed RhD antibodies in our transplant setting of reduced immunosuppression.

\section{DISCUSSION}

In our transplant center we aim to minimize the adverse effects of long-term treatment with immunosuppressive agents by reducing the immune suppression early after transplantation. Since anti-RhD prophylaxis is not administered in our transplant center and because there is an increase in the number of pregnancies in kidney transplant recipients ${ }^{10}$, we examined how frequent RhD antibodies are formed after RhD incompatible kidney transplantation.

We have demonstrated the prevalence of RhD incompatible kidney transplantation in a total of 156 RhD- recipients transplanted in the period from 1993 until 2015 (22 years). Only 1 out of 156 (0.6\%) RhD- recipients showed the development of RhD antibodies after a first kidney transplantation with a RhD+ donor graft (donation after cardiac death (DCD) donor). This female RhD- recipient had no history of RhD immunisation from RhD+ blood transfusions or pregnancies before and after the transplantation (3 months). Therefore, it is likely that the antibody response that is observed represents a primary immune response that develops as a result of the transplanted RhD+ kidney. In addition, since RhD antibodies persist for a very long time in the blood, this also indicates that there was no preceding RhD immunization ${ }^{4}$. Although DCD donor grafts undergo machine perfusion, probably passenger RBCs that were not completely washed out during the perfusion of the RhD+ donor graft were responsible for this RhD immunization. The study of Quan et al. demonstrated that RhD antibodies were able to develop even in the presence of immunosuppressive drugs cyclosporine, prednisolone, and azathioprine given to the kidney patients who had RhD incompatible transplantation in the period 1988 to $1994{ }^{5}$. Their study showed that 5\% (2 


\section{Chapter 2}

out of 42 ) of the RhD- recipients developed RhD antibodies after kidney transplantation. In contrast, we identified that only $0.6 \%$ (1 out of 156 ) of the RhD- recipients developed RhD antibodies in our transplant setting of reduced immunosuppression. To this end, this $1 \mathrm{RhD}-$ recipient received regimen 4 after kidney transplantation (1 out of 76; 1.3\%), demonstrating that even when administrating reduced immunosuppression, we do not observe an increase in the development of RhD antibodies as compared to existing literature. Notably, although RhD incompatibility results in RhD antibody production, it was already shown that these RhD antibodies in RhD- recipients had no influence on renal function or survival of RhD+ donor grafts $^{13}$.

Even though infrequent, our observation indicates that RhD antibody formation can occur after RhD incompatible kidney transplantation and therefore anti-RhD prophylaxis may be advisable when transplant recipients want to have a future pregnancy. Without anti-RhD prophylaxis, a RhD- transplanted woman with RhD antibodies who carries a RhD+ fetus may develop HDFN.

In our transplant cohort, we observed a high incidence of RhD antibodies (5/156 = $3.2 \%$ ) as compared to the general population and even higher than that observed in women after RhD incompatible pregnancies in the presence of anti-RhD prophylaxis $(0.1-0.3 \%)^{15,16}$. Notably, all these $5 \mathrm{RhD}$ - recipients with RhD antibodies prior to kidney transplantation were female, in which RhD sensitization was a consequence of pregnancy (1-4 times). Only 1 RhDrecipient developed $\mathrm{RhD}$ antibodies due to $\mathrm{RhD}$ incompatible transplantation.

In 1996, Quan et al. suggested to administer anti-RhD prophylaxis to female RhDkidney transplant recipients who want to get pregnant after receiving RhD incompatible kidney transplantation. The development of RhD antibodies can be prevented with a normal dose of anti-RhD prophylaxis (e.g. $500 \mathrm{IU}$ ), which may be sufficient to neutralize $10 \mathrm{~mL}$ of blood as it is highly unlikely that after perfusion of the transplanted donor graft more than 10 $\mathrm{mL}$ is present ${ }^{5}$. Since we observed that the percentage of RhD antibody formation after RhD incompatible kidney transplantation is infrequent, but that the number of pregnancies after transplantation is increasing in kidney transplant recipients, the administration of anti-RhD prophylaxis may be advisable in case of female kidney transplant recipients under the age of 45 who want to have future pregnancies.

In conclusion, in a setting with reduced immunosuppression and in absence of antiRhD prophylaxis, we observed only 1 out of 156 (0.6\%) RhD- recipients who developed RhD antibodies after RhD incompatible kidney transplantation. Although very infrequent, RhD 
incompatible transplantation can lead to the development of these antibodies, which is a reflection that even with current perfusion media not all erythrocytes are washed from the kidney graft. Therefore, anti-RhD prophylaxis may be advisable for females under the age of 45 undergoing a kidney transplantation.

\section{ACKNOWLEDGEMENTS}

The authors would like to thank Esther Schaepkens, Simone van der Linden, and Ilse Houba for their technical assistance.

\section{REFERENCES}

1. Susal C, Opelz G. Current role of human leukocyte antigen matching in kidney transplantation. Curr Opin Organ Transplant. 2013;18(4):438-444.

2. Rydberg L. ABO-incompatibility in solid organ transplantation. Transfus Med. 2001;11(4):325-342.

3. Gunson HH, Stratton F, Phillips PK. The primary Rho(D) immune response in male volunteers. Br J Haematol. 1976;32(3):317-329.

4. Reverberi R. The persistence of red cell alloantibodies. Blood Transfus. 2008;6(4):225-234.

5. Quan VA, Kemp LJ, Andrews PA, Sacks SH. Rhesus immunization after renal transplantation. Transplantation. 1996;61(1):149-150.

6. Bowman JM. RhD hemolytic disease of the newborn. N Engl J Med. 1998;339(24):1775-1777.

7. Kumpel BM. On the immunologic basis of Rh (anti-D) prophylaxis. Transfusion. 2006;46(9):1652-1656.

8. Woodrow JC. Rh immunisation and its prevention. Ser Haematol. 1970;3(3):1-151.

9. Mollison PL, Contreras M. Blood Transfusion in Clinical Medicine. Oxford: Blackwell Science; 1997.

10. McKay DB, Josephson MA. Pregnancy in recipients of solid organs--effects on mother and child. N Engl J Med. 2006;354(12):1281-1293.

11. Murray S, Dewar PJ, Dinning G. Development of RhD antibodies after kidney transplantation. Br Med J. 1976;2(6035):585-586.

12. Kenwright MG, Sangster JM, Sachs JA. Development of RhD antibodies after kidney transplantation. Br Med J. 1976;2(6028):151-152.

13. Gluckman JC, Foucault C, Beaufils H, Luciani J, Cartron J, Frantz PF. Rh antibodies after kidney transplantation. Transplantation. 1981;32(3):260-262.

14. Christiaans M, Gelens M, van Duijnhoven E, van Heurn E, Vanderlocht J, van Hooff J. Abstract A206: Ten years follow-up data of Tac QD treated renal transplant patients. American Journal of Transplantation. 2014;14(S3):458.

15. Engelfriet CP, Reesink HW, Judd WJ, et al. Current status of immunoprophylaxis with anti-D immunoglobin. Vox Sang. 2003;85(4):328-337.

16. Koelewijn JM, de Haas M, Vrijkotte TG, Bonsel GJ, van der Schoot CE. One single dose of 200 microg of antenatal RhIG halves the risk of anti-D immunization and hemolytic disease of the fetus and newborn in the next pregnancy. Transfusion. 2008;48(8):1721-1729. 


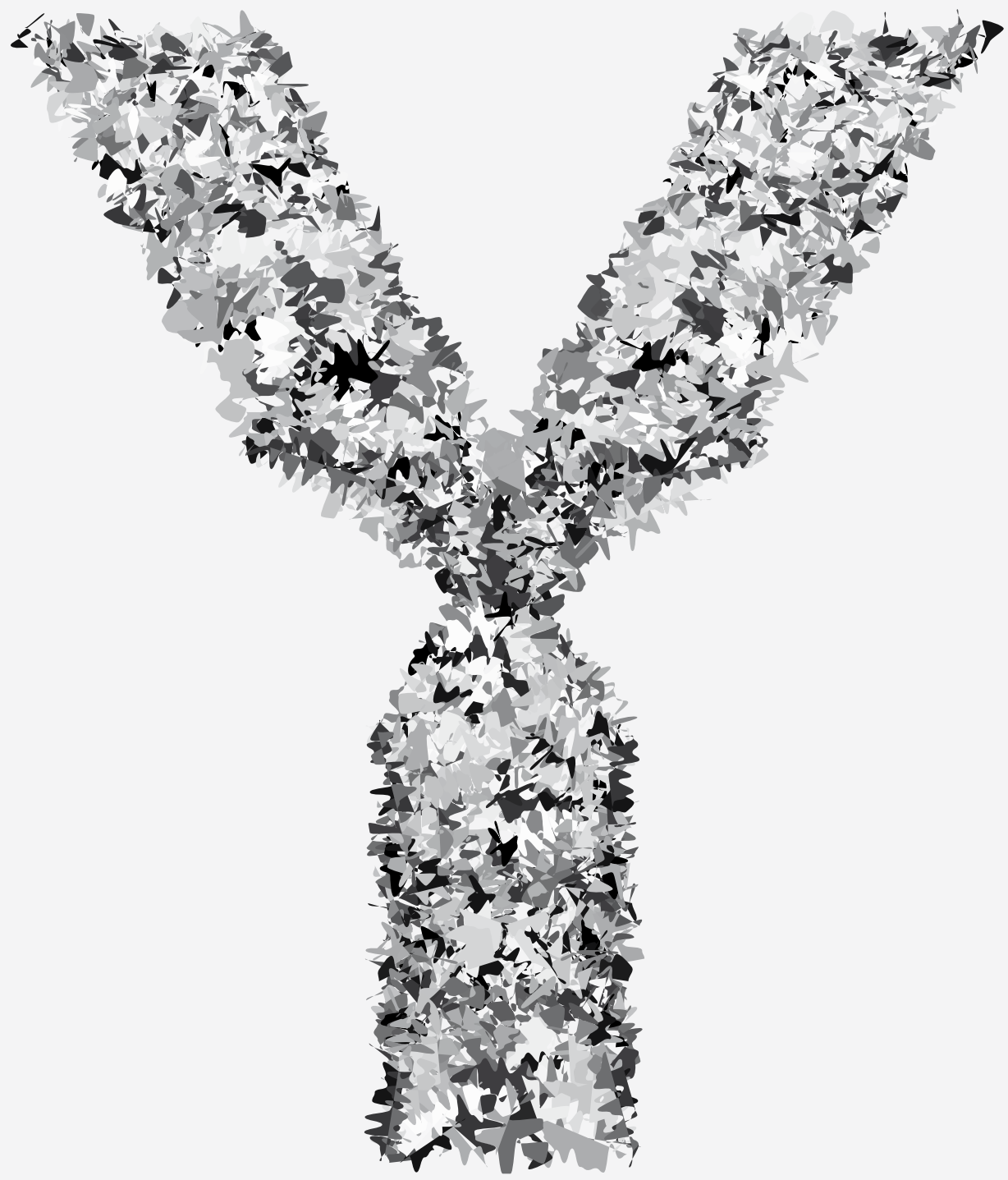




\section{CHAPTER

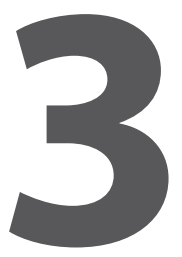

\section{The prevalence of antibodies against the HLA-DRB3 protein in kidney transplantation and the correlation with HLA expression}

Thomas H.P.M. Habets ${ }^{1,2}$, Bouke G. Hepkema ${ }^{3}$, Niels Kouprie ${ }^{3}$, Melanie C.A. Schnijderberg ${ }^{2}$, Tim C. van Smaalen ${ }^{4}$, Laura B. Bungener ${ }^{3}$, Maarten H.L. Christiaans ${ }^{5}$, Christina E.M. Voorter ${ }^{1}$, Gerard M.J. Bos $^{2,6}$, Marcel G.J. Tilanus ${ }^{1}$, Joris Vanderlocht ${ }^{1}$

\footnotetext{
1 Tissue Typing Laboratory, Department of Transplantation Immunology, MUMC+, Maastricht

2 Division of Hematology, Department of Internal Medicine, MUMC+, Maastricht

3 Transplantation Immunology, Department of Laboratory Medicine, UMCG, Groningen

4 Department of Surgery, MUMC+, Maastricht

5 Division of Nephrology, Department of Internal Medicine, MUMC+, Maastricht

6 CiMaas BV, Maastricht
}

In preparation 


\section{Chapter 3}

\section{ABSTRACT}

Human leukocyte antigen (HLA)-DRB3 is a functional HLA class II gene, which has a limited diversity in the human population. Since its presence is tightly associated with certain HLADRB1 allele groups, the HLA-DRB3 gene is only present in a subset of individuals. Therefore, in organ transplantation this HLA molecule is often mismatched between patient and donor and antibodies against this mismatched HLA molecule can develop. In this study, we aimed to evaluate the prevalence and reactivity of these antibodies and aimed to identify factors that underlie antibody formation against HLA-DRB3.

We showed in our patient cohort that HLA-DRB3 antibodies are identified in about $7 \%$ of all patients that were screened with solid phase assays. In these assays we observed multiple antibody reactivity patterns indicating that HLA-DRB3 harbours multiple epitopes. In those cases, where we succeeded at tracing back the induction of these antibodies to the molecular HLA typing of the immunogenic event, we noticed an altered distribution of HLADRB1 allele groups in the donors as compared to a control group. To a certain extent this distribution (e.g. HLA-DRB1*11 individuals) could be linked to an altered expression level. However, it also appears that different HLA-DRB3 alleles (e.g. HLA-DRB3*01 group) vary in their immunogenicity without having an expression difference.

In conclusion, our study provides information on the immunogenicity and reactivity patterns of antibodies against HLA-DRB3 in kidney transplantation, and it points towards the possibility of HLA expression as a factor underlying antibody formation. 


\section{INTRODUCTION}

Human leukocyte antigen (HLA) class II molecules, such as HLA-DR, play an important role in the presentation of processed peptides from extracellular pathogens to the $T$ cell receptor (TCR) of CD4+ helper T cells ${ }^{1,2}$. They are expressed on the surface of antigen presenting cells (APC) like B cells, macrophages, and dendritic cells ${ }^{3,4}$. The HLA-DR molecules are heterodimers that consist of a conserved alpha ( $\alpha$ )-chain (encoded by HLA-DRA) that shows limited diversity and a beta ( $\beta$ )-chain (encoded by e.g. HLA-DRB1) that is highly polymorphic in the population ${ }^{3,5}$. This high diversity influences the peptide presentation and as such determines an individuals' ability to respond to a wide variety of pathogens. In addition, the allelic variation in the population is thought to be a result of natural selection and represents a mechanism by which the population is protected against rapidly evolving pathogens ${ }^{6}$.

The HLA-DRB1 gene was duplicated in evolution and subsequently some individuals have a second $H L A-D R B$ gene that encodes a functional protein on a single haplotype (Figure S1) ${ }^{7,8}$. These associated HLA-DRB proteins are tightly associated with HLA-DRB1 and are encoded by HLA-DRB3, HLA-DRB4, and HLA-DRB5. Which of the associated HLA-DRB genes is present on a single haplotype depends on which HLA-DRB1 allele is present. The HLADRB1*03, *11,*12,*13,*14 groups of alleles have a HLA-DRB3 gene, whereas the HLADRB1*04, *07, *09 groups of alleles have a HLA-DRB4 gene, the HLA-DRB1*15, *16 alleles have a $H L A-D R B 5$ gene, and the $H L A-D R B 1 * 01, * 08, * 10$, groups of alleles have no functional associated HLA-DRB gene ${ }^{9,10}$. The associated HLA-DRB gene products form together with the conserved $\alpha$-chain (encoded by HLA-DRA) associated HLA-DRB proteins. Importantly, these associated HLA-DRB proteins are not present in all individuals, but only in a subset. For example, HLA-DRB3 is present in $43 \%$ of the caucasoid population. Furthermore, these associated HLA-DRB genes show allelic variation in the population, e.g. the HLA-DRB3 gene shows modest allelic diversity with 121 alleles as compared to 1929 alleles of HLA-DRB1 ${ }^{10-14}$.

For HLA-DRB3 it has been shown that it contributes to antigen presentation and host defence. In addition, the allelic variation of HLA-DRB3 has been proven to influence peptide presentation. The most convincing evidence of this involves the presentation of the human platelet antigen 1a (HPA-1a). The presentation of this HPA-1a peptide is highly restricted to HLA-DRB3*01:01 ${ }^{15}$. Therefore only carriers of this HLA-DRB3 allele are at risk to develop HPA-1a antibodies, which induce neonatal alloimmune thrombocytopenia (NAIT) and fetalmaternal alloimmune thrombocytopenia (FMAIT) ${ }^{16-19}$. Besides NAIT and FMAIT in which the 


\section{Chapter 3}

presence of a specific HLA-DRB3 allele is a prerequisite for disease susceptibility, HLA-DRB3 also contributes to the overall disease susceptibility for several autoimmune diseases. These diseases include myasthenia gravis, Graves' disease, Crohns' sarcoidosis, celiac disease, and primary sclerosing cholangitis ${ }^{20-24}$.

In the context of organ transplantation, it is well established that matching patients and donors with respect to the HLA molecules has a major impact on the transplant survival 25. The HLA loci that have the most impact on transplant outcome are HLA-DRB1 followed by $H L A-B^{26}$. It is speculated that the importance of HLA-DRB1 and HLA-B is related to their high expression on the cell surface. In this line, there are studies that link the expression levels of different HLA molecules to an altered capacity to induce an immune response against viral pathogens. For example, the expression level of HLA-C affects the risk of graft versus host disease (GVHD) after hematopoietic stem cell transplantation (HSCT), but also the clinical outcome of human immunodeficiency virus infection and Crohn's disease ${ }^{27,28}$. Additionally, high expression of HLA-DPB1 was associated with the risk of GVHD ${ }^{29}$.

Since the number of HLA mismatches is correlated with inferior transplant outcome, it is possible that the impact of HLA-DR matching is larger because HLA-DRB1 is associated with the co-expressed HLA-DRB genes such as HLA-DRB3. Another factor contributing to the survival of transplanted organs is the occurrence of rejection episodes. Even though major improvements in the immunosuppressive strategies were made over the last decades, they do not prevent rejection episodes and antibody mediated rejection (AMR), which still plays a fundamental role in graft loss. In the majority of cases these antibodies are directed against mismatched HLA molecules of the donor graft and are associated with inferior transplant outcome ${ }^{30-33}$. Until now, there is limited insight in the prevalence and importance of the antibody formation against HLA-DRB3 in organ (e.g. kidney) transplantation. Furthermore, it remains unclear whether factors such as expression levels of mismatched HLA molecules of the donor induce antibody formation in transplant recipients.

In the current study, we aimed to examine in a kidney transplantation cohort how frequent antibodies are observed against the HLA-DRB3 protein. We analysed the antibody reactivity patterns and correlated the patterns to the immunizing event in order to establish whether certain HLA-DRB3 alleles are more immunogenic. Furthermore, we determined the gene and protein expression of HLA-DRB3 and evaluated the graft outcome in recipients that develop HLA-DRB3 antibodies after transplantation. 


\section{MATERIALS AND METHODS}

\section{Sera from patients}

We made use of routine antibody screening of patients that undergo or await transplantation in the transplant centers of Maastricht and Groningen (located in the Netherlands). The sera used in this study are defined as left-over from clinical purposes and further use for research purposes is in accordance to Dutch ethical regulations. Maastricht. A total of 1800 kidney patients were transplanted in the period 1982 to 2014, but only 645 of these patients were tested for the presence of HLA class II antibodies in the serum using solid phase assays. Groningen. We applied a comprehensive database search for patients in whom HLA-DRB3 was defined as unacceptable mismatch.

\section{Control groups}

In order to define the distribution of the percentage of HLA-DRB3*01, HLA-DRB3*02, and HLA-DRB3*03, we selected a total of 140 controls with a high resolution HLA-DRB3 typing. In order to define the distribution of the HLA-DRB1 typing in HLA-DRB3 positive individuals in our patient cohort, we selected 258 HLA-DRB3 positive individuals without the presence of HLA-DRB3 antibodies.

\section{Detection of HLA-DRB3 antibodies using the Luminex Single Antigen assay}

The HLA-DRB3 antibodies in the serum of patients were detected using the LABScreen SA HLA class II assay (One Lambda, Thermo Fisher, Canoga Park, CA, USA) and Lifecodes LSA class II assay (Immucor, Norcross, GA, USA) according to the manufacturers' protocol. The LABScreen (Lot: 009) and Lifecodes (Lot: 01145C) kits contained three microbeads coated with single HLA-DRB3 alleles that represent the three major allele groups of the HLA-DRB3 protein: HLADRB3*01:01, HLA-DRB3*02:02, and HLA-DRB3*03:01. In brief, the microbeads coated with purified HLA class II molecules were incubated with patient serum for $30 \mathrm{~min}$. Subsequently, antibodies that bound to HLA-DRB3 proteins coated on the microbeads were detected with PE (phyco-erythrine)-conjugated goat anti-human IgG after an incubation of 30min (at RT). After washing, all the microbeads were measured with the Luminex 100 multiplex analyser 
Chapter 3

(Luminex, Austin, TX, USA) and analysed using HLA Fusion v.3.4 (One Lambda) and MatchIT V.1.2 (Immucor) software. In Figure S2a, a graphical representation shows the LSA assay and the position of the HLA-DRB3 microbeads of the different vendors. The microbeads with a MFI value $\geq 1000$ were considered positive for HLA-DRB3.

\section{Sequence based typing (SBT) of the HLA-DRB3 gene}

The sequence based typing of HLA-DRB3 was previously described ${ }^{34}$. In short, the amplification reactions of $H L A-D R B 3$ were performed in a total mix volume of $30 \mu \mathrm{L}$ that included $67 \mathrm{mM}$ Tris- $\mathrm{HCl}$ (pH 8.8) (Merck, Darmstadt, Germany), 5 \% glycerol (Alfa Aesar, Karlsruhe, Germany), $1.5 \mathrm{mM} \mathrm{MgCl}$ (Life Technologies), 0.01 \% Tween 20 (Merck), 16.6 mM ammonium sulphate (Merck), $0.2 \mathrm{mM}$ of each dNTP (GE Healthcare, Diegem, Belgium), 15 pmol of each primer (Sigma-Aldrich, Zwijndrecht, The Netherlands), $0.1 \mu \mathrm{g} / \mu \mathrm{L}$ cresol red (Sigma-Aldrich), $300 \mathrm{ng}$ DNA, and $1.4 \mathrm{U}$ expand high fidelity enzyme mix (Roche, Basel, Switzerland). The cycling conditions consisted of $2 \mathrm{~min}$ at $94^{\circ} \mathrm{C} ; 10$ cycles of $15 \mathrm{~s}$ at $94^{\circ} \mathrm{C}, 30 \mathrm{~s}$ at $63^{\circ} \mathrm{C}, 4 \mathrm{~min}$ at $68^{\circ} \mathrm{C}$; followed by 10 cycles of $15 \mathrm{~s}$ at $94^{\circ} \mathrm{C}, 30 \mathrm{~s}$ at $60^{\circ} \mathrm{C}, 6 \mathrm{~min}$ at $68^{\circ} \mathrm{C}$; followed by 10 cycles of $15 \mathrm{~s}$ at $94^{\circ} \mathrm{C}, 30 \mathrm{~s}$ at $60^{\circ} \mathrm{C}, 10 \mathrm{~min}$ at $68^{\circ} \mathrm{C}$, and $7 \mathrm{~min}$ at $68^{\circ} \mathrm{C}$. The amplified products were visualized and checked for size on a $1.5 \%$ agarose gel (Life Technologies) with a concentration of $0.5 \mu \mathrm{g} /$ $\mathrm{mL}$ ethidium bromide (Sigma-Aldrich).

The amplified products were sequenced using 4 sequence primers that covered exon 2 and exon 3 of HLA-DRB3. The total sequence volume of $10 \mu \mathrm{L}$ included $6 \mu \mathrm{L}$ water, 0.5 $\mu \mathrm{L}$ primer (5 pmol), $1 \mu \mathrm{L}$ BigDye Terminator v1.1 mix, $1.5 \mu \mathrm{L}$ BigDye Terminator sequencing buffer (Life Technologies), and $1 \mu \mathrm{L}$ purified amplification product. The cycling conditions consisted of $1 \mathrm{~min}$ at $96^{\circ} \mathrm{C} ; 25$ cycles of $10 \mathrm{~s}$ at $96^{\circ} \mathrm{C}$; $5 \mathrm{~s}$ at $50^{\circ} \mathrm{C}$, and $4 \mathrm{~min}$ at $60^{\circ} \mathrm{C}$. After sequencing, the products were purified with Sephadex G-50 (GE) and electrophoresed on the ABI 3730 DNA analyzer (Applied Biosystems, Foster City, CA, USA). The sequence data were analysed using Seqpilot v.3.5.2 software (JSI, Kippenheim, Germany).

\section{B cell isolation for HLA-DRB1 and HLA-DRB3 quantitative PCR}

During routine diagnostics, splenocytes from deceased donors were isolated for crossmatch and typing purposes. The human materials used in this study are defined as left-over and the use of this material for research aims is in accordance to Dutch ethical regulations. To 
this end, splenic parts were homogenized into a single cell suspension using a gentleMACS dissociator (Miltenyi Biotec, Leiden, The Netherlands) (Table S1; donors). The mononuclear cells were separated from the single cell suspension using Lymphoprep. The obtained cells were frozen in RPMI-1640 medium containing 10\% DMSO, 10\% FCS and 1\% PenStrep and stored in liquid nitrogen. Upon thawing, $10 * 10^{6}$ splenocytes were washed and resuspended. Subsequently, B cells were isolated using the CD19 positive B cell isolation kit according to the manufacturers' protocol (Miltenyi Biotec). The obtained B cells were stained for purity after the isolation using CD19 (clone HIB19, BD, APC), CD3 (clone UCHT1, BD, Horizon V450), CD56 (clone B159, BD, PE-Cy7) and CD14 (clone M5E2, BD, FITC) and measured using flow cytometry (BD FACS Canto II). The purity of the B cells exceeded $\geq 99 \%$ (Figure $\mathbf{S 4}$; $=5$ ).

\section{Quantitative PCR to determine relative gene expression of HLA-DRB1 and HLA-DRB3}

Total RNA was isolated from lysed B cells (positive B cell isolation kit) using the RNeasy Mini kit according to manufacturers' protocol (Qiagen). Residual genomic DNA was removed by DNase I treatment followed by reverse transcription using random hexonucleotide primers and Superscript III Reverse Transcriptase according to a standard protocol (Invitrogen). The forward and reverse primers for quantitative PCR are shown in Table S2. To prevent DNA amplification, both the HLA-DRB1 and HLA-DRB3 primers were designed to span exon-exon boundaries with a maximal amplification length of 300bp. A standard curve of a reference sample (cDNA of a total B cell fraction) was generated for relative quantification. The realtime (RT)PCR was performed with SYBR green detection (SensiMix SYBR, Bioline Reagents, London, UK) using the iCycler iQ (Biorad Laboratories, Hercules, CA, USA) and 10 pmol of the specific primer. The PCR program consisted of $10 \mathrm{~min}$ initial heating at $95^{\circ} \mathrm{C}$, followed by 35 cycles of amplification ( $30 \mathrm{~s}$ at $95^{\circ} \mathrm{C}, 20 \mathrm{~s}$ at $62^{\circ} \mathrm{C}, 20 \mathrm{~s}$ at $72^{\circ} \mathrm{C}$ ) and a heating up to $92^{\circ} \mathrm{C}$ to create a melting curve (increased $0.5^{\circ} \mathrm{C} / 7 \mathrm{~s}$ ). The data represent the expression of the gene of interest normalized to HuPo (human acidic ribosomal protein) or GAPDH ${ }^{35}$, which were used as reference genes in our study (Table S2).

\section{Assessment of the cell surface expression of HLA-DRB3 by flow cytometry}

Splenocytes from deceased donors were used to determine the cell surface expression of the HLA-DRB3 protein (Table S1). As described previously, spleens were homogenised to 


\section{Chapter 3}

a single cell suspension, separated with Lymphoprep, and the cells were stored in liquid nitrogen. At the moment of flow cytometric assessment, $10 * 10^{6}$ splenocytes were thawed, washed, resuspended, and counted. The flow cytometric procedure is shown in Figure S6. In short, a total of $1 * 10^{5}$ splenocytes were blocked with heat-inactivated fetal calf serum to prevent non-specific antibody binding to Fc receptors on B cells (20min, RT). Subsequently, mouse monoclonal antibody 7.3.19.1 specific for epitope $77 \mathrm{~N}$ (Thermo Fischer) that is only present on HLA-DRB3 (exception of HLA-DRB1*03) proteins was incubated for $30 \mathrm{~min}$. As control condition the $\operatorname{lgG}_{2 b}$ isotype control was added (clone 27-35, BD) to check for nonspecific binding. The B cell fraction was further specified with CD19 (clone HIB19, BD, APC). The 7.3.19.1 antibody was detected with a PE labelled goat anti-mouse Ig antibody (20min, polyclonal, BD). In between all incubation steps the cells were washed with buffer (PBS 1X, $1 \% \mathrm{FCS}, 0.02 \% \mathrm{NaN}_{3}$ ). Prior to staining of mouse anti-human CD19, mouse serum (20min, Dako) was added to block the binding sites of the goat anti-mouse Ig antibody. A life to death marker 7-AAD was added before measurement (BD). The cells were measured and analysed using BD FACSCanto II and FACSDiva software. To standardize for the fluorescence intensity irrespective of the instrument and software, PE labelled beads were used (Bangs Laboratories Inc., Fishers, IN, USA). The mean fluorescent intensities (MFI) were adjusted to molecules of equivalent soluble fluorochromes (MESF) units, as described previously ${ }^{36}$.

\section{CDC assay to determine the panel reactive antibody index}

$1 \mu \mathrm{L}$ serum of the patient was incubated with a screening panel of 60 different lymphocytesuspensions ( $1 \mu \mathrm{L}$ lymphocyte suspension with a concentration of $4 * 10^{6}$ cells $/ \mathrm{mL}$ ) for $30 \mathrm{~min}$ (RT). Next, $5 \mu \mathrm{L}$ rabbit complement (Life Technologies) was added and incubated for 60min (RT) to initiate lymphocyte lysis via CDC. The addition of $5 \mu \mathrm{L}$ FluoroQuench (One Lambda) for 10min (RT) allowed discrimination of intact versus lysed cells by means of automated fluorescence microscopy (Leica). In this way, the panel-reactive antibody (PRA) index can be determined. In case we were not able to determine the PRA, we calculated the virtual PRA (vPRA) index using the Eurotransplant reference laboratory vPRA calculator.

\section{Figures and statistics}

The statistical analyses were performed in GraphPad Prism Pro v.6.01 (GraphPad Software, 
La Jolla, CA, USA). The figures were generated in Graphpad and further combined in Adobe Illustrator (Adobe Systems, San Jose, CA, USA). The difference in allele frequencies of HLADRB1 was determined using the Odds Ratio (OR). The Mann-Whitney t-test was used to define a statistical significance between groups. The Kaplan-Meier survival curves were compared using the log-rank (Mantel-Cox) test. For all analyses, a P value $<0.05\left(^{*}\right)$ was considered to be statistically significant. P-values $<0.01$ were graphically presented as $\left({ }^{* *}\right)$.

\section{RESULTS}

\section{The prevalence and Luminex Single Antigen (LSA) reactivity patterns of HLA-DRB3 antibodies in the sera of organ transplant recipients.}

In order to assess the prevalence of antibodies against the HLA-DRB3 protein, we made use of routine antibody screening of patients that undergo or await kidney transplantation in the transplant centers of Maastricht and Groningen. In Maastricht, 1800 kidney patients were included and 645 of these patients were tested in solid phase assays (LSA: Luminex Single Antigen) in addition to cytotoxicity testing. A retrospective LSA analysis of these 645 patients demonstrated that 43 kidney patients were positive for HLA-DRB3 microbeads, which is $\pm 7 \%$ of these 645 patients. In addition, in the center of Groningen we applied a database search for patients in which HLA-DRB3 is defined as unacceptable mismatch. Using this approach, we identified 42 additional patients with HLA-DRB3 antibodies. Notably, 6 out of these 42 patients were awaiting lung or heart transplantation. Since the lung or heart transplantation were not the immunogenic event inducing HLA-DRB3 antibody formation, we consider these 6 patients as patients on the waiting list for organ transplantation, and therefore pregnancy or transfusion is the event that triggered HLA-DRB3 antibody formation. All cases where we identified organ transplantation as immunogenic event were kidney transplant recipients.

To assess the presence of allele-specific HLA class II antibodies in the sera of kidney patients, we made use of the LSA microbead assays in Maastricht and Groningen from One Lambda and Immucor respectively. As is shown in Figure S2a, the LSA kits from One Lambda and Immucor contained three microbeads coated with HLA-DRB3*01:01, HLA-DRB3*02:02, and HLA-DRB3*03:01 proteins. Although the LSA assays are similar in terms of methodology, both centers use a different LSA vendor. As a consequence, the LSA kits may have different antibody reactivity as a result of the purification and coating of HLA-DRB3 proteins on the microbeads. Therefore, we examined to what extent the LSA kits from the different vendors 
were consistent in terms of antibody reactivity patterns. The data of this technical validation are presented in Figure $\mathbf{S 2} \mathbf{b}$ and in the supporting results (File S1). The conclusion of this LSA assay validation was that both kits are reproducible in terms of determining whether a serum contains antibodies reacting against HLA-DRB3 or not. However, both kits displayed discrepancies when detecting antibodies against specific HLA-DRB3 alleles. We observed this especially in the sera of patients that are HLA-DRB3 carriers.

As shown in Figure 1, evaluation of the LSA reactivity patterns for 85 patients showed a total of seven HLA-DRB3 antibody reactivity patterns (group I to VII), indicating that the HLA-DRB3 protein has multiple epitopes. These patients were divided into four groups based on their immunizing event and whether patients were carrying the HLA-DRB3 gene (Table 1). We observed that most of the patients (52 out of 85 ) displayed an antibody reactivity to all three HLA-DRB3 microbeads (group VII). In these 52 patients, the mean fluorescent intensity (MFI) value of all three microbeads was \pm 8500 . Additionally, the majority of patients (67 out

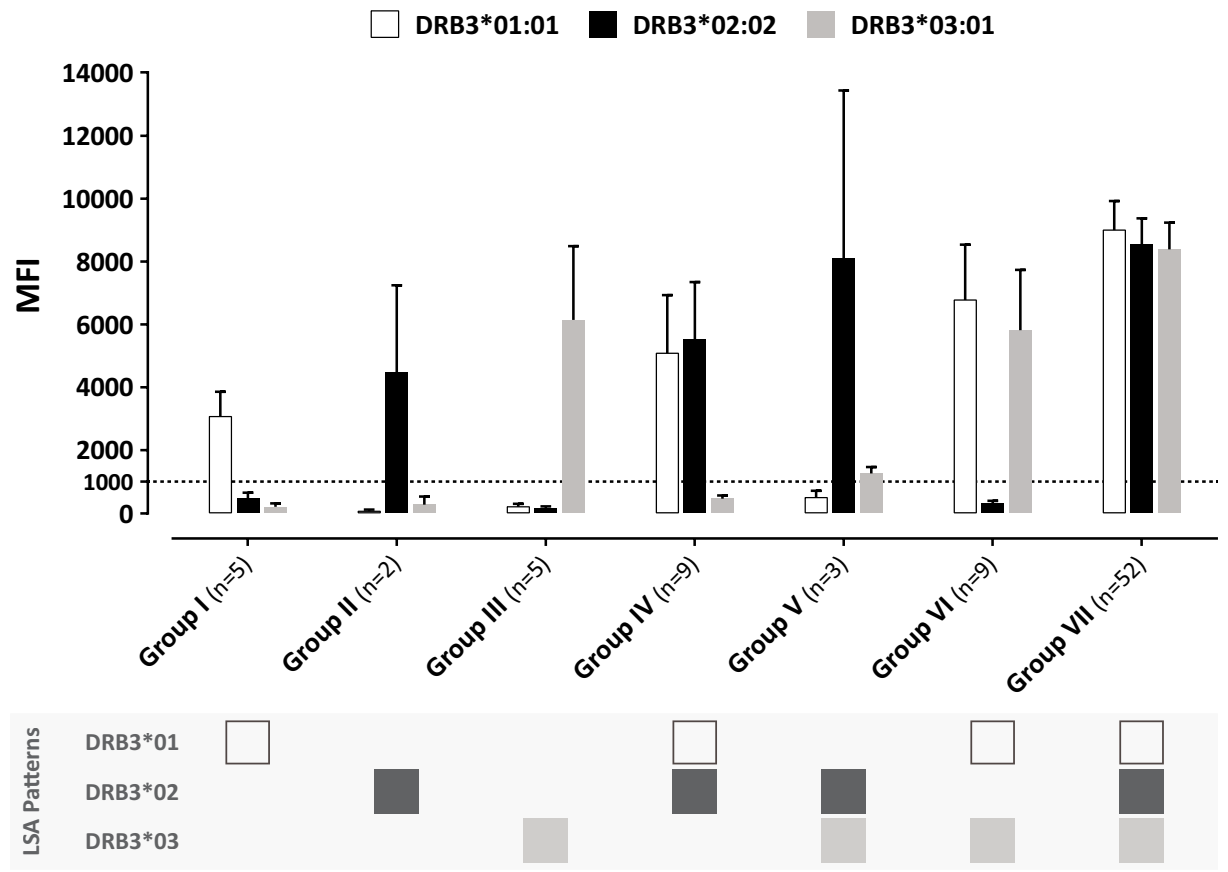

Figure 1: The reactivity patterns of HLA-DRB3 antibodies against Luminex SA microbeads. The reactivity patterns of HLA-DRB3 antibodies against three LSA microbeads (One Lambda and Immucor) in 85 patients. The groups represent the binding of HLA-DRB3 antibodies in the sera of patients to one, two, or three microbeads coated with HLA-DRB3*01:01, HLA-DRB3*02:02, and HLA-DRB3*03:01 proteins. A MFI value of $\geq 1000$ was considered to be positive for HLA-DRB3. The data is plotted as mean and SEM. 
Table 1: The clinical characteristics of 85 patients with HLA-DRB3 antibodies.

\begin{tabular}{lll}
\hline Transplantation & & \\
\hline Patient (DRB3) & - & + \\
Donor (DRB3) & + & + \\
\hline$n$ & 29 & 11 \\
Male & 18 & 5 \\
Female $\left(^{*}\right)$ & $11(6)$ & $6(5)$ \\
DRB3 antibodies after & & \\
$\quad$ Transplant 1 & 24 & 10 \\
$\quad$ Transplant 2 & 5 & 1 \\
\hline **) Transplantation and pregnancy $^{2}$ & \\
\hline
\end{tabular}

\begin{tabular}{lcc}
\hline Pregnancy $(P)$ and Transfusion (TF) & \\
\hline Patient (DRB3) & - & + \\
P and/or TF (DRB3) & + & + \\
\hline$n$ & 38 & 7 \\
Male & 4 & 1 \\
Female & 34 & 6 \\
DRB3 antibodies after & & \\
$\quad$ P and TF & 28 & 5 \\
TF & 10 & 2 \\
\hline
\end{tabular}

of 85) who showed antibodies against HLA-DRB3 are individuals who do not carry the HLA$D R B 3$ gene. However, among the 85 patients with such antibodies, we identified 18 patients who are HLA-DRB3 gene carriers. In terms of reactivity patterns of the sera, these HLA-DRB3 carrying individuals are different (Figure $\mathbf{S 3} \mathbf{b}$ ). These sera showed reactivity against one or two microbeads (17 out of 18) (group I to VI). In contrast, the sera of patients who do not carry the HLA-DRB3 gene (52 out of 67) showed an antibody reactivity that was primarily against all three microbeads (Figure S3a) (group VII).

\section{Immunization with HLA-DRB3*01 and HLA-DRB3*02 displayed more induction of HLA-DRB3 antibodies in kidney patients as compared to HLA-DRB3*03.}

In order to examine which HLA-DRB3 allele is the most immunogenic in terms of antibody induction, we determined the HLA-DRB3 typing of the immunizing events (graft donor or child in case of pregnancy). We performed an HLA typing of the graft donors or children for HLA-DRB3*01, HLA-DRB3*02, and HLA-DRB3*03 using SBT (exon 2 and 3). In 52 out of 85 patients we succeeded to identify the immunizing event and was it possible to obtain DNA for molecular typing of HLA-DRB3. In 28 cases the immunizing event was a transplantation (graft), and in 24 cases a pregnancy. In Figure 2a, we showed that $54 \%$ of the microbead reactivity patterns in the patients had an immunizing event with HLA-DRB3*01, whereas 33\% had HLADRB3*02, and $13 \%$ had HLA-DRB3*03. This distribution of HLA-DRB3*01 and HLA-DRB3*02 was discrepant as compared to a control group with 140 HLA-DRB3 gene carriers without HLA-DRB3 antibodies. In this control group, we observed that 28\% had HLA-DRB3*01, 55\% had HLA-DRB3*02, and $17 \%$ had HLA-DRB3*03. In Figure $\mathbf{2 b}$, the correlation between the 


\section{Chapter 3}

microbead reactivity pattern and the nature of the immunizing event is shown. We did not observe reactivity patterns that did not include the microbead of sensitization. The reactivity pattern that recognized all three microbeads was observed most frequent (35 out of 52). Furthermore, we observed that all possible reactivity patterns containing the microbead
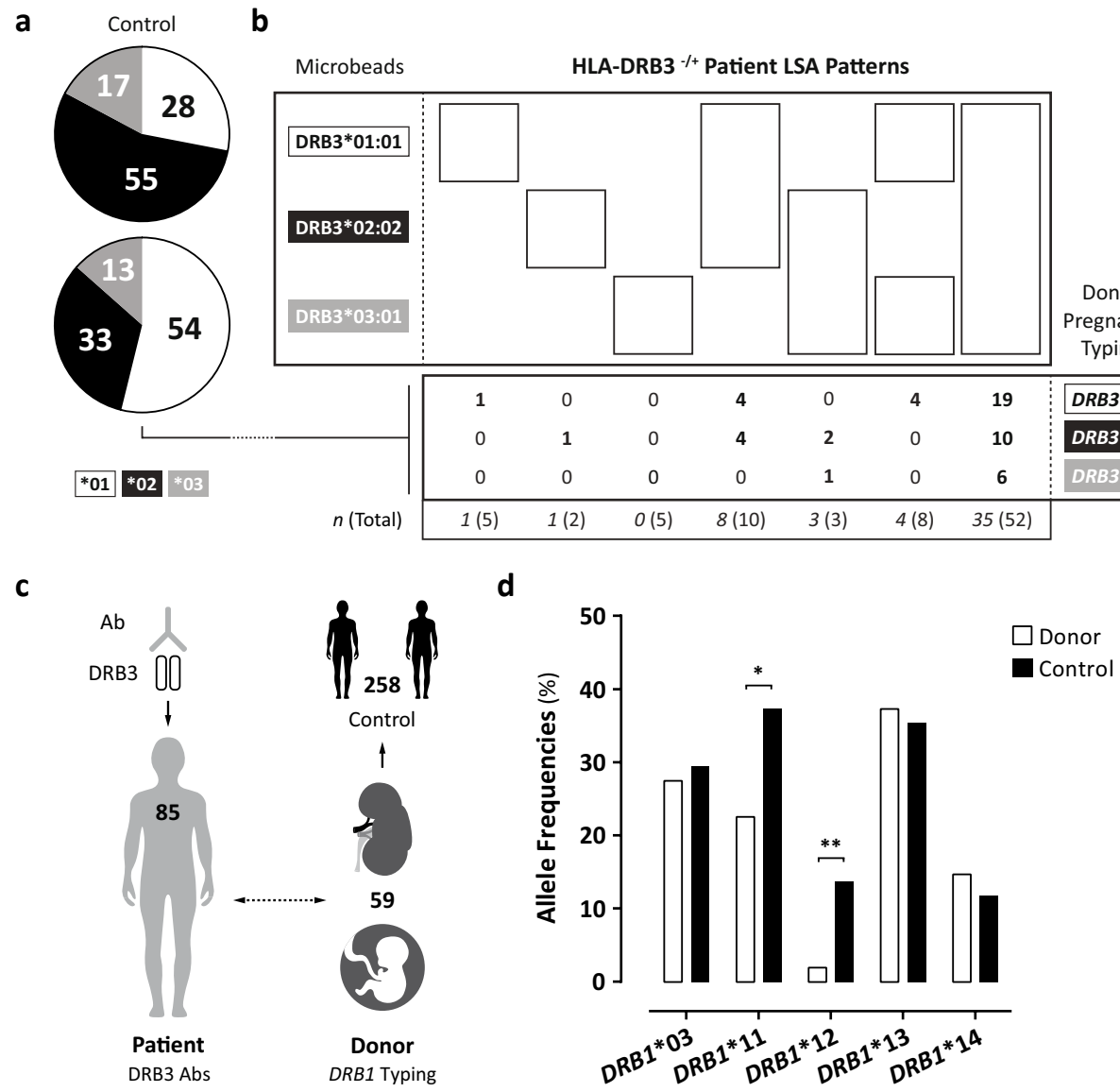

Figure 2: The immunologic events of HLA-DRB3*01, ${ }^{*} 02,{ }^{*} 03$ and the allele frequencies of HLA-DRB1 in the donors. $a, b$. The immunologic events defined as the HLA-DRB3 $\left({ }^{*} 01,{ }^{*} 02,{ }^{*} 03\right)$ typing of the graft donors or children (pregnancies) and the reactivity patterns of HLA-DRB3 antibodies against LSA microbeads HLA-DRB3*01:01, *02:02, and *03:01 that were detected in HLA-DRB3 negative and positive kidney patients $(n=52)$. The percentages of the patients' LSA reactivity pattern that correspond with the HLA-DRB3 donor typing are shown in the pie chart. The distribution of the HLA-DRB3 alleles of the graft donors or children are compared with a control group (HLA-DRB3 positive individuals without antibodies against HLA-DRB3). c. In 85 kidney patients HLA-DRB3 antibodies were detected. With respect to the donor group, 59 graft donors or children were typed for HLA-DRB1. These HLA-DRB1 alleles (linked to HLA-DRB3) were compared with a control group in a case-control setting. $d$. The allele frequencies of $\operatorname{HLA}_{-D R B 1 * 03}{ }^{*} 11, * 12, * 13$, and $* 14$ are displayed as percentage. The difference between donor and control groups was calculated using the odds ratio (OR). The P values of $<0.05\left(^{*}\right)$ and $<0.01\left({ }^{* *}\right)$ were statistically significant. 
coated with the HLA-DRB3 allele of the sensitizing event were observed.

Taken together, our data suggest that in kidney patients with HLA-DRB3 antibodies, HLA-DRB3*01 was more immunogenic than HLA-DRB3*02, and HLA-DRB3*03. In addition, the correlation of the donor typing with the microbead reactivity pattern showed that allele group specific reactivity is a consequence of immunization and not an artefact of solid phase assays. Therefore, also the allelic diversity of HLA-DRB3 is immunogenic.

\section{The frequencies (as measured by the $H L A-D R B 1$ alleles that are associated with $H L A-$ DRB3) are different in the donor group as compared to a control group.}

To address the hypothesis whether certain donors are more prone to induce an HLA-DRB3 antibody response, we investigated the HLA-DRB1 distribution in the donor group and a control group. With respect to HLA molecules, the expression can be dependent on the haplotype organization. In case of broad antigens HLA-DRB3, HLA-DRB4, and HLA-DRB5 the expression levels can be studied by analysing the linked $H L A-D R B 1$ gene. This means that we assessed whether the allele frequencies of the HLA-DRB1 alleles (HLA-DRB1*03, *11, *12, *13, and *14) that are linked with HLA-DRB3 of the donors or children (pregnancies) showed a discrepancy in distribution as compared to control individuals. To this end, we compared the distribution of $H L A-D R B 1 * 03, * 11, * 12, * 13$, and *14 alleles in the donor group (grafts or children) to a total of 258 HLA-DRB3 gene carriers without HLA-DRB3 antibodies (control). As illustrated in Figure 2c, we started with 85 patients who had HLA-DRB3 antibodies and in 59 cases we had DNA to perform HLA-DRB1 typing. As shown in Figure 2d, we noted a reduced allele frequency of HLA-DRB1*11 and HLA-DRB1*12 in the donor group as compared to the control group. In addition, the allele frequencies of HLA-DRB1*03, HLA-DRB1*13, and HLA$D R B 1^{*} 14$ were similar in the donor group as compared to the control group. The altered distribution of the HLA-DRB1 alleles may indicate that certain HLA-DRB1 alleles are more or less prone to induce antibodies in patients with HLA-DRB3 antibodies.

\section{The relative mRNA and protein expression of HLA-DRB1 and HLA-DRB3.}

In order to determine whether variation in expression contributes to antibody induction, we assessed the relative mRNA and protein expression of HLA-DRB1 and HLA-DRB3. The relative mRNA expression of the HLA-DRB1 and HLA-DRB3 genes was determined with quantitative PCR. To this end, we developed and optimized specific forward primers for HLA-DRB1 alleles HLA-DRB1*03, HLA-DRB1*11, HLA-DRB1*13, and HLA-DRB1*14 and for HLA-DRB3 (Table 
S2). HLA-DRB1*01 (no secondary HLA-DRB gene) was used as negative control for both HLADRB1 and HLA-DRB3 primers (illustration Figure 3c). In our study, the HLA-DRB1 primer did not allow amplification of HLA-DRB1*12. As the allele frequency of HLA-DRB1*12 is very low in the caucasoid population, we did not develop separate primers. To this end, we isolated B cells from splenocytes with HLA-DRB1*03, *11,*12,*13,*14, and *01 typing (Figure S4) (Table S1). Then, the relative mRNA expression of $H L A-D R B 1^{*} 03, * 11, * 13$, and *14 and HLA$D R B 3$ was determined in $B$ cells, and the values were normalized to reference gene HuPo.

As shown in Figure 3a, B cells from individuals with HLA-DRB3*01 displayed a higher relative mRNA expression than HLA-DRB3*02 ( $\mathrm{P}<0.001)$ and HLA-DRB3*03 ( $\mathrm{P}<0.01)$. Notably, in four individuals with $H L A-D R B 3^{*} 01$ we observed a higher relative mRNA expression than the other (five) individuals. Additionally, there was no difference between $H L A-D R B 3^{*} 02$ and $H L A-D R B 3^{*} 03$. Regarding HLA-DRB1, we observed that the relative mRNA expression of all HLA-DRB1 alleles (HLA-DRB1*03, *11,*13, *14) was higher than HLA-DRB3 (Figure 3c). The expression difference of HLA-DRB1 and HLA-DRB3 had an average of $5.3 \pm 1.9$ fold. However, we did not notice a substantial difference in relative mRNA expression among the different HLA-DRB1 alleles (HLA-DRB1*03, *11, *13,*14) and their linked HLA-DRB3. Similar results were observed when using GAPDH as reference gene (5.3 \pm 1.9 fold data; Figure S5).

Next, we determined whether the HLA-DRB3 protein expression is different across these HLA-DRB1 alleles. To this end, we also measured the expression of HLA-DRB3 on the cell surface of B cells using flow cytometry (illustrated in Figure S6a). In short, we incubated 1 $* 10^{5}$ splenocytes with the monoclonal 7.3.19.1 antibody that interacts with the $77 \mathrm{~N}$ epitope restricted to HLA-DRB3*01, HLA-DRB3*02, HLA-DRB3*03, and HLA-DRB1*03 alleles (Figure 3e). We preferred to use this monoclonal antibody, since HLA molecules are highly polymorphic and due to this feature polyclonal antibodies or sera may display increased cross-reactivity

Figure 3: The relative mRNA and protein expression of HLA-DRB1 and HLA-DRB3. $a$. The relative mRNA expression of HLA-DRB3*01 ( $n=9),{ }^{*} 02(n=16)$, and ${ }^{*} 03(n=11)$ in isolated B cells from deceased donors. The relative mRNA expression was determined by quantitative PCR (Q-PCR) and the values were normalized to reference gene HuPo. $b$. The cell surface expression of HLA-DRB3*01 $(n=7),{ }^{*} 02(n=15)$, and *03 $(n=9)$ on B cells. Splenocytes from the donors were incubated with monoclonal 7.3.19.1 antibody, which binds to the specific epitope $77 \mathrm{~N}$ that is present on HLADRB3*01, *02, and ${ }^{*} 03$ (and HLA-DRB1*03). The B cells were gated using a fluorescently labelled CD19 antibody and the MFI values were corrected to MESF units using PE labelled beads. c. The relative mRNA expression of HLADRB1*03, *11,*13, and *14 and HLA-DRB3 in isolated B cells from deceased donors ( $n=5$ per group) determined by Q-PCR (normalized to HUPO). HLA-DRB1*01 was used as negative control for HLA-DRB1/3 primers. A primer for HLA-DRB1*12 was not included, therefore the products are not amplified. $d$, e. The expression of HLA-DRB3 on $B$

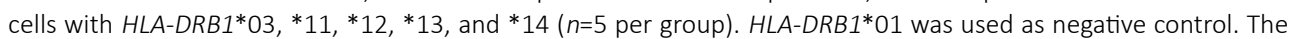
cell surface expression is shown as MESF units. The HLA-DRB1 typing is shown in Table S1. Mann-Whitney t-test. The $P$ values of $<0.05(*),<0.01(* *)$, and $<0.001(* * *)$ were significant. 
a

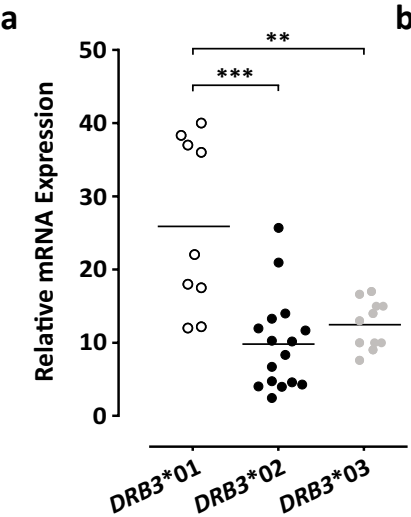

C

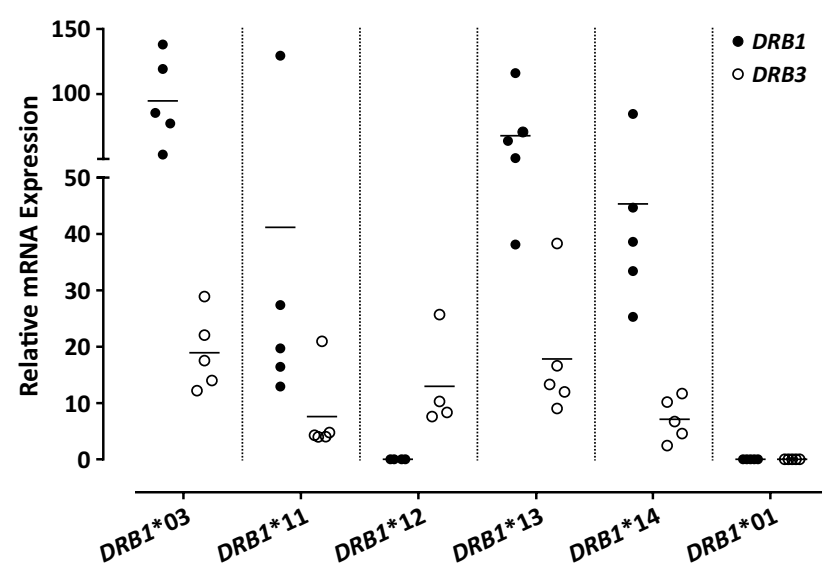

d
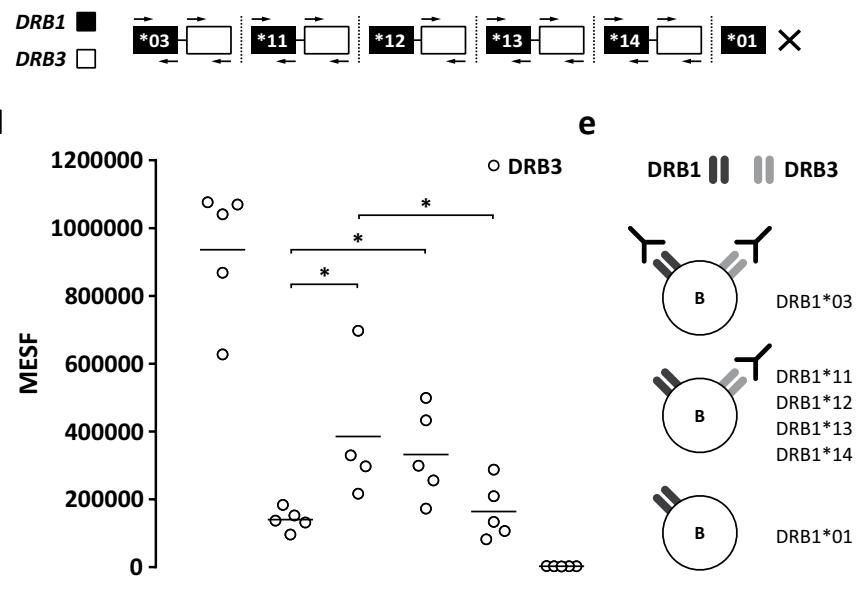
Chapter 3

with other HLA molecules. This makes it difficult to assess the cell surface expression of a specific HLA molecule. The monoclonal 7.3.19.1 antibody was detected using a PE labelled Ig antibody and B cells were selected with CD19 positivity (Figure S6b). To standardize the fluorescence intensity across different experiments, the MFI values were corrected to MESF units using PE labelled beads. As positive control we included five donors with $H L A-D R B 1^{*} 03$, since the monoclonal antibody will bind to HLA-DRB1 and HLA-DRB3. In addition, as negative control we selected five donors with $H L A-D R B 1^{*} 01$, since the 7.3.19.1 antibody will not bind to HLA-DRB1*01, and HLA-DRB3 is absent in these donors (HLA-DRB1*01 is not linked to $H L A-D R B 3)$. The use of this flow cytometric assay with the 7.3.19.1 antibody allows us to compare the HLA-DRB3 expression in donors with HLA-DRB1*11, *12, *13, and *14.

As shown in Figure $\mathbf{3 b}$, there was no difference in cell surface expression of HLADRB3 alleles HLA-DRB3*01, HLA-DRB3*02, and HLA-DRB3*03. This indicates that the increased relative mRNA expression of HLA-DRB3*01 did not result in elevated cell surface expression. With respect to the HLA-DRB1 alleles, we observed a reduced expression of the HLA-DRB3 protein in five donors with HLA-DRB1*11 as compared to HLA-DRB1*12, and HLA$D R B 1 * 13$, but not to HLA-DRB1*14 (Figure 3d). In case of $H L A-D R B 1 * 14$, the expression of the HLA-DRB3 protein is lower as compared to HLA-DRB1*12, but not to HLA-DRB1*11 and HLA-DRB1*13. Likewise, we showed that the 7.3.19.1 antibody reacted with HLA-DRB1 and HLA-DRB3 in five donors with HLA-DRB1*03. We also observed that five donors with HLA$D R B 1^{*} 01$ showed no antibody reactivity. The antibody reactivity is illustrated in Figure $\mathbf{3 e}$.

Taken together, HLA-DRB3*01 showed a higher relative mRNA expression than HLADRB3*02 and HLA-DRB3*03. Though, there was no difference in protein expression among the HLA-DRB3 alleles. Likewise, we did not observe substantial differences in relative mRNA expression of HLA-DRB3 between the linked HLA-DRB1 alleles. Nevertheless, we displayed a reduced protein expression of HLA-DRB3 in case of HLA-DRB1*11 and *14.

\section{Transplant recipients with HLA-DRB3 antibodies showed an inferior graft survival as compared to transplant recipients without HLA-DRB3 antibodies.}

In order to assess whether HLA-DRB3 antibodies develop in a specific subgroup of patients, we retrospectively determined graft outcome in patients $(n=20)$ who developed antibodies after transplantation. In 19 out of 20 patients the HLA-DRB3 antibodies were detected after transplantation. The loss of a transplanted kidney (displayed as survival) was defined as the date of graft failure after transplantation. As shown in Figure 4a, 10 patients that developed 
HLA-DRB3 antibodies demonstrated a transplant failure within 20 days after transplantation. Notably, the patients who showed these antibodies after transplantation displayed at the same time antibodies against many other HLA class II molecules, which is indicated by a panel-reactive antibody (PRA) index of $74 \pm 21 \%$ (Figure 4b). This means that these patients showed an antibody reactivity against $74 \%$ of the donor population, which reflect the HLA distribution of the caucasoid population. In $45 \%$ of the patients the HLA-DRB3 antibody was detected after a transplantectomy. Furthermore, in 15 out of 20 patients with HLA-DRB3 antibodies data was available of the donor origin of the transplanted grafts. All kidney grafts were derived from post-mortem donors further defined as five grafts from donation after brain death (DBD) and 10 grafts from donation after cardiac death (DCD) donors.
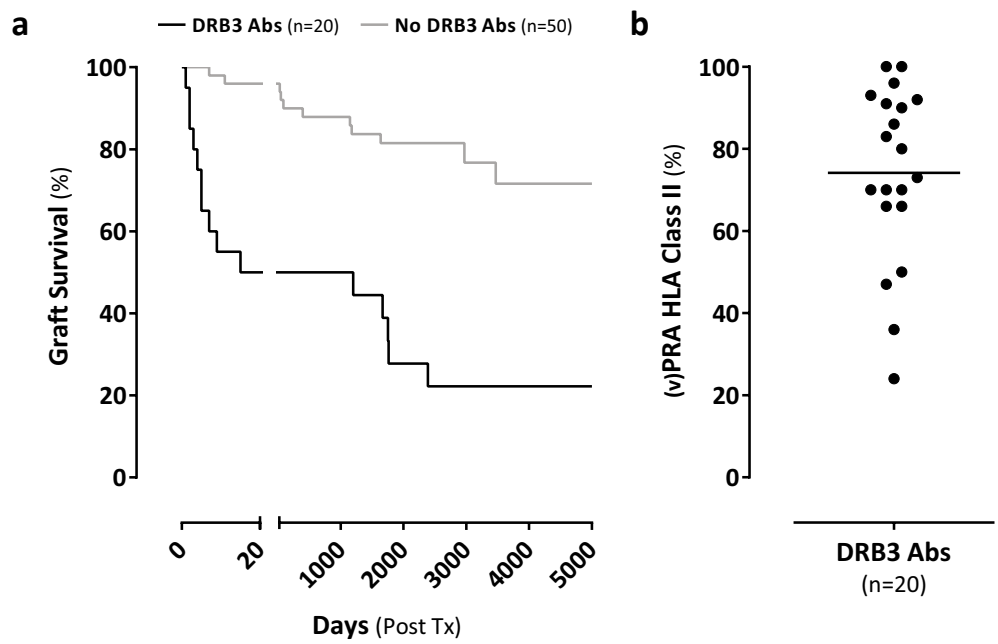

Figure 4: Graft survival in kidney transplant recipients with or without antibodies against HLA-DRB3. a. KaplanMeier survival curve of transplanted grafts in recipients with $(n=20)$ or without $(n=50)$ HLA-DRB3 antibodies. The loss of a transplanted graft (survival) was defined as the date of graft failure after transplantation. Log-rank (Mantel-Cox) test with $\mathrm{P}<0.0001$. b. The (v)PRA HLA class II percentage of the recipients with HLA-DRB3 antibodies. The (v)PRA was determined in the same serum sample as the HLA-DRB3 antibodies. (v)PRA, (virtual) panel reactive antibodies.

\section{DISCUSSION}

In our HLA-DRB3 study, we included a total of 85 transplant patients at two transplantation centres displaying HLA-DRB3 antibodies. In a comprehensive screening of 645 patients with solid phase assays we estimate that $\pm 7 \%$ of patients will develop antibodies throughout their time on the waiting list. We observed that HLA-DRB3 antibodies can develop upon different 


\section{Chapter 3}

kinds of immunogenic events including kidney transplantation, pregnancy, and transfusion. 79\% of patients displaying antibodies against HLA-DRB3 did not carry the HLA-DRB3 gene, whereas $21 \%$ of patients who also show these antibodies are carriers of the HLA-DRB3 gene. This indicates that not only the presence or absence of this gene is immunogenic but also the allelic variation of the HLA-DRB3 gene in different carriers.

In terms of reactivity of these HLA-DRB3 antibodies we demonstrated in solid phase assays that multiple reactivity patterns are observed, indicating that HLA-DRB3 harbours multiple epitopes. The reactivity patterns observed in patients that do not carry HLA-DRB3 are different from those observed in HLA-DRB3 carriers. The pattern where all microbeads are recognized is the most abundant in all patients, but it is only observed in patients that do not carry the HLA-DRB3 gene. In HLA-DRB3 carriers the HLA-DRB3 antibodies mostly reacted with one or two microbeads. This observation is a clear indication that the epitopes, which are preferentially recognized in $H L A-D R B 3$ carrying patients are different from those patients that do not carry the HLA-DRB3 gene. A limitation of these LSA assays is that there are only three microbeads covering the major HLA-DRB3 alleles, which is inadequate to determine all epitopes that are important in the immunogenicity of HLA-DRB3. To define all the epitopes that are important for antibody development, specific microbeads may be developed that cover more HLA-DRB3 alleles.

When we correlated the microbead reactivity pattern with the high resolution HLADRB3 typing of the immunizing events, we observed in almost all cases that the microbead of immunization was included in the reactivity pattern. However, we did observe a bias when comparing microbead-specific reactivity patterns with two different vendors. This is primarily confined to individuals carrying the HLA-DRB3 gene. All microbeads displayed discrepancies in reactivity, but the most were observed with the microbead containing HLA-DRB3*03:01. The differences in reactivity can be a result of the purification and coating of HLA-DRB3 proteins on the surface of microbeads or this reactivity can also be affected by a different protein conformation of the coated HLA-DRB3 proteins ${ }^{37}$. Reed et al. performed a comprehensive analysis of solid phase multiplex bead arrays in the field of HLA antibodies, in which they demonstrated that the MFI was dependent on the vendor and microbead type ${ }^{38}$. Currently, it remains unclear what the precise clinical relevance of these allele-specific antibodies is. Nevertheless, our results indicate that these antibodies develop as a result of immunization and that they are not artefacts in solid phase detection systems.

When assessing the graft outcome in kidney transplant recipients who develop HLA- 
DRB3 antibodies, we observed that these patients demonstrate an inferior graft outcome as compared with a control group that did not develop these HLA-DRB3 antibodies. It should be noted that this is not considered proof of the clinical relevance of these antibodies, since in almost all patients (except 1) these antibodies developed after transplantation. Additionally, in approximately 50\% of these patients HLA-DRB3 antibodies developed after kidney graft failure or transplantectomy and are therefore presumably not involved in transplant loss. This data and our observation that these HLA-DRB3 antibodies in kidney transplant recipients are observed after a wide antibody response against a variety of HLA molecules, may indicate that HLA-DRB3 antibodies are induced preferentially when a robust and broad reactive response is seen. A short graft survival followed by rapid transplantectomy (defined as the immunizing event) is apparently associated with the occurrence of these antibodies. Notably, the HLADRB3 antibodies that are induced as a result of other immunizing events are not invariably associated with a diverse antibody response (data not shown). In addition, the inferior graft outcome in these recipients can be a consequence of the donor origin, since all transplanted patients had post-mortem grafts from either DBD or DCD donors. The quality of post-mortem grafts is associated with inferior transplant outcome as compared to living graft donors ${ }^{39}$. Although these data provide an indication about the role of HLA-DRB3 antibodies in kidney transplantation, this study has some limitations as the number of patients is limited and our population is homogeneously caucasian. Increasing the number of patients in a multicenter study is necessary to gain more insight in the overall prevalence of HLA-DRB3 antibodies and the clinical relevance of these antibodies in transplantation.

Since the induction of an antibody response may be dependent on the dose of the antigen on the kidney transplant, we questioned whether there are differences in the mRNA and protein expression of different donors depending on their HLA-DRB3 typing or based on their HLA-DRB1 allele. In order to address this issue, we made use of a large depository of HLA-typed frozen splenocytes from which we selected vials (based on their typing) to isolate $B$ cells and perform our expression studies. Importantly, the disadvantage of using this material may be that the total process of harvesting splenocytes and isolating B cells may influence the stability of the mRNA and proteins. Still, we observed comparable mRNA and protein levels of HLA-DRB3 when we used fresh blood samples (data not shown). Furthermore, our findings are in line with previous studies that reported that the relative mRNA expression of HLA-DRB1 is always higher than HLA-DRB3 ${ }^{40,41}$. Emery et al. showed that this difference in expression between HLA-DRB1 and HLA-DRB3 is caused by the presence of specific motifs (to which 


\section{Chapter 3}

transcription factors bind) in the $X$ box region of the promotors of these genes ${ }^{42}$. Although HLA-DRB3 is always lower expressed as compared to HLA-DRB1, we observed consistent differences in the HLA-DRB3 expression across different HLA-DRB1 alleles. We have not addressed the issue whether this expression difference is due to differences in the promotor of HLA-DRB3 or whether regulatory motifs in cis outside the promotor region are involved in this expression difference. However, we did observe an altered distribution in the donors that lead to the induction of HLA-DRB3 antibodies as compared to a control population without HLA-DRB3 antibodies. The reduced preponderance of HLA-DRB1*11 in the donors was in line with a reduced cell surface (protein) expression of HLA-DRB3 in case of HLA-DRB1*11. Although this expression study is limited in size, it provides support for the hypothesis that the capacity to induce an antibody response to the HLA-DRB3 protein of a mismatched HLA molecule may be dependent on the expression level of the molecule. These data add up to previous reports that HLA expression levels contribute to transplant outcome. Petersdorf et al. reported that the expression level of HLA-C and HLA-DP is of significant importance in influencing the strength of alloimmune responses in recipients that had mismatched HLA loci ${ }^{27,29}$. Furthermore, Zilinska et al. showed that HLA-G mRNA expression was increased in recipients with acute rejection (AMR and T cell-mediated rejection) as compared to patients with dysfunctional non-rejected grafts ${ }^{43}$.

In addition to our observation that the expression level of a mismatched HLA-DRB3 molecule may be involved in antibody formation, we also observed that not all HLA-DRB3 alleles are equally immunogenic. When comparing the distribution of the HLA-DRB3 alleles in the immunizing events with a control population we observed a preponderance of the HLA-DRB3*01 group of alleles. This may point towards an increased immunogenicity of HLADRB3*01 as compared to HLA-DRB3*02 and HLA-DRB3*03. Furthermore, we observed that also the exact $H L A-D R B 3$ allele determines the capacity to induce an antibody response and it is not plausible that a difference in expression is the cause of this discrepancy. With regard to our expression study, we observed that the relative mRNA expression of HLA-DRB3*01 in B cells was higher as compared to HLA-DRB3*02 and *03, which was not reflected in the cell surface expression of HLA-DRB3. Contradictory, Faner et al. demonstrated that there was no difference in relative mRNA expression of HLA-DRB3*01 and *02 in B cells and monocytes, probably because the alleles share the same sequence in their promoter region ${ }^{10}$.

In conclusion, our study showed that HLA-DRB3 antibodies are frequently detected in kidney patients after different immunologic events including transplantation, pregnancy, 
and transfusion. The induction of these antibodies after transplantation or transplant failure is associated with a wide allosensitization. To date, the clinical relevance of these antibodies remains unclear. We demonstrated that HLA-DRB3 and its' allelic diversity is immunogenic, and that HLA-DRB3 harbours multiple epitopes. Importantly, we provide a first indication that the risk of developing an antibody response against HLA-DRB3 is to a certain extent dependent on HLA expression. In addition, it appears that the HLA-DRB3*01 group of alleles is more immunogenic than the other groups.

\section{ACKNOWLEDGEMENTS}

The authors would like to thank Kevin Gerritsen, Jacqueline Frijns, Stefan Molenbroeck, Els Bielen, and Maud Limpens for their technical contribution.

\section{REFERENCES}

1. Dai S, Crawford F, Marrack P, Kappler JW. The structure of HLA-DR52c: comparison to other HLA-DRB3 alleles. Proc Natl Acad Sci U S A. 2008;105(33):11893-11897.

2. Davis SJ, Ikemizu S, Evans EJ, Fugger L, Bakker TR, van der Merwe PA. The nature of molecular recognition by T cells. Nat Immunol. 2003;4(3):217-224.

3. Klein J, Sato A. The HLA system. First of two parts. N Engl J Med. 2000;343(10):702-709.

4. Andersson G, Andersson L, Larhammar D, Rask L, Sigurdardottir S. Simplifying genetic locus assignment of HLA-DRB genes. Immunol Today. 1994;15(2):58-62.

5. Kaufman JF, Auffray C, Korman AJ, Shackelford DA, Strominger J. The class II molecules of the human and murine major histocompatibility complex. Cell. 1984;36(1):1-13.

6. Sanchez-Mazas A, Lemaitre JF, Currat M. Distinct evolutionary strategies of human leucocyte antigen loci in pathogen-rich environments. Philos Trans R Soc Lond B Biol Sci. 2012;367(1590):830-839.

7. Bergstrom TF, Erlandsson R, Engkvist H, Josefsson A, Erlich HA, Gyllensten U. Phylogenetic history of hominoid DRB loci and alleles inferred from intron sequences. Immunol Rev. 1999;167:351-365.

8. Texier C, Pouvelle-Moratille S, Charron D, Menez A, Maillere B. Complementarity and redundancy of the binding specificity of HLA-DRB1, -DRB3, -DRB4 and -DRB5 molecules. Eur J Immunol. 2001;31(6):1837-1846.

9. Parry CS, Gorski J, Stern LJ. Crystallographic structure of the human leukocyte antigen DRA, DRB3*0101: models of a directional alloimmune response and autoimmunity. J Mol Biol. 2007;371(2):435-446.

10. Faner R, James E, Huston L, Pujol-Borrel R, Kwok WW, Juan M. Reassessing the role of HLA-DRB3 T-cell responses: evidence for significant expression and complementary antigen presentation. Eur J Immunol. 2010;40(1):91-102.

11. Robinson J, Halliwell JA, Hayhurst JD, Flicek P, Parham P, Marsh SG. The IPD and IMGT/HLA database: allele variant databases. Nucleic Acids Res. 2015;43(Database issue):D423-431.

12. Schreuder GM, Hurley CK, Marsh SG, et al. The HLA Dictionary 2004: a summary of HLA-A, -B, -C, -DRB1/3/4/5 and -DQB1 alleles and their association with serologically defined HLA-A, -B, -C, -DR and -DQ antigens. Tissue Antigens. 2005;65(1):1-55.

13. Gorski J, Mach B. Polymorphism of human la antigens: gene conversion between two DR beta loci results in a new HLA-D/DR specificity. Nature. 1986;322(6074):67-70. 


\section{Chapter 3}

14. Tiercy JM, Gorski J, Jeannet M, Mach B. Identification and distribution of three serologically undetected alleles of HLA-DR by oligonucleotide.DNA typing analysis. Proc Natl Acad Sci U S A. 1988;85(1):198-202.

15. Decary F, L'Abbe D, Tremblay L, Chartrand P. The immune response to the HPA-1a antigen: association with HLA-DRw52a. Transfus Med. 1991;1(1):55-62.

16. Williamson LM, Hackett $\mathrm{G}$, Rennie J, et al. The natural history of fetomaternal alloimmunization to the plateletspecific antigen HPA-1a (PIA1, Zwa) as determined by antenatal screening. Blood. 1998;92(7):2280-2287.

17. Bouwmans EE, Smethurst PA, Garner SF, Ouwehand WH, Morley SL. Expression of a single-chain human leukocyte antigen-DRA/DRB3*01:01 molecule and differential binding of a monoclonal antibody in the presence of specifically bound human platelet antigen-1a peptide. Transfusion. 2014;54(6):1478-1485.

18. Sukati H, Bessos H, Barker RN, Urbaniak SJ. Characterization of the alloreactive helper T-cell response to the platelet membrane glycoprotein IIla (integrin-beta3) in human platelet antigen-1a alloimmunized human platelet antigen-1b1b women. Transfusion. 2005;45(7):1165-1177.

19. Gandemer V, Kaplan C, Quelvennec E, et al. Pregnancy-associated autoimmune neonatal thrombocytopenia: role of maternal HLA genotype. Br J Haematol. 1999;104(4):878-885.

20. Ishihara $\mathrm{M}$, Ishida $\mathrm{T}$, Mizuki $\mathrm{N}$, Inoko $\mathrm{H}$, Ando $\mathrm{H}$, Ohno $\mathrm{S}$. Clinical features of sarcoidosis in relation to HLA distribution and HLA-DRB3 genotyping by PCR-RFLP. Br J Ophthalmol. 1995;79(4):322-325.

21. Chen QY, Huang W, Baxter F, Volpe R, Maclaren NK. HLA-DRB1*08, DRB1*03/DRB3*0101, and DRB3*0202 are susceptibility genes for Graves' disease in North American Caucasians, whereas DRB1*07 is protective. J Clin Endocrinol Metab. 1999;84(9):3182-3186.

22. Hill M, Moss $\mathrm{P}$, et al. Early-onset myasthenia gravis: a recurring T-cell epitope in the adult-specific acetylcholine receptor epsilon subunit presented by the susceptibility allele HLA-DR52a. Ann Neurol. 1999;45(2):224-231.

23. Tighe MR, Hall MA, Barbado M, Cardi E, Welsh KI, Ciclitira PJ. HLA class II alleles associated with celiac disease susceptibility in a southern European population. Tissue Antigens. 1992;40(2):90-97.

24. Donaldson PT, Norris S. Evaluation of the role of MHC class II alleles, haplotypes and selected amino acid sequences in primary sclerosing cholangitis. Autoimmunity. 2002;35(8):555-564.

25. Opelz G, Dohler B. Effect of human leukocyte antigen compatibility on kidney graft survival: comparative analysis of two decades. Transplantation. 2007;84(2):137-143.

26. Susal C, Opelz G. Current role of human leukocyte antigen matching in kidney transplantation. Curr Opin Organ Transplant. 2013;18(4):438-444.

27. Petersdorf EW, Gooley TA, et al. HLA-C expression levels define permissible mismatches in hematopoietic cell transplantation. Blood. 2014;124(26):3996-4003.

28. Apps R, Carlson JM, et al. Influence of HLA-C expression level on HIV control. Science. 2013;340(6128):87-91.

29. Petersdorf EW, Malkki M, O'HUigin C, et al. High HLA-DP Expression and Graft-versus-Host Disease. N Engl J Med. 2015;373(7):599-609.

30. Sellares J, de Freitas DG, Mengel M, et al. Understanding the causes of kidney transplant failure: the dominant role of antibody-mediated rejection and nonadherence. Am J Transplant. 2012;12(2):388-399.

31. Gaston RS, Cecka JM, Kasiske BL, et al. Evidence for antibody-mediated injury as a major determinant of late kidney allograft failure. Transplantation. 2010;90(1):68-74.

32. Terasaki PI, Ozawa M. Predicting kidney graft failure by HLA antibodies: a prospective trial. Am J Transplant. 2004;4(3):438-443.

33. Einecke G, Sis B, Reeve J, et al. Antibody-mediated microcirculation injury is the major cause of late kidney transplant failure. Am J Transplant. 2009;9(11):2520-2531.

34. Voorter CE, Palusci F, Tilanus MG. Sequence-based typing of HLA: an improved group-specific full-length gene sequencing approach. Methods Mol Biol. 2014;1109:101-114.

35. Dheda K, Huggett JF, Bustin SA, Johnson MA, Rook G, Zumla A. Validation of housekeeping genes for normalizing RNA expression in real-time PCR. Biotechniques. 2004;37(1):112-114, 116, 118-119.

36. Mizutani K, Terasaki P, Hamdani E, et al. The importance of anti-HLA-specific antibody strength in monitoring kidney transplant patients. Am J Transplant. 2007;7(4):1027-1031.

37. Konvalinka A, Tinckam K. Utility of HLA Antibody Testing in Kidney Transplantation. J Am Soc Nephrol. 2015;26(7):1489-1502. 
38. Reed EF, Rao P, Zhang Z, et al. Comprehensive assessment and standardization of solid phase multiplex-bead arrays for the detection of antibodies to HLA. Am J Transplant. 2013;13(7):1859-1870.

39. Bos EM, Leuvenink HG, van Goor H, Ploeg RJ. Kidney grafts from brain dead donors: Inferior quality or opportunity for improvement? Kidney Int. 2007;72(7):797-805.

40. Cotner T, Charbonneau H, Pious D. mRNA abundance, rather than differences in subunit assembly, determine differential expression of HLA-DR beta 1 and -DR beta 3 molecules. J Biol Chem. 1989;264(19):11107-11111.

41. Berdoz J, Gorski J, Termijtelen AM, et al. Constitutive and induced expression of the individual HLA-DR beta and alpha chain loci in different cell types. J Immunol. 1987;139(4):1336-1341.

42. Emery P, Mach B, Reith W. The different level of expression of HLA-DRB1 and -DRB3 genes is controlled by conserved isotypic differences in promoter sequence. Hum Immunol. 1993;38(2):137-147.

43. Zilinska Z, Bandzuchova H, Chrastina M, et al. Expression of HLA-G transcripts in graft biopsy samples of renal transplant recipients. Transpl Immunol. 2015;33(3):159-165.

44. Voorter CE, Rozemuller EH, de Bruyn-Geraets D, van der Zwan AW, Tilanus MG, van den Berg-Loonen EM. Comparison of DRB sequence-based typing using different strategies. Tissue Antigens. 1997;49(5):471-476. 


\section{SUPPORTING INFORMATION}

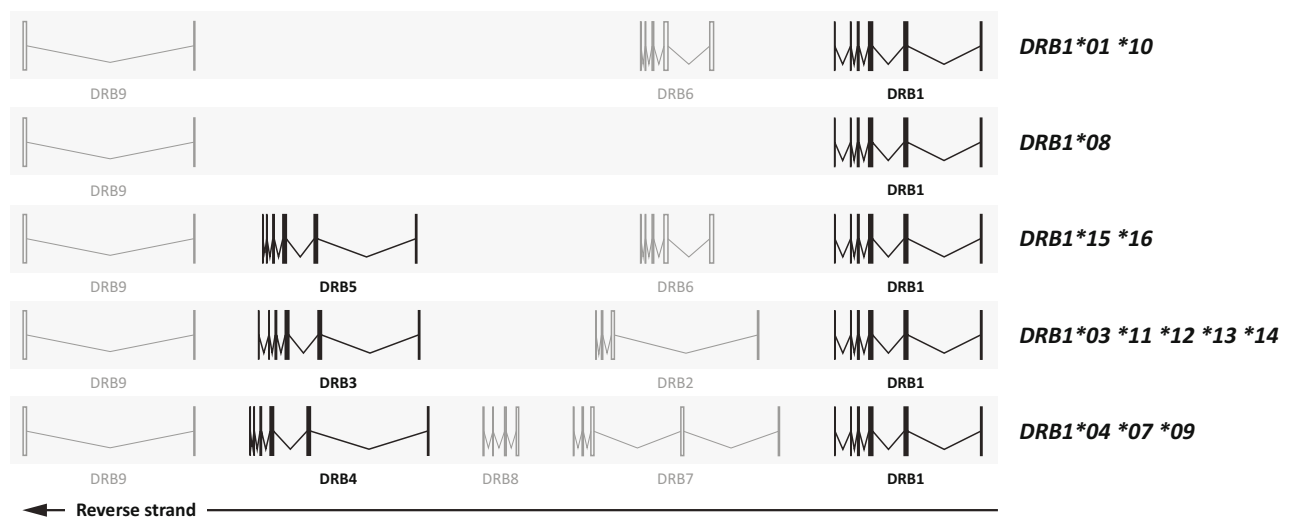

Figure S1: Schematic representation of the HLA-DR genes. The functional HLA-DRB genes are shown in black (DRB1, and $D R B 3, D R B 4, D R B 5)$, whereas pseudogenes are shown in gray (DRB2, DRB6, DRB7, DRB8, DRB9). The HLA-DRB1 allelic variants can be divided into five haplogroups: HLA-DRB1*01, *10 (DR1), HLA-DRB1*08 (DR8), HLA-DRB1*15, *16 (DR51/HLA-DRB5), HLA-DRB1*03, *11, *12,*13,*14 (DR52/HLA-DRB3), HLA-DRB1*04, *07, *09 (DR53/HLA$D R B 4)$. The gene transcripts are adapted from Ensembl.

\section{(File S1) SUPPLEMENTARY RESULTS}

Validation of antibody reactivity patterns against three LSA HLA-DRB3 microbeads using two different vendors (One Lambda and Immucor).

Both centers use a different LSA vendor as described previously and as a consequence the LSA kits may have different antibody reactivity. Therefore, we examined to what extent the LSA kits were consistent in terms of antibody reactivity patterns. A pilot study of 10 serum samples with reactivity to one, two, or all three microbeads indicated that only the patients with antibody reactivity to one or two microbeads demonstrated discrepancies across the two vendors (data not shown). However, as shown in Figure S2b, we identified 32 sera that did not show antibody reactivity with all three microbeads. In order to determine whether the antibody reactivity pattern was consistent across the vendors we tested these sera with both vendors. In these tests, 29 out of 32 samples showed reactivity against HLA-DRB3 with both vendors. In one of the samples the antibody reactivity was borderline with one vendor and just below the threshold with the other vendor. In the other two cases we observed antibody reactivity with only one microbead that was completely negative with the other vendor. Among the 29 out of 32 samples that showed antibody reactivity against HLA-DRB3 
with both vendors we identified 12 aberrant microbead reactivities. Interestingly, 10 out of 12 cases with aberrant reactivities were patients who were HLA-DRB3 gene carriers. We observed discrepancies in all three microbeads, however the most were observed in HLADRB3*03:01 coated microbeads.

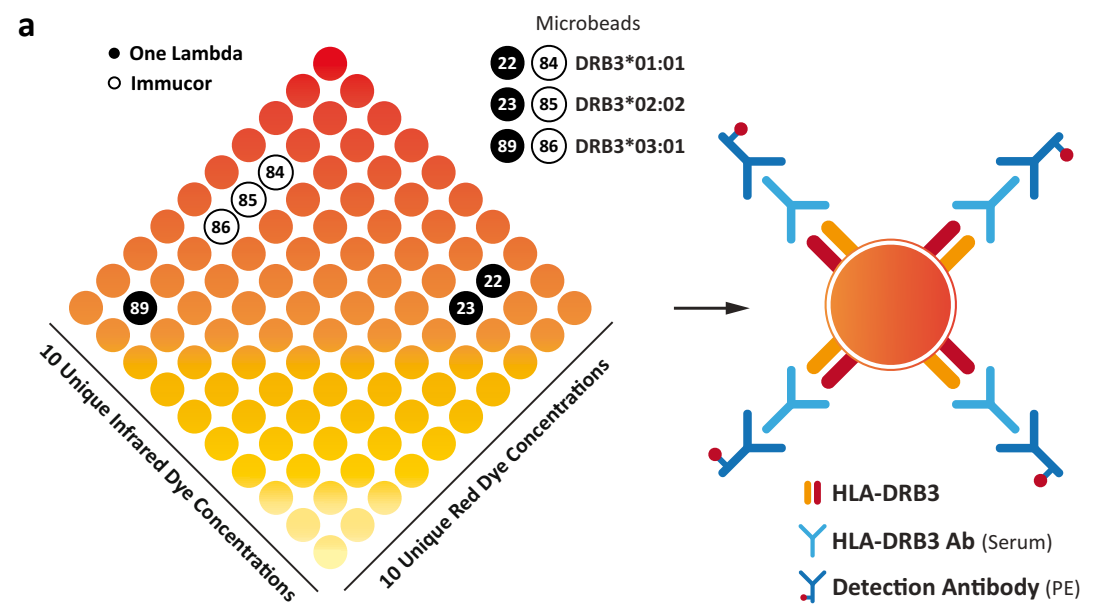

b

\section{- One Lambda $\circ$ Immucor}

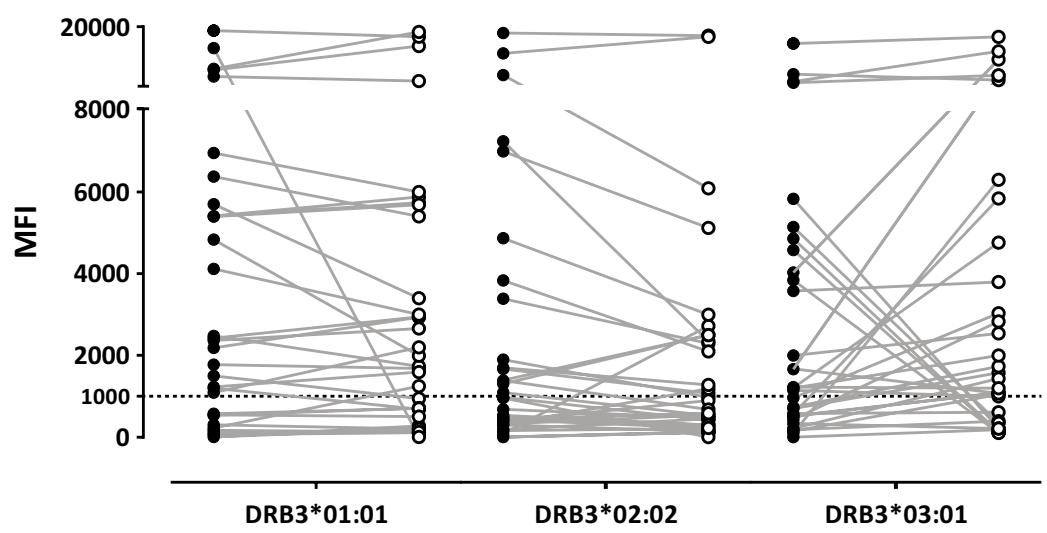

Figure S2: The reactivity patterns of HLA-DRB3 antibodies against Luminex SA microbeads using two vendors. a. A schematic representation of the LSA assay from One Lambda (Lot: 009) and Immucor (Lot: 01145C). The kits contained three microbeads coated with single HLA-DRB3 alleles: HLA-DRB3*01:01 (bead 22 or 84), HLA-DRB3*02:02 (bead 23 or 85), and HLA-DRB3*03:01 (bead 89 or 86). These microbeads were incubated with sera from patients and the HLA-DRB3 antibodies were stained with a PE labelled detection antibody. b. The sera $(n=32)$ that were positive for one or two microbeads were analysed using the One Lambda and the Immucor kit. The values are shown as mean fluorescent intensity (MFI) and represent antibodies that bound to HLA-DRB3*01:01, HLA-DRB3*02:02, or HLA-DRB3*03:01 coated microbeads. 


\section{Chapter 3}

a

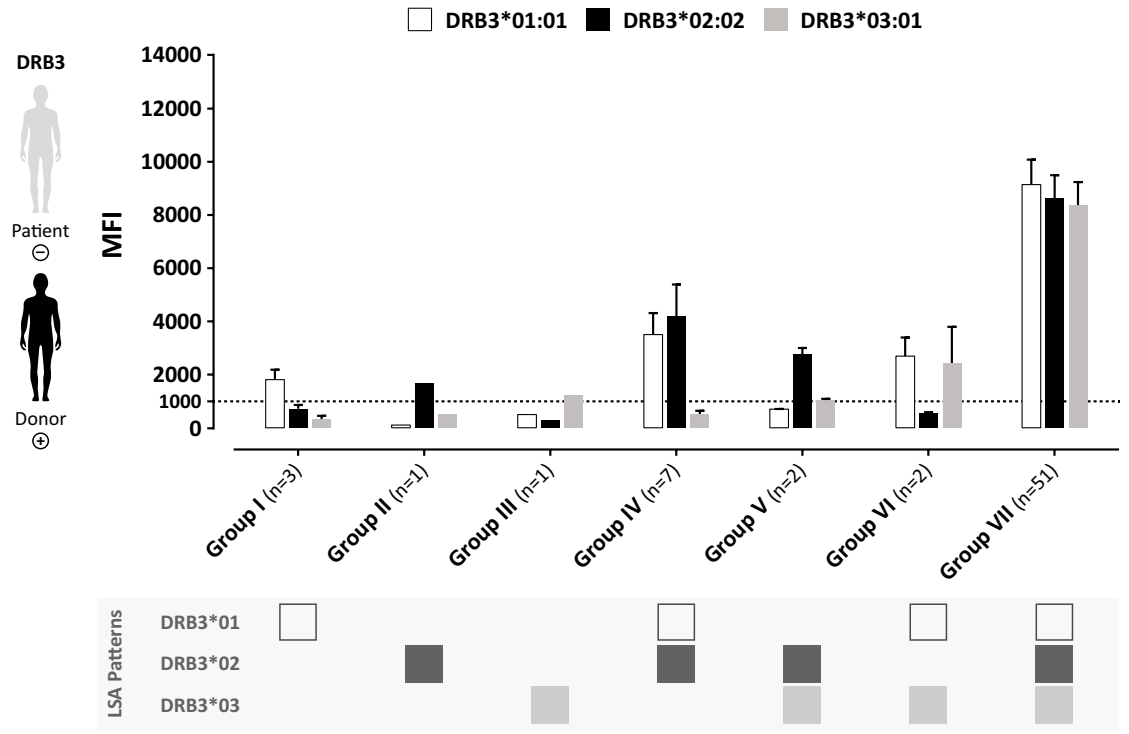

b

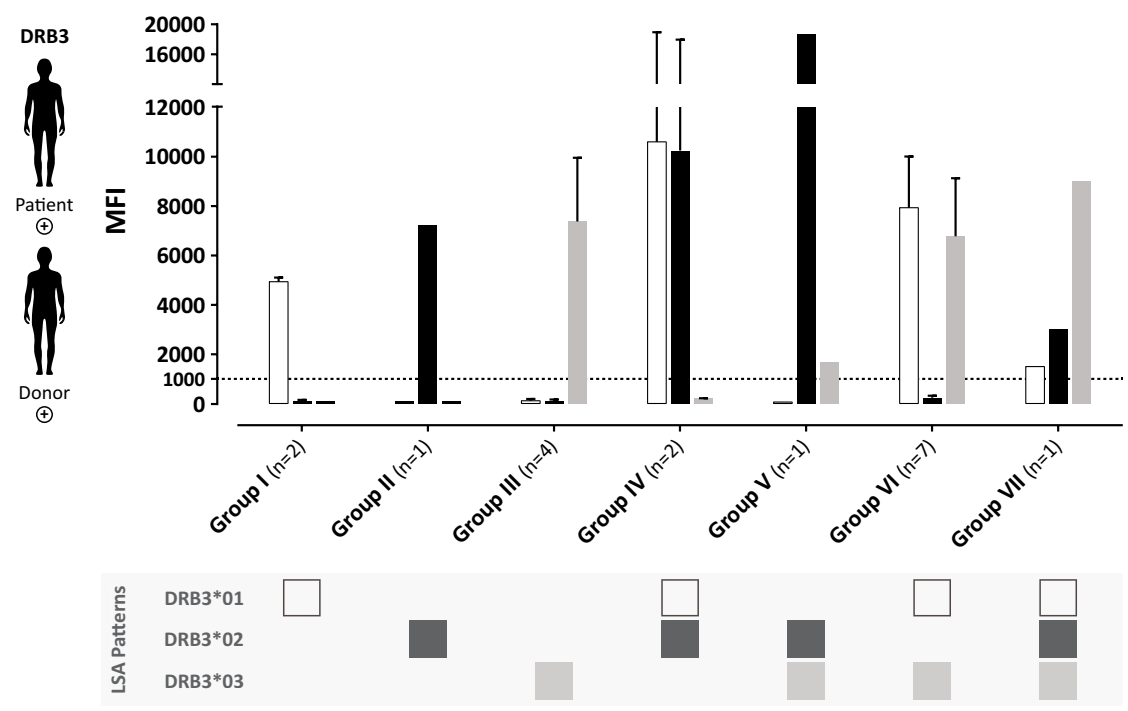

Figure S3: The reactivity patterns of HLA-DRB3 alloantibodies or intra-allele antibodies against LSA microbeads in 85 patients. a. The alloantibodies against HLA-DRB3 were observed in 67 patients who do not carry the HLA$D R B 3$ gene and who had HLA-DRB3 positive kidney transplantation, pregnancy, and/or transfusion $b$. The intra-allele antibodies against HLA-DRB3 were observed in 18 patients who were HLA-DRB3 gene carriers and who had HLA$D R B 3$ positive kidney transplantation, pregnancy, and/or transfusion. The different groups represent the binding of HLA-DRB3 antibodies in the sera of patients to microbeads coated with HLA-DRB3*01:01, HLA-DRB3*02:02, and HLA-DRB3*03:01 proteins. A MFI value of $\geq 1000$ was considered to be positive for HLA-DRB3. The data is plotted as mean and SEM. 

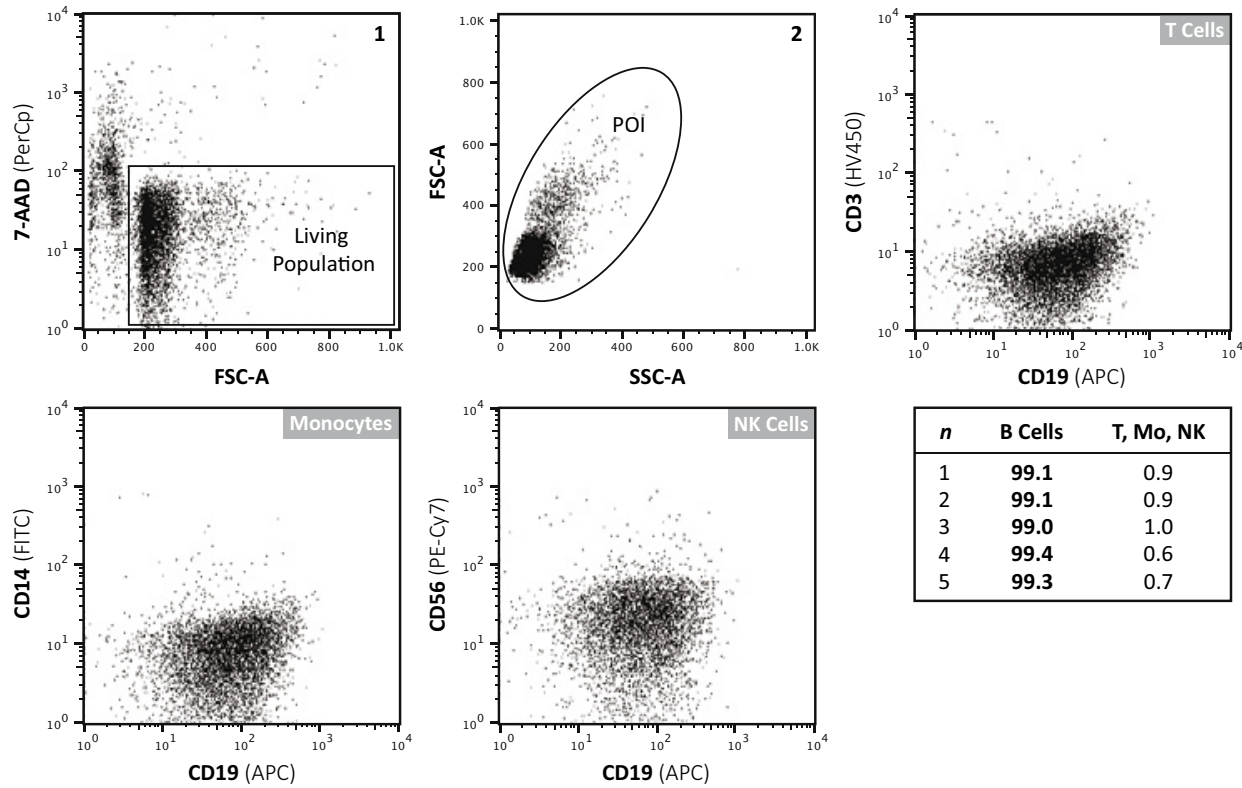

\begin{tabular}{|ccc|}
\hline $\boldsymbol{n}$ & B Cells & T, Mo, NK \\
\hline 1 & 99.1 & 0.9 \\
2 & 99.1 & 0.9 \\
3 & 99.0 & 1.0 \\
4 & 99.4 & 0.6 \\
5 & 99.3 & 0.7 \\
\hline
\end{tabular}

Figure S4: The purity staining of isolated B cells from splenocytes using flow cytometry. The cells that were isolated with the CD19+ B cell kit were fluorescently labelled with CD19 (clone HIB19, BD, APC), CD3 (clone UCHT1, BD, Horizon V450), CD56 (clone B159, BD, PE-Cy7), and CD14 (clone M5E2, BD, FITC). As shown in plot 1, the living population was gated using life/death marker 7-AAD (PerCp). Subsequently, the POI (population of interest; plot 2) was determined (FSC-SSC). As the density plots show, there was no contamination of CD3 (T), CD14 (monocytes), and CD56 (NK) cells. In short, the B cell purity was $\geq 99 \%(n=5)$. 
Chapter 3

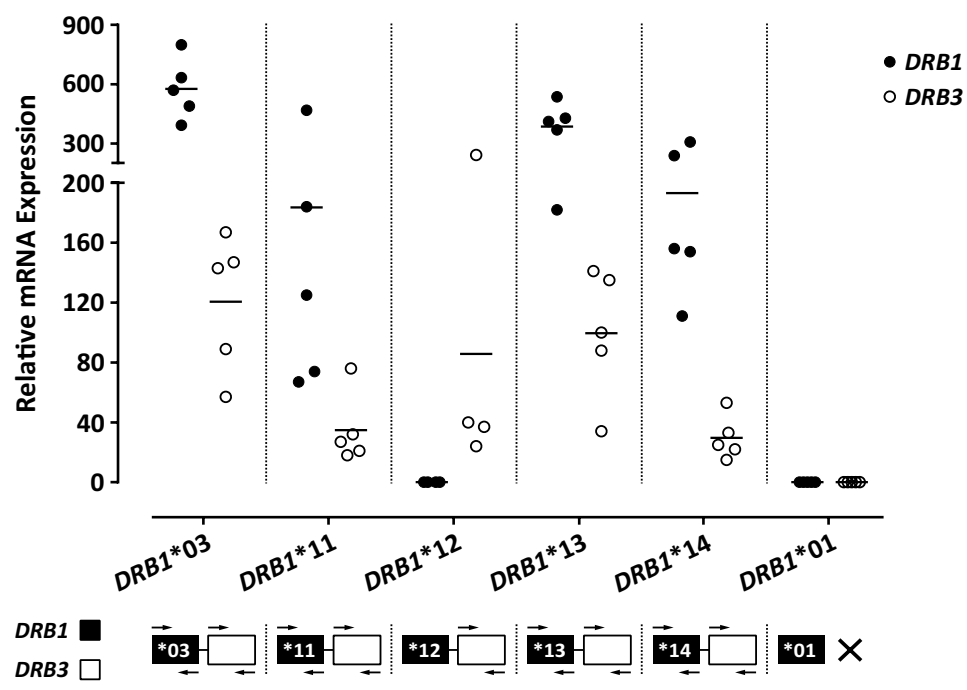

Figure S5: The relative mRNA expression of HLA-DRB1 and HLA-DRB3 in B cells determined with quantitative PCR and normalized to GAPDH. The relative mRNA expression of HLA-DRB1*03, *11, *13, and *14 as compared to HLA-DRB3 in isolated CD19+ B cells from deceased donors ( $n=5$ per group). The values were normalized to reference gene GAPDH. HLA-DRB1*01 was used as negative control for HLA-DRB1/3 primers. A primer for HLA-DRB1*12 was not included, therefore the products are not amplified. The HLA-DRB1 typing is shown in Table S1. 
a

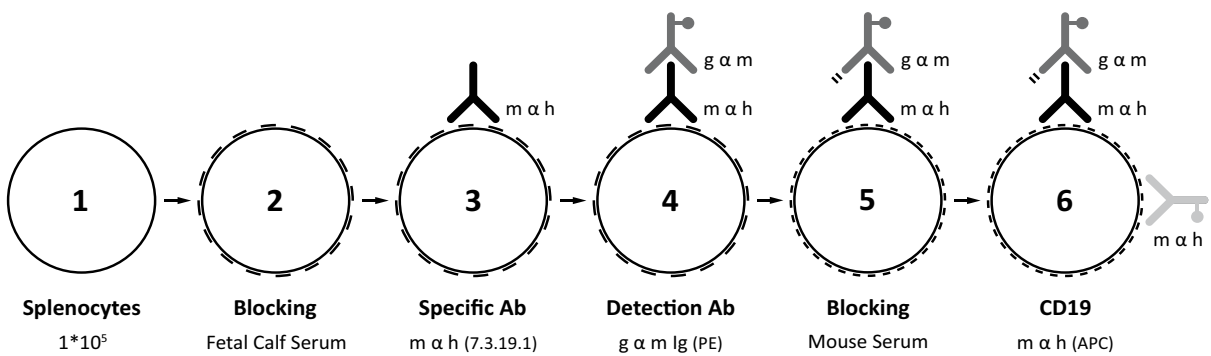

b
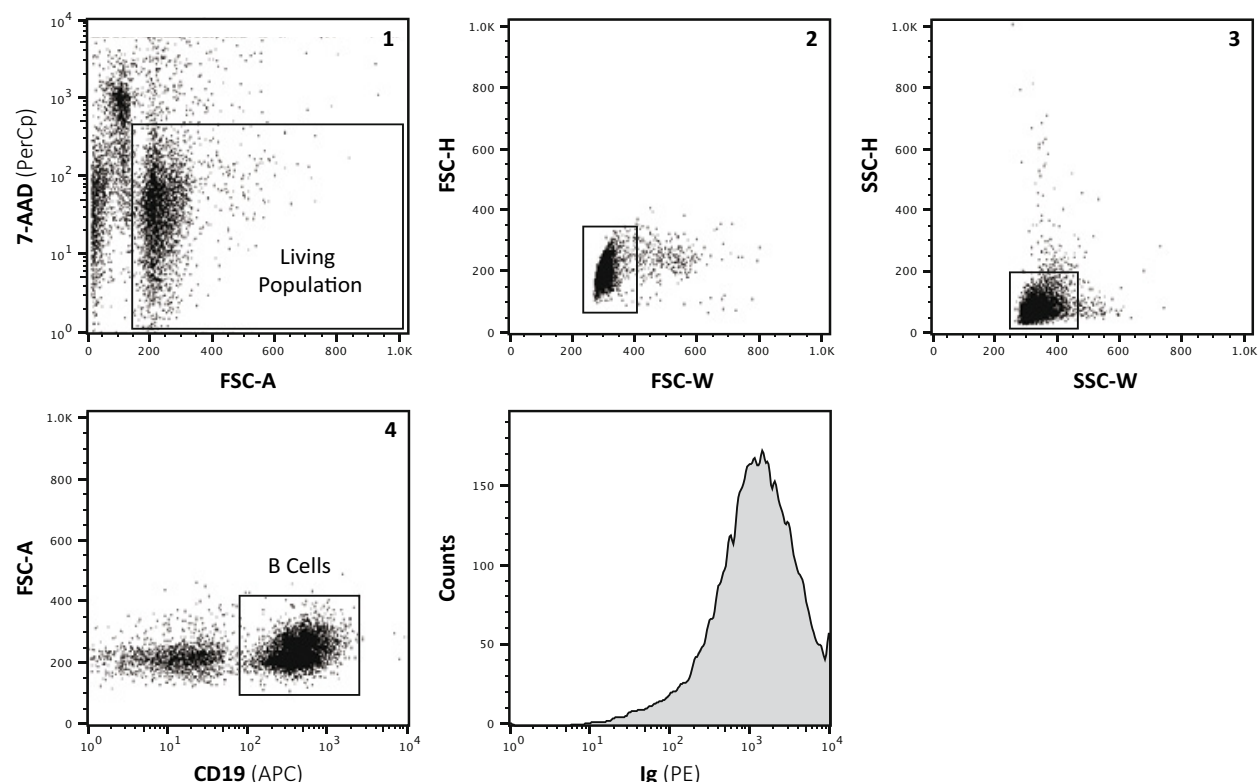

Figure S6: Schematic overview of the flow cytometric procedure and gating strategy to determine B cells that express HLA-DRB3. a. A total of $1 * 10^{5}$ splenocytes were incubated with fetal calf serum to prevent non-specific antibody binding. The mouse anti-human 7.3.19.1 antibody detected HLA-DRB3 (and HLA-DRB1*03), which were stained with a PE labelled goat anti-mouse Ig antibody. To prevent non-specific binding of mouse anti-human CD19 to the goat anti-mouse Ig antibody, the splenocytes were incubated with mouse serum. To select CD19+ B cells in the splenocyte fraction, the cells were also stained with APC labelled mouse anti-human CD19. b. (1) Living (7AAD negative) splenocytes were selected, and to obtain single cells, doublets were removed using the forward and sideward scatter (2-3). In plot 4, CD19 B cells were gated in the splenocyte fraction and the HLA-DRB3 expression was determined using the fluorescent intensity of PE. The MFI values of PE were corrected using PE labelled beads and used as MESF units. 
Chapter 3

Table S1: The HLA-DRB1 typing of splenocytes from deceased donors.

\begin{tabular}{|c|c|c|c|c|c|}
\hline DR (Ser) & DRB1 (DNA) & $\mathbf{n}$ & Allele & Allele & He/Hom \\
\hline \multirow[t]{5}{*}{ DR1 } & \multirow[t]{5}{*}{$D R B 1 * 01$} & 1 & $* 01$ & & hom \\
\hline & & 2 & $* 01$ & $* 08$ & he \\
\hline & & 3 & $* 01$ & & hom \\
\hline & & 4 & $* 01$ & *10 & he \\
\hline & & 5 & $* 01$ & & hom \\
\hline \multirow[t]{5}{*}{ DR3 } & \multirow[t]{5}{*}{$D R B 1 * 03$} & 1 & *03 & & hom \\
\hline & & 2 & $* 01$ & *03 & he \\
\hline & & 3 & $* 03$ & & hom \\
\hline & & 4 & $* 03$ & & hom \\
\hline & & 5 & $* 03$ & & hom \\
\hline \multirow[t]{9}{*}{ DR5 } & \multirow[t]{5}{*}{ DRB1*11 } & 1 & $* 11$ & *15 & he \\
\hline & & 2 & $* 11$ & & hom \\
\hline & & 3 & $* 11$ & *15 & he \\
\hline & & 4 & $* 01$ & $* 11$ & he \\
\hline & & 5 & $* 11$ & *15 & he \\
\hline & \multirow[t]{4}{*}{ DRB1*12 } & 1 & $* 01$ & $* 12$ & he \\
\hline & & 2 & $* 01$ & $* 12$ & he \\
\hline & & 3 & $* 12$ & & hom \\
\hline & & 4 & $* 12$ & *15 & he \\
\hline \multirow[t]{10}{*}{ DR6 } & \multirow[t]{5}{*}{$D R B 1 * 13$} & 1 & $* 13$ & & hom \\
\hline & & 2 & $* 13$ & & hom \\
\hline & & 3 & $* 13$ & & hom \\
\hline & & 4 & $* 13$ & & hom \\
\hline & & 5 & $* 13$ & & hom \\
\hline & \multirow[t]{5}{*}{ DRB1*14 } & 1 & $* 08$ & $* 14$ & he \\
\hline & & 2 & $* 08$ & $* 14$ & he \\
\hline & & 3 & $* 14$ & $* 15$ & he \\
\hline & & 4 & $* 08$ & $* 14$ & he \\
\hline & & 5 & $* 10$ & *14 & he \\
\hline
\end{tabular}

Ser, seromic analysis. He, heterozygous. Hom, homozygous. 
Table S2: The HLA-DRB1 (*03, *11, *13, and *14), HLA-DRB3 $(* 01, * 02$, and $* 03), H u P o$, and GAPDH primers (forward and reverse) used for quantitative PCR.

\begin{tabular}{lllll}
\hline \multicolumn{2}{l}{ Forward 5' primers } & & \\
Gene & Alleles & $\mathbf{5}^{\prime}$ primer $\left(\mathbf{5}^{\prime} \mathbf{-} \mathbf{3}^{\prime}\right)$ & Location & Exon \\
\hline HLA-DRB1 & ${ }^{*} 03,{ }^{*} 11,{ }^{*} 13,{ }^{*} 14$ & GTTTCTTGGAGTACTCTACGTC & $104-125$ & Exon 2 \\
HLA-DRB3 & ${ }^{*} 01,{ }^{*} 02,{ }^{*} 03$ & GACCACGTTTCTYGGAGCT & $97-116$ & Exon 2 \\
HUPO & $\mathrm{n} / \mathrm{a}$ & ACGGGTACAAACGAGTCCTG & $\mathrm{n} / \mathrm{a}$ & $\mathrm{n} / \mathrm{a}$ \\
GAPDH & $\mathrm{n} / \mathrm{a}$ & GCTCTCCAGAACATCATCCCTGCC & $\mathrm{n} / \mathrm{a}$ & $\mathrm{n} / \mathrm{a}$
\end{tabular}

Reverse 3' primer

\begin{tabular}{lllll} 
Gene & Alleles & $\mathbf{3}^{\prime}$ primer $\left(\mathbf{5}^{\prime} \mathbf{-} \mathbf{3}^{\prime}\right)$ & Location & Exon \\
\hline HLA-DRB1 & ${ }^{*} 03,{ }^{*} 11,{ }^{*} 13,{ }^{*} 14$ & CTGACTTCAATGCTGCCTGG & $457-476$ & Exon 3 \\
HLA-DRB3 & ${ }^{*} 01,{ }^{*} 02,{ }^{*} 03$ & CTGACTTCAATGCTGCCTGG & $457-476$ & Exon 3 \\
HUPO & $\mathrm{n} / \mathrm{a}$ & TATCCTCGTCCGACTCCTCC & $\mathrm{n} / \mathrm{a}$ & $\mathrm{n} / \mathrm{a}$ \\
GAPDH & $\mathrm{n} / \mathrm{a}$ & CGTTGTCATACCAGGAAATGAGCTT & $\mathrm{n} / \mathrm{a}$ & $\mathrm{n} / \mathrm{a}$ \\
\hline
\end{tabular}

HLA, human leukocyte antigen. HuPo, human acidic ribosomal protein.

Primer ${ }^{\#}$ is adapted from ${ }^{44}$. Location is indicated as position in the DNA sequence. 


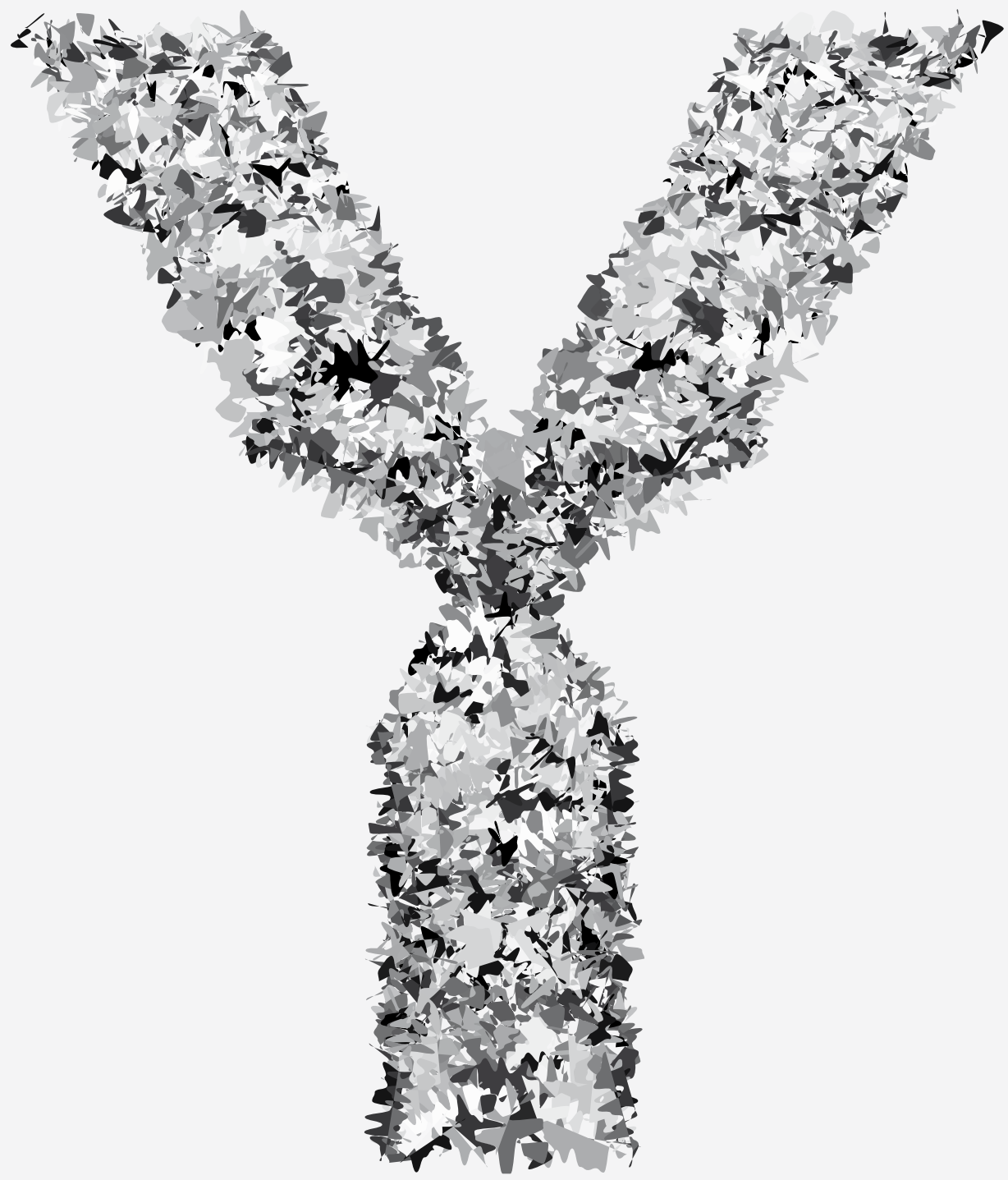




\section{CHAPTER 4}

\section{The dynamics of serum free light chain (sFLC) immunoglobulin (lg) normalization after kidney transplantation}

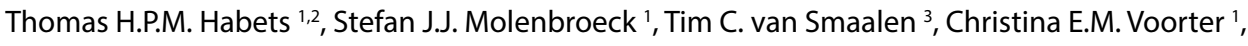
Jan Damoiseaux ${ }^{4}$, Gerard M.J. Bos ${ }^{2,5}$, Frank A. Redegeld ${ }^{6}$, Maarten H.L. Christiaans ${ }^{7}$, Marcel G.J. Tilanus ${ }^{1}$, Joris Vanderlocht ${ }^{1}$

1 Tissue Typing Laboratory, Department of Transplantation Immunology, MUMC+, Maastricht

2 Division of Hematology, Department of Internal Medicine, MUMC+, Maastricht

3 Department of Surgery, MUMC+, Maastricht

4 Central Diagnostic Laboratory, Cluster for Celldiagnostics and Celltherapy, MUMC+, Maastricht

5 CiMaas BV, Maastricht

6 Utrecht Institute for Pharmaceutical Sciences, Utrecht University, Utrecht

7 Division of Nephrology, Department of Internal Medicine, MUMC+, Maastricht

Submitted for publication 


\section{Chapter 4}

\section{ABSTRACT}

Background: Kappa ( $\mathrm{K}$ ) and lambda ( $\lambda$ ) free light chain immunoglobulins (FLC Igs) are always overproduced in normal antibody synthesis. In general, serum FLC (sFLC) Igs are efficiently reabsorbed in the kidneys. However, patients with kidney failure lose their capacity to retain normal SFLC Ig levels and also during dialysis SFLC Igs are not removed from the circulation. We examined how rapid SFLC Igs normalize after transplantation and whether the dynamics correlate with serum creatinine (SCr), beta2-microglobulin ( $\beta 2-\mathrm{M})$, and human leukocyte antigen (HLA) antibodies.

Methods: We monitored the levels of sFLC Igs, SCr, $\beta 2-\mathrm{M}$, MDRD (modified of diet in renal disease), and HLA antibodies in the serum from 63 transplant recipients who received kidney transplantation with a graft from living donors, brain death donors (DBD), or cardiac death donors (DCD).

Results: We showed that ESRD patients on dialysis had increased SFLC Ig levels that rapidly normalized after transplantation. After transplantectomy, the SFLC Ig levels increased to the levels observed before transplantation. There was no correlation of the sFLC Igs with HLA antibody responses against the graft. We demonstrated that the $\mathrm{K}$ SFLC Igs normalized faster as compared to SCr, MDRD, and $\beta 2-\mathrm{M}$ after transplantation irrespective of the type of graft. However, complete k sFLC Ig normalization within the first week after transplantation was a hallmark in all recipients with immediate graft function (IGF), whereas incomplete $\mathrm{k}$ sFLC Ig normalization was observed in recipients with delayed graft function.

Conclusion: Although, sFLC Igs were weakly correlated with SCr and MDRD, the rapid decline and normalization after transplantation in recipients with IGF reflects immediate proximal tubular function. 


\section{INTRODUCTION}

Immunoglobulins (Ig) are molecules consisting of two heavy chains and two light chains produced by $B$ cells and plasma cells ${ }^{1}$. The light chains are further classified as either kappa ( $\mathrm{k}$ ) or lambda $(\lambda)$ isotype, each having a constant and variable region domain. During normal Ig synthesis, plasma cells and other cells of the B cell lineage show $10-40 \%$ overproduction of light chains as compared to heavy chains ${ }^{2}$. About $500 \mathrm{mg} /$ day of polyclonal serum free light chain (sFLC) Igs are secreted in the blood circulation and $\pm 80 \%$ of these sFLC Igs rapidly disperse towards extracellular compartments ${ }^{3,4}$. The $\mathrm{k}$ light chains are generally monomeric with a molecular weight of $\pm 25 \mathrm{kDa}$ and the $\lambda$ light chains are dimeric with a molecular weight of $\pm 50 \mathrm{kDa}$. In addition, $\pm 67 \%$ of the produced light chains are $\mathrm{k}$ and $\pm 33 \%$ are $\lambda^{5}$.

The $\mathrm{k}$ and $\lambda$ sFLC Igs are primarily removed by proximal tubular epithelial cells (PTEC) in the nephrons of the kidneys. Individuals with normal kidney function show a $\mathrm{k}$ half-live of $2-4 \mathrm{~h}$ and $\mathrm{a} \lambda$ half-live of $3-6 \mathrm{~h}$, and due to differential clearance of these sFLC Igs the $\mathrm{k} / \lambda$ ratio is 0.26:1.65 in all age groups ${ }^{5,6}$. These sFLC Igs are filtrated through the glomerulus and are for $99 \%$ internalized by (rapid and saturable) megalin and cubilin scavenger receptors that are expressed on PTECs ${ }^{7,8}$. The endocytosed sFLC Igs undergo proteolysis in the endosomallysosomal pathway, which is an efficient mechanism for conserving amino acids and proteinbound molecules. Only 1-10 mg/day is present in the urine in individuals with normal kidney function.

Currently, several diseases such as multiple myeloma, light chain deposition disease, autoimmune disorders, but also kidney damage (e.g. due to years of hypertension) result in elevated FLC Ig levels in the circulation ${ }^{9-11}$. In particular patients with chronic kidney disease (CKD) have elevated FLC Ig levels in their blood, since sFLC Igs are primarily cleared by PTECS in the kidneys ${ }^{12}$. The progression of CKD is accompanied with further decline of kidney function, which results in even higher SFLC Ig levels ${ }^{13,14}$. In addition, the half-lives of $\mathrm{k}$ and $\lambda$ SFLC Igs can rise up to $32 \mathrm{~h}$ or even more ${ }^{15}$. Due to oversaturation of the receptor-mediated endocytosis of sFLC Igs in the PTECs, sFLC Igs bind to Tamm-Horsfall proteins and form casts in the distal tubules of the nephrons ${ }^{16,17}$. These casts lead to loss of the nephrons and over time the failed SFLC Ig clearance results in enhanced nephropathy. Ultimately, the patients develop end stage renal disease (ESRD) and require renal replacement therapy by means of dialysis and/or kidney transplantation.

For many ESRD patients, kidney transplantation is the treatment of choice based on 


\section{Chapter 4}

the gain in life expectancy and an increased quality of life. Nevertheless, the opportunity to perform kidney transplantation is determined by the availability of donor organs and in most countries the demand for possible organs exceeds the supply of postmortal donors. In many countries, programs were initiated to increase living donation and also programs to expand the total donor pool by the introduction of donation after cardiac death ${ }^{18,19}$.

The success of kidney transplantation depends mainly on the ability to discriminate between an early rejection, infectious complication or a delayed graft function (DGF) early after transplantation. Therefore, the levels of C-reactive protein (CRP) and serum creatinine $(\mathrm{SCr})$ are monitored on a daily basis. Furthermore, transplant physicians can examine donor HLA-specific antibodies (DSA) or minor antigens. In CKD patients, kidney function is assessed by means of the MDRD (modified for diet in renal disease) equation. Using this equation, the estimated glomerular filtration rate (eGFR) can be calculated via the corrected SCr levels ${ }^{20,21}$. Although $\mathrm{SCr}$ is defined as the 'golden' standard to evaluate kidney function, $\mathrm{SCr}$ is also insensitive, nonspecific, and a relatively late marker for kidney damage ${ }^{22}$. Currently, novel markers for kidney function are evaluated such as HLA class I component $\beta 2$-microglobulin $(\beta 2-M)$. Several studies demonstrated that $\beta 2-M$ is correlated with the eGFR in patients with kidney disease ${ }^{23-26}$. In kidney transplantation, high serum $\beta 2-\mathrm{M}$ levels at discharge predicts long-term mortality and graft loss providing vital information on allograft function beyond that of $\mathrm{SCr}^{27}$. Although various novel markers to determine the eGFR are proposed, a fast marker to assess kidney function after transplantation is absent and is essential to improve transplant outcome especially in case of recipients with DGF.

Since elevated SFLC Igs are maintained in ESRD patients and these are incompletely removed during conventional dialysis, we examined the dynamics of sFLC Ig normalization after kidney transplantation. In addition, we correlated the sFLC Ig normalization in different graft types with markers for kidney function such as SCr and $\beta 2-\mathrm{M}$, and with HLA antibody levels.

\section{MATERIALS AND METHODS}

\section{Kidney transplant recipients}

The human materials used in this study are defined as left-over from clinical purposes and further use for research aims is in accordance to Dutch ethical regulations. In order to study 
how the dynamics of SFLC Igs fluctuate throughout the disease course of kidney transplant recipients, we selected 15 kidney transplant recipients who underwent multiple kidney transplantations and transplantectomies in the period from 1986 until 2012. The sera were routinely collected for antibody assessment purposes.

In order to study whether sFLC Ig normalization was altered dependent on the type of kidney graft, we selected 48 transplant recipients who received kidney transplantation from living donors $(n=16)$, brain death donors (DBD) $(n=16)$, or cardiac death donors (DCD) $(n=16)$ in the period from 2000 till 2008. In a follow-up of five years, these transplant recipients did not undergo another kidney transplantation. Regarding DCD donors: kidneys were obtained from controlled and non-controlled donors that were classified according to the Maastricht classification into category II, III, and IV ${ }^{28}$. At the transplantation center of Maastricht, sera are always routinely collected before kidney transplantation (time point 0); and 1, 2, 3, 4, and 12 weeks after transplantation for antibody assessment purposes. The characteristics of these 48 kidney transplant recipients are represented in Table 1.

The kidney (graft) function was evaluated with the Modified of Diet in Renal Disease

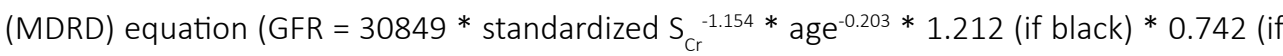
female) [GFR in $\left.\left.\mathrm{mL} \bullet \mathrm{min}^{-1} \bullet\left(1.73 \mathrm{~m}^{2}\right)^{-1}\right]\right)$ for estimated glomerular filtration rate (eGFR) ${ }^{20,21}$. The requirement for dialysis within the first week after kidney transplantation was defined as delayed graft function (DGF). Graft rejections were proven by ultrasound-guided needle core biopsy that were scored and classified using the Banff'07 scheme ${ }^{29}$.

\section{Detection of serum free light chain immunoglobulins}

The concentrations of $\mathrm{k}$ and $\lambda$ SFLC Igs were measured using an ELISA adapted from Abe et al. and Davern et al. ${ }^{30,31}$. In brief, ELISA plates (Greiner Bio-One, Kremsmünster, Austria) were coated with goat anti-mouse IgG (polyclonal, M4280, Sigma-Aldrich, Zwijndrecht, The Netherlands) overnight at $4^{\circ} \mathrm{C}$. The plates were blocked with $1 \%$ BSA for $1 \mathrm{~h}$ (RT) and afterwards incubated with mouse anti-human $\mathrm{k}$ or $\lambda$ free light chain monoclonal antibodies (kindly provided by Dr. A. Solomon, TN, USA). The monoclonal antibodies recognize a part of the light chain that is hidden when attached to the heavy chain (cryptic epitope), therefore no $\mathrm{k}$ or $\lambda$ light chains of intact Igs are detected. The sera with different dilutions (1:1000 and 1:2000) and standards obtained from The Binding Site were incubated for $1 \mathrm{~h}$ (RT). $\mathrm{k}$ or $\lambda$ sFLC Igs were detected with polyclonal HRP-labelled goat $\mathrm{F}\left(\mathrm{ab}^{\prime}\right)_{2}$ anti-human $\mathrm{k}$ or $\lambda \mathrm{FLC}$ Ig 


\section{Chapter 4}

antibodies (k GWB-FC599F, Genway, San Diego, CA, USA; and $\lambda$ AHI0904, Invitrogen, Carlsbad, CA, USA). Subsequently, TMB substrate (Thermo Scientific, Waltham, MA, USA) was added and the enzymatic reaction was stopped with $0.9 \mathrm{M} \mathrm{H}_{2} \mathrm{SO}_{4}$. The absorbance was measured at 450nm and 595nm (BioTek Synergy HTX, Winooski, VT, USA). In between steps, plates were washed with PBS containing 0.1\% Tween 20.

Table 1: Recipient, graft, and donor characteristics of $\mathbf{4 8}$ kidney transplant recipients.

\begin{tabular}{|c|c|c|c|}
\hline Recipient-related & Living Donors & DBD & DCD \\
\hline n (recipient) & 16 & 16 & 16 \\
\hline Age (year, transplant) & $47 \pm 16$ & $51 \pm 14$ & $53 \pm 13$ \\
\hline Gender (M/F) & $9 / 7$ & $8 / 8$ & $12 / 4$ \\
\hline Transplantation & $1.25 \pm 0.75$ & $1.56 \pm 0.70$ & $1.38 \pm 0.48$ \\
\hline Period (transplant) & $2000-2008$ & $2000-2008$ & $2000-2008$ \\
\hline Immediate graft function & 16 & 12 & 4 \\
\hline Delayed graft function & 0 & 4 & 12 \\
\hline Rejection & 4 & 1 & 2 \\
\hline Serum creatinine ( 3 months) & $143 \pm 36$ & $141 \pm 46$ & $186 \pm 85$ \\
\hline Serum creatinine (1 year) & $133 \pm 25$ & $127 \pm 39$ & $170 \pm 79$ \\
\hline Serum creatinine (3 years) & $131 \pm 35$ & $145 \pm 62$ & $158 \pm 59$ \\
\hline \multicolumn{4}{|l|}{ Graft-related } \\
\hline HLA-A mismatches & $0.94 \pm 0.66$ & $0.44 \pm 0.50$ & $0.88 \pm 0.70$ \\
\hline HLA-B mismatches & $1.25 \pm 0.75$ & $0.63 \pm 0.60$ & $0.94 \pm 0.24$ \\
\hline HLA-DR mismatches & $1.25 \pm 0.75$ & $0.56 \pm 0.61$ & $0.63 \pm 0.48$ \\
\hline Cold ischemia time (min) & $145 \pm 42$ & $1176 \pm 279$ & $1495 \pm 311$ \\
\hline Warm ischemia time 1 (min) & 0 & 0 & $24 \pm 8$ \\
\hline Warm ischemia time 2 (min) & $34 \pm 15$ & $41 \pm 16$ & $37 \pm 10$ \\
\hline \multicolumn{4}{|l|}{ Donor-related } \\
\hline Age (year) & $51 \pm 11$ & $42 \pm 15$ & $47 \pm 14$ \\
\hline Gender (M/F) & $7 / 9$ & $8 / 8$ & $12 / 4$ \\
\hline Category DCD (1/2/3/4) & $n / a$ & $\mathrm{n} / \mathrm{a}$ & $0 / 3 / 12 / 1$ \\
\hline
\end{tabular}

DBD, brain death donors. DCD, cardiac death donors.

HLA, human leukocyte antigen. Serum creatinine in $\mu \mathrm{mol} / \mathrm{L} . \pm=\mathrm{SD}$. 


\section{Measurement of creatinine and $\beta 2$-microglobulin in the serum}

The serum creatinine ( $\mathrm{SCr}$ ) levels were determined (routine diagnostics) using a Cobas 8000 clinical chemistry analyser (Roche, Basel, Switzerland) with a commercial available assay based on the enzymatic CREP2 reaction (Roche). In short, creatinine was hydrolysed to creatine by creatininase. The formed creatine was hydrolysed to sarcosine and urea by creatinase. Sarcosine oxidase catalysed the oxidative demethylation of sarcosine to $\mathrm{H}_{2} \mathrm{O}_{2}$, glycine, and formaldehyde. Afterwards peroxidase converted $\mathrm{H}_{2} \mathrm{O}_{2}, 4$-aminophenazone, and 2,4,6-triiodo3-hydroxybenzoic acid to quinoneimine. The absorbance of the formed quinoneimine was detected at 540nm, which was a measure for creatinine concentration ( $\mu \mathrm{mol} / \mathrm{L})$.

The serum $\beta 2$-microglobulin ( $\beta 2-\mathrm{M}$ ) levels were measured with a competitive ELISA kit (BioVendor, Brno, Czech Republic) according to the manufacturers' protocol. In short, the serum samples and standards were mixed with a HRP-labelled $\beta 2$-microglobulin conjugate. Then, the samples were incubated in an ELISA plate that contained pre-coated mouse antihuman $\beta 2$-microglobulin monoclonal antibody (1h, RT). TMB substrate was added (20min, $\mathrm{RT}$ ) and the reaction was terminated via a stopping solution. The absorbance was measured at 450nm (BioTek Synergy HTX).

\section{Detection of HLA class I and class II antibodies in serum}

The antibodies against HLA class I and II were detected during routine diagnostics by means of three methods: Lambda antigen trays (LATM), complement-dependent cytotoxicity (CDC), and Luminex single antigen (LSA) assays.

LATM. The sera and controls were incubated in Terasaki microwells (One Lambda, Thermo Scientific) that were pre-coated with a defined amount of affinity purified HLA antigens ( $1 \mathrm{~h}$, RT). Subsequently, the sera were incubated with alkaline-phosphatase (AP) conjugated antihuman IgG (polyclonal, 40min, RT). The BCIP (BluePhos) substrate was added $\left(15 \mathrm{~min}, 37^{\circ} \mathrm{C}\right.$ ) and the reaction was terminated using a stopping solution. The absorbance was measured at 630nm (BioTek ELX800).

CDC assay. Serum ( $1 \mu \mathrm{L}$ ) of the patient was incubated with $1 \mu \mathrm{L}$ lymphocyte-suspension (4 $* 10^{6}$ cells $/ \mathrm{mL}$, a screening panel of 60 different lymphocyte-suspensions) for $30 \mathrm{~min}$ (RT). To initiate lymphocyte lysis via CDC, $5 \mu \mathrm{L}$ rabbit complement (Life Technologies) was added and incubated for $60 \mathrm{~min}$ (RT). The addition of $5 \mu \mathrm{L}$ FluoroQuench (One Lambda) for 10min (RT) 
allowed discrimination of intact vs. lysed lymphocytes by means of automated fluorescence microscopy (Leica). In this way, the panel-reactive antibody (PRA) index can be determined. LSA assay. Allele-specific HLA antibodies were detected using the LABScreen Single Antigen (SA) HLA class II assay (One Lambda) according to the manufacturers' protocol. The LSA kit contained microbeads coated with purified HLA proteins representing single HLA alleles. The microbeads were incubated with serum of the patient for 30min (RT). The serum antibodies that bound to the purified HLA proteins on the microbeads were detected with PE (phycoerythrine)-conjugated goat anti-human IgG after 30min (RT) incubation. After washing, the microbeads were measured using the Luminex 100 multiplex analyser (Luminex, Austin, TX, USA) and further analysed by HLA Fusion v.3.4 (One Lambda) software. The microbeads with a corrected MFI value of $\geq 4000$ were considered positive.

\section{Figures and statistics}

The statistical analyses were performed in GraphPad Prism Pro v.6.01 (GraphPad Software Inc., La Jolla, CA, USA). The figures were made and combined in Adobe Illustrator (Adobe Systems, San Jose, CA, USA). The Wilcoxon t-test was used to determine a significant difference between two time points within the same patient group. The Mann-Whitney t-test was used to determine a difference between the patient group and healthy controls. The correlation coefficient $(r)$ and 95\% confidence interval were calculated using the Pearson $r$ test. For all data, a $P$ value of $<0.05(*)$ was considered to be significant. The P-values $<0.01,<0.001$, and $<0.0001$ are presented as $(* *),(* * *)$, and $(* * * *)$ respectively.

\section{RESULTS}

\section{Longitudinal evaluation of sFLC Ig levels before and after kidney transplantation and transplantectomy.}

In order to determine the dynamics of sFLC Igs in kidney transplant recipients, we measured the sFLC Ig levels of 15 kidney transplant recipients who received multiple transplantations and/or transplantectomies and from whom serum was collected for diagnostic purposes.

In Figure 1a, we show a representative example of a kidney transplant recipient who underwent two transplantations and one transplantectomy. As shown, both $\mathrm{k}$ and $\lambda$ sFLC Ig levels remain high before both transplantations at day 0 and 2400, indicating that 
sFLC Igs are not removed by conventional dialysis. After transplantation, the $\mathrm{k}$ and $\lambda$ sFLC Ig levels rapidly normalized (reference level). In contrast, transplantectomy at day 800 resulted in an increase of sFLC Igs. We also observed increased SFLC Igs at the time of graft failure (day 550). In addition, we measured the $\mathrm{K}$ and $\lambda$ sFLC Ig levels in the other kidney transplant recipients before and after kidney transplantation (3 months). We showed that all dialyzing kidney patients (ESRD) had elevated $\mathrm{k}$ and $\lambda \mathrm{sFLC}$ Ig levels as compared to healthy individuals $(n=12)$. After transplantation, the $\mathrm{k}$ and $\lambda \mathrm{sFLC}$ Ig levels normalized in most recipients within 3 months (Figure 1b; $\mathrm{P}<0.05$ ).

Since SFLC Igs are produced by B cells and plasma cells, we addressed the question to what extent the sFLC Ig level is influenced when an HLA antibody response is induced. Because a transplantectomy is associated (in the majority of cases) with the induction of a robust (HLA) antibody response, we examined the $\mathrm{k}$ and $\lambda \mathrm{sFLC}$ Ig levels before and 3 months after transplantectomy. As shown in Figure 1c, we observed that both $\mathrm{k}$ and $\lambda$ sFLC Ig levels are increased before and after transplantectomy $(P<0.05)$. After removal of the graft, the $\mathrm{K}$ and $\lambda$ SFLC Ig levels further increased to comparable levels as ESRD patients on dialysis (Figure $\mathbf{1 b}, \mathbf{c}$ ). In order to address the question whether the increase of sFLC Ig levels after tectomy were partially induced by the HLA antibody response, we performed a correlation analysis of the total SFLC Igs with the total HLA antibodies in 15 transplant recipients before and after transplantation and transplantectomy. There was a moderate correlation observed before transplantectomy ( $r=0.5612)$, while the other analyses regarding transplantation and after transplantectomy showed no correlation (Figure 1d, e).

Taken together, these findings indicate that the total level of sFLC Igs is not invariably associated with the HLA antibody responses in these transplant recipients. Additionally, we did not observe correlations with panel reactive antibodies, and Luminex donor HLA-specific antibodies indicative for antigen-specific B cell production (data not shown).

\section{The majority of transplant recipients demonstrate complete $\mathrm{\kappa}$ sFLC Ig normalization irrespective of graft type within 12 weeks after transplantation.}

In order to examine whether the dynamics of sFLC Ig normalization can be linked to graft function after kidney transplantation, we measured the $\mathrm{k}$ SFLC Ig levels and evaluated the $\mathrm{SCr}$ levels that are used as 'golden' standard to determine kidney function. In addition, the MDRD equation was used to define the eGFR. Because the $\mathrm{k}$ and $\lambda$ sFLC Igs demonstrated a similar normalization after transplantation, we only measured the $\mathrm{k}$ SFLC Igs. To this end, 
a

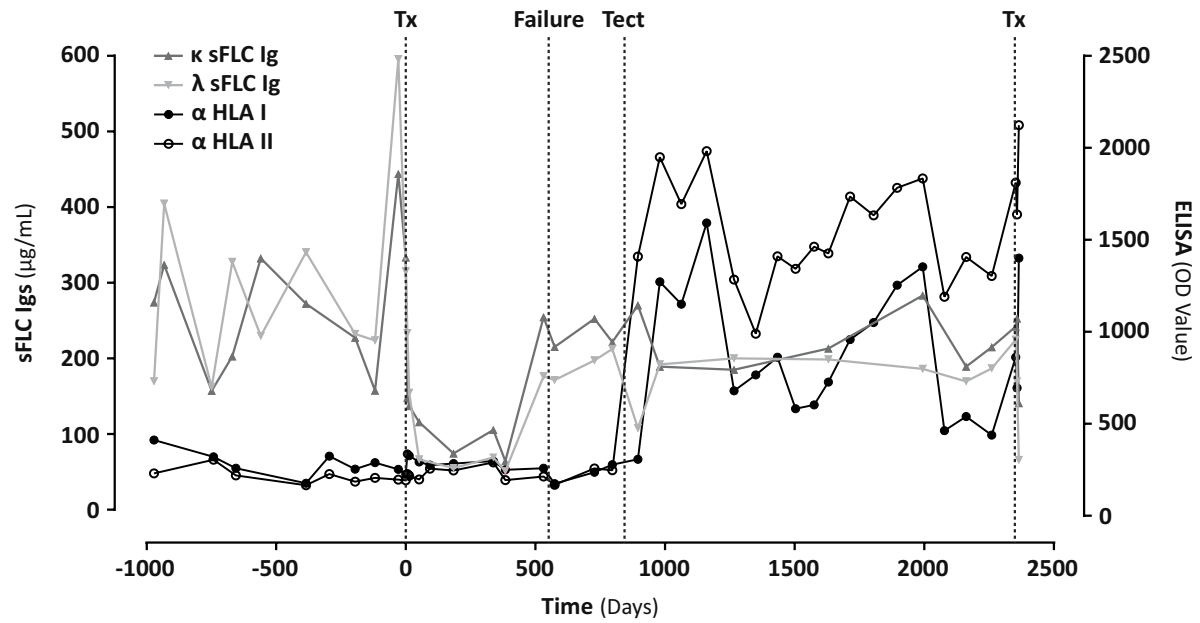

b

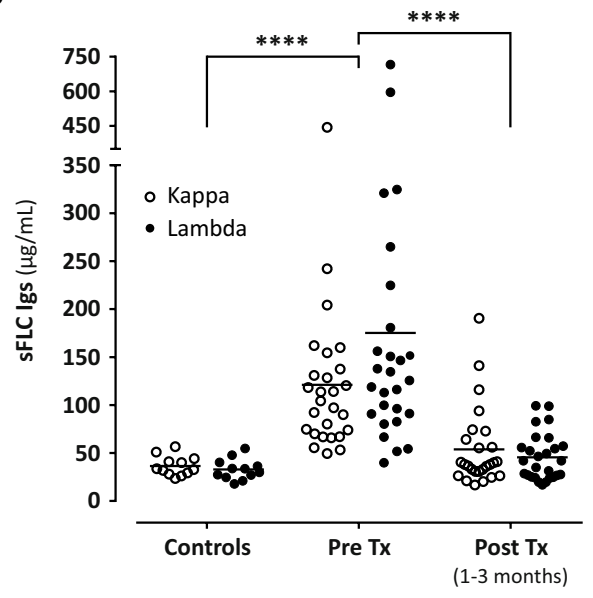

d

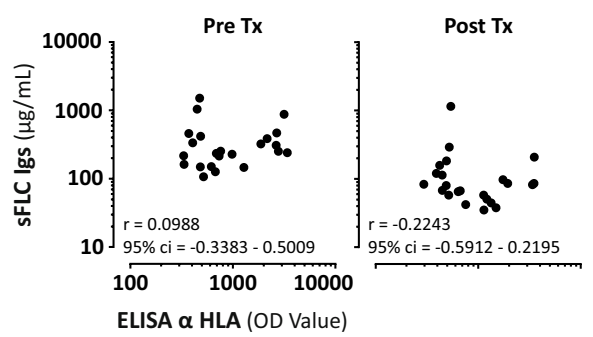

C

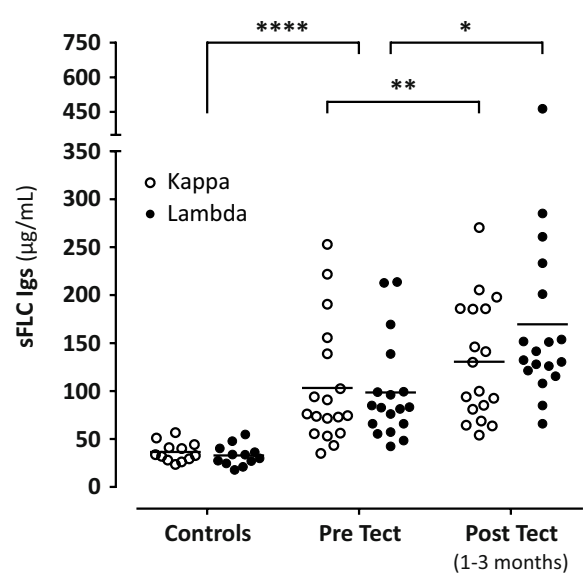

e

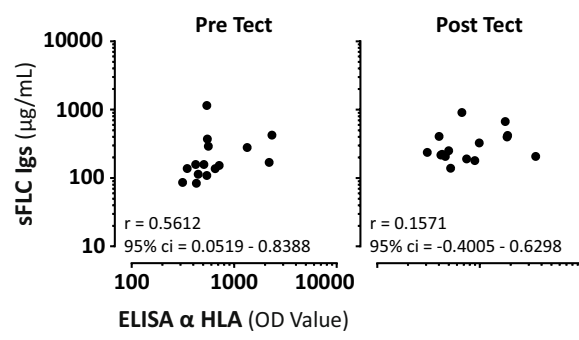

Figure 1: The levels of $\mathrm{\kappa}$ and $\boldsymbol{\lambda}$ sFLC Igs and HLA antibodies in kidney transplant recipients who had transplantation or transplantectomy. $a$. The dynamics of $\mathrm{k}$ and $\lambda$ sFLC Igs and HLA antibodies in a transplant recipient who had two kidney transplantations (day 0, 2400) and one transplantectomy (day 850) in a time period of 3500 days. b. The $\mathrm{k}$ and $\lambda$ sFLC Ig levels in 15 transplant recipients before and after transplantation (pre and post Tx) in a period of 1 to 
3 months. c. The $\mathrm{k}$ and $\lambda \mathrm{sFLC}$ Ig levels in 15 transplant recipients before and after transplantectomy (pre and post Tect) in a period of 1 to 3 months. $d$, e. Correlation graphs of the total ( $k$ and $\lambda$ ) sFLC Ig levels with the total HLA (class I and II) antibody levels before and after transplantation or transplantectomy. The Wilcoxon t-test was used for pre vs. post Tx and pre vs. post Tect. The Mann-Whitney t-test was used for pre Tx vs. controls and pre Tect vs. controls. A $\mathrm{P}$ value of $<0.05\left({ }^{*}\right),<0.01\left({ }^{* *}\right),<0.0001\left({ }^{* * * *}\right)$ were significant. The $r$ values and $95 \%$ confidence intervals (ci) were calculated using the Pearson $r$ test; all 4 correlation graphs were not significant. OD, optical density.

we examined the dynamics of $\mathrm{K}$ SFLC Igs, SCr, and MDRD in 48 kidney transplant recipients. The transplant recipients were categorized in transplant recipients who received a graft from living donors, brain death (DBD) donors, or cardiac death (DCD) donors ( $n=16$ per group; Table 1). The K SFLC Ig, SCr, and MDRD levels were measured before ( $t=0)$; and 1, 2, 3, 4, and 12 weeks after transplantation.

As shown in Figure 2a, the k sFLC Ig levels of all 48 transplant recipients normalized (to control levels) within 12 weeks after kidney transplantation, whereas the SCr and MDRD levels did not normalize in this period of time. Furthermore, we observed a rapid decline of the $\mathrm{k}$ sFLC Ig levels in the first week after kidney transplantation as compared to the gradual decline of SCr or the increase of the eGFR (MDRD). Although the SCr or MDRD values are the standard measurements to assess kidney function, the renal clearance mechanism is totally different as compared to sFLC Igs. Therefore, we aimed to compare the dynamics of sFLC Igs with a substance that is cleared in the kidney by a similar mechanism as SFLC Igs. To this end, we compared SFLC Ig normalization with serum $\beta 2-\mathrm{M}$, which is a newly proposed biomarker for kidney function. We analysed the $\beta 2-\mathrm{M}$ levels in sera before and after transplantation, and we observed a similar trend of $\beta 2-\mathrm{M}$ clearance as compared to the $\mathrm{K}$ sFLC Igs. Notably, the $\beta 2-\mathrm{M}$ levels did not completely normalize within 12 weeks after transplantation.

To address the question to what extent the dynamics of $\mathrm{k}$ sFLC Ig normalization is associated with the graft quality, we divided the transplant recipients based on their type of graft (living donors, DBD, and DCD). As shown in Figure $\mathbf{2} \mathbf{b}$, we observed rapid and complete K SFLC Ig normalization in all transplant recipients who had a graft from either a living donor, DBD, or DCD within 12 weeks after transplantation. In contrast, we observed an incomplete normalization of SCr, MDRD, and $\beta 2-\mathrm{M}$. Furthermore, the transplant recipients with a graft from DCD displayed incomplete K SFLC Ig normalization (week 1 and 2 after transplantation) when kidney function was delayed (SCr and MDRD). In addition, we observed a clear donordependent clearance pattern of SCr, MDRD, and $\beta 2-\mathrm{M}$, since the transplant recipients with living graft donors had faster clearance than DBD, and DBD were in turn faster than DCD.

In order to determine whether $\mathrm{k}$ sFLC Igs correlate with markers for kidney function, 
a

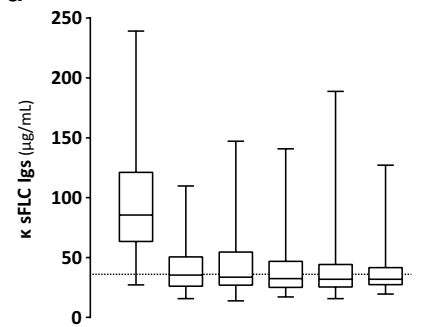

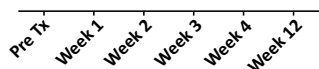
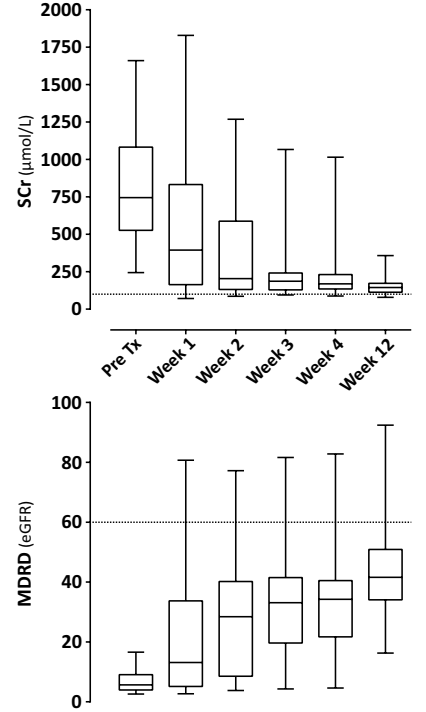

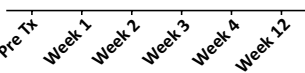

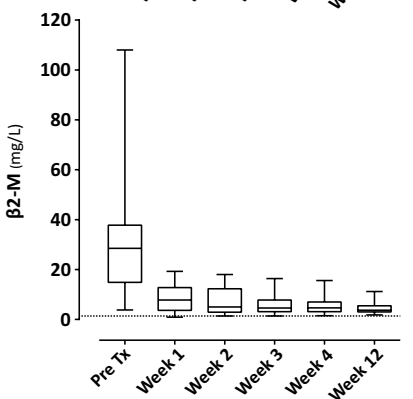

b
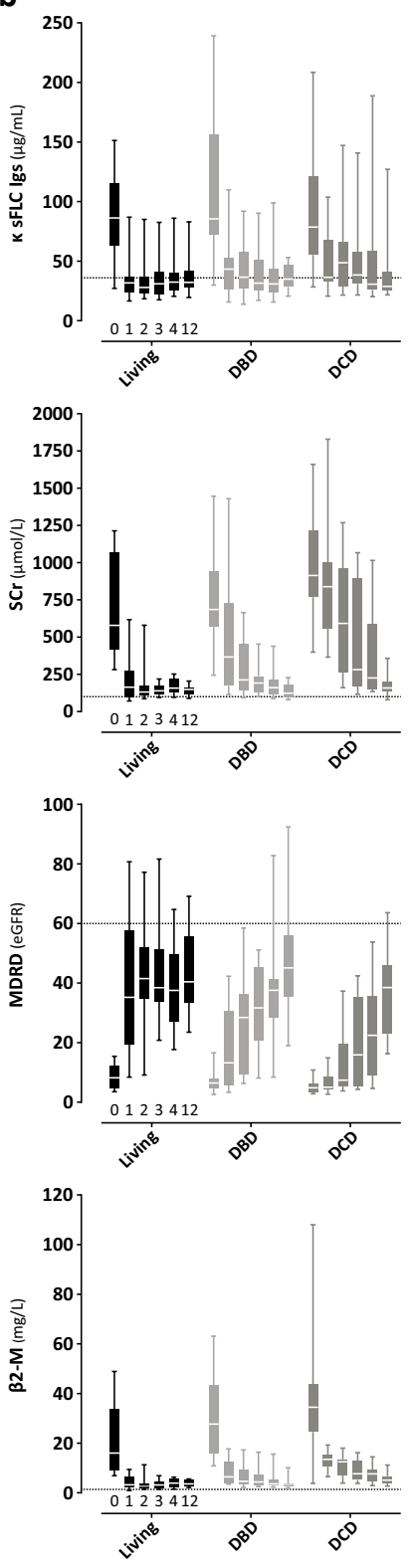

C
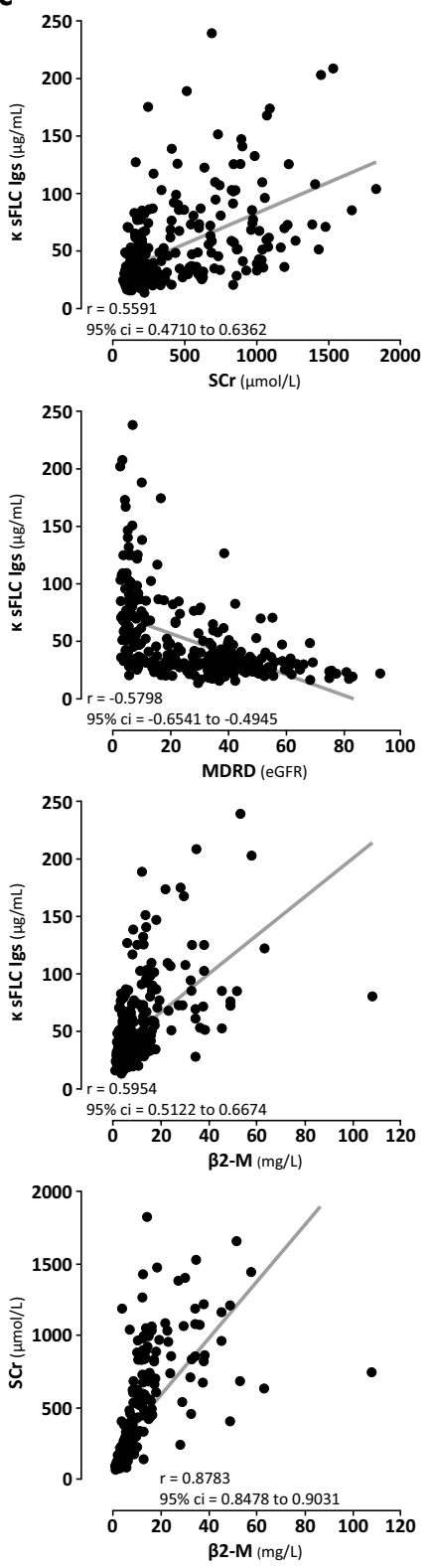

Figure 2: The dynamics of $\mathrm{K}$ sFLC Igs, SCr, MDRD, and $\beta 2-\mathrm{M}$ in kidney transplant recipients who had transplantation with a graft from living donors, DBD, or DCD. a. The dynamics of $\mathrm{K} s \mathrm{FLC}$ Igs $(\mu \mathrm{g} / \mathrm{mL}), \mathrm{SCr}(\mu \mathrm{mol} / \mathrm{L}), \mathrm{MDRD}(\mathrm{eGFR})$, and $\beta 2-\mathrm{M}(\mathrm{mg} / \mathrm{L})$ in all 48 kidney transplant recipients. The values are shown at time points: before transplantation 0 (pre Tx), and 1, 2, 3, 4, 12 weeks after transplantation. b. The dynamics of $\mathrm{k}$ sFLC Igs, SCr, MDRD, and $\beta 2-\mathrm{M}$ in transplant recipients who had transplantation with a graft from living donors, DBD, or DCD ( $n=16$ per group). The dashed line represents the reference level. c. Correlation graphs of $\mathrm{K}$ sFLC Igs with SCr, MDRD, and $\beta 2-\mathrm{M}$ of 48 kidney 
transplant recipients during the first month (weeks 1, 2, 3, 4) after transplantation. The correlation of SCr with $\beta 2-\mathrm{M}$ was used as reference. The $r$ values and $95 \%$ confidence intervals (ci) were calculated using the Pearson $r$ test; all graphs were significant $\mathrm{P}<0.01$.

we performed correlation analyses of $\mathrm{K}$ sFLC Igs with SCr, MDRD, and $\beta 2-\mathrm{M}$. As shown in Figure 2c, we correlated the $\mathrm{K}$ SFLC Igs levels with the SCr, MDRD, and $\beta 2-\mathrm{M}$ levels in all 48 kidney transplant recipients during the first month (weeks 1, 2, 3, 4) after transplantation. To be able to compare our results, we performed reference analyses of $\mathrm{SCr}$ with $\beta 2-\mathrm{M}$. We observed moderate correlations of the K SFLC Igs with SCr ( $r=0.56), \operatorname{MDRD}(r=-0.58)$, and $\beta 2-\mathrm{M}(r=0.59)$. However, when we compared these findings of the $\mathrm{k}$ sFLC Igs with the reference analysis of standard marker SCr with $\beta 2-\mathrm{M}$, a strong correlation was observed ( $r=0.88)$. The moderate correlations are a reflection of the fact that the $\mathrm{k} F \mathrm{CL}$ Ig normalization is different (faster) than $\mathrm{SCr}, \mathrm{MDRD}$, and $\beta 2-\mathrm{M}$. In contrast, the $\beta 2-\mathrm{M}$ levels after transplantation closely resemble the course of $\mathrm{SCr}$ (strong correlation).

We also examined whether there is a dissimilarity in the correlations of $\mathrm{K}$ SFLC Igs with SCr, MDRD, and $\beta 2-\mathrm{M}$ during the first month after kidney transplantation based on the graft type. Therefore, we performed correlation analyses of $\mathrm{k}$ SFLC Igs with SCr, MDRD, and $\beta 2-\mathrm{M}$ in the transplant recipients who received a graft from living donors, $\mathrm{DBD}$, or $\mathrm{DCD}$ ( $n=16$ per group). As shown in Figure S1, the correlations of $\mathrm{k}$ sFLC Igs with $\mathrm{SCr}$, MDRD, and $\beta 2-\mathrm{M}$ in transplant recipients with living donors are weak ( $r=0.28, r=-0.40, r=0.28)$, whereas the DBD showed moderate $(r=0.41, r=-0.42, r=0.49)$, and the DCD showed moderate-strong correlations ( $r=0.59, r=-0.59, r=0.62)$. Notably, the reference correlations of SCr with $\beta 2-\mathrm{M}$ demonstrated strong correlations in all graft types $(r=0.80, r=0.80, r=0.82)$. The correlations indicate that the $\mathrm{K} \mathrm{SFLC} \mathrm{Ig} \mathrm{normalization} \mathrm{is} \mathrm{faster} \mathrm{in} \mathrm{transplant} \mathrm{recipients} \mathrm{with} \mathrm{living} \mathrm{donors} \mathrm{as}$ compared to SCr, MDRD, and $\beta 2-\mathrm{M}$ (weak correlation). Although transplant recipients with DCD normalize within 12 weeks after transplantation they show a more gradual decline of $\mathrm{k}$ sFLC Ig levels, which resembles the course of SCr, MDRD, and $\beta 2-\mathrm{M}$.

\section{Transplant recipients with IGF in contrast to DGF demonstrate complete $\mathrm{K}$ sFLC Ig normalization within the first week after transplantation.}

Since we observed a dissimilarity in K SFLC Ig normalization in the different graft types, we questioned to what extent the difference between these donor groups is caused by graft function after transplantation. Therefore, we categorized the transplant recipients according to the criteria whether they required dialysis within the first week after transplantation 
a
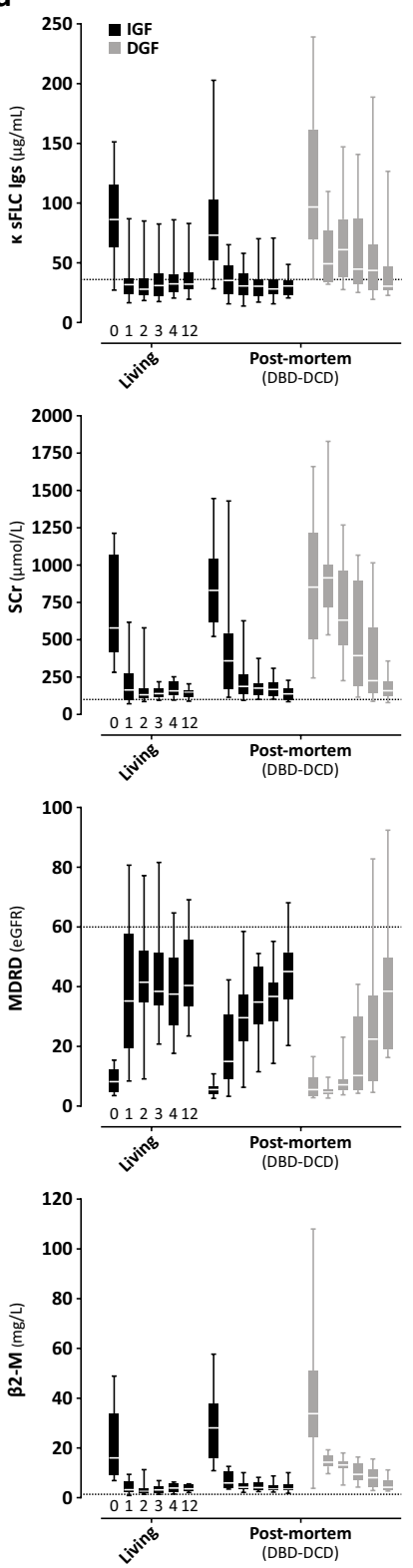

b
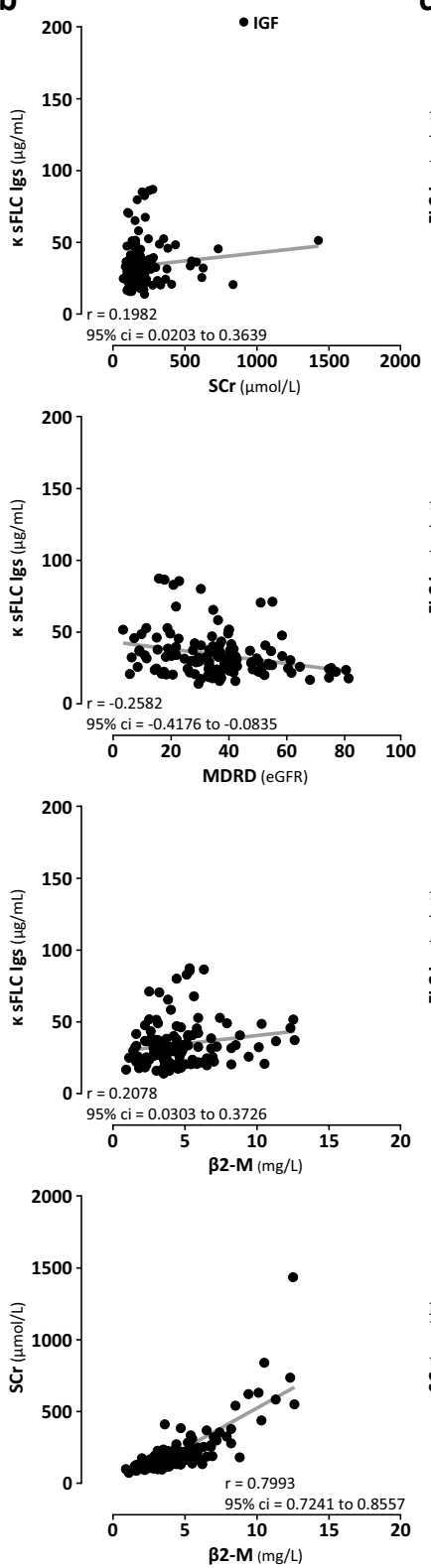
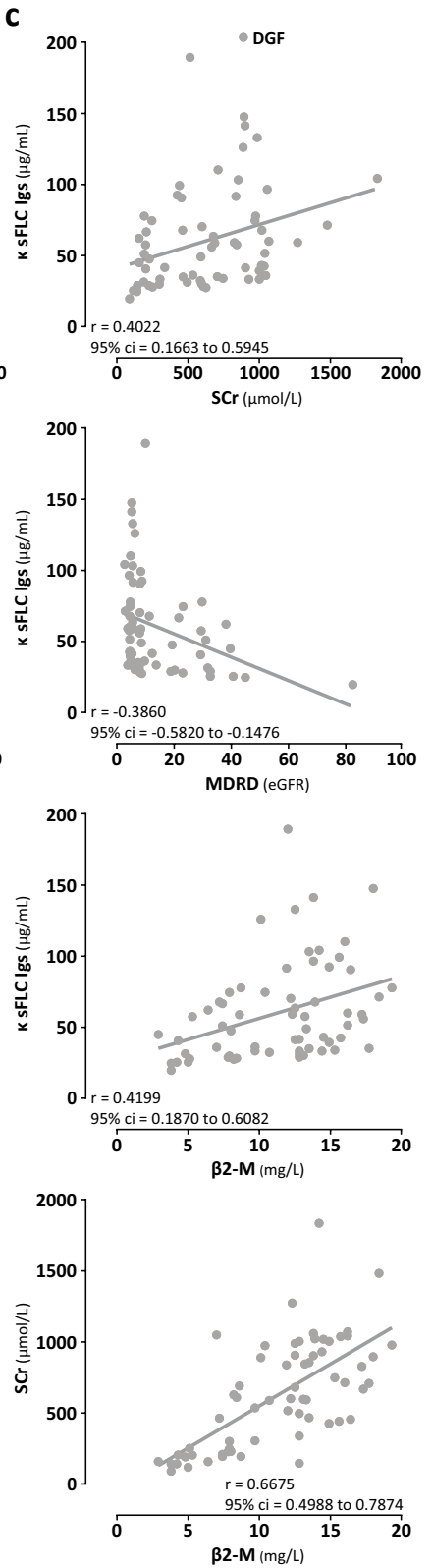

Figure 3: The dynamics of $\mathrm{K}$ sFLC Igs, SCr, MDRD, and $\beta 2-\mathrm{M}$ in kidney transplant recipients who show IGF or DGF after kidney transplantation. $a$. The dynamics of $\mathrm{k} \mathrm{sFLC} \operatorname{lgs}(\mu \mathrm{g} / \mathrm{mL}), \mathrm{SCr}(\mu \mathrm{mol} / \mathrm{L}), \mathrm{MDRD}(\mathrm{eGFR})$, and $\beta 2-\mathrm{M}(\mathrm{mg} / \mathrm{L})$ in all 48 kidney transplant recipients who show IGF $(n=32)$ or DGF $(n=16)$. The transplant recipients are further divided based on their graft type: living or post-mortem donors (DBD, DCD). The values are shown at time points: 0 (before transplantation), and 1, 2, 3, 4, 12 weeks after transplantation. The dashed line represents the reference level. b, c. Correlation graphs of $\mathrm{K}$ SFLC Igs with SCr, MDRD, and $\beta 2-\mathrm{M}$ of 48 kidney transplant recipients showing IGF ( $n=32$ ) 
or DGF ( $n=16$ ) during the first month (weeks 1, 2, 3, 4) after transplantation. The correlation of SCr with $\beta 2-\mathrm{M}$ was used as reference. The $r$ values and $95 \%$ confidence intervals (ci) were calculated using the Pearson $r$ test; all graphs were significant $\mathrm{P}<0.01$.

(DGF) or not (IGF). Indeed, the groups were different in the frequency of DGF with $n=0$ in the transplant recipients of a living donor graft and $n=4$ and $n=12$ in respectively DBD and DCD.

As shown in Figure 3a, it was evident that all 32 transplant recipients with IGF (living $n=16$, DBD $n=12$, and DCD $n=4$ ) displayed complete $\mathrm{k}$ sFLC Ig normalization within the first week after transplantation, whereas 16 transplant recipients with DGF (DBD $n=4, D C D n=12$ ) displayed incomplete normalization. In contrast, the SCr, MDRD, and $\beta 2-\mathrm{M}$ levels did not normalize after transplantation in transplant recipients showing IGF and DGF. In addition, the SCr and MDRD levels showed a donor-dependent clearance pattern, in which transplant recipients with living and deceased donors (DBD and DCD) having IGF did not show a similar pattern as compared to the $\mathrm{k}$ sFLC Igs. Although, $\beta 2-\mathrm{M}$ demonstrated a comparable trend as compared to the $\mathrm{K}$ SFLC Igs, the transplant recipients showing IGF and DGF did not display a complete normalization within 12 weeks after transplantation.

To assess whether K SFLC Igs display a different correlation with markers for kidney function in case of IGF and DGF, we performed correlation analyses of $\mathrm{K}$ sFLC Igs with $\mathrm{SCr}$, MDRD, and $\beta 2-M$ in transplant recipients showing IGF $(n=32)$ or DGF $(n=16)$ during the first month (weeks 1, 2, 3,4) after transplantation. The transplant recipients with IGF showed weak correlations of $\mathrm{k} \mathrm{sFLC} \mathrm{Igs} \mathrm{with} \mathrm{SCr}(r=0.20)$, MDRD ( $r=-0.26)$, and $\beta 2-\mathrm{M}(r=0.21)$ during the first month after transplantation (Figure $\mathbf{3 b}$ ). However, the transplant recipients with DGF showed moderate correlations during the first month after transplantation of $\mathrm{k}$ sFLC Igs with $\mathrm{SCr}(\mathrm{r}=0.40), \mathrm{MDRD}(\mathrm{r}=-0.39)$, and $\beta 2-\mathrm{M}(\mathrm{r}=0.42)$ (Figure 3c). The reference analysis of $\mathrm{SCr}$ with $\beta 2-\mathrm{M}$ showed a strong correlation $(r=0.80)$ in transplant recipients with IGF, but a moderate-strong correlation in case of DGF ( $r=0.67)$. These correlations indicate a clear difference in K SFLC Ig normalization in transplant recipients showing IGF or DGF and that the dynamics of $\mathrm{K}$ SFLC Igs do not follow SCr, MDRD, and $\beta 2-\mathrm{M}$ (weak to moderate correlations).

\section{DISCUSSION}

We demonstrated in our study that elevated $\mathrm{k}$ and $\lambda \mathrm{sFLC} \mathrm{Ig} \mathrm{levels} \mathrm{are} \mathrm{a} \mathrm{hallmark} \mathrm{in} \mathrm{patients}$ with ESRD. Previous research described that CKD patients had increased levels of SFLC Igs, which was correlated with CKD progression (CKD stage 1 to 5$)^{12-14}$. Although elevated sFLC Ig 


\section{Chapter 4}

levels are known to contribute to the loss of nephrons by cast formation, most conventional dialysis membranes fail to remove these SFLC Igs from the circulation as their pore sizes of 10 to $15 \mathrm{kDa}$ are smaller than the sFLC Igs ( $\mathrm{k} \pm 25 \mathrm{kDa}$ and $\lambda \pm 50 \mathrm{kDa})^{2,3}$. Only high cut-off membranes with a pore size up to $\pm 65 \mathrm{kDa}$ are able to remove the sFLC Igs from the blood circulation, however, these membranes are not used in conventional dialysis ${ }^{32}$. Immediately after kidney transplantation, both $\mathrm{k}$ and $\lambda \mathrm{sFLC}$ Ig levels normalized to levels observed in individuals without a kidney problem, which indicated that a proper functioning kidney was required and sufficient to maintain normal sFLC Ig levels in the serum. In addition, this also means that the reticulo-endothelial system in the liver was not capable to maintain normal sFLC Ig levels in ESRD patients on dialysis ${ }^{2}$. In patients with transplantectomy, we observed elevated SFLC Ig levels after removal of the transplanted kidney graft. Because this elevation was not correlated with the induction of HLA antibody responses, this increase presumably reflects a sink function of the transplanted graft.

At present, it remains unclear what the functional consequence or origin of sFLC Igs in ESRD patients is. It is known that B cells and plasma cells produce an excess of light chains as compared to heavy chains during normal antibody synthesis. This overproduction varies in the range of 10 to $40 \%$ and appears to be genetically determined ${ }^{2}$. However, in certain patients it is clear that specific SFLC Igs are contributing to a loss of kidney function. These include MM patients (monoclonal SFLC Igs), but also patients with light chain deposition disease (LCDD). Such patients were excluded in our study. Therefore, in most ESRD patients the accumulated SFLC Igs are polyclonal. In the content of a failed transplantation, loss of the graft can be caused by the induction of an antibody response directed against HLA molecules of the donor. It is possible that HLA-specific light chains are contributing to the total amount of sFLC Igs. However, we demonstrated that the transplanted patients that developed HLA class I and II antibodies did not show a correlation with the total ( $k$ and $\lambda$ ) sFLC Ig levels after transplantation. The antibody response against the graft by means of HLA antibodies produced by $B$ cells and plasma cells was probably not the main source of all the detected SFLC Igs. Although we did not observe a correlation with HLA antibodies in the recipients, previous research by Thio et al. showed that SFLC Igs are able to bind antigen-specific ${ }^{33}$. Therefore, the SFLC Igs derived from the HLA antibody production may participate in antibody-mediated rejection, however the precise role of these SFLC Igs remain elusive. Taken together, the sFLC Igs that were detected in ESRD patients on dialysis are probably a variety of antibodies that are not only restricted to the HLA antibody response against the transplanted graft. 
In an effort to examine the dynamics of $\mathrm{k}$ sFLC Igs after kidney transplantation, we demonstrated in 48 kidney transplant recipients that the $\mathrm{K}$ SFLC Ig levels declined faster as compared to kidney function markers SCr, MDRD, and $\beta 2-\mathrm{M}$. It was also evident that the $\mathrm{k}$ SFLC Ig levels normalized within the first week after transplantation, which was not observed in case of SCr, MDRD, and $\beta 2-\mathrm{M}$. The fact that these $\mathrm{k}$ sFLC Igs normalized faster was also reflected in the moderate correlations with SCr, MDRD, and $\beta 2-\mathrm{M}$ in the period 1 to 4 weeks after transplantation. Furthermore, we showed that complete $\mathrm{k} \mathrm{SFLC} \mathrm{Ig} \mathrm{normalization} \mathrm{was} \mathrm{a}$ hallmark for all recipients with IGF, whereas recipients with DGF showed incomplete $\mathrm{k}$ sFLC Ig normalization within the first week after transplantation. To determine whether $\mathrm{k}$ sFLC Igs or total SFLC Igs are a predictive marker for complete kidney function, a prospective study is required. In addition, it is also interesting to question whether increases in SFLC Igs precedes $\mathrm{SCr}$ levels in the context of chronic graft dysfunction or acute and chronic rejection episodes.

It should be noted that we only measured the $\mathrm{k}$ and not the $\lambda \mathrm{sFLC}$ Ig levels in these 48 transplant recipients. Although we showed in 15 transplant recipients a similar $\mathrm{k}$ and $\lambda$ sFLC Ig level 1 to 3 months after transplantation, it is unknown whether $\lambda$ sFLC Igs (dimeric conformation) display a similar normalization within the first week after transplantation. In addition, the transplant recipients received immunosuppressive drugs after transplantation including corticosteroids, mycophenolic acid (MMF), and tacrolimus. Although steroids are only administered in the first two days and then duo-therapy with MMF and tacrolimus, these drugs target and inhibit the proliferation and activation capacity of $T$ cells and $B$ cells 34-36. This means that the antibody synthesis by $B$ cells and plasma cells may be impaired. The rapid decline and normalization of $\mathrm{k}$ SFLC Igs after transplantation may be explained by the fact that the immunosuppressive drugs inhibited the synthesis of additional SFLC Igs. In addition, the HLA class I protein $\beta 2-\mathrm{M}$, present on every nucleated cell and who's expression is dependent on the activation status of several immune cells, may also be influenced by the immunosuppressive drugs. Although we observed a rapid decline of the $\beta 2-\mathrm{M}$ levels after transplantation, there was no complete normalization and the $\beta 2-\mathrm{M}$ levels did not correlate well with $\mathrm{k}$ sFLC Igs. In contrast, the reference analysis of $\mathrm{SCr}$ with $\beta 2-\mathrm{M}$ showed a strong correlation.

The renal clearance mechanisms of SFLC Igs, SCr, and $\beta 2-\mathrm{M}$ are schematically shown in Figure 4. $\mathrm{SCr}$ is filtrated for $90 \%$ through the glomerulus and partially $( \pm 10 \%)$ secreted by endothelial cells of the proximal tubules. The $\mathrm{SCr}$ that is filtrated and secreted in the tubules is excreted in the urine ${ }^{37}$. In contrast, $\mathrm{k}$ and $\lambda$ sFLC Igs are filtrated through the glomerulus 
and reabsorbed for $99 \%$ by receptors on the PTECs. In individuals without kidney problems, less than $1 \%$ is excreted in the urine ${ }^{38}$. However, ESRD patients display impaired receptormediated uptake of sFLC Igs due to disease-related damage of the nephrons. Consequently, sFLC Igs are not internalized by PTECS and bind to a specific epitope of the Tamm-Horsfall
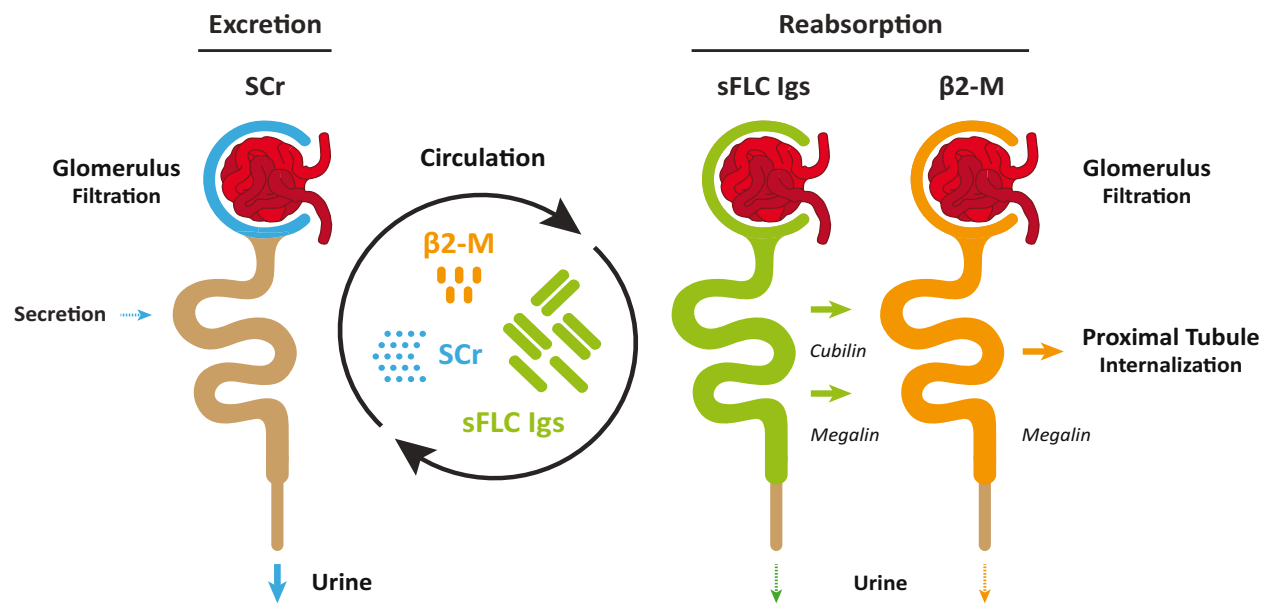

Figure 4: The clearance mechanisms of SCr versus SFLC Igs and $\boldsymbol{\beta 2}-\mathrm{M}$ in the nephrons of the kidneys. $\mathrm{SCr}$ is for $90 \%$ freely filtrated through the glomerulus and excreted in the urine. Additionally, PTECs in the proximal tubule of the nephron secrete $\pm 10 \%$ of the total excreted SCr. In contrast, sFLC Igs are filtrated through the glomerulus and internalized (99\%) by the megalin and cubilin receptors on PTECs in the proximal tubule of the nephron. Less than $1 \%$ is excreted in the urine. $\beta 2-\mathrm{M}$ is also filtrated through the glomerulus, but the internalization (PTECs) in the proximal tubule is only performed by the megalin receptor. Similar as the sFLC Igs, $\beta 2-\mathrm{M}$ shows almost no excretion in the urine. SCr, serum creatinine. SFLC Igs, serum free light chain immunoglobulins. $\beta 2-\mathrm{M}$, beta2-microglobulin.

protein that is present in the distal tubules ${ }^{17}$. Elevated sFLC Ig levels and increased binding of SFLC Igs to these proteins results in cast formation and further damages the nephrons of the kidney ${ }^{8,39}$. After kidney transplantation, the sFLC Ig levels dramatically declined probably due to efficient reuptake of sFLC Igs by the PTECs, which is dependent on graft origin and IGF or DGF. In order to compare the SFLC Ig normalization with a marker that is cleared with a similar mechanism, we selected serum $\beta 2-\mathrm{M}$ that is filtrated through the glomerulus and also reabsorbed in the proximal tubules of the nephrons and of which only $0.3 \%$ is excreted in the urine ${ }^{40,41}$. In contrast to $\mathrm{K}$ SFLC Ig normalization, there was no complete normalization obtained after transplantation. The only dissimilarity between the clearance mechanism of sFLC Igs and $\beta 2-M$ is that both the $\mathrm{k}$ and $\lambda$ sFLC Igs are internalized by megalin and cubilin receptors, whereas $\beta 2-\mathrm{M}$ is only internalized by megalin receptors ${ }^{42}$.

Currently, there remains need for new markers to assess kidney function early after 
kidney transplantation. In routine practice, kidney function is determined using $\mathrm{SCr}$, though it has been shown that $\mathrm{SCr}$ is not an early marker for kidney damage and is also dependent on muscle mass and dietary intake ${ }^{43,44}$. In the search for a new marker, sFLC Igs have limited applicability since we displayed weak correlations with SCr, MDRD, and $\beta 2-\mathrm{M}$ after kidney transplantation. However, the SFLC Ig and $\beta 2-\mathrm{M}$ levels may reflect proximal tubular function as the serum levels of these proteins rapidly declined after kidney transplantation. Notably, the SFLC Ig levels are dependent on antibody synthesis by B cells and plasma cells, therefore multiple diseases that are B cell-related display elevated SFLC Ig levels. Furthermore, these transplant recipients received a cocktail of immunosuppressive drugs after transplantation, which may affect the sFLC Ig and $\beta 2-M$ levels.

In conclusion, our study showed that ESRD patients on dialysis maintain elevated $\mathrm{k}$ and $\lambda$ sFLC Ig levels. We displayed that the $\mathrm{K}$ SFLC Ig normalization was faster as compared to $\mathrm{SCr}, \mathrm{MDRD}$, and $\beta 2-\mathrm{M}$ normalization after kidney transplantation with a graft from either a living donor, DBD, or DCD. The SFLC Ig levels did not correlate with HLA antibody responses against the transplanted kidney graft. These data indicate that SFLC Igs do not completely reflect other markers of kidney function, as transplant recipients who displayed complete K SFLC Ig normalization did not show complete SCr and MDRD normalization. However, we demonstrated that complete $\mathrm{k} \mathrm{SFLC} \mathrm{Ig} \mathrm{normalization} \mathrm{was} \mathrm{a} \mathrm{hallmark} \mathrm{for} \mathrm{recipients} \mathrm{with} \mathrm{IGF,}$ whereas incomplete $\mathrm{k}$ sFLC Ig normalization was observed in recipients with DGF within the first week after transplantation. Although, our findings showed that the sFLC Ig levels did not correlate with SCr and MDRD, the rapid decline of the SFLC Ig and $\beta 2-\mathrm{M}$ levels after kidney transplantation indicates that these proteins may reflect effective and immediate proximal tubular function.

\section{ACKNOWLEDGEMENTS}

The authors would like to thank Jacqueline Frijns, Els Bielen, and Steven Meex for their technical contribution.

\section{REFERENCES}

1. Edelman GM, Waxdal MJ, Konigsberg WH. The covalent structure of a human gamma G-immunoglobulin. I. Isolation and characterization of the whole molecule, the polypeptide chains, and the tryptic fragments. Biochemistry. 1968;7(5):1950-1958. 


\section{Chapter 4}

2. Bradwell AR. Serum Free Light Chain Analysis. Birmingham: The Binding Site Ltd.; 2010.

3. Waldmann TA, Strober W, Mogielnicki RP. The renal handling of low molecular weight proteins. II. Disorders of serum protein catabolism in patients with tubular proteinuria, the nephrotic syndrome, or uremia. J Clin Invest. 1972;51(8):2162-2174.

4. Hutchison CA, Cockwell P, Reid S, et al. Efficient removal of immunoglobulin free light chains by hemodialysis for multiple myeloma: in vitro and in vivo studies. J Am Soc Nephrol. 2007;18(3):886-895.

5. Katzmann JA, Clark RJ, Abraham RS, et al. Serum reference intervals and diagnostic ranges for free kappa and free lambda immunoglobulin light chains: relative sensitivity for detection of monoclonal light chains. Clin Chem. 2002;48(9):1437-1444.

6. Wochner RD, Strober W, Waldmann TA. The role of the kidney in the catabolism of Bence Jones proteins and immunoglobulin fragments. J Exp Med. 1967;126(2):207-221.

7. Christensen EI, Birn H. Megalin and cubilin: multifunctional endocytic receptors. Nat Rev Mol Cell Biol. 2002;3(4):256-266.

8. Basnayake K, Stringer SJ, Hutchison CA, Cockwell P. The biology of immunoglobulin free light chains and kidney injury. Kidney Int. 2011;79(12):1289-1301.

9. Redegeld FA, Thio M, Groot Kormelink T. Polyclonal immunoglobulin free light chain and chronic inflammation. Mayo Clin Proc. 2012;87(10):1032-1033; author reply 1033.

10. Solling K, Nielsen JL, Solling J, Ellegaard J. Free light chains of immunoglobulins in serum from patients with leukaemias and multiple myeloma. Scand J Haematol. 1982;28(4):309-318.

11. Randall RE, Williamson WC, Jr., Mullinax F, Tung MY, Still WJ. Manifestations of systemic light chain deposition. Am J Med. 1976;60(2):293-299.

12. Erdem BK, Davran F, Yilmaz VT, Cetinkaya R, Akbas H. The association of serum-free light-chain levels with markers of renal function. Ren Fail. 2015:1-4.

13. Jacobs JF, Hoedemakers RM, Teunissen E, Te Velthuis H. N Latex FLC serum free light-chain assays in patients with renal impairment. Clin Chem Lab Med. 2014;52(6):853-859.

14. Desjardins L, Liabeuf S, Lenglet A, et al. Association between free light chain levels, and disease progression and mortality in chronic kidney disease. Toxins (Basel). 2013;5(11):2058-2073.

15. Miettinen TA, Kekki M. Effect of impaired hepatic and renal function on Bence Jones protein catabolism in human subjects. Clin Chim Acta. 1967;18:395-407.

16. Herrera GA, Joseph L, Gu X, Hough A, Barlogie B. Renal pathologic spectrum in an autopsy series of patients with plasma cell dyscrasia. Arch Pathol Lab Med. 2004;128(8):875-879.

17. Ying WZ, Sanders PW. Mapping the binding domain of immunoglobulin light chains for Tamm-Horsfall protein. Am J Pathol. 2001;158(5):1859-1866.

18. Daemen JW, Kootstra G, Wijnen RM, Yin M, Heineman E. Nonheart-beating donors: the Maastricht experience. Clin Transpl. 1994:303-316.

19. van der Vliet JA, Slooff MJ, Kootstra G, Krom RA, Rijkmans BG. Non-heartbeating donors, is it worthwhile? Proc Eur Dial Transplant Assoc. 1980;17:445-449.

20. Poge U, Gerhardt T, Palmedo H, Klehr HU, Sauerbruch T, Woitas RP. MDRD equations for estimation of GFR in renal transplant recipients. Am J Transplant. 2005;5(6):1306-1311.

21. Levey AS, Coresh J, et al. Expressing the Modification of Diet in Renal Disease Study equation for estimating glomerular filtration rate with standardized serum creatinine values. Clin Chem. 2007;53(4):766-772.

22. Bonventre JV, Vaidya VS, Schmouder R, Feig P, Dieterle F. Next-generation biomarkers for detecting kidney toxicity. Nat Biotechnol. 2010;28(5):436-440.

23. Liabeuf $\mathrm{S}$, Lenglet A, Desjardins L, et al. Plasma beta-2 microglobulin is associated with cardiovascular disease in uremic patients. Kidney Int. 2012;82(12):1297-1303.

24. Donadio C, Lucchesi A, Giordani R. Cystatin C, beta 2-microglobulin, and retinol-binding protein as indicators of glomerular filtration rate: comparison with plasma creatinine. J Pharm Biomed Anal. 2001;24(5-6):835-842.

25. Edwards LC, Helderman JH, Hamm LL, Ludwin D, Gailiunas P, Jr., Hull AR. Noninvasive monitoring of renal transplant function by analysis of beta2-microglobulin. Kidney Int. 1983;23(5):767-770.

26. Bianchi C, Donadio C, Tramonti G, Consani C, Lorusso P, Rossi G. Reappraisal of serum beta2-microglobulin as 
marker of GFR. Ren Fail. 2001;23(3-4):419-429.

27. Astor BC, Muth B, Pirsch JD, Michael Hofmann R, Djamali A. Serum beta2-microglobulin at discharge predicts mortality and graft loss following kidney transplantation. Kidney Int. 2013;84(4):810-817.

28. Kootstra G, Oomen AP. Categories of non-heart-beating donors. Transplant Proc. 1995;27(5):2893-2894.

29. Solez K, Colvin RB, Racusen LC, et al. Banff 07 classification of renal allograft pathology: updates and future directions. Am J Transplant. 2008;8(4):753-760.

30. Abe M, Goto T, Kosaka M, Wolfenbarger D, Weiss DT, Solomon A. Differences in kappa to lambda (kappa:lambda) ratios of serum and urinary free light chains. Clin Exp Immunol. 1998;111(2):457-462.

31. Davern S, Tang LX, Williams TK, et al. Immunodiagnostic capabilities of anti-free immunoglobulin light chain monoclonal antibodies. Am J Clin Pathol. 2008;130(5):702-711.

32. Gondouin B, Hutchison CA. High cut-off dialysis membranes: current uses and future potential. Adv Chronic Kidney Dis. 2011;18(3):180-187.

33. Thio M, Groot Kormelink T, Fischer MJ, Blokhuis BR, Nijkamp FP, Redegeld FA. Antigen binding characteristics of immunoglobulin free light chains: crosslinking by antigen is essential to induce allergic inflammation. PLoS One. 2012;7(7):e40986.

34. Heidt S, Roelen DL, Eijsink C, van Kooten C, Claas FH, Mulder A. Effects of immunosuppressive drugs on purified human B cells: evidence supporting the use of MMF and rapamycin. Transplantation. 2008;86(9):1292-1300.

35. Sollinger HW. Mycophenolates in transplantation. Clin Transplant. 2004;18(5):485-492.

36. Wiseman AC. Immunosuppressive Medications. Clin J Am Soc Nephrol. 2016;11(2):332-343.

37. Stevens LA, Coresh J, Greene T, Levey AS. Assessing kidney function--measured and estimated glomerular filtration rate. N Engl J Med. 2006;354(23):2473-2483.

38. Hutchison CA, Batuman V, Behrens J, et al. The pathogenesis and diagnosis of acute kidney injury in multiple myeloma. Nat Rev Nephrol. 2012;8(1):43-51.

39. Sanders PW. Mechanisms of light chain injury in the tubular nephron. J Am Nephrol. 2012;23(11):1777-1781.

40. Dieterle F, Perentes E, Cordier A, et al. Urinary clusterin, cystatin C, beta2-microglobulin and total protein as markers to detect drug-induced kidney injury. Nat Biotechnol. 2010;28(5):463-469.

41. Okuno S, Ishimura E, Kohno K, et al. Serum beta2-microglobulin level is a significant predictor of mortality in maintenance haemodialysis patients. Nephrol Dial Transplant. 2009;24(2):571-577.

42. Nielsen R, Christensen E, Birn H. Megalin and cubilin in proximal tubule protein reabsorption: from experimental models to human disease. Kidney Int. 2016;89(1):58-67.

43. Vinge E, Lindergard B, Nilsson-Ehle P, Grubb A. Relationships among serum cystatin C, serum creatinine, lean tissue mass and glomerular filtration rate in healthy adults. Scand J Clin Lab Invest. 1999;59(8):587-592.

44. Preiss DJ, Godber IM, Lamb EJ, Dalton RN, Gunn IR. The influence of a cooked-meat meal on estimated glomerular filtration rate. Ann Clin Biochem. 2007;44(Pt 1):35-42. 


\section{SUPPORTING INFORMATION}

Living Donors
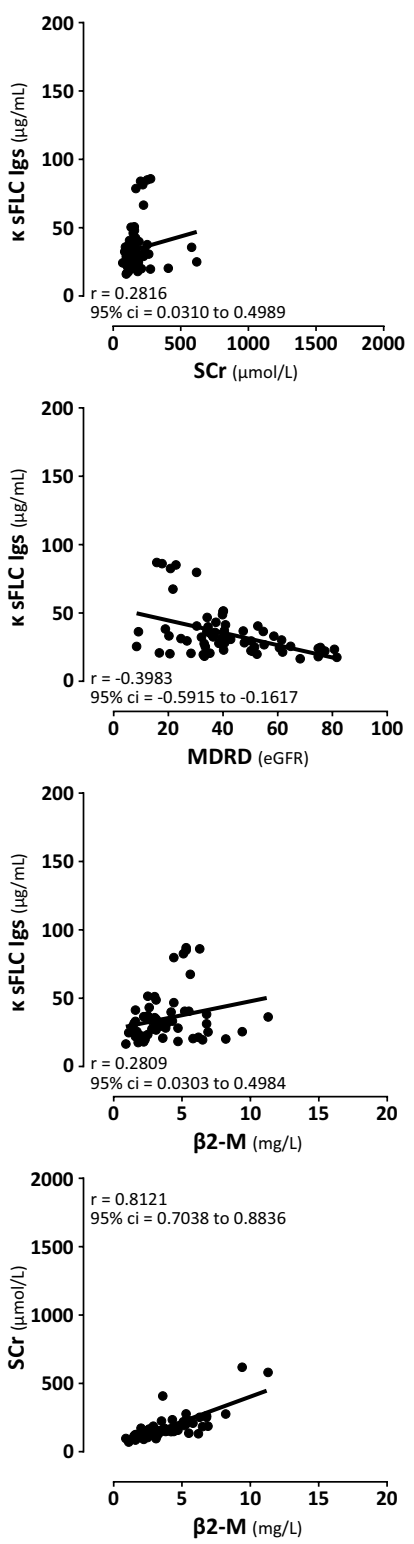

DBD
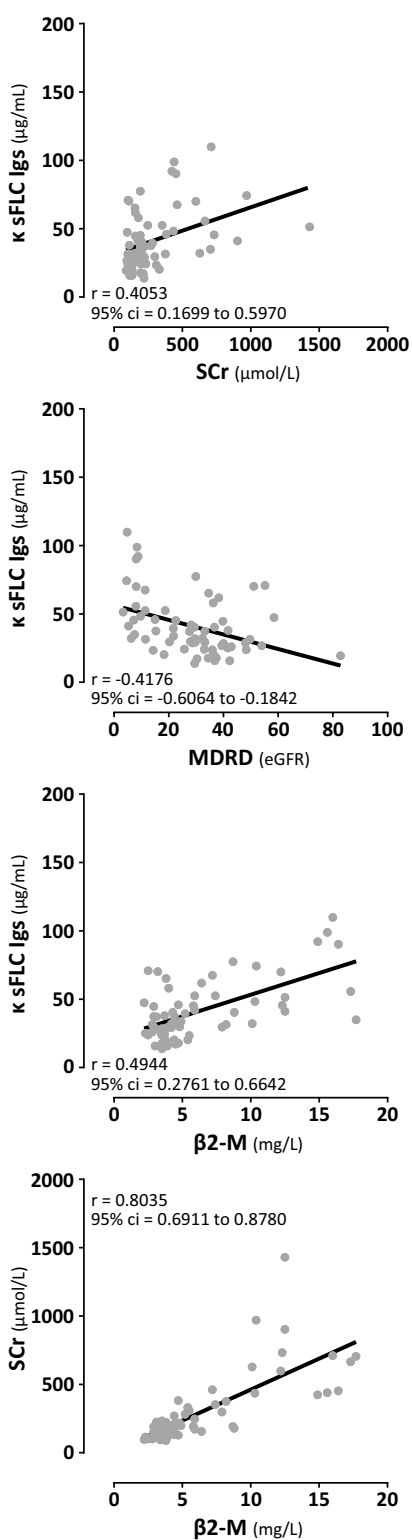

DCD
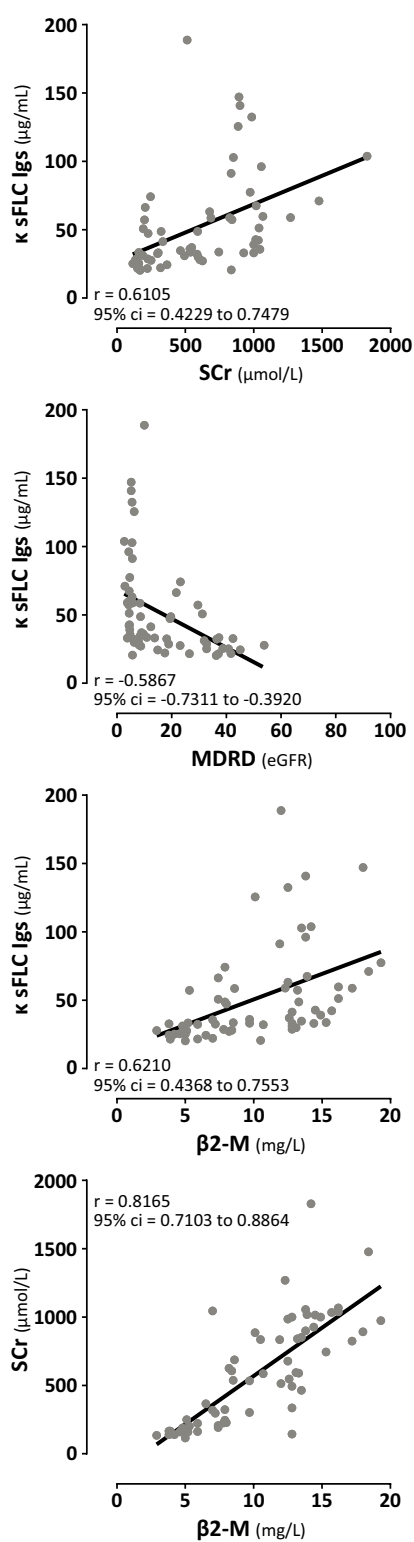
Figure S1: The correlations of $\mathrm{K}$ SFLC Igs, SCr, MDRD, and $\beta 2-\mathrm{M}$ in kidney transplant recipients during the first month (weeks 1, 2, 3, 4) after transplantation with a graft from living donors, DBD, or DCD. Correlation graphs of $\mathrm{K}$ SFLC Igs with SCr, MDRD, and $\beta 2-\mathrm{M}$ in all 48 kidney transplant recipients who received a graft from living donors ( $n=16$, black), DBD ( $n=16$, light grey), or DCD ( $n=16$, dark grey) during the first month (weeks $1,2,3,4)$ after transplantation. The correlation of $\mathrm{SCr}$ with $\beta 2-\mathrm{M}$ was used as reference. The $r$ values and $95 \%$ confidence intervals (ci) were calculated using the Pearson $r$ test; all correlation graphs were significant $P<0.01$. 


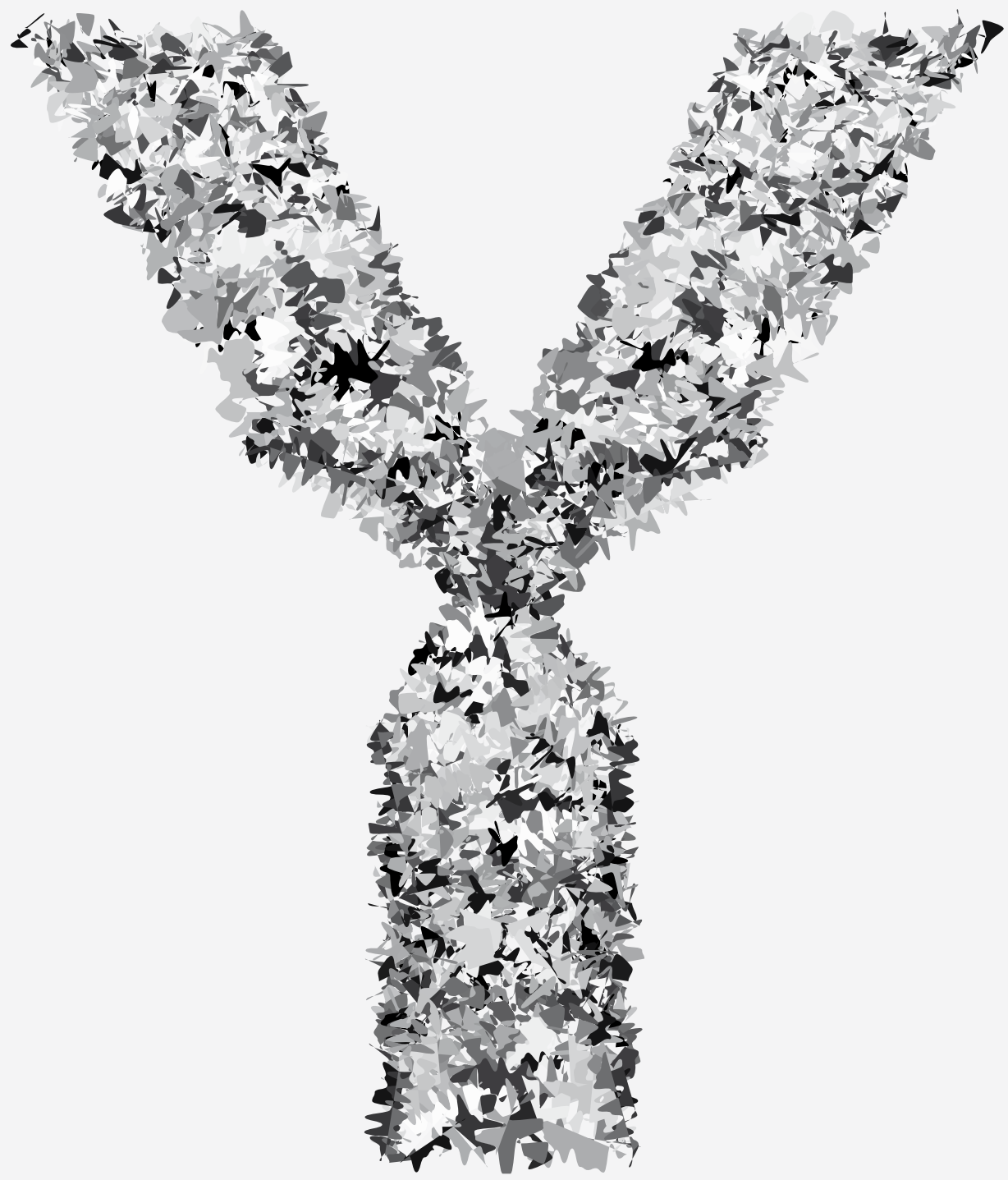




\section{CHAPTER

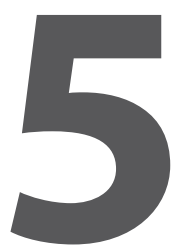

\section{Fractionated radiotherapy with $3 \times 8$ Gy induces systemic anti-tumour responses and abscopal tumour inhibition without modulating the humoral anti-tumour response}

Thomas H.P.M. Habets ${ }^{1,2}$, Tammy Oth ${ }^{1}$, Ans W. Houben ${ }^{1,3}$, Mirelle J.A.J. Huijskens ' ${ }^{1}$, Birgit L.M.G. Senden-Gijsbers ' ${ }^{1}$, Melanie C.A. Schnijderberg ${ }^{1}$, Boudewijn Brans ${ }^{3}$, Ludwig J. Dubois ${ }^{4}$, Philippe Lambin ${ }^{4}$, Marijke De Saint-Hubert ${ }^{3}$, Wilfred T.V. Germeraad ${ }^{1,5}$, Marcel G.J. Tilanus ${ }^{2}$, Felix M. Mottaghy ${ }^{3}$, Gerard M.J. Bos ${ }^{1,5}$, Joris Vanderlocht ${ }^{2}$

1 Division of Hematology, Department of Internal Medicine, MUMC+, Maastricht

2 Tissue Typing Laboratory, Department of Transplantation Immunology, MUMC+, Maastricht

3 Division of Nuclear Medicine, Department of Internal Medicine, MUMC+, Maastricht

4 MaastRO Laboratory, Department of Radiation Oncology, MUMC+, Maastricht

5 CiMaas BV, Maastricht

PLoS ONE. 2016 July 18; 11(7): e0159515

doi: 10.1371/journal.pone.0159515 


\section{Chapter 5}

\section{ABSTRACT}

Accumulating evidence indicates that fractionated radiotherapy (RT) can result in distant non-irradiated (abscopal) tumour regression. Although preclinical studies indicate the importance of $\mathrm{T}$ cells in this infrequent phenomenon, these studies do not preclude that other immune mechanisms exhibit an additional role in the abscopal effect. We therefore addressed the question whether in addition to T cell-mediated responses also humoral antitumour responses are modulated after fractionated RT and whether systemic dendritic cell (DC) stimulation can enhance tumour-specific antibody production. We selected the 67NR mammary carcinoma model since this tumour showed spontaneous antibody production in all tumour-bearing mice. Fractionated RT to the primary tumour was associated with a survival benefit and a delayed growth of a non-irradiated (contralateral) secondary tumour. Notably, fractionated RT did not affect anti-tumour antibody titers and the composition of the immunoglobulin (Ig) isotypes. Likewise, we demonstrated that treatment of tumour-bearing Balb/C mice with DC stimulating growth factor Flt3-L did neither modulate the magnitude nor the composition of the humoral immune response. Finally, we evaluated the immune infiltrate and Ig isotype content of the tumour tissue using flow cytometry and we found no differences between treatment groups that were indicative for local antibody production. In conclusion, we demonstrate that the 67NR mammary carcinoma in Balb/C mice is associated with a pre-existing antibody response. And, we show that in tumour-bearing Balb/C mice with abscopal tumour regression such pre-existing antibody responses are not altered upon fractionated RT and/or DC stimulation with Flt3-L. Our research indicates that evaluating the humoral immune response in the setting of abscopal tumour regression is not invariably associated with therapeutic effects. 


\section{INTRODUCTION}

The main goal of optimized radiotherapy (RT) is to maximize the therapeutic ratio in which tumours receive a high dose of irradiation while sparing the normal healthy tissue. However certain radiation-induced bystander effects of non-irradiated cells exhibit biological effects which can be beneficial for treatment outcome ${ }^{1-3}$. Already in 1953, R.J. Mole described the 'abscopal' effect (ab: position away from; and scopos: a target for shooting at), in which tumour cells regressed or even disappeared outside the field of primary irradiation 4,5 . Although this phenomenon is certainly infrequent it has become clear that it is not confined to a specific type of cancer. So far, several clinical case studies reported the regression of non-irradiated metastasis after conventional RT combined with or without immunotherapy 6,7 . These abscopal effects were observed in melanoma ${ }^{8-12}$, lung carcinoma ${ }^{13,14}$, renal cell carcinoma ${ }^{15}$, hepatocellular carcinoma ${ }^{16}$, and chronic lymphocytic leukemia ${ }^{17}$. To date, the complete picture of the biologic mechanisms underlying these radiation-induced bystander effects remains elusive, but the most likely explanation is that non-irradiated tumour regression is a consequence of systemic immune activation induced by immunogenic cell death (ICD) of irradiated tumour tissue ${ }^{10,18}$.

Over the last decades significant progress was made in our knowledge on how the immune system can be activated by injured tissue and various molecular pathways triggered by damage-associated molecular patterns (DAMPs) ${ }^{19}$. Therefore, authors postulated that abscopal tumours regress as a result of ICD by irradiated tumours that in turn activate both the local and systemic immune system ${ }^{20}$. As a consequence of this irradiation, dying tumour cells can release DAMPs that activate dendritic cells (DC) ${ }^{19,21}$ allowing them to travel to adjacent lymph nodes, present their tumour-associated antigenic material in the context of major histocompatibility complex (MHC) class I and class II molecules and induce both antigen-specific $\mathrm{T}$ - and $\mathrm{B}$ cell responses ${ }^{18,22}$. Due to systemic release of these antigen-specific cells and their secreted products both the primary irradiated and non-irradiated tumour cells are eradicated (Figure 1). Even though this phenomenon is only occasionally observed in patients that are treated with RT only, it indicates that the immune system harbours potent pathways for the control of metastatic tumours and the identification of these pathways may reveal targets for therapeutic intervention.

In an effort to gain fundamental insight into the immunological mechanism of the abscopal effect, Demaria et al. described an animal model (67NR mammary carcinoma) in 


\section{Chapter 5}

which RT also influenced the tumour outside the field of irradiation ${ }^{23}$. In this model they further showed that this inhibition of the secondary tumour is not observed if an unrelated tumour (the murine B cell lymphoma A20) was inoculated as a secondary tumour indicating that the anti-tumour effect was antigen-specific. Importantly, they demonstrated that these effects were not observed in immunodeficient (nude) mice, indicating that $T$ cells were necessary for radiation-induced bystander effects ${ }^{23}$. The authors confirmed the importance of $T$ cells by combining fractionated RT and CTLA-4 blockade that resulted in CD8 T cellmediated tumour regression of irradiated and distant non-irradiated tumours ${ }^{24}$.

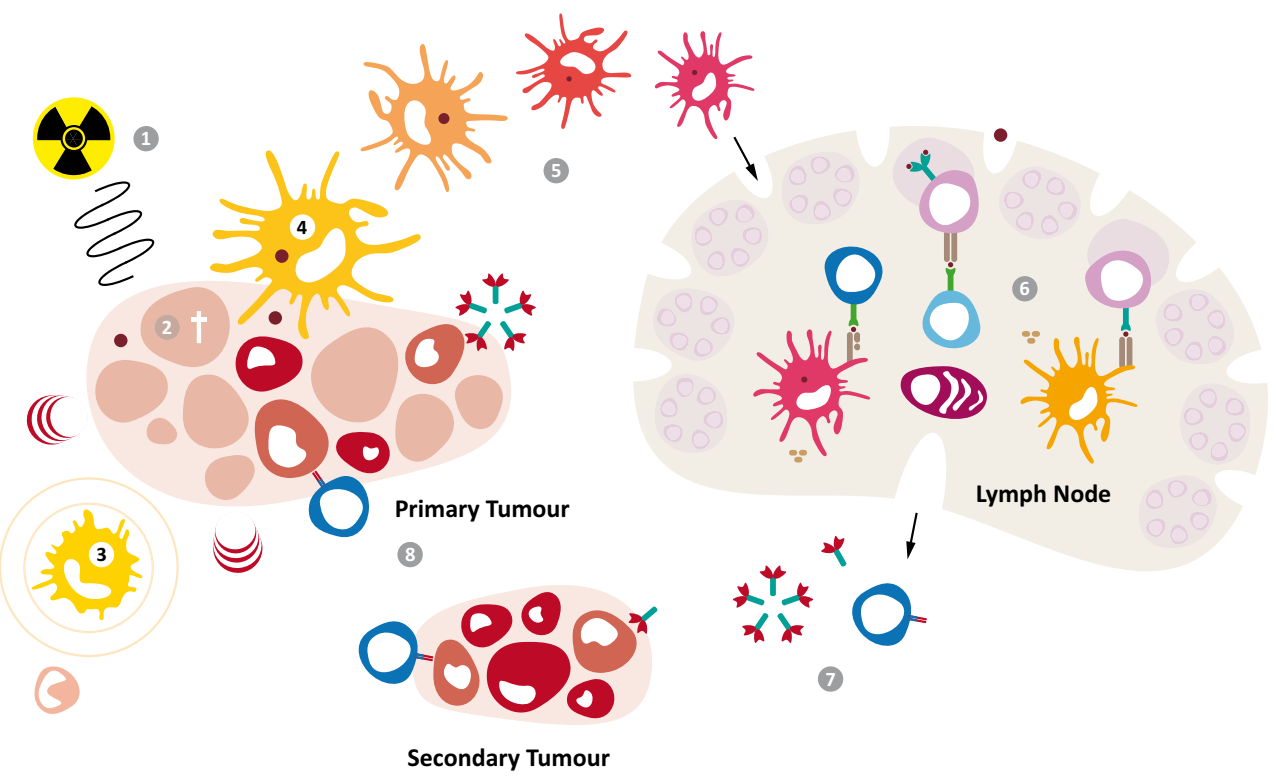

Figure 1: Schematic representation of the proposed systemic immune activation in the abscopal effect. (1) Fractionated radiotherapy with $3 * 8$ Gy to the primary tumour induces immunogenic cell death. (2) The dying tumour cells release immunostimulatory signals such as damage-associated molecular patterns (DAMPs). (3) Immature DCs respond to these 'danger' signals by the uptake of antigens and DAMPs, which subsequently results in (4) DC maturation. (5) Maturated DCs migrate to adjacent lymph nodes presenting their antigens in the content of $\mathrm{MHC}$ molecules (6) to T cells and B cells. (7) Activated T cells and antibodies produced by B cells and plasma cells are released in the circulation. (8) Important, both the primary- and secondary tumours are targeted by these $T$ cells and antibodies.

In line with observations on the importance of T cells, also evidence was provided that stimulating the endogenous DC compartment augments the efficacy of the RT-induced activity against metastasis ${ }^{23-25}$. Treatment with FMS-like tyrosine kinase 3 ligand (FIt3-L) to stimulate DC and local RT in a mouse model for Lewis carcinoma showed a reduction of 
metastases and prolonged disease-free survival ${ }^{25}$. This was also observed by combining RT and Flt3-L administration that resulted in tumour regression of both irradiated and distant non-irradiated tumours ${ }^{23}$. Furthermore, another essential DC growth factor granulocytemacrophage colony stimulating factor (GM-CSF) stimulated a robust and long-lived antitumour immune response in a murine melanoma model ${ }^{26}$. Importantly, Golden et al. recently showed that the concept of DC stimulation extends beyond animal models and they provided proof-of-principle that stimulating the endogenous DC compartment with GM-CSF combined with RT resulted in objective abscopal responses in more than $20 \%$ of patients with metastatic cancer. The presence of abscopal effects was also associated with a survival benefit in these patients ${ }^{27}$.

Taken together these findings clearly indicate the importance of DC-induced T cell responses in abscopal tumour regression. This concept is further supported by the fact that abscopal effects can be enhanced by immune checkpoint inhibitors such as CTLA-4 blockade in animal models ${ }^{24}$ as well as in clinical studies ${ }^{10}$. However, these studies do not preclude that other immune mechanisms play additional roles in radiation-induced bystander effects. Although the study design of Golden et al. was not aimed for immune monitoring, they showed differences in baseline blood parameters in abscopal responders and nonresponders ${ }^{27}$. Additionally, Postow et al. observed that the abscopal effect was paralleled with the induction of antibody responses against the tumour in a patient with metastatic melanoma ${ }^{10}$. In this patient a pre-existing antibody response to the melanoma antigen NYESO-1 was boosted 30 fold upon treatment correlating with the time of disease resolution. Besides boosting of the pre-existing B cell response, the patient also displayed antibodies to a different epitope of the same antigen. Furthermore, seromic analysis of the patient's serum showed an induction of antibody responses against ten novel cancer antigens. A similar effect was observed in a different study in which a melanoma patient displayed an increased level of MAGE-3 antibodies upon radiation-induced abscopal effects ${ }^{11}$.

Nowadays, it remains to be established whether the induction of antibody responses against the tumour is directly involved in abscopal tumour inhibition, or whether the induction of such antibodies only serves as a biomarker indicating the development of novel immune responses in a subset of patients. Alternatively, it is possible that the presence of such antibody responses is a prerequisite for abscopal effects.

In the current study, we aimed to assess whether the abscopal tumour growth delay that is observed after fractionated RT is paralleled with the modulation of a pre-existing 


\section{Chapter 5}

humoral anti-tumour response in the 67NR mammary carcinoma animal model. In addition, we assessed whether stimulation of plasmacytoid (pDC) and conventional ( $C D C)$ DC with Flt3-L alone or combined with fractionated RT can modulate a pre-existing humoral immune response.

\section{MATERIALS AND METHODS}

\section{Cell culture}

The murine (Balb/C) 67NR mammary carcinoma cell line was kindly provided by S. Demaria (Department of Pathology, New York University School of Medicine, New York, New York). The 67NR cell line was cultured in Dulbecco's Modified Eagle Medium (DMEM 1X with 4.5g/L D-glucose, L-glutamine, and pyruvate; Gibco) supplemented with $10 \%$ fetal calf serum (Greiner Bio One) and 1\% penicillin-streptomycin (Gibco). The metastatic murine 4T1 mammary carcinoma (a differentiated subclone of the non-metastatic 67NR cell line) and C26 colon carcinoma cell lines (both obtained from the ATCC) were cultured in Roswell Park Memorial Institute Medium (RPMI 1640 1X with L-glutamine, and 25mM HEPES; Gibco) supplemented with $10 \%$ fetal calf serum and $1 \%$ penicillin-streptomycin. The cell lines were incubated in a humidified $20 \% \mathrm{O}_{2}$ and $5 \% \mathrm{CO}_{2}$ chamber at $37^{\circ} \mathrm{C}$.

\section{Mouse model}

In order to investigate abscopal tumour regression, we took advantage of the mouse model previously generated and optimized by Demaria et al. ${ }^{23}$. In short, a total of $1 * 10^{5} 67 \mathrm{NR}$ cells were subcutaneously injected in immunocompetent Balb/C mice (8 to 10 weeks of age; Harlan Laboratories). The mice were anesthetized with isoflurane (IsoFlo, Abbott) prior to cell injections. The cells were injected in the right (primary tumour) and left flank (secondary tumour) at day 0 and day 2 respectively. At day 14, tumour-bearing mice were randomised based on primary tumour size and assigned to four groups: untreated, Flt3-L, RT, RT+Flt3-L. The tumour-bearing mice were housed separately, had free access to food and water, and were checked every day for animal well-being according to local institutional guidelines for animal welfare. The tumour size was assessed three times a week by palpation (caliper; three dimensions), and corrected using the following formula: $L^{*} W^{*} H^{*}(\pi / 6)^{28}$. At the predefined 
human endpoint (maximum volume of $2 \mathrm{~cm}^{3}$ for both tumours) or at the end of the experiment (day 162), mice were anesthetized and sacrificed by cervical dislocation. None of the mice died without euthanasia. The blood and both tumours were collected for further analysis. The blood was incubated with heparin (LEO Pharma) and centrifuged to separate the plasma. Half of the tumour was homogenized and used as a single cell suspension for flow cytometric analysis and the other half of the tumour was embedded in TissueTec and further stored at $-80^{\circ} \mathrm{C}$ for immunohistochemistry $(\mathrm{IHC})$. The animal experiments were performed according to Dutch government guidelines, approved by the Animal Ethical Committee of Maastricht University (Maastricht, The Netherlands, permit number DEC2010-171).
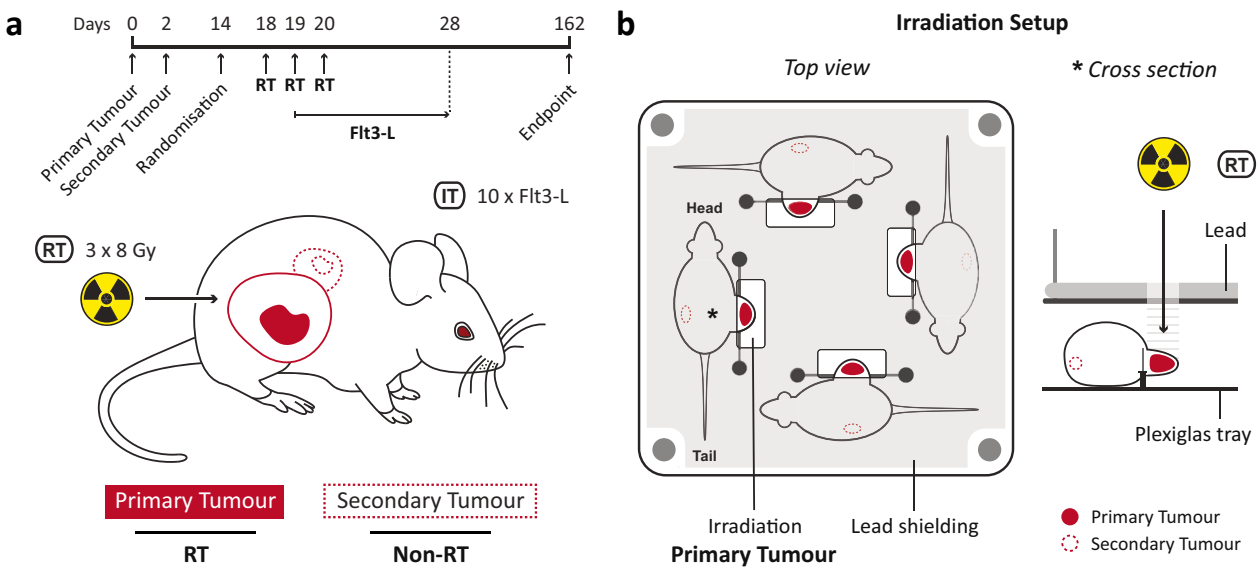

Figure 2: Mouse model to investigate the abscopal effect. a. Schematic representation of the $67 \mathrm{NR}$ mammary carcinoma Balb/C mouse model and the timeline of treatments. $1 * 10^{5} 67 \mathrm{NR}$ tumour cells were inoculated in the right (primary, straight line) and left (secondary, dashed line) flank on day 0 and 2, respectively. At day 14 , animals were randomised based on the primary tumour size and assigned to four groups (untreated, Flt3-L, RT, RT+Flt3-L). Fractionated radiotherapy (RT, $3 \times 8 \mathrm{~Gy}$ ) was only given to the primary tumour at day 18,19 , and 20 . Immunotherapy (IT, DC growth factor Flt3-L) was administered for ten consecutive days, started at day 19. The endpoint was at day 162 or a total tumour volume of $2 \mathrm{~cm}^{3}$. b. Schematic representation of the irradiation setup. Four tumour-bearing mice (per session) were positioned in a customized Plexiglas tray. The animals' body was protected by lead shielding except for the primary tumour that was placed under a linear accelerator. * The position of the cross section view.

\section{Treatments}

Fractionated radiotherapy $(R T)$. Only the primary tumour was irradiated with three times 8 Gy $( \pm 45.5 \mathrm{mGy} / \mathrm{s})$ in three consecutive days (Figure 2a). The tumour-bearing mice in groups RT and RT+Flt3-L were anesthetized via i.p. injection of pentobarbital $(60 \mathrm{mg} / \mathrm{mL}$ in $\mathrm{NaCl} 0.9 \%)$. The mice (four per session) were positioned in a customized Plexiglas tray. The animals' body 
was protected by lead shielding except for the primary tumour that was placed under a linear accelerator (Varian Truebeam; 15 MeV electrons) as is schematically illustrated in Figure $\mathbf{2 b}$. Growth factor. The tumour-bearing mice in groups Flt3-L and RT+Flt3-L received i.p. injections of 10 $\mathrm{g}$ F Flt3-L (human Flt3-L; Miltenyi Biotec) for ten consecutive days as previously described 23. The administration of Flt3-L started at day two of RT (Figure 2a).

\section{Vaccination of mice with heat-killed tumour cells}

In order to obtain heat-killed 67NR cells, a total of $10^{*} 10^{6} 67$ NR cells were cultured, harvested in PBS, and heat-killed for $30 \mathrm{~min}$ at $60^{\circ} \mathrm{C}$. The heat-killed cells were resuspended in incomplete Freund's adjuvant (IFA; Sigma) containing $200 \mu \mathrm{g}$ DNAse, and $0.5 \mathrm{mg} / \mathrm{mL}$ CpG ODN 1826 (VacciGrade, InvivoGen). The mixture was injected in immunocompetent Balb/C mice. Primary immunized mice received a booster injection containing IFA, CpG ODNs and heat-killed 67NR cells after 3 weeks. The immunized mice were anesthetized and sacrificed by cervical dislocation 1 to 3 weeks after the boost injection. The blood was collected by cardiac puncture and centrifuged to separate the plasma.

\section{Cellular flow cytometry and ELISA-based systems for the detection of tumour-binding antibodies (TBAs)}

We optimized two independent methods for demonstrating the presence of TBAs in the plasma of 67NR tumour-bearing mice. For both methods we intentionally used different antibody clones for detection. In this manner, we used fluorescent detection with flow cytometry (FC), which has the advantage of a higher dynamic range in samples with a higher concentration. The second method used enzymatic amplification for a more sensitive detection in the lower concentration range.

Flow cytometry. $1 * 10^{5}$ 67NR cells were transferred to a 96 wells v-bottom plate. The cells were incubated with 10\% FCS for 30min (Greiner Bio One) to prevent non-specific binding. Then, diluted plasma (1:20) samples were added for 30min at room temperature (RT). TBAs in the plasma were stained with APC labelled anti-mouse pan-Ig (polyclonal; BD) for 20min (RT). In case of immunoglobulin (Ig) isotype determination in the plasma, APC labelled antimouse IgG ${ }_{1}$ (clone RMG1-1, BioLegend), PE labelled anti-mouse IgG ${ }_{2 a}$ (clone RMG2a-62, BioLegend), FITC labelled anti-mouse $\operatorname{lgG}_{2 b}$ (clone RMG2b-1, BioLegend), and PE-Cy7 anti- 
mouse IgM (clone RMM-1, BioLegend) were used. In between all steps, cells were washed with buffer (PBS $1 \mathrm{X}, 1 \% \mathrm{FCS}, 0.02 \% \mathrm{NaN}_{3}$ ) and centrifuged for $3 \mathrm{~min}, 800 \mathrm{~g}$ at $4^{\circ} \mathrm{C}$. The stained samples were measured and analysed using the FACSCanto II (BD) and FACSDiva software v6.0 (BD) respectively.

ELISA. $1 * 10^{5} 67$ NR cells were added to a flat-bottom 96 wells cell culture plate and cultured for $18 \mathrm{hrs}$ at $37^{\circ} \mathrm{C}$. The adherent cells were washed with buffer (PBS 1X, 0.05\% Tween 20) and fixated with $3.8 \%$ formaldehyde (Sigma) for $45 \mathrm{~min}$ at RT. To prevent non-specific binding, the plate was subsequently incubated with 1\% BSA (Sigma) for 1 h at RT. Then, diluted plasma (1:20) samples of the intervention mice were added for $1 \mathrm{~h}$ at RT. TBAs in the plasma were detected with HRP labelled anti-mouse pan-Ig (polyclonal; Dako) and TMB substrate (Thermo Scientific). The enzymatic reaction was stopped by $0.9 \mathrm{M} \mathrm{H}_{2} \mathrm{SO}_{4}$. In between all steps, 67NR cells were washed with buffer. The absorbance was measured at 450nm (BioTek Synergy HTX).

\section{Cytometric bead assay for the detection of Ig isotypes in tumour lysates}

The immunoglobulin isotypes that were present in the tumour tissue were determined using the cytometric bead array (CBA) kit (BD). TissueTec embedded tumour tissue was homogenized using a mini-bead beater (BioSpec) for 2x20s and 1x30s in CellLytic MT Mammalian Tissue Extraction buffer (Sigma). The total protein concentration in $\mu \mathrm{g} / \mathrm{mL}$ was measured using the BCA (bicinchoninic acid assay) method (Thermo Scientific). The tumour lysates were incubated with microbeads coated with capture antibodies for the different Ig isotypes. The bound Ig isotypes were stained with fluorescent-labelled detection antibodies. Subsequently, the samples were measured using flow cytometry according to the manufacturers protocol. FCAP Array analysis software v3.0 (BD) was used for data analysis. The concentration of all Ig isotypes was normalized for total protein quantity of the tumour lysates.

\section{Detection of B cells and T cells by FC and IHC}

Flow cytometry. $1.5 * 10^{6}$ tumour cells were added to a 96 wells v-bottom plate. The cells were incubated with mouse serum (Dako) to prevent non-specific binding (20min). Upon incubation, APC labelled anti-mouse CD45 (clone 30-F11), PE-Cy7 labelled anti-mouse CD11c (clone HL3), V500 labelled anti-mouse CD4 (clone RM4-5), FITC labelled anti-mouse 
Chapter 5

CD19 (clone 1D3), V450 labelled anti-mouse CD8 $\alpha$ (clone 53-6.7; eBioscience) were added for $15 \mathrm{~min}$ at RT. The life-death marker 7-AAD (BD) was added before measurement. All fluorescent labelled antibodies were purchased from BD, unless otherwise specified. In between all steps, the cells were washed with buffer (PBS 1X,1\% FCS, 0.02\% $\mathrm{NaN}_{3}$ ) and centrifuged for $3 \mathrm{~min}, 800 \mathrm{~g}$ at $4^{\circ} \mathrm{C}$. The stained cells were measured and analysed (FACSCanto II and FACSDiva software; BD).

Immunohistochemistry. Half of the tumours embedded in TissueTec were sectioned (10 $\mu \mathrm{m})$ using a cryostat (Leica) and fixated with acetone. The unconjugated rat anti-mouse B220CD45r, CD3, CD4, and CD8 antibodies (hybridoma cell lines) were added for $1 \mathrm{~h}$ at RT. Then, peroxidase blocker and biotinylated anti-rat Ig (polyclonal; BD) were added for 30min at RT. These biotinylated antibodies were detected with HRP labelled streptavidin (30min) and DAB substrate (BD). The tumour sections were dehydrated in 50\%, 70\%, 96\%, and $100 \%$ ethanol (5min) and analysed using the Carl Zeiss Axioskop 40 microscope.

\section{Figures and statistics}

The graphs, figures, and statistical analyses were made with GraphPad Prism Pro version 6 (GraphPad Software) and combined in Adobe Illustrator CS6/CC (Adobe Systems). The Kaplan-Meier survival curves were compared using the log-rank (Mantel-Cox) test. The MannWhitney t-test was used to determine statistical significance between the treatment groups. For all data, a P value of $<0.05(*)$ was considered to be statistically significant. P-values $<0.01$ were graphically presented as $(* *)$.

\section{RESULTS}

\section{Fractionated radiotherapy (but not systemic DC stimulation with Flt3-L) of the primary tumour associates with delayed tumour growth, which turns into a survival benefit.}

In an effort to gain fundamental insight into the immunological mechanisms of the abscopal effect, we took advantage of the animal model that was developed and optimized by Demaria et al., in which RT of the primary tumour resulted in growth delay of the distant tumour outside the field of irradiation ${ }^{23}$. Furthermore, we wanted to address whether besides fractionated RT, stimulation of DC with growth factor Flt3-L would enhance the anti-tumour immune response in that animal model. 
In this model, Balb/C mice were inoculated with a primary and secondary tumour by injecting $10^{5}$ 67NR tumour cells in both flanks with a temporal separation of 2 days between the primary (right flank) and the secondary (left flank) (Figure 2a). At day 14, we observed that in many animals the tumour growth differs in time of onset and in growth kinetics, therefore we randomised the animals based on their primary tumour size and assigned them to four groups (untreated, Flt3-L, RT, and RT+Flt3-L). Only the primary tumour received fractionated RT ( 8 Gy at day 18, 19, and 20), while the secondary tumour was non-irradiated (Figure $2 \mathbf{b}$ ). Immunotherapy (IT) in terms of Flt3-L was administered for ten consecutive days (started at day 19).

To evaluate tumour growth delay in mice that were non-irradiated or irradiated, we took the tumour growth variation into account and we decided to utilize the number of days to reach four times (quadruplication) the tumour volume that they had after randomization (day 14). The groups RT and RT+Flt3-L (RT) demonstrated a delay in primary (30 \pm 10 days) and secondary ( $23 \pm 7$ days) tumour growth as compared to the groups untreated and Flt3-L (non-RT; primary $15 \pm 7$ days; secondary $17 \pm 13$ days) (Figure 3a, b; $\mathbf{P}<0.05$ ). Furthermore, in the RT groups, there were six mice without a detectable primary tumour, as compared to zero mice in the non-RT groups (Figure 3a; TF). Additionally, we also observed six animals in the RT groups without a secondary tumour as compared to only two mice in the nonRT groups (Figure 3b; TF). Although the effect on the secondary tumour was not a uniform trend observed in all animals, the presence of more animals without a detectable secondary tumour in the RT groups was apparent (Figure 3b; TF). Importantly, the tumours that showed total regression (TF) at the end of the experiment was not a feature confined to animals with a small tumour at the point of randomization (primary $8.3 \pm 4.5 \mathrm{~mm}^{3}$; secondary $3.9 \pm 4.5$ $\mathrm{mm}^{3}$ ) (Figure S1).

To determine whether fractionated RT and DC stimulation with Flt3-L is associated with a survival benefit, we followed the untreated and treated animals for 162 days. As shown in Figure 3c, there was a significant survival benefit in mice treated with RT (fraction survival 0.25) as compared to mice that did not receive RT (fraction survival 0.08; P<0.05). However, we could not observe a survival benefit with Flt3-L alone (data not shown), nor in combination with RT (Figure 3d).

\section{Detection of TBAs in the plasma of 67NR tumour-bearing Balb/C mice.}

In order to investigate whether inoculation of the 67NR tumour itself results in the induction 


\section{Chapter 5}

of antibodies we measured the immunoglobulin (Ig) levels in the plasma of tumour-bearing Balb/C mice using two detection methods. The optimization of both detection methods is shown in Figure $\mathbf{S 2}$ and $\mathbf{S 3}$ and these are further described in the supplementary materials

a

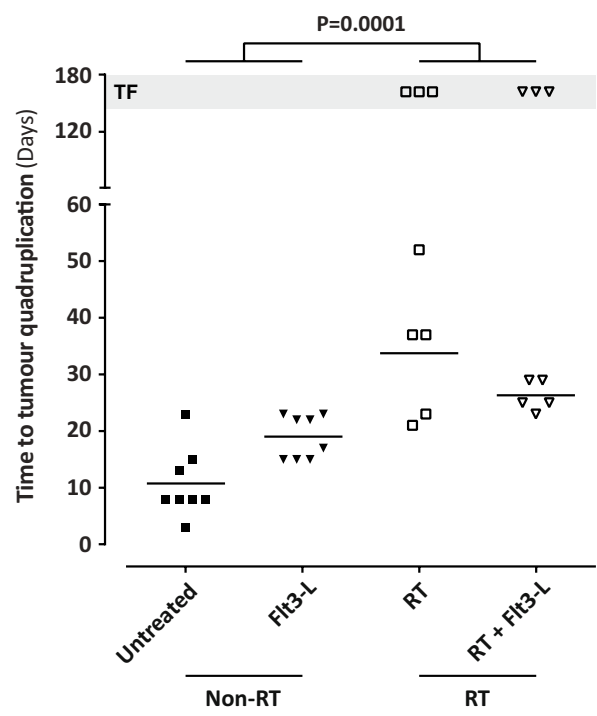

C

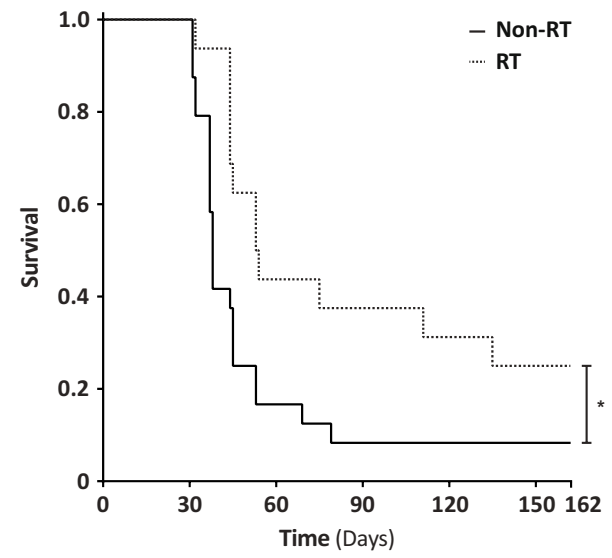

b

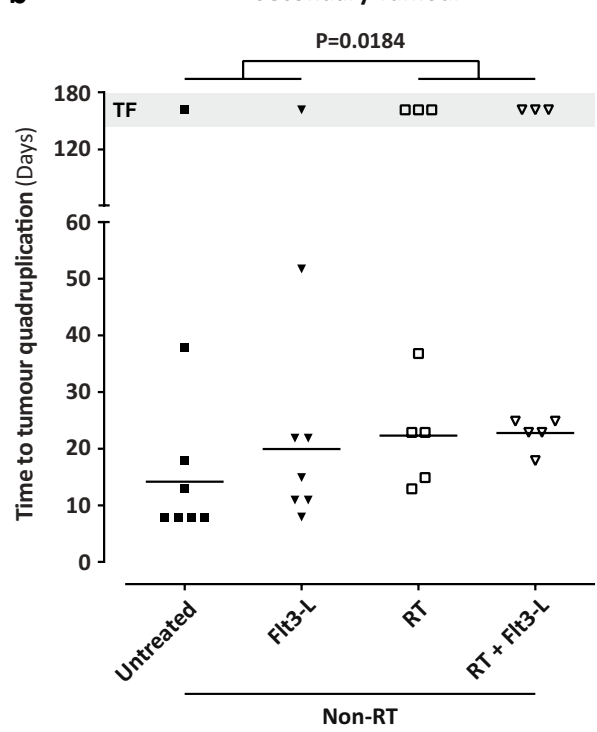

d

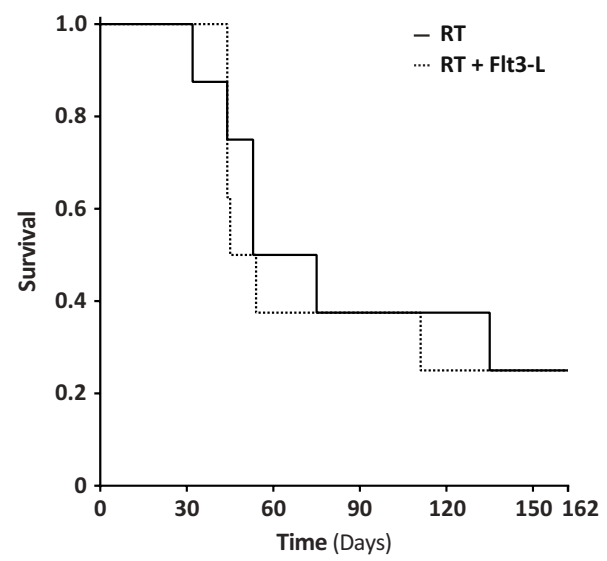

Figure 3: 67NR tumour growth and survival following treatment with RT and Flt3-L in tumour-bearing Balb/C mice. $a, b$. Time (days) to reach quadruplication of the primary and secondary tumour as measure for 67NR tumour growth. The measurement started 14 days after inoculation of the 67NR tumours. The primary and secondary tumour of the RT groups showed a growth delay as compared to the non-RT groups $\left(P<0.05^{*}\right)$ (TF: tumour free mice are excluded from Mann-Whitney t-test). c, d. The Kaplan-Meier survival curves of the (un)-treated animals. The non-irradiated (non-RT) animals were untreated or received injections of Flt3-L (10 days). The irradiated (RT) animals received $\mathrm{RT}(3 \times 8 \mathrm{~Gy})$ or $\mathrm{RT}+\mathrm{Flt3-L}$ ( $3 \times 8 \mathrm{~Gy}+10$ days). Log-rank (Mantel-Cox) test $\mathrm{P}<0.05$ * 
and methods section (File S1). Using these two independent methods we detected elevated levels of TBAs (MFI $4818 \pm 1306$; 450nm $1.8 \pm 0.7$ ) in tumour-bearing mice as compared to healthy immunocompetent (-control; MFI $1043 \pm 385$; 450nm $0.6 \pm 0.04)$ mice $(P<0.05$ and $\mathrm{P}<0.01$ ). As compared to the vaccinated mice (+control; MFI $7133 \pm 1795 ; 450 \mathrm{~nm} 2.6 \pm 0.05$ ), more variation was observed within the tumour-bearing mice (ELISA) but all animals showed increased TBAs as compared to healthy (-control) mice (Figure $\mathbf{4 a}, \mathbf{b}$ ).
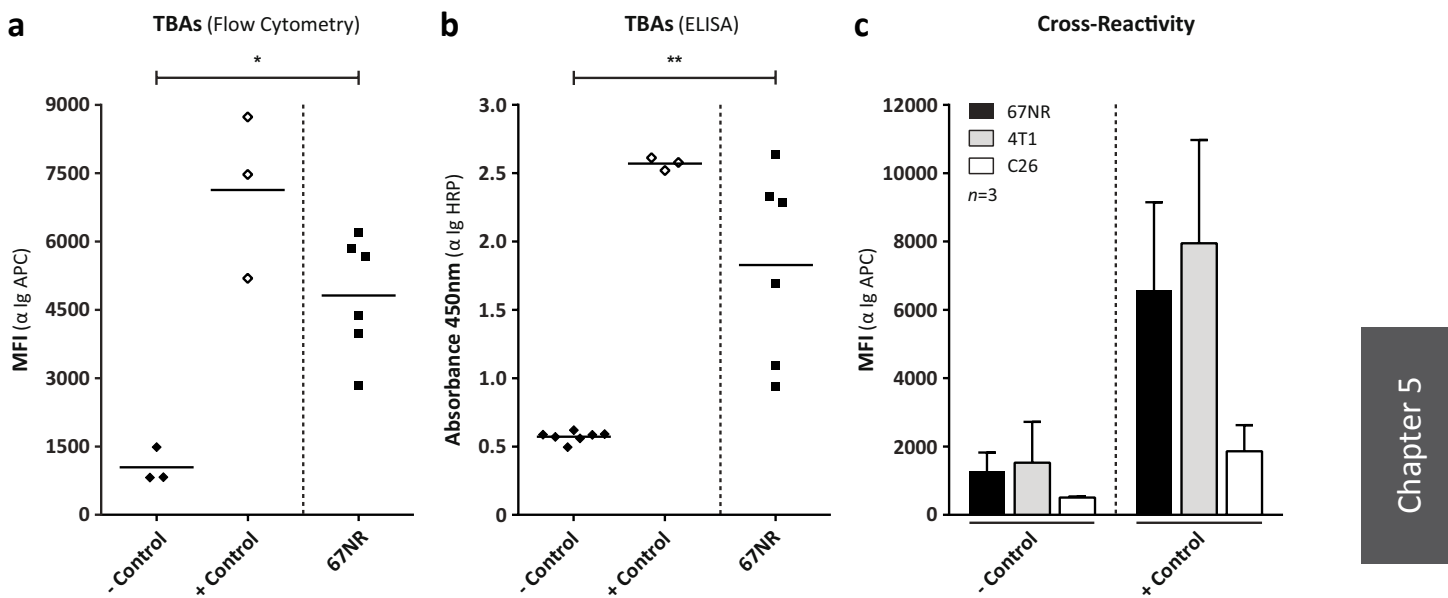

Figure 4: Detection and crossreactivity of TBAs in the plasma of immunocompetent, vaccinated, and 67NR tumour-bearing Balb/C mice. $a, b$. Detection of TBAs in the plasma of immunocompetent (-control), vaccinated (+control), and 67NR tumour-bearing mice using cellular flow cytometry ( $\alpha$ Ig APC) and ELISA ( $\alpha$ Ig HRP) based systems. Mann-Whitney t-test with $\mathrm{P}<0.05^{*}$ and $\mathrm{P}<0.01 * *$. c. To determine whether the antibodies are 67NR specific, $1 * 10^{5}$ murine $67 \mathrm{NR}, 4 \mathrm{~T} 1$ (mammary), and C26 (colon) carcinoma cells were incubated with plasma from -control and +control Balb/C mice to determine the crossreactivity of plasma containing antibodies. MFI, mean fluorescent intensity.

In order to determine whether the detected antibodies were specific for 67NR, we incubated plasma from healthy immunocompetent (-control) and vaccinated (+control) mice with murine carcinoma cell lines 67NR, 4T1 (mammary), and C26 (colon) and visualized antibody binding by means of flow cytometric detection. The detected antibodies in the plasma of vaccinated Balb/C mice showed crossreactivity with the $4 \mathrm{~T} 1$ cell line (-control MFI $1530 \pm 1191$; +control MFI $7947 \pm 3023$ ), as the level of antibody binding was similar to the 67NR cell line (-control MFI $1278 \pm 546$; +control MFI $6575 \pm 2575$ ) (Figure 4c). In contrast, there was minimal antibody binding to the murine colon carcinoma C26 cell line indicating less crossreactivity (-control MFI $509 \pm 33$; +control MFI $1862 \pm 764$ ). The metastatic mammary carcinoma $4 \mathrm{~T} 1$ cell line is a differentiated subclone of the non-metastatic $67 \mathrm{NR}$ cell 
Chapter 5

line, which might clarify the similar binding of antibodies from ' $67 N R^{\prime}$ ' vaccinated mice to 4 T1 tumour cells.

Taken together these data indicate that 67NR inoculation is sufficient to drive the induction of a humoral immune response against the tumour in all mice. These antibodies bind specifically to the 67NR tumour and its related cell line 4T1 but not to the C26 cell line.

\section{Fractionated RT and DC stimulation did neither influence the levels nor the Ig isotype composition of TBAs in the plasma of tumour-bearing Balb/C mice.}

To assess whether the abscopal tumour growth inhibition that is observed after fractionated RT is paralleled with the modulation of the humoral anti-tumour response, we evaluated the quantity of TBAs in the plasma of sacrificed tumour-bearing mice that were either untreated or treated with Flt3-L, RT, or RT+Flt3-L. As shown in Figure 5a, we could not observe a difference in the total amount of TBAs between the experimental animal groups (FIt3-L MFI

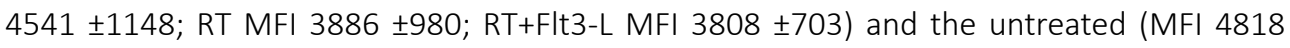
\pm 1306 ) animal group indicating that the therapeutic effect of RT is not paralleled with an increase in the total amount of TBAs in the plasma. These findings were confirmed by ELISA (450nm: untreated 1.8 \pm 0.7 ; Flt3-L $1.6 \pm 0.3$; RT 1.6 \pm 0.3 ; RT+Flt3-L $1.5 \pm 0.3$ ) (Figure S4c).

Although we did not observe a quantitative difference between the experimental groups in the induction of antibodies, it remains possible that the Ig isotype composition of these TBAs is altered upon treatment. Because both detection assays utilize pan-Ig reactive secondary antibodies it is possible that the antibody response in the untreated group is an IgM dominated response whereas more polarized IgG responses are observed upon intervention. Using an optimized flow cytometric assay shown in Figure $\mathbf{S 5}$ and described in the supplementary materials and methods (File $\mathbf{S 1}$ ), the $T$ cell-dependent isotypes $\lg G_{1}, \operatorname{lgG}_{2 a^{\prime}}$ $\lg _{2 b^{\prime}}$ and natural isotype $\lg \mathrm{M}$ were measured in plasma of vaccinated (+control), untreated and treated (Flt3-L, RT, RT+Flt3-L) tumour-bearing mice. Vaccinated (+control) mice showed a different percentual composition of isotypes IgG ( $\operatorname{lgG}_{1} 25 \%$; $\operatorname{lgg}_{2 a} 40 \%$; $\left.\operatorname{lgG}_{2 b} 12 \%\right)$ and $\lg M$ (23\%) as compared to tumour-bearing mice in non-RT and RT groups ( $\operatorname{lgG}_{1} 19 \pm 1.2 \%$; $\operatorname{lgG}_{2 a} 34$ $\pm 0.8 \%$; $\operatorname{lgG}_{2 b} 17 \pm 0.5 \%$; $\lg M 30 \pm 1.5 \%$ ) (Figure $5 \mathbf{b}$ ). In particular, $\lg _{1}$ and $\lg _{2 a}$ were induced upon vaccination whereas $\lg _{2 b}$ and $\lg \mathrm{M}$ were decreased in relative percentage as compared to the other isotypes. However, they were not reduced in absolute MFI (Figure S6). Notably we did neither observe differences in percentual composition of the Ig isotypes, nor in the quantity (IgG MFI $3976 \pm 661 ; \operatorname{lgG}_{2 a}$ MFI $7039 \pm 1011 ; \operatorname{lgG}_{2 b}$ MFI $3533 \pm 479$; IgM MFI 6180 
\pm 1940 ) (Figure S6) between the tumour-bearing mice in the different treatment groups.

a

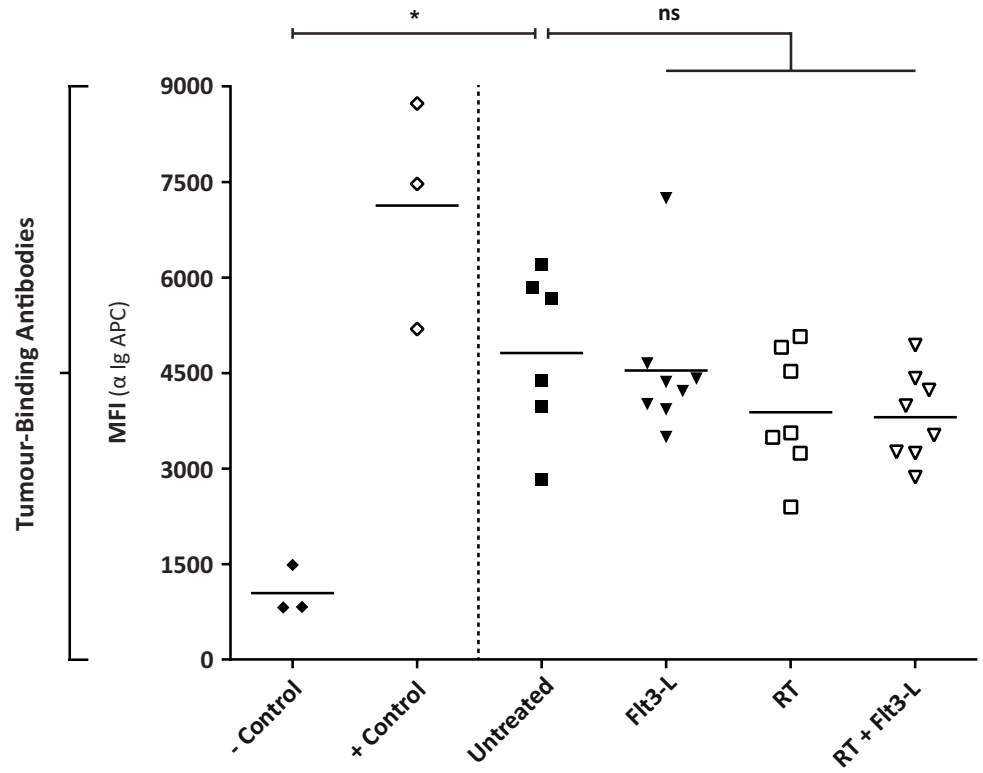

b
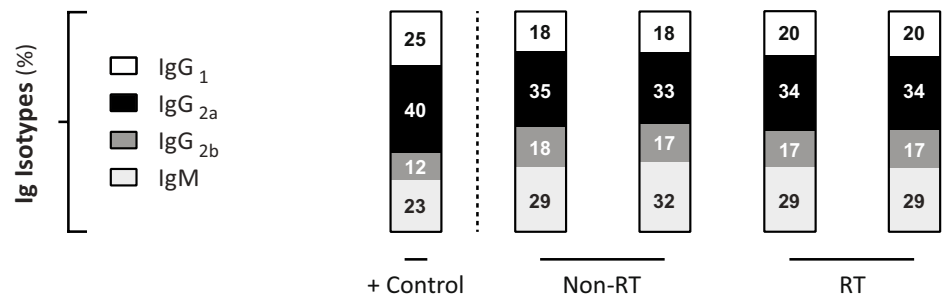

Figure 5: The levels and Ig isotype composition of TBAs in the plasma of (un)-treated mice. a. To assess the quantity of TBAs in the plasma, $1 * 10^{5} 67 \mathrm{NR}$ tumour cells were incubated with plasma from immunocompetent (-control), vaccinated (+control), untreated, and treated (Flt3-L, RT, RT+Flt3-L) Balb/C mice. An APC conjugated antibody against total pan-Ig detected the TBAs. Mann-Whitney t-test with $\mathrm{P}<0.05^{*}$. b. To determine the Ig isotype composition of the TBAs in the plasma, $1 * 10^{5} 67$ NR tumour cells were incubated with plasma from vaccinated (+control), non-irradiated (non-RT: untreated, Flt3-L), and irradiated (RT: RT, RT+Flt3-L) Balb/C mice. The different isotypes were detected using fluorescent labelled $\lg G_{1^{\prime}}, \lg G_{2 a^{\prime}} \lg G_{2 b^{\prime}}$ and $\operatorname{lgM}$ antibodies. The MFI values of the four Ig isotypes (Figure S6) were combined and displayed as percentage of the total.

\section{Immunoglobulins, B cells, and T cells were present in the primary and secondary tumour.}

In order to determine whether antibodies and immune cells are present at the site of the tumour, we measured the presence and Ig isotype composition ( $T$ cell-dependent isotypes $\lg G_{1}, \lg G_{2 a^{\prime}}, \lg _{2 b^{\prime}}$ and natural isotype $\left.\lg M\right)$ of TBAs in homogenized tumour tissues using a cytometric bead assay. We detected $\lg$ isotypes $\lg G_{1}, \lg G_{2 a^{\prime}} \lg G_{2 b^{\prime}}$ and $\lg M$ in the primary and 


\section{Chapter 5}

a

Ig Isotypes in Tumours (CBA)
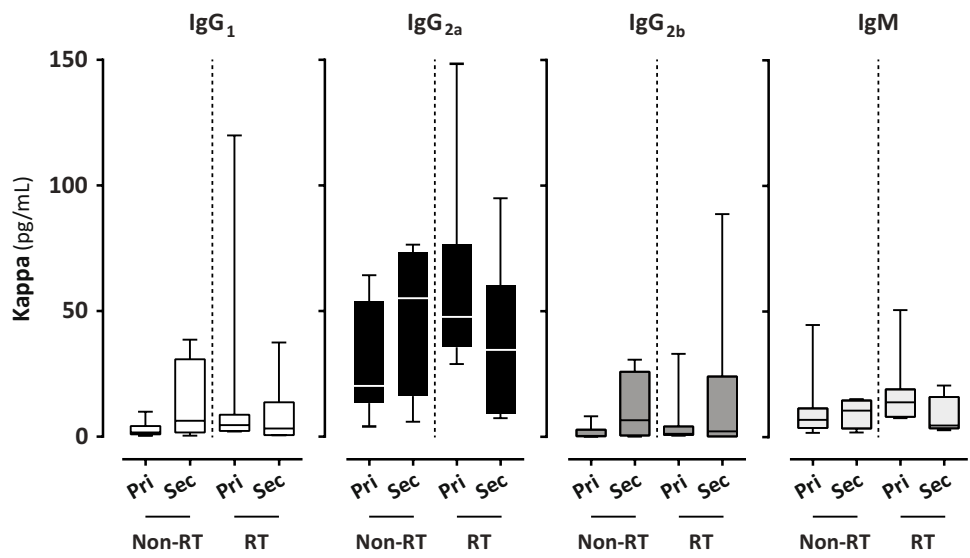

b

Tumour Infiltrating B Cells (IHC)

Primary

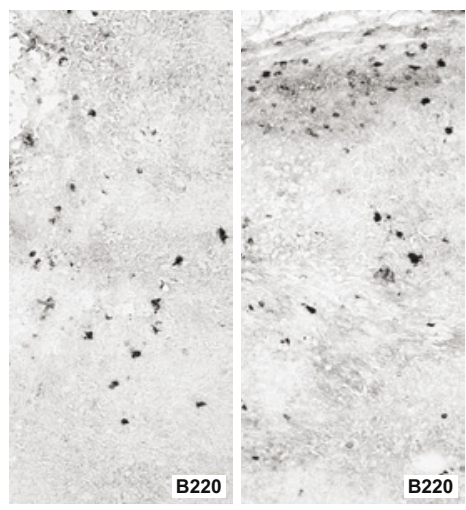

C

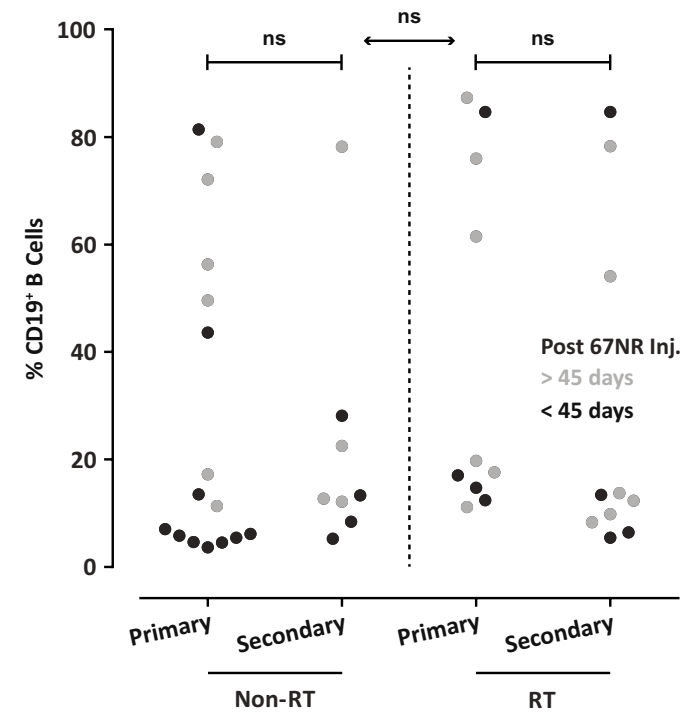

Figure 6: Infiltration of immunoglobulins and B cells in the primary and secondary tumour. a. To determine the quantity of immunoglobulin (Ig) isotypes $\left(\operatorname{lgG}_{1}, \operatorname{lgG}_{2 a^{\prime}} \lg G_{2 b^{\prime}}\right.$ and $\left.\operatorname{lgM}\right)$ in both tumours, we used a cytometric bead assay (CBA). The isotype quantity was determined using a standard curve per isotype. These values were corrected for total protein content of the tumour lysates and displayed as $\mu \mathrm{g} / \mathrm{mL}$ for isotypes kappa $\operatorname{lgG}_{1}, \operatorname{lgG}_{2 a^{\prime}} \lg G_{2 b^{\prime}}$ and IgM. b. Immunohistochemical (IHC) staining of tumour infiltrating B cells (B220) in the primary and secondary tumour (data representative for all animals). c. Detection of B cells in the primary and secondary tumours using flow cytometry (FC). Gating strategy: Living haematopoietic cells (CD45+ vs. 7-AAD-) were gated. In this gate, the lymphocyte population was selected based on the forward- (FSC) vs. sideward (SSC) scatter. To ensure that only lymphocytes were gated, CD11c+ cells were excluded. The CD19+ B cells were selected in the CD11c- gate. The percentage $\mathrm{CD} 19+\mathrm{B}$ cells in the primary and secondary tumour of (non)- vs. irradiated animals (black or grey, respectively $<45$ or $>45$ days after 67 NR tumour inoculation). Mann-Whitney t-test. 
secondary tumour of mice in non-RT and RT groups (Figure 6a). Both irradiated and nonirradiated tumour-bearing mice showed an increased quantity of kappa $\operatorname{lgG}_{2 a}(65 \pm 46 \mathrm{pg} /$ $\mathrm{mL})$ as compared to kappa $\operatorname{lgG}_{1}(14 \pm 26 \mathrm{pg} / \mathrm{mL}), \operatorname{lgG}_{2 b}(12 \pm 22 \mathrm{pg} / \mathrm{mL})$ and $\operatorname{lgM}(17 \pm 14 \mathrm{pg} /$ $\mathrm{mL}$ ). The Ig isotypes kappa $\lg _{3}, \lg A$, and $\lg E$ were absent in both tumours (data not shown).

In addition, we evaluated the presence of B cells (and T cells) in the tumours. First, we evaluated the localisation of these cells using IHC. Therefore, we performed IHC and visualized $\mathrm{B}$ cells and $\mathrm{CD} 3+, \mathrm{CD} 4+$, and $\mathrm{CD} 8+\mathrm{T}$ cells in the primary and secondary tumours (Figure 6b; Figure S7a). In none of the evaluated IHC tumour specimens we observed the presence of B or T cells in a tertiary lymphoid structure. We only observed solitary B cells and T cells that infiltrated throughout the tumour or small clusters around the tumour.

Second, in order to quantitate the infiltration of CD19+ B cells and CD4+, CD8+ T cells we performed flow cytometric stainings on single tumour cell suspensions. Using this approach, we confirmed and quantitated the presence of CD19+ B cells as well as CD4+, CD8+ T cells in the tumour at the end of the experiment (Figure 6c; Figure S7b-d). Notably, in a subset of tumour specimens we observed that B cells predominated the immune infiltrate accounting up to $90 \%$ of the infiltrate. This was not correlated with higher TBA titers in the plasma. Furthermore, our flow cytometric analysis of the infiltrate at the human endpoint of the experiment showed that $T$ cells are more abundant in the infiltrate in non-irradiated tumours (CD4+ $14 \pm 11 \%$; CD8+ $19 \pm 14 \%$ ) as compared to irradiated tumours (CD4+ $5 \pm 2 \%$; CD8+ $8 \pm 11 \%$ ) (Figure S7c, d).

Taken together these data indicate that we did not find evidence indicating tertiary lymphoid structures or local production of TBAs at site of the tumours. In cases where primary tumours could be collected in the irradiated animals at the end of the experiment there were less $T$ cells infiltrating the tumour as compared to the primary tumours of non-irradiated animals. It should, however, be emphasized that this evaluation takes place after reaching the endpoint of the experiment that is often characterized by exponential growth of the tumour. In cases where one of the tumours was resolved these specimens could not be collected.

\section{DISCUSSION}

Undebatable T cells play a crucial role in abscopal tumour regression as illustrated by several lines of evidence in literature. The most compelling proof of concept was the demonstration of Demaria et al. that abscopal tumour regression depended totally on the presence of T cells 


\section{Chapter 5}

23. In subsequent research, Dewan et al. further showed that predominantly cytotoxic CD8+ T cells were associated with abscopal tumour regression ${ }^{24}$. However, in human individuals demonstrating abscopal tumour regression data were gathered implicating the involvement of additional immune mechanisms ${ }^{10,27}$. Certain immunological phenomena like humoral immune responses may be involved in tumour control or serve as a biomarker identifying responding patients.

Based on two clinical case studies that reported an association between abscopal tumour regression and the induction of humoral responses ${ }^{10,11}$, we set out to analyse the humoral immune response in an animal model (67NR mammary carcinoma) showing abscopal effects ${ }^{23}$. We observed that whereas a booster vaccine was necessary to induce durable antibody responses against heat-killed tumour cells in Balb/C mice, all mice that were inoculated with a 67NR tumour showed an antibody response against the tumour. This observation together with the previously reported pre-existing antibody response in patients displaying abscopal tumour regression triggers the question whether such a pre-existing antibody response is a prerequisite for responses against metastatic disease ${ }^{27}$. Regardless of the direct role of such antibodies in the control of disease their mere presence indicates that the tumour has not escaped immune recognition.

Based on our findings we cannot specify the antigens that are expressed on the cell surface of 67NR tumours. Presumably the antibodies in the plasma bind to epitopes that are shared between various tumours that target tumour-associated rather than tumour-specific antigens. Nevertheless these antigens are clearly more abundant on 67NR tumour cells and its derived cell line 4T1 selected for being more metastatic ${ }^{29,30}$ as compared to the colon carcinoma C26 cell line, which could reflect a certain contribution of antibodies targeting tumour-specific antigens. Furthermore, we observed that these durable antibody responses were not limited to an IgM profile, but were quite diverse in terms of the Ig isotypes, which is most likely a reflection that multiple antigens are recognized during 67NR tumour progression. Additionally, the fact that the antibody response is dominated by IgG can be considered as direct proof that CD4+ T cell-dependent responses are triggered upon tumour inoculation as immunoglobulin class switching occurred ${ }^{31}$. Currently, it remains unknown whether the induction of antibody responses against the tumour is directly involved in abscopal tumour regression, or whether the induction of such antibodies only serves as a biomarker indicating a novel immune response in a subset of patients.

In order to address a potential role of this humoral immune response we evaluated 
how this was altered upon fractionated RT. We showed that abscopal tumour growth inhibition is observed after fractionated RT in the 67NR mouse model. Fractionated RT in combination with or without Flt3-L administration resulted in growth delay of both irradiated and nonirradiated tumours, indicating abscopal effects. The groups receiving RT also showed an increased number of surviving tumour free mice. However, several of these irradiated tumourbearing mice demonstrated exponential tumour growth, suggesting the importance of the immunogenic state of the Balb/C mice as well as the 67NR tumour. We applied fractionated RT to the primary tumour to reduce harmful side effects to the surrounding healthy tissue for clinical translation. This approach resulted in abscopal effects (RT groups), which was also observed by Dewan et al. They demonstrated that fractionated RT was more effective than a single dose of RT. This latter finding is in line with previous research of Demaria et al. who indicated that a single dose of RT did not result in abscopal effects ${ }^{23,24}$. Importantly, it should be noted that all depends on the trigger dose of RT that is applied, if this is large enough abscopal effects could be seen. In addition, our objective of the Flt3-L group was to evaluate whether stimulating pDC and $\mathrm{CDC}$ might be effective at boosting immune responses that can be read out via monitoring the $B$ cells. Notably, the tumour growth inhibition we observed in irradiated groups in presence or absence of Flt3-L was not paralleled with the modulation of the pre-existing antibody response. Likewise, we demonstrated that DC stimulation with Flt3-L did neither modulate the magnitude nor the composition of the humoral immune response. In contrast, preclinical studies showed an increased anti-tumour effect mediated by $T$ cells using the same Flt3-L concentrations and treatment days ${ }^{23,32}$. Notably, we showed that administration of Flt3-L had no additive effect in humoral immune responses. Finally, we found no differences in immune infiltrate and Ig isotype content of all tumours that were indicative for local Ig production. Because the main endpoint of our study was observing the survival benefit we did not sacrifice animals at the time of abscopal tumour shrinkage, but only at the predefined human endpoint or at the end of the experiment. Furthermore, the aim of the histology and flow cytometry of the tumour was to exclude that there was local antibody production at the site of the tumour. This study design does presumably not allow the identification of the mechanism leading to abscopal tumour shrinkage. For this reason, we observed the differences in T cell infiltration of non-irradiated and irradiated tumours.

The lack of modulating the antibody response upon RT suggests that antibodies do not play a key role in abscopal tumour regression in the 67NR mouse model. However, current immunotherapy approaches that use monoclonal antibodies targeting immune checkpoints 


\section{Chapter 5}

show significant anti-tumour responses in multiple cancer types, so monitoring B cell- as well as antibody responses might be of great value ${ }^{33}$. Although, Ig isotype classification in the 67NR mouse model indicated that the TBAs were predominantly $\operatorname{lgG}_{2 a^{\prime}}$, which is the most effective at complement fixation and antibody-dependent cellular cytotoxicity (ADCC) ${ }^{34-36}$, it is also well documented that tumour cells have several evading mechanisms for antibodymediated complement-dependent cytotoxicity $(C D C)$ by the expression of membrane complement regulatory proteins (mCRPs) and proteases degrading complement at the cell surface that may interfere with the efficacy of the antibody-mediated killing ${ }^{37}$. This is in line with Demaria et al. who showed the crucial role of T cells in abscopal tumour regression ${ }^{23,24}$. Furthermore, the lack of correlation between the occurrence of abscopal tumour regression and modulation of the humoral immune response in our 67NR mouse model also indicates that monitoring the humoral immune response is not a surrogate marker that is invariably associated with the induction of systemic immune responses. Golden et al. demonstrated in a subset of patients with abscopal effects that not only the pre-existing antibody response was enhanced in magnitude but also antibodies targeting different epitopes of the same antigen and seromic analysis demonstrated that in one patient a novel antibody response against ten new antigens was observed ${ }^{10}$. Based on the contradicting results demonstrated in our study using an animal model inoculated with a single tumour cell line and the clinical case reports, it remains too early to assess to what extent monitoring the course of the antibody response can be applicable in the clinic for monitoring abscopal immune responses. So, in future more preclinical work should be performed to evaluate the antibody response in multiple types of cancer that demonstrate abscopal effects and if these TBAs correlate with responders that show (abscopal) tumour regression.

Until now, abscopal tumour regression after RT alone is only anecdotally observed in patients with cancer. However, recent studies have demonstrated that combination therapy with fractionated RT and CTLA-4 blockade (ipilimumab) or GM-CSF treatment, the percentage of patients showing abscopal tumour regression increased up to $20 \%{ }^{10,13,27}$. Importantly, accumulating evidence demonstrates that in particular RT in combination with immune modulation induces local and systemic anti-tumour responses and future approaches should be evaluated to boost the link between the innate and adaptive immune systems to increase the occurrence of abscopal effects ${ }^{38,39}$. To this end, the stimulation of pDC and cDC by immunotherapeutic agents like toll-like receptor (TLR) agonists could enhance effector T cell priming ${ }^{40}$. In addition, immune checkpoint inhibitors like CTLA-4, the PD-1/PD-L1 axis, and 
CD40 could overcome the suppressive microenvironment of the tumour, and prevent $\mathrm{T}$ cell exhaustion and apoptosis ${ }^{33,41-43}$. The blockade of these particular immune checkpoints with monoclonal antibodies promotes the endogenous anti-tumour activation of immune cells that resulted in significant benefits for cancer patients ${ }^{44}$. With respect to CTLA-4, Dewan et al. showed CD8+ T cell-mediated abscopal effects in a preclinical animal model in which fractionated RT was combined with CTLA-4 blockade ${ }^{24}$. It might be of value to study the relevance of antibodies in these treatment systems.

In conclusion, our study demonstrated that fractionated RT with or without Flt3-L administration induces abscopal effects in the 67NR mouse model. Here, we observed a preexisting antibody response that is also observed in abscopal responders in human studies. However, such humoral immune responses in terms of total quantity of plasma antibodies or the Ig isotype composition are not altered upon fractionated RT and/or upon DC stimulation with Flt3-L in this model. Taken together, our data demonstrate that monitoring antibodies in the setting of abscopal tumour regression does not invariably associates with therapeutic effects.

\section{ACKNOWLEDGEMENTS}

The authors would like to thank Dana Quaden and Yannick Schrooders for their technical assistance.

\section{REFERENCES}

1. Demaria S, Formenti SC. Radiation as an immunological adjuvant: current evidence on dose and fractionation. Front Oncol. 2012;2:153.

2. Formenti SC, Demaria S. Systemic effects of local radiotherapy. Lancet Oncol. 2009;10(7):718-726.

3. Liauw SL, Connell PP, Weichselbaum RR. New paradigms and future challenges in radiation oncology: an update of biological targets and technology. Sci Transl Med. 2013;5(173):173sr172.

4. Mole RH. Whole body irradiation; radiobiology or medicine? Br J Radiol. 1953;26(305):234-241.

5. Kaminski JM, Shinohara E, Summers JB, Niermann KJ, Morimoto A, Brousal J. The controversial abscopal effect. Cancer Treat Rev. 2005;31(3):159-172.

6. Siva S, Macmanus MP, Martin RF, Martin OA. Abscopal effects of radiation therapy: A clinical review for the radiobiologist. Cancer Lett. 2013.

7. Abuodeh Y, Venkat P, Kim S. Systematic review of case reports on the abscopal effect. Curr Probl Cancer. 2015.

8. Bramhall RJ, Mahady K, Peach AH. Spontaneous regression of metastatic melanoma - clinical evidence of the abscopal effect. Eur J Surg Oncol. 2014;40(1):34-41.

9. Grimaldi AM, Simeone E, Giannarelli D, et al. Abscopal effects of radiotherapy on advanced melanoma patients who progressed after ipilimumab immunotherapy. Oncoimmunology. 2014;3:e28780. 


\section{Chapter 5}

10. Postow MA, Callahan MK, Barker CA, et al. Immunologic correlates of the abscopal effect in a patient with melanoma. N Engl J Med. 2012;366(10):925-931.

11. Stamell EF, Wolchok JD, Gnjatic S, Lee NY, Brownell I. The abscopal effect associated with a systemic antimelanoma immune response. Int J Radiat Oncol Biol Phys. 2013;85(2):293-295.

12. Sullivan RJ, Lawrence DP, Wargo JA, Oh KS, Gonzalez RG, Piris A. Case records of the Massachusetts General Hospital. Case 21-2013. A 68-year-old man with metastatic melanoma. N Engl J Med. 2013;369(2):173-183.

13. Golden EB, Demaria S, Schiff PB, Chachoua A, Formenti SC. An abscopal response to radiation and ipilimumab in a patient with metastatic non-small cell lung cancer. Cancer Immunol Res. 2013;1(6):365-372.

14. Okuma K, Yamashita H, Niibe Y, Hayakawa K, Nakagawa K. Abscopal effect of radiation on lung metastases of hepatocellular carcinoma: a case report. J Med Case Rep. 2011;5:111.

15. Wersall PJ, Blomgren H, Pisa P, Lax I, Kalkner KM, Svedman C. Regression of non-irradiated metastases after extracranial stereotactic radiotherapy in metastatic renal cell carcinoma. Acta Oncol. 2006;45(4):493-497.

16. Ohba K, Omagari K, Nakamura T, et al. Abscopal regression of hepatocellular carcinoma after radiotherapy for bone metastasis. Gut. 1998;43(4):575-577.

17. Lakshmanagowda PB, Viswanath L, Thimmaiah N, Dasappa L, Supe SS, Kallur P. Abscopal effect in a patient with chronic lymphocytic leukemia during radiation therapy: a case report. Cases J. 2009;2:204.

18. Golden EB, Apetoh L. Radiotherapy and Immunogenic Cell Death. Semin Radiat Oncol. 2015;25(1):11-17.

19. Tesniere A, Apetoh L, Ghiringhelli F, et al. Immunogenic cancer cell death: a key-lock paradigm. Curr Opin Immunol. 2008;20(5):504-511.

20. Kono K, Mimura K, Kiessling R. Immunogenic tumor cell death induced by chemoradiotherapy: molecular mechanisms and a clinical translation. Cell Death Dis. 2013;4:e688.

21. Vatner RE, Cooper BT, Vanpouille-Box C, Demaria S, Formenti SC. Combinations of immunotherapy and radiation in cancer therapy. Front Oncol. 2014;4:325.

22. Formenti SC, Demaria S. Combining radiotherapy and cancer immunotherapy: a paradigm shift. J Natl Cancer Inst. 2013;105(4):256-265.

23. Demaria S, Ng B, Devitt ML, et al. Ionizing radiation inhibition of distant untreated tumors (abscopal effect) is immune mediated. Int J Radiat Oncol Biol Phys. 2004;58(3):862-870.

24. Dewan $\mathrm{MZ}$, Kawashima $\mathrm{N}$, et al. Fractionated but not single-dose radiotherapy induces an immune-mediated abscopal effect when combined with anti-CTLA-4 antibody. Clin Cancer Res. 2009;15(17):5379-5388.

25. Chakravarty PK, Alfieri A, Thomas EK, et al. Flt3-ligand administration after radiation therapy prolongs survival in a murine model of metastatic lung cancer. Cancer Res. 1999;59(24):6028-6032.

26. Dranoff G, Jaffee E, Lazenby A, et al. Vaccination with irradiated tumor cells engineered to secrete murine granulocyte-macrophage colony-stimulating factor stimulates potent, specific, and long-lasting anti-tumor immunity. Proc Natl Acad Sci U S A. 1993;90(8):3539-3543.

27. Golden EB, Chhabra A, Chachoua A, et al. Local radiotherapy and granulocyte-macrophage colony-stimulating factor to generate abscopal responses in patients with metastatic solid tumours: a proof-of-principle trial. Lancet Oncol. 2015;16(7):795-803.

28. Girit IC, Jure-Kunkel M, McIntyre KW. A structured light-based system for scanning subcutaneous tumors in laboratory animals. Comp Med. 2008;58(3):264-270.

29. Kowanetz $\mathrm{M}, \mathrm{Wu} \mathrm{X}$, Lee J, et al. Granulocyte-colony stimulating factor promotes lung metastasis through mobilization of Ly6G+Ly6C+ granulocytes. Proc Natl Acad Sci U S A. 2010;107(50):21248-21255.

30. Aslakson CJ, Miller FR. Selective events in the metastatic process defined by analysis of the sequential dissemination of subpopulations of a mouse mammary tumor. Cancer Res. 1992;52(6):1399-1405.

31. Smith KM, Pottage L, Thomas ER, et al. Th1 and Th2 CD4+ T cells provide help for B cell clonal expansion and antibody synthesis in a similar manner in vivo. J Immunol. 2000;165(6):3136-3144.

32. Lynch DH, Andreasen A, Maraskovsky E, Whitmore J, Miller RE, Schuh JC. Flt3 ligand induces tumor regression and antitumor immune responses in vivo. Nat Med. 1997;3(6):625-631.

33. Melero I, Berman DM, Aznar MA, Korman AJ, Perez Gracia JL, Haanen J. Evolving synergistic combinations of targeted immunotherapies to combat cancer. Nat Rev Cancer. 2015;15(8):457-472.

34. Spiegelberg HL. Biological activities of immunoglobulins of different classes and subclasses. Adv Immunol. 
1974;19(0):259-294.

35. Greenberg AH, Medley G. Characteristics of the effector cells mediating cytotoxicity against antibody-coated target cells. I. Phagocytic and non-phagocytic effector cell activity against erythrocyte and tumour target cells in a 51Cr release cytotoxicity assay and [125I]IUdR growth inhibition assay. Immunology. 1975;29(4):719-729.

36. Herlyn D, Koprowski H. IgG2a monoclonal antibodies inhibit human tumor growth through interaction with effector cells. Proc Natl Acad Sci U S A. 1982;79(15):4761-4765.

37. Pio R, Corrales L, Lambris JD. The role of complement in tumor growth. Adv Exp Med Biol. 2014;772:229-262.

38. Derer A, Deloch L, Rubner Y, Fietkau R, Frey B, Gaipl US. Radio-Immunotherapy-Induced Immunogenic Cancer Cells as Basis for Induction of Systemic Anti-Tumor Immune Responses - Pre-Clinical Evidence and Ongoing Clinical Applications. Front Immunol. 2015;6:505.

39. Derer A, Frey B, Gaipl US. Immune-modulating properties of ionizing radiation: rationale for the treatment of cancer by combination radiotherapy and immune checkpoint inhibitors. Cancer Immunol Immunother. 2015.

40. Kaczanowska S, Joseph AM, Davila E. TLR agonists: our best frenemy in cancer immunotherapy. J Leukoc Biol. 2013;93(6):847-863.

41. Blank CU. The perspective of immunotherapy: new molecules and new mechanisms of action in immune modulation. Curr Opin Oncol. 2014;26(2):204-214.

42. Honeychurch J, Cheadle EJ, Dovedi SJ, Illidge TM. Immuno-regulatory antibodies for the treatment of cancer. Expert Opin Biol Ther. 2015;15(6):787-801.

43. Blank CU, Enk A. Therapeutic use of anti-CTLA-4 antibodies. Int Immunol. 2015;27(1):3-10.

44. Ito A, Kondo S, Tada K, Kitano S. Clinical Development of Immune Checkpoint Inhibitors. Biomed Res Int. 2015;2015:605478. 


\section{SUPPORTING INFORMATION}
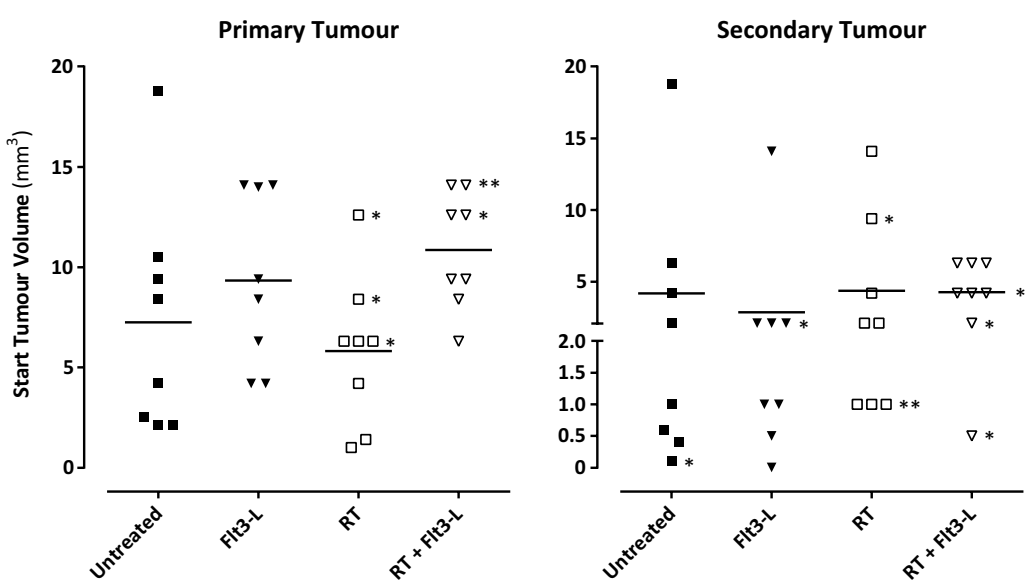

Figure S1: The tumour volume in $\mathrm{mm}^{3}$ of the primary and secondary tumour in Balb/C mice 14 days after 67NR inoculation. The size $\left(\mathrm{mm}^{3}\right)$ of both 67NR tumours in Balb/C mice assigned to groups untreated, Flt3-L, RT, and $\mathrm{RT}+\mathrm{Flt} 3-\mathrm{L}$. All Balb/C mice had palpable tumours at the start of the experiment (before the treatments). The stars indicate Balb/C mice that were tumour free at the end of the experiment (day 162).

\section{(File S1) SUPPLEMENTARY MATERIALS AND METHODS}

Development of cellular read-out systems for the detection of TBAs in the plasma of Balb/C mice.

In order to have a system that allows the detection of tumour-specific antibodies we set out to develop cellular-based detection assays using flow cytometry and ELISA. In order to establish whether these assays quantitatively reflect the antibody concentration or whether they are influenced by undesired protein factors in the plasma sample also defined as matrix effects we performed dilution experiments of an antibody of known concentration in different concentrations of plasma (Figure S2b). For this assay we stained $10^{5} 67$ NR tumour cells with five concentrations $(0.5,0.1,0.05,0.01,0.005 \mu \mathrm{g} / \mu \mathrm{L})$ of a monoclonal unconjugated antibody against the $\mathrm{MHC}$ molecules $\left(\mathrm{H}-2 \mathrm{~K}^{\mathrm{d}}\right)$ of the cell line in 5 different concentrations of mouse plasma $(1: 2,1: 10,1: 20,1: 40,1: 80)$ or in buffer.

As shown in Figure S2a (right panel), the $\mathrm{H}-2 \mathrm{~K}^{\mathrm{d}}$ binding to the cells was dependent on the plasma dilution. In particular, a plasma dilution of 1:2 showed reduced binding of the $\mathrm{H}-2 \mathrm{~K}^{\mathrm{d}}$ recognizing antibody to the 67NR tumour cells. Additionally, in this plasma dilution no dose-dependency could be observed when more of the monoclonal antibody was added. 
These matrix effects were only observed in the 1:2 dilution of the plasma and all other plasma dilutions demonstrated a dose-dependent increase in antibody binding. Notably, the MFI values were highest in the condition where the plasma was diluted 1:10 and 1:20 and these MFIs exceed the MFI values observed in a typical buffer used for flow cytometry (PBS $+10 \%$ FCS $+0.05 \%$ Tween 20) with a lower protein content. With exceeding dilution of the plasma the MFI values resemble more closely those that are observed in buffer. Based on these data the highest signal to noise ratio was observed at dilutions above 1:10 and a plasma dilution of 1:20 was used for all antibody detection experiments. Using this serum concentration there is a dose-dependent correlation between the MFI and the quantity of the antibody that is spiked in the plasma.

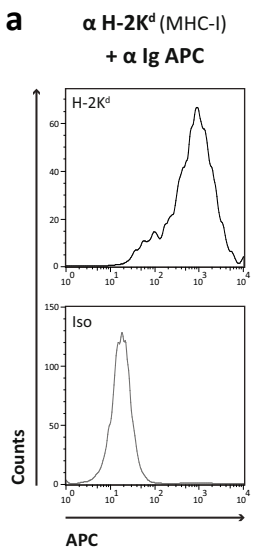

APC

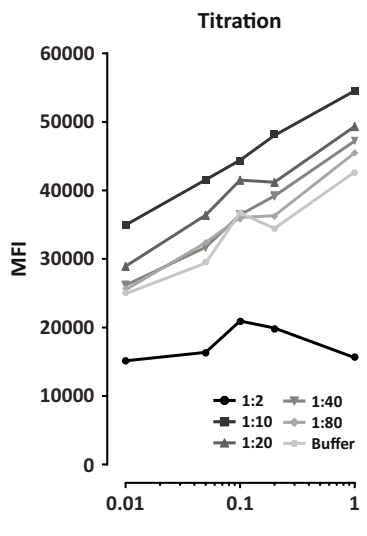

[ ] $\mathbf{H}-2 \mathrm{~K}^{\mathrm{d}}$

Unconjugated

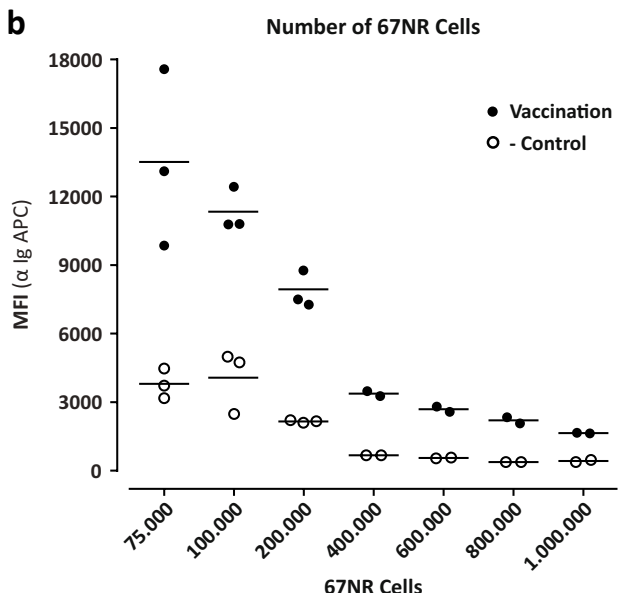

67NR Cells

Figure S2: Experimental optimization of a flow cytometric detection system to analyse Igs in the plasma of Balb/C mice. a. The surface expression of $\mathrm{H}-2 \mathrm{~K}^{\mathrm{d}}(\mathrm{MHC}-\mathrm{I})$ on 67NR tumour cells. An APC-conjugated antibody against total immunoglobulins ( $\alpha$ Ig APC) detected the un-conjugated $\mathrm{H}-2 \mathrm{~K}^{\mathrm{d}}$ antibody $(0.5 \mathrm{mg} / \mathrm{mL}$ ) using flow cytometry (FC). In order to quantitatively analyse the antibody concentration without the influence of matrix effects that originate from undesired protein factors in the plasma, we performed a dilution experiment of an antibody of known concentration in different concentrations of plasma. We stained $10^{5}$ cells with 5 concentrations $(0.5,0.1,0.05,0.01,0.005 \mu \mathrm{g} / \mu \mathrm{L})$ of a monoclonal unconjugated $\mathrm{H}-2 \mathrm{~K}^{\mathrm{d}}$ antibody in 5 concentrations of mouse plasma $(1: 2,1: 10,1: 20,1: 40,1: 80)$ or in buffer. b. Different numbers $\left(0.75 * 10^{5}\right.$ to $\left.10 * 10^{5}\right)$ of 67 NR tumour cells were incubated with vaccinated (+control) or -control plasma and detected using an $\alpha$ Ig APC antibody to determine the optimal signal to background ratio. Iso, Ig isotype control. MFI, mean fluorescent intensity.

In order to evaluate whether this flow cytometric methodology also allows the detection of a de novo induced polyclonal antibody response in an animal, we vaccinated healthy Balb/C mice with $10^{7}$ heat killed 67NR cells in incomplete Freund's adjuvant and CpG. Besides the generation of positive control sera, the secondary aim of this experiment 


\section{Chapter 5}

was to study whether it is possible to generate antibodies against the 67NR tumour cell line in animals with the same genetic background as the cell line. Additionally, this vaccination experiment allows studying to what extent the induction of an antibody response against the tumour (after vaccination) is transient (and whether a booster vaccine was required for a durable antibody response). To this end, we vaccinated animals with a cocktail of IFA, CpG ODN, and heat-killed 67NR cells to boost 67NR specific antibody responses. At week 3, 4, and 5 plasma samples were collected. Additional animals received a booster vaccine at week 3 and plasma was collected on week 1, 2, and 3 after the booster. In order to demonstrate the induction of an antibody response against 67NR we incubated $10^{5}$ 67NR cells with 1:20 diluted plasma of control and vaccinated mice. As shown in Figure S3, we demonstrated antibody binding in the plasma collected 3 weeks after the first vaccination. However, this antibody response was not a durable response as antibody binding decreased in the plasma collected after 4 or 5 weeks. Upon boost vaccination we observed increased antibody binding to the $67 \mathrm{NR}$ cells that lasted until at least 3 weeks after the first vaccination. The sera that were collected after the boost vaccination were used to further optimize the flow cytometric and cellular ELISA-based methods.

Because both the sensitivity as the variability of antibody detection is dependent

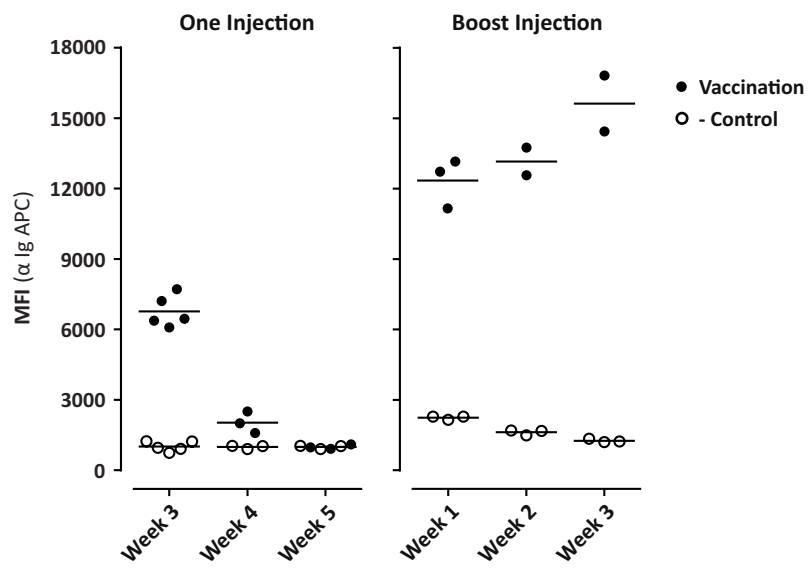

Figure S3: Vaccine-induced antibody response in immunocompetent Balb/C mice. Balb/C mice were vaccinated (immunocompetent) with incomplete Freund's adjuvant (IFA), CpG oligodeoxynucleotides (ODNs), and heat-killed 67NR cells. To boost the antibody response, a secondary vaccination cocktail of IFA, CpG ODNs, and heat-killed 67NR cells was injected in primary immunized Balb/C mice. Per week one injected mouse was sacrificed and the plasma was collected (technical replicates). The levels of immunoglobulins ( $\alpha$ Ig APC) in the plasma were measured after one injection (week 3, 4, 5) or boost injection (week 1, 2, 3). The plasma samples from the boosted mice were used as positive control in the cellular flow cytometry and ELISA-based detection systems. Control immunocompetent $\mathrm{Balb} / \mathrm{C}$ mice were injected with phosphate buffered saline (PBS). 
on the amount of antigen, we performed titration experiments in which various numbers of 67NR tumour cells were incubated with 1:20 diluted plasma derived from healthy (-control) or vaccinated (Figure S3) Balb/C mice. As shown in Figure S2b, the maximal signal to noise ratio (vaccination to -control ratio) with minimal technical variation was reached when the experiment was performed with $1 * 10^{5}$ 67NR tumour cells per condition. The variation was increased in conditions where $75 * 10^{3}$ cells were used and the sensitivity decreased when more than $2 * 10^{5}$ 67NR tumour cells were used (Figure S2b).

In addition to the development of a flow cytometric detection system we also set out to develop an ELISA-based system for the detection of humoral antibodies. To this end, we seeded tissue culture plates with different numbers of 67NR cells and incubated them for 18 hours. Although, 67NR cells showed a strong adherent phenotype (fibroblast-like structure), they detached from the culture plates during these washing steps. Therefore, we fixated 67NR cells with formaldehyde for 15, 20,30, and $45 \mathrm{~min}$. These results (not shown) indicated that 15 minutes was not sufficient, whereas 45 minutes was.

After washing the 67NR cells, we fixated the cells using paraformaldehyde for 45 minutes and blocked remaining binding sites with 1\% BSA. After incubation with plasma of the animals we detected primary antibody binding using an HRP-labelled anti-mouse Ig. In order to validate this cellular ELISA-based protocol, we spiked plasma with the primary $\mathrm{H}-2 \mathrm{~K}^{\mathrm{d}}$ antibody as described above, followed by titration of the detection antibody with plasma from vaccinated and healthy Balb/C mice (Figure S4a). Using this assay, we demonstrated that seeding of $10^{5}$ cells resulted in a higher signal and less internal variation as compared to seeding of $0.75 * 10^{5}$ cells. In addition, we questioned in these experiments whether the fixation protocol could account for background staining. Therefore, we determined the binding of the $\mathrm{H}-2 \mathrm{~K}^{\mathrm{d}}$ antibody and the secondary antibody Ig-HRP (background) on fixated $67 N R$ cells $(15,20,30$ and $45 \mathrm{~min})$. We observed no increased binding of the $\mathrm{H}-2 \mathrm{~K}^{\mathrm{d}}$ antibody with longer fixation protocols and even observed less binding of the secondary antibody with longer fixations (data not shown). Subsequently, we determined the optimal dilution for the plasma. Therefore, binding of antibodies of the vaccinated Balb/C mice and control mice was evaluated when plasmas were diluted 20, 40, 80, 160, and 320 times (Figure S4b). As shown in Figure S4b, the largest percentual difference between vaccinated and negative control plasma was observed at a plasma dilution of 1:20.

In order to measure the Ig isotype composition in plasma of tumour-bearing mice we selected antibodies that show minimal crossreactivity with Igs from another subclass. 


\section{Chapter 5}

Freshly isolated human peripheral blood mononuclear cells (PBMCs) were incubated with unconjugated mouse anti-human antibodies specific for CD28 ( $\left.\operatorname{lgG}_{1}\right), C D 3\left(\lg G_{2 a}\right), C D 158 b$ $\left(\operatorname{lgG}_{2 b}\right)$, and CD158a (IgM) (Figure S5a). Binding of these antibodies was detected with an antibody cocktail containing rat anti-mouse $\operatorname{lgG}_{1}(\mathrm{APC}), \operatorname{lgG}_{2 a}(\mathrm{PE}), \operatorname{lgG}_{2 \mathrm{~b}}$ (FITC), and IgM (PE-

a

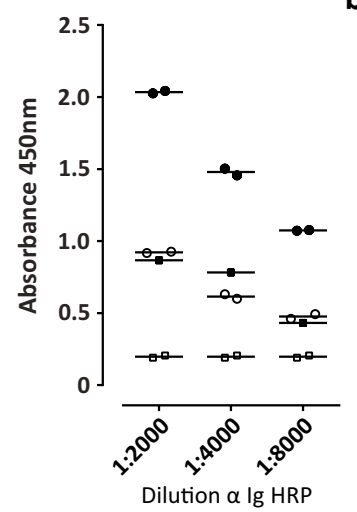

b

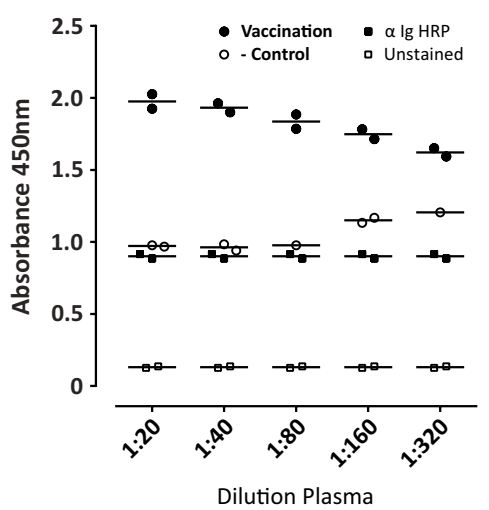

C

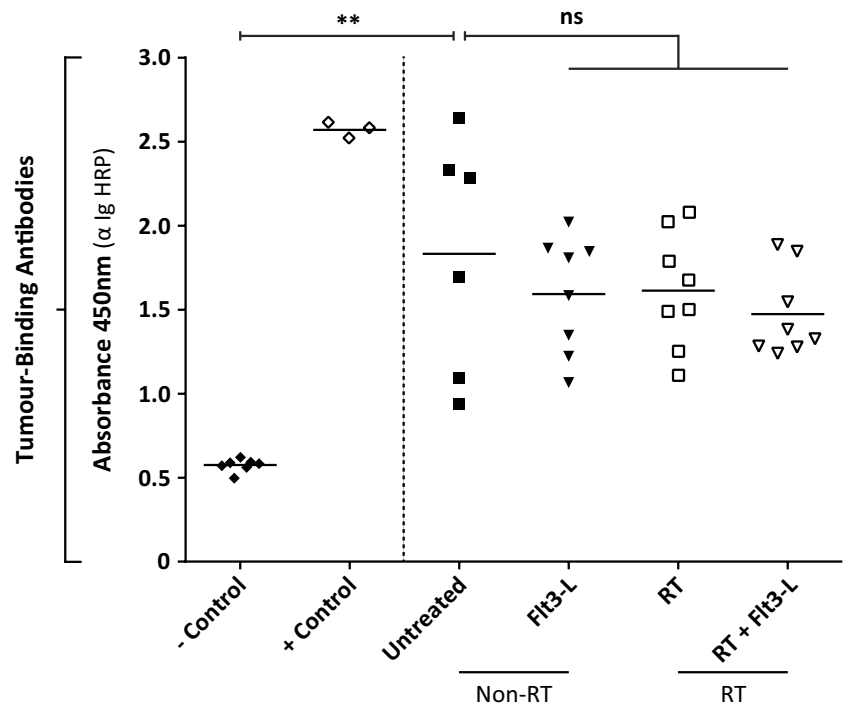

Figure S4: Detection of TBAs in the plasma of (un)-treated Balb/C mice using an optimized cellular ELISA based system. a. To define the optimal concentration of the detection antibody, we titrated the $\alpha$ Ig HRP antibody (1:2000, $1: 4000,1: 8000)$ using vaccinated and -control plasma. To control for background staining we included the $\alpha$ Ig HRP only and unstained. $b$. After determining the optimal $\alpha$ Ig HRP dilution, the plasma of vaccinated and -control was titrated (1:20, 1:40, 1:80, 1:160, 1:320) and detected using a 1:2000 dilution of $\alpha$ Ig HRP. The background staining was determined as described previously. c. A total of $1 * 10^{5} 67$ NR tumour cells were coated and incubated with plasma from immunocompetent (-control), vaccinated (+control), untreated, and treated (Flt3-L, RT, RT+Flt3-L) Balb/C mice. An HRP conjugated antibody against total Ig detected the TBAs. Tumour-bearing mice received fractionated RT (RT, RT+Flt3-L) or no RT (untreated, Flt3-L). Mann-Whitney t-test with $\mathrm{P}<0.01$ **. 
Cy7). As shown in Figure $55 b$, the gating on $\operatorname{lgG}_{1}$ positive cells displayed no crossreactivity with the other subclass specific detection antibodies, which was also confirmed for the other subclasses. In all cases less than $5 \%$ of the MFI was observed when the mouse anti-human antibodies were stained with antibodies that are reactive with another subclass (Figure S5c).

a

$\lg G_{1}$

$\lg G_{2 a}$

$\operatorname{lgG}_{2 b}$

$\lg M$
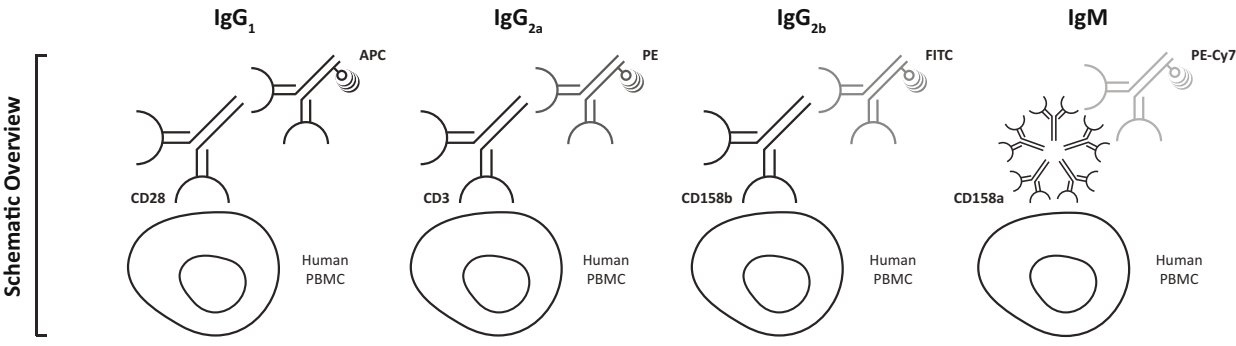

b
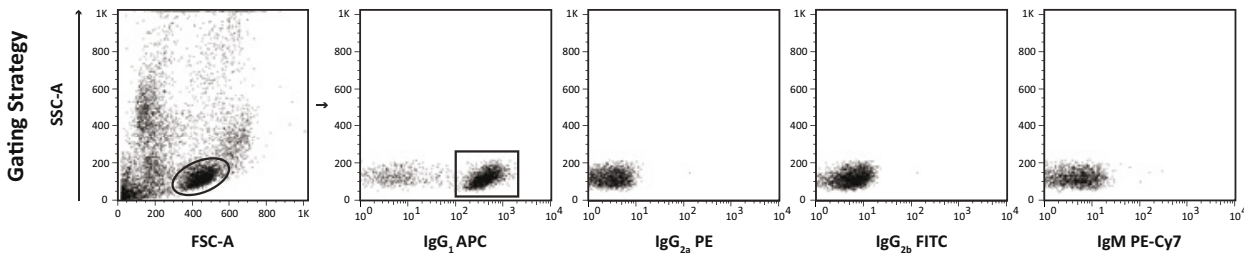

$\mathrm{IgG}_{1}$

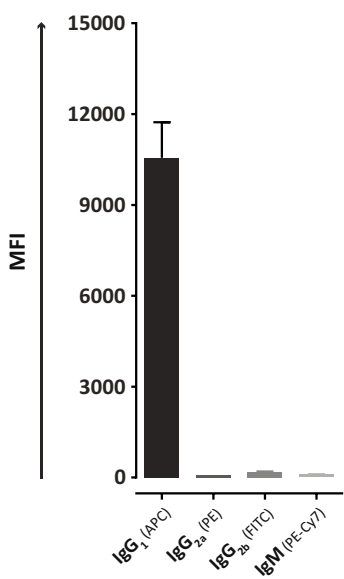

$\lg G_{2 a}$

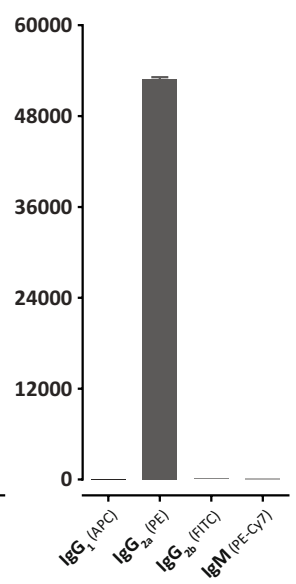

$\operatorname{lgG}_{2 b}$

IgM PE-Cy7

Figure S5: No crossreactivity of specific mouse anti-Ig isotype antibodies. a. Schematic outline of the optimization procedure. Freshly isolated human peripheral blood mononuclear cells (PBMCs) were incubated with unconjugated mouse anti-human antibodies specific for CD28 ( $\left.\operatorname{lgG}_{1}\right), C D 3\left(\operatorname{lgG}_{2 a}\right), C D 158 b\left(\lg G_{2 b}\right)$, and CD158a (IgM). These mouse anti-human antibodies were detected with an antibody cocktail containing rat anti-mouse $\operatorname{lgG}_{1}(A P C), \operatorname{lgG}_{2 a}(P E), \lg G_{2 b}$ (FITC), and IgM (PE-Cy7). b. FC dotplots of the gating strategy. The lymphocyte population was gated in the FSC vs. SSC dotplot. The positive $\lg G_{1}$ population was negative for isotypes $\lg G_{2 a^{\prime}} \lg G_{2 b^{\prime}}$ and $\lg M$, indicating no crossreactivity. This strategy was repeated for all Ig isotypes. c. The MFI levels of isotypes $\lg G_{1}, \lg G_{2 a^{\prime}} \lg G_{2 b^{\prime}}$ and $\lg M$. These rat antimouse Ig isotype antibodies show minimal crossreactivity. 


\section{Chapter 5}
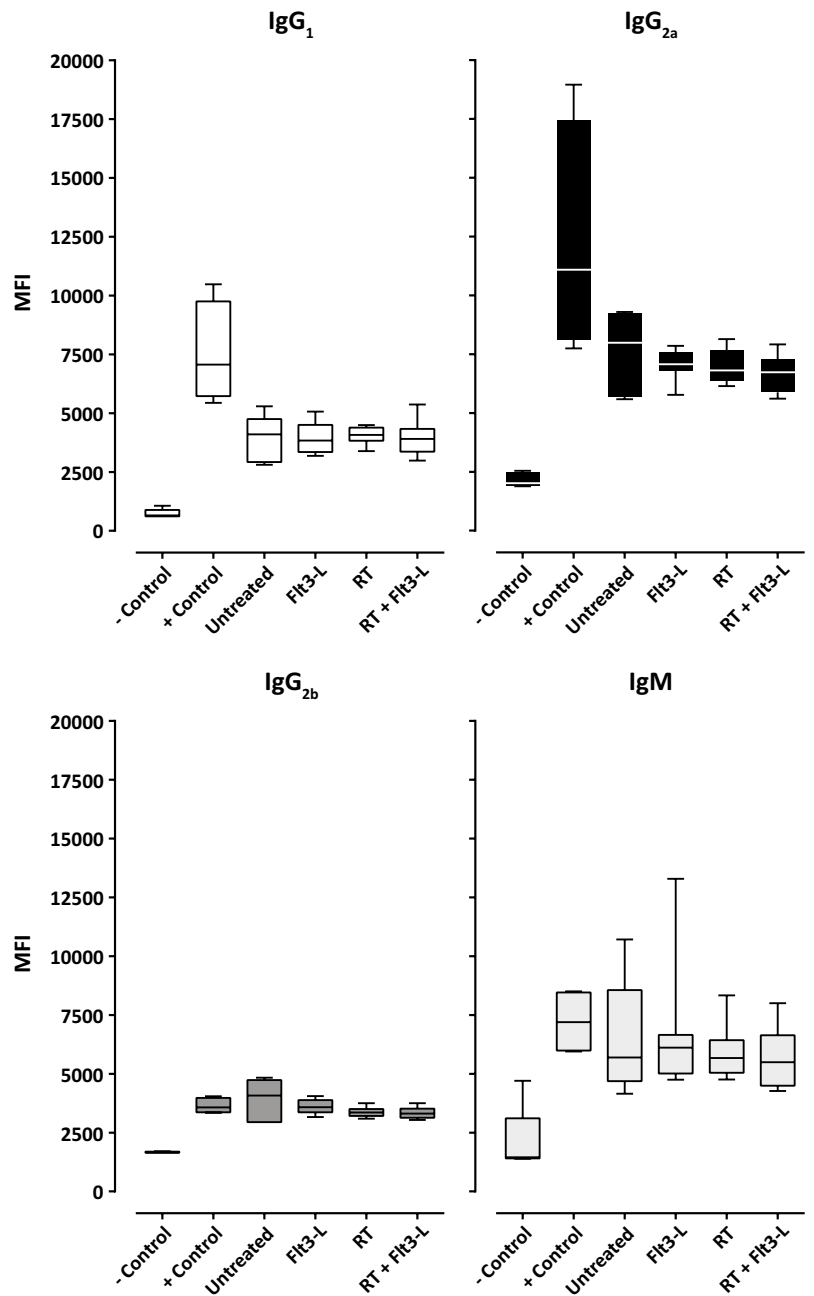

Figure S6: The Ig isotype composition of the TBAs in the plasma of tumour-bearing Balb/C mice displayed as MFI values. To determine the Ig isotypes in the plasma of tumour-bearing mice, $1 * 10^{5} 67 N R$ tumour cells were incubated with plasma from vaccinated (+control), non-irradiated (untreated, Flt3-L), and irradiated (RT, RT+Flt3-L) $\mathrm{Balb} / \mathrm{C}$ mice. The -control plasma was used to assess the background of each isotype staining. The four different isotypes were detected using fluorescent labelled $\lg _{1}(A P C), \operatorname{lgG}_{2 a}(P E), \operatorname{lgG}_{2 b}(F I T C)$, and IgM (PE-Cy7) antibodies. 
a Tumour Infiltrating T Cells (IHC)
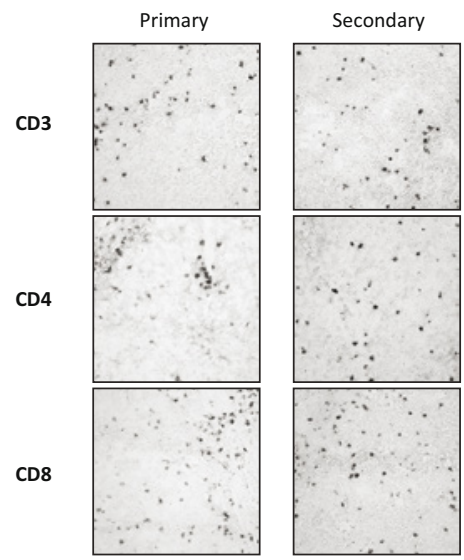

C Tumour Infiltrating CD4 ${ }^{+} \mathrm{T}$ Cells (FC)

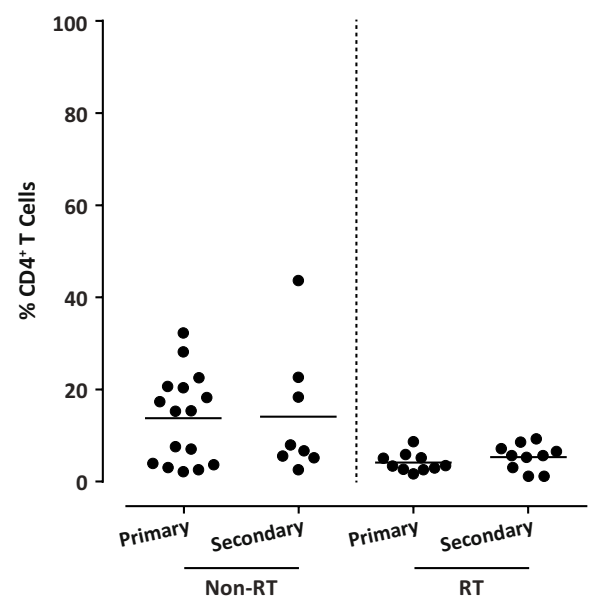

b Gating Strategy
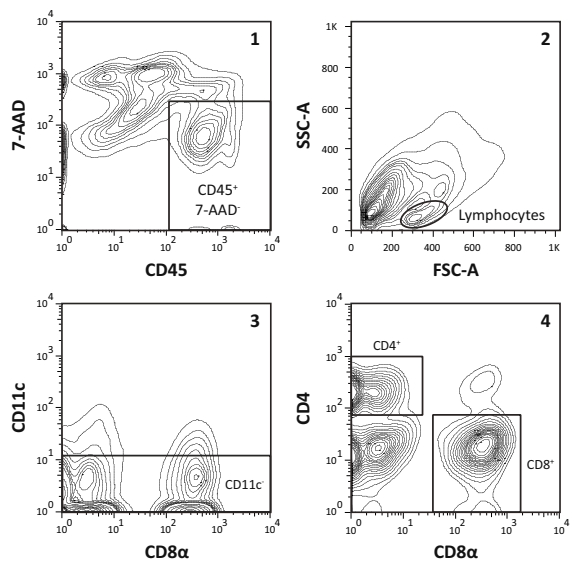

d

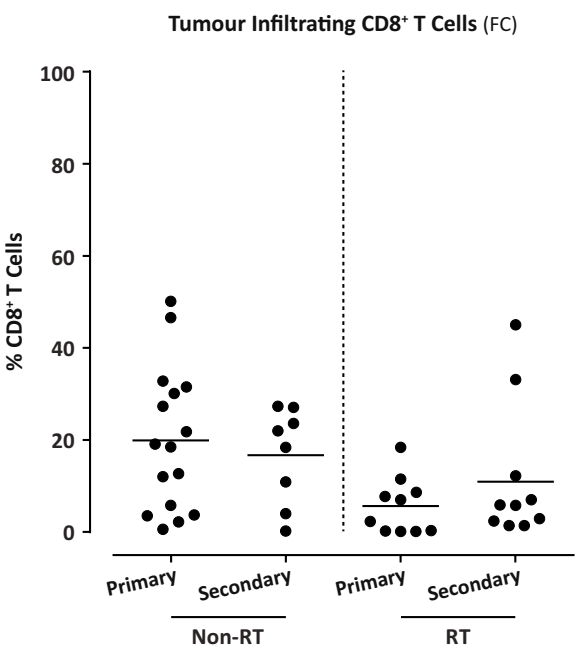

Figure S7: Infiltration of $\mathrm{CD} 3+, \mathrm{CD} 4+$, and CD8+T cells in the primary and secondary tumour. a. Immunohistochemical (IHC) staining of $\mathrm{CD} 3+, \mathrm{CD} 4+$, and $\mathrm{CD} 8+$ tumour infiltrating $T$ cells in both the primary and secondary tumour (data representative for all animals). b. FC density plots of the gating strategy. Living haematopoietic cells (CD45+ vs. 7-AAD-) were gated. In this gate, the lymphocyte population was selected based on the FSC vs. SSC. To ensure that only lymphocytes were gated, CD11c+ cells were excluded. In the CD11c- (CD8 $\alpha$ ) gate, CD4+ and CD8 $\alpha+T$ cells were selected. c, d. The percentage CD4+ and CD8 $\alpha+$ T cells in the primary and secondary tumour of (non)- vs. irradiated animals measured with FC. 


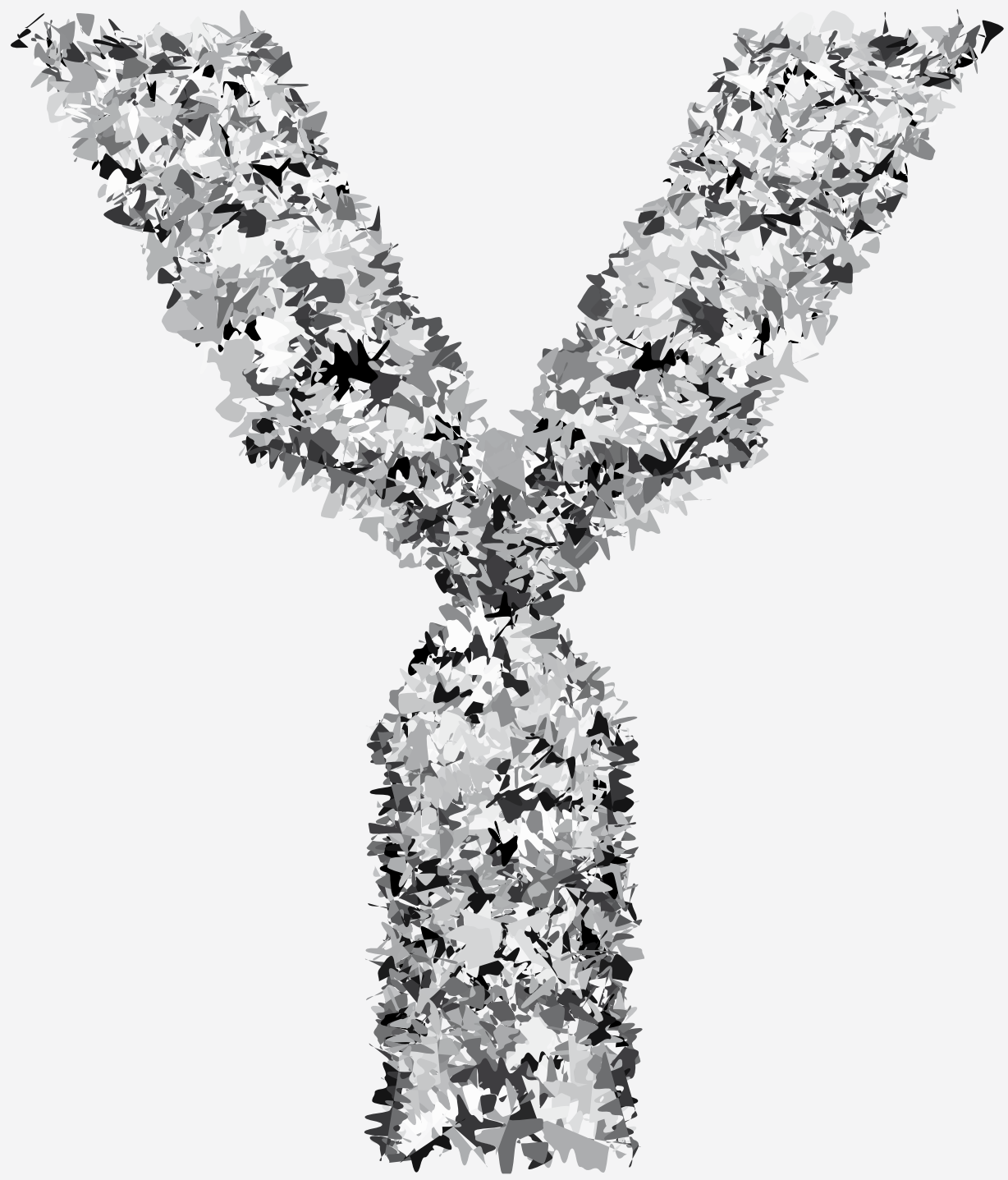




\section{CHAPTER}

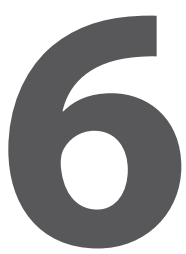

\section{The JAK1 and JAK2 inhibitor ruxolitinib inhibits the activation and proliferation of polyclonally stimulated peripheral B cells}

Thomas H.P.M. Habets ${ }^{1,2}$, Melanie C.A. Schnijderberg ${ }^{1}$, Michel van Gelder ${ }^{1}$, Joris Vanderlocht ${ }^{2}$, Gerard M.J. Bos ${ }^{1,3}$

1 Division of Hematology, Department of Internal Medicine, MUMC+, Maastricht

2 Tissue Typing Laboratory, Department of Transplantation Immunology, MUMC+, Maastricht

3 CiMaas BV, Maastricht

Submitted for publication 



\section{LETTER TO THE EDITOR}

Chronic graft-versus-host disease (cGVHD) is a major cause of morbidity, impaired quality of life, and mortality after allogeneic hematopoietic stem cell transplantation (HSCT) ${ }^{1}$. Current immunosuppressive drugs are frequently ineffective, and novel therapeutic approaches are needed. Although donor T cells play a critical role in cGVHD pathophysiology, it has been shown that B cells also contribute to the pathology of $\mathrm{CGVHD}^{2}$. Research by Miklos et al. demonstrated that $B$ cell responses directed against minor histocompatibility antigens ( $\mathrm{mHAs}$ ) were involved in $\mathrm{CGVHD}^{3}$. B cell targeting strategies such as rituximab (anti-CD20 monoclonal antibody) were proven to be effective in the management and can even prevent cGVHD in patients with HSCT, which demonstrates the role of these B cells ${ }^{4}$. Ruxolitinib an inhibitor of Janus kinase (JAK) 1 and JAK2 with potent anti-inflammatory properties was the first drug approved to treat patients with myelofibrosis ${ }^{5}$. The JAKs are essential signal transducers for cytokines and growth factors, which have a major role in haematopoiesis and immune function ${ }^{6}$. Interestingly, several studies showed that ruxolitinib was also effective in the treatment of acute GVHD and CGVHD in patients with HSCT. The inhibitory mechanism of ruxolitinib was suggested to target $T$ cells and dendritic cells (DC) ${ }^{7,8}$. This was further investigated by Heine et al. who showed in vitro and in vivo that DC exposed to ruxolitinib demonstrated almost complete blockade of human monocyte-derived DC differentiation, less DC-derived IL-12 production, decreased expression of activation markers, and reduced potency of DC to stimulate T cells ${ }^{9}$. Because the JAK-STAT pathway is important for normal B cell function ${ }^{10}$, we studied whether the JAK1/2 inhibitor ruxolitinib influences B cell proliferation and activation.

In order to examine the effect of JAK inhibitors on the proliferation and activation of $B$ cells, we made use of a proliferation assay in which negatively isolated peripheral $B$ cells were polyclonally stimulated with a cocktail of anti-CD40, toll-like receptor (TLR) 9 ligand CpG ODN 2006, IL-21, and human serum. The JAK inhibitors ruxolitinib (JAK1/2) and the more selective JAK2 inhibitor fedratinib were added in the concentrations of $0.1,1$, and $10 \mu \mathrm{M}$ based on the non-toxic plasma concentrations that were found in healthy individuals ${ }^{11,12}$.

To investigate the effect of these JAK inhibitors on the proliferation and activation of $B$ cells we performed a pilot study in which B cells from 4 donors were incubated with 10 $\mu \mathrm{M}$ ruxolitinib, fedratinib, and DMSO solvent. In this pilot study, we observed a significant decrease in the percentage of proliferating B cells in the ruxolitinib and fedratinib conditions as compared to the control and DMSO condition ( $P<0.05$, data not shown). The addition of 


\section{Chapter 6}

the solvent of ruxolitinib (10 $\mu \mathrm{M}$ DMSO) had no effect on the percentage of proliferating $B$ cells as compared to the control (data not shown). In order to determine whether there is a dose-dependent reduction in proliferation, we added three concentrations $(0.1,1,10 \mu \mathrm{M})$ of ruxolitinib (Figure 1) and fedratinib (Figure 2). We observed that B cells of all 4 healthy donors

a

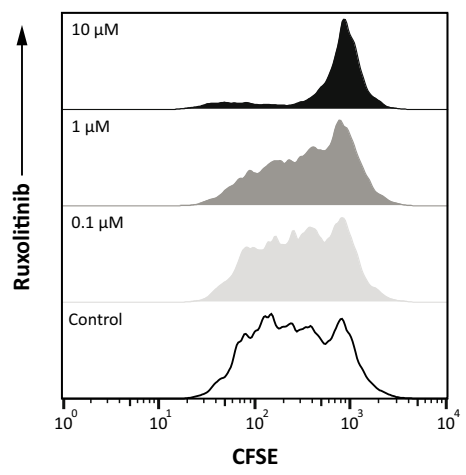

C

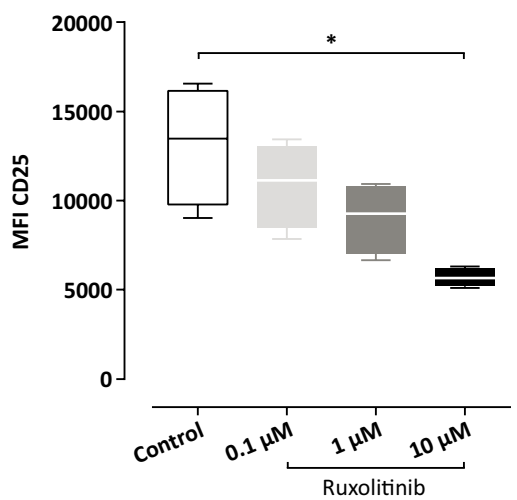

b

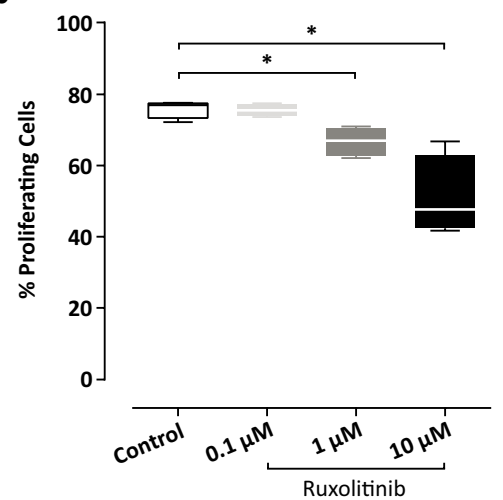

d

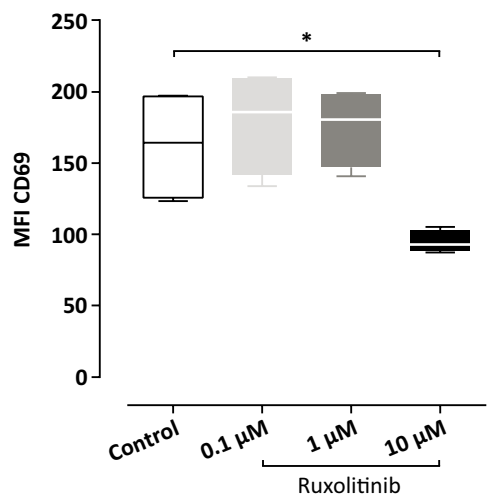

Figure 1: The effect of JAK1/2 inhibitor ruxolitinib on the proliferation and activation of polyclonally stimulated peripheral $B$ cells determined with flow cytometry. The B cells were isolated from PBMCs using negative $B$ cell isolation (Miltenyi). This resulted in a B cell purity of $>99 \%$ as determined with CD19 positivity (flow cytometry). To assess proliferation, B cells were labelled with $1 \mu \mathrm{M}$ proliferation marker CFSE. Per condition, $1 * 10^{5} \mathrm{~B}$ cells were seeded in 96-wells plates and cultured in AIM-V medium supplemented with $500 \mathrm{ng} / \mathrm{mL}$ anti-CD40 (R\&D), $5 \mu \mathrm{g} / \mathrm{mL}$ CpG ODN2006 (InvivoGen), $100 \mathrm{ng} / \mathrm{mL}$ IL-21 (Gibco), and $10 \%$ human serum. After 4 days of incubation at $37^{\circ} \mathrm{C}$, the $B$ cells were analysed for the expression of activation markers CD69 and CD25 (BD), and proliferation was assessed by evaluating CFSE dilution. The B cells were measured on the FACSCanto II flow cytometer and analysed using FACSDiva and Flowjo software. Living cells were gated by 7-AAD (BD) exclusion. Statistical analyses were performed in GraphPad Prism Pro using the Mann-Whitney t-test and a P value $<0.05$ was statistically significant. a. Overlay of CFSE histograms representing the proliferation of B cells incubated with $0.1,1$, and $10 \mu \mathrm{M}$ ruxolitinib. These histograms are representative for 4 donors. $b$. The percentage of proliferating $B$ cells after incubation with ruxolitinib. c, d. The level of B cell activation by means of CD25 and CD69 expression after incubation with $0.1,1$, and $10 \mu \mathrm{M}$ ruxolitinib. The values are displayed as mean fluorescent intensity (MFI). Mann-Whitney t-test, $\mathrm{P}<0.05\left({ }^{*}\right)$. 
incubated with ruxolitinib showed a dose-dependent decrease in proliferation by means of the number of dividing cell peaks (Figure 1a). In addition, we showed that the percentage of proliferating $B$ cells is significant reduced in the conditions with 1 and $10 \mu \mathrm{M}$ ruxolitinib as compared to the control and $0.1 \mu \mathrm{M}$ condition ( $\mathrm{P}<0.05$; Figure $\mathbf{1 b}$ ). The $\mathrm{B}$ cells that were incubated with $10 \mu \mathrm{M}$ ruxolitinib demonstrated less activation by means of CD25 and CD69 MFI levels as compared to the control $(P<0.05$; Figure $1 \mathbf{c}, \mathbf{d})$. The conditions with 0.1 and 1 $\mu \mathrm{M}$ ruxolitinib were not different from the control. In addition to ruxolitinib, we observed a similar dose-dependent decrease of proliferation and activation with fedratinib (Figure 2). Furthermore, we noticed an increased cell death in the conditions with $10 \mu \mathrm{M}$ ruxolitinib

a

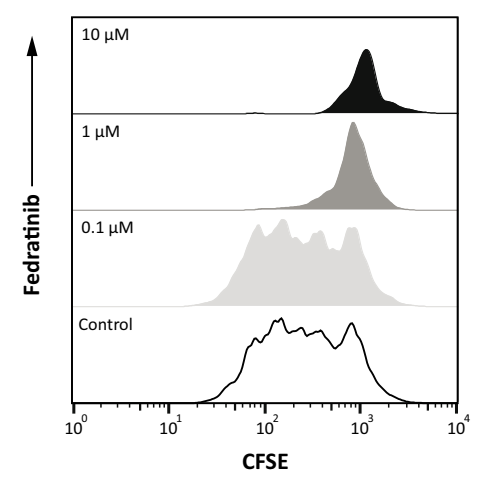

C

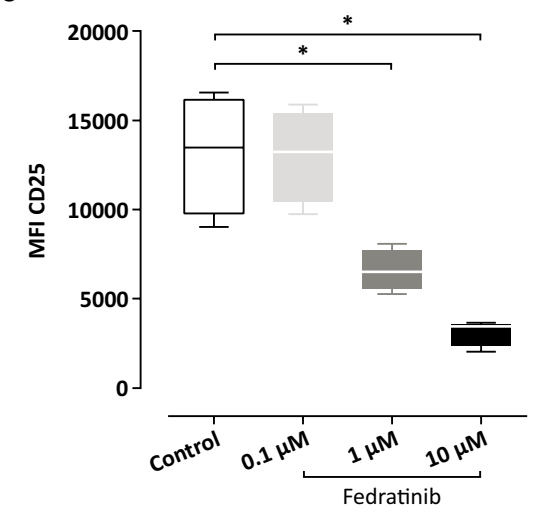

b

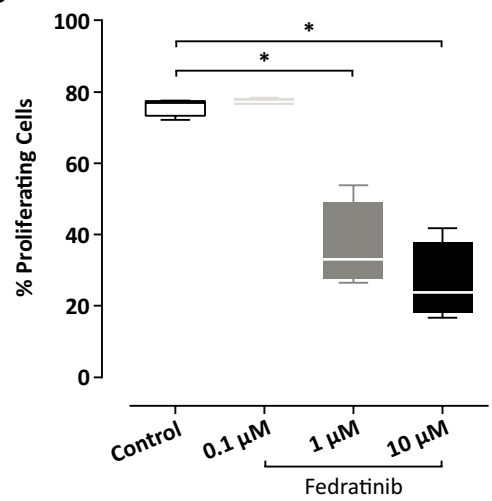

d

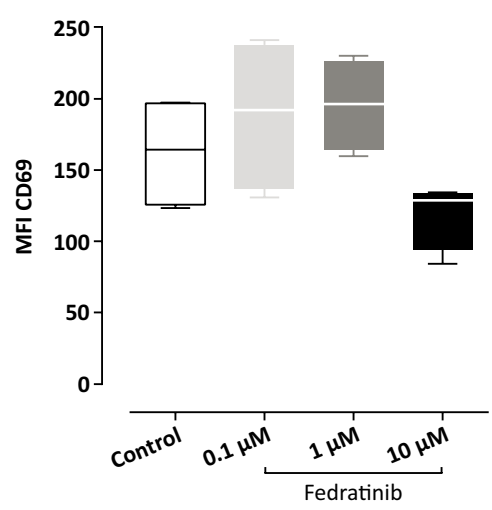

Figure 2: The effect of JAK2 inhibitor fedratinib on the proliferation and activation of polyclonally stimulated peripheral B cells determined with flow cytometry. The experimental procedure is described in the legend of Figure 1. a. Overlay of CFSE histograms representing the proliferation of B cells incubated with $0.1,1$, and $10 \mu \mathrm{M}$ fedratinib. These histograms are representative for 4 donors. b. The percentage of proliferating $B$ cells after incubation with fedratinib. $c$, d. The level of B cell activation by means of CD25 and CD69 expression after incubation with 0.1, 1, and $10 \mu \mathrm{M}$ fedratinib. The values are displayed as mean fluorescent intensity (MFI). Mann-Whitney t-test, $\mathrm{P}<0.05\left({ }^{*}\right)$. 


\section{Chapter 6}

and fedratinib, suggesting a certain level of drug toxicity in the higher concentration range (data not shown). The concentration of $10 \mu \mathrm{M}$ at which in vitro reduced $\mathrm{B}$ cell viability was observed did only slightly differ from the non-toxic plasma concentrations that were found in healthy individuals ${ }^{11,12}$.

We showed that the JAK1/2 inhibitor ruxolitinib and the JAK2 inhibitor fedratinib inhibited $B$ cell proliferation and activation in a dose-dependent manner. Previously Wang et al. reported that another JAK inhibitor (JAK1/3 tofacinitib) suppressed B cell differentiation and class switching while maintaining the regulatory function of $B$ cells ${ }^{13}$. Taken together, these data imply that JAK inhibitors have in addition to their known inhibitory role on T cells and DC also a profound inhibitory effect on the $B$ cell response. This effect may represent an additional mechanism how JAK inhibitors interfere with cGVHD. Therefore, these agents might be the first drug that work on all the relevant immunological pathways that are known in cGVHD. Notably, our study has its limitations by means of the B cell stimulation cocktail that contains IL-21, which signals via the JAK-STAT pathway. Though, it is currently unknown whether similar pathways are active in patients with cGVHD. Therefore, we are planning to analyse whether B cell activity can be blocked in patients with cGVHD and whether specific pathways that are involved in B cell proliferation can be blocked via JAK inhibition. We also observed more cell death (drug toxicity) in the $10 \mu \mathrm{M}$ concentration of both JAK inhibitors, however the type of cell death (e.g. apoptosis or necrosis) should be further elucidated. Our observations may also shed new light on the mechanism behind the therapeutic effects of JAK inhibitors in autoimmune diseases such as rheumatoid arthritis and systemic lupus erythematous ${ }^{14,15}$. Additionally, these data can open novel therapeutic approaches in other B cell-related diseases.

\section{ACKNOWLEDGEMENTS}

The authors would like to thank Niken Mahaweni for her technical contribution.

\section{REFERENCES}

1. Socie G, Stone JV, Wingard JR, et al. Long-term survival and late deaths after allogeneic bone marrow transplantation. Late Effects Working Committee of the International Bone Marrow Transplant Registry. N Engl J Med. 1999;341(1):14-21.

2. Sarantopoulos S, Ritz J. Aberrant B-cell homeostasis in chronic GVHD. Blood. 2015;125(11):1703-1707. 
3. Miklos DB, Kim HT, Miller KH, et al. Antibody responses to $\mathrm{H}-\mathrm{Y}$ minor histocompatibility antigens correlate with chronic graft-versus-host disease and disease remission. Blood. 2005;105(7):2973-2978.

4. Cutler C, Kim HT, Bindra B, et al. Rituximab prophylaxis prevents corticosteroid-requiring chronic GVHD after allogeneic peripheral blood stem cell transplantation: results of a phase 2 trial. Blood. 2013;122(8):1510-1517.

5. Harrison C, Kiladjian JJ, Al-Ali HK, et al. JAK inhibition with ruxolitinib versus best available therapy for myelofibrosis. N Engl J Med. 2012;366(9):787-798.

6. Quintas-Cardama A, Kantarjian H, Cortes J, Verstovsek S. Janus kinase inhibitors for the treatment of myeloproliferative neoplasias and beyond. Nat Rev Drug Discov. 2011;10(2):127-140.

7. Spoerl S, Mathew NR, Bscheider M, et al. Activity of therapeutic JAK $1 / 2$ blockade in graft-versus-host disease. Blood. 2014;123(24):3832-3842.

8. Betts BC, Abdel-Wahab $\mathrm{O}$, et al. Janus kinase-2 inhibition induces durable tolerance to alloantigen by human dendritic cell-stimulated T cells yet preserves immunity to recall antigen. Blood. 2011;118(19):5330-5339.

9. Heine A, Held SA, Daecke SN, et al. The JAK-inhibitor ruxolitinib impairs dendritic cell function in vitro and in vivo. Blood. 2013;122(7):1192-1202.

10. Papin JA, Palsson BO. The JAK-STAT signaling network in the human B-cell: an extreme signaling pathway analysis. Biophys J. 2004;87(1):37-46.

11. Shi JG, Chen X, McGee RF, et al. The pharmacokinetics, pharmacodynamics, and safety of orally dosed INCB018424 phosphate in healthy volunteers. J Clin Pharmacol. 2011;51(12):1644-1654.

12. Zhang $M, X u C R$, Shamiyeh $E$, et al. A randomized, placebo-controlled study of the pharmacokinetics, pharmacodynamics, and tolerability of the oral JAK2 inhibitor fedratinib (SAR302503) in healthy volunteers. J Clin Pharmacol. 2014;54(4):415-421.

13. Wang SP, Iwata S, Nakayamada S, Sakata K, Yamaoka K, Tanaka Y. Tofacitinib, a JAK inhibitor, inhibits human B cell activation in vitro. Ann Rheum Dis. 2014;73(12):2213-2215.

14. Boyle DL, Soma K, Hodge J, et al. The JAK inhibitor tofacitinib suppresses synovial JAK1-STAT signalling in rheumatoid arthritis. Ann Rheum Dis. 2015;74(6):1311-1316.

15. Goropevsek A, Holcar M, Avcin T. The Role of STAT Signaling Pathways in the Pathogenesis of Systemic Lupus Erythematosus. Clin Rev Allergy Immunol. 2016. 


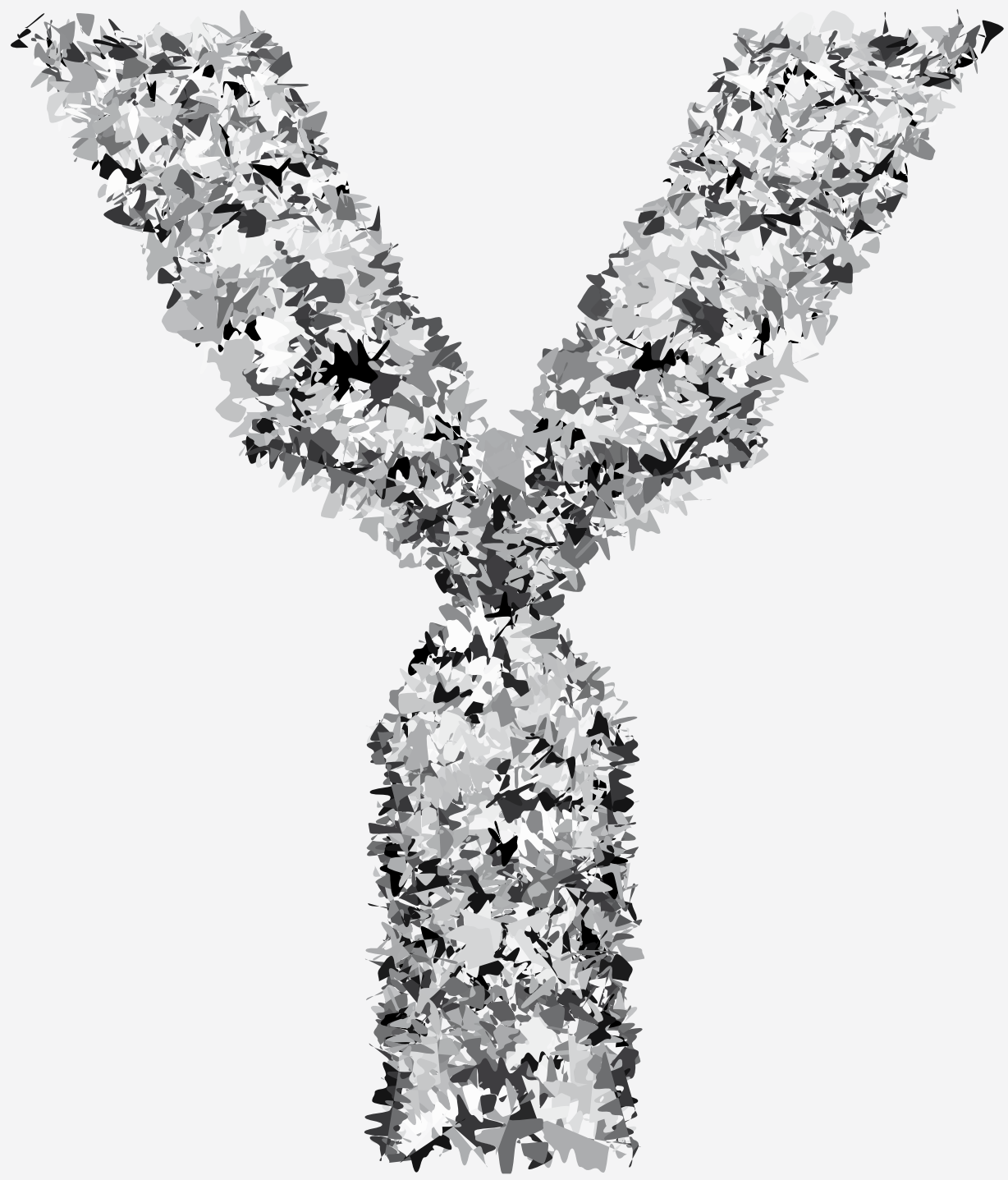




\section{CHAPTER

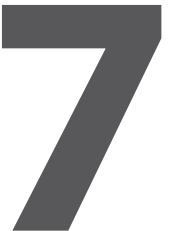

\section{Serum free light chain immunoglobulins (sFLC Igs) do not modulate the activation and proliferation of polyclonally stimulated $B$ cells and T cells}

Thomas H.P.M. Habets ${ }^{1,2}$, Melanie C.A. Schnijderberg ${ }^{1}$, Jan Damoiseaux ${ }^{3}$, Frank A. Redegeld 4 , Marcel G.J. Tilanus ${ }^{2}$, Joris Vanderlocht ${ }^{2}$, Gerard M.J. Bos ${ }^{1,5}$

1 Division of Hematology, Department of Internal Medicine, MUMC+, Maastricht

2 Tissue Typing Laboratory, Department of Transplantation Immunology, MUMC+, Maastricht

3 Central Diagnostic Laboratory, Cluster for Celldiagnostics and Celltherapy, MUMC+, Maastricht

4 Utrecht Institute for Pharmaceutical Sciences, Utrecht University, Utrecht

5 CiMaas BV, Maastricht

Submitted for publication 


\section{Chapter 7}

\section{ABSTRACT}

Kappa ( $\mathrm{k}$ ) and lambda ( $\lambda$ ) free light chain immunoglobulins (FLC Igs) are overproduced during regular antibody synthesis. To maintain normal levels of FLC Igs in the serum (sFLC Igs), there is rapid renal clearance. Although, patients with chronic kidney disease (CKD) and multiple myeloma (MM) show an increased SFLC Ig level, there is limited knowledge about possible biological functions of sFLC Igs. However, it has been shown that SFLC Igs bind to B cells and T cells. We examined whether sera from CKD and MM patients with increased sFLC Ig levels modulate the activation and proliferation of B cells and T cells. Furthermore, we determined whether purified SFLC Igs have an immunomodulatory role on B cells and T cells. We showed that high sFLC Ig levels in sera from CKD and MM patients did not influence the activation and proliferation of B cells and T cells. Additionally, we showed that purified $\mathrm{k}$ and $\lambda \mathrm{sFLC}$ Igs did not affect the activation and proliferation of $B$ cells and $T$ cells at physiologically relevant doses. In conclusion, purified SFLC Igs and increased SFLC Ig levels in sera from patients did not modulate the activation and proliferation of $B$ cells and $T$ cells. 


\section{INTRODUCTION}

In normal antibody synthesis, the produced antibodies each consist of two identical heavy chains and two identical light chains linked together with disulphide bonds ${ }^{1}$. There are two light chains isotypes, kappa $(\kappa)$ and lambda $(\lambda)$. Each antibody contains only one of these isotypes. In contrast to heavy chains, light chains are overproduced in the range of $10-40 \%$ by normal differentiated B cells and plasma cells ${ }^{2}$. Excess light chains can be found in all body fluids, and in the blood these are defined as serum free light chain immunoglobulins ( $\mathrm{FFLC}$ Igs). The $\mathrm{k}$ and $\lambda \mathrm{sFLC}$ Igs show rapid renal clearance via megalin and cubilin scavenger receptors that are located in the proximal tubules of the nephrons ${ }^{3,4}$. This results in a half-life of 2-4 ( $\mathrm{k}$ ) and 3-6 ( $\lambda$ ) hours as compared to 20-25 days of an intact immunoglobulin $\mathrm{G}$ (IgG). Using automatic immunoassays, Katzmann et al. described the reference levels for $\mathrm{k}$ and $\lambda$ sFLC Igs as follows: $\mathrm{k} 3.3-19.4 \mu \mathrm{g} / \mathrm{mL} ; \lambda$ 5.7-26.3 $\mu \mathrm{g} / \mathrm{mL} ; \mathrm{k} / \lambda$ ratio 0.26-1.65 ${ }^{5}$.

Importantly, the amount of circulating $\mathrm{SFLC}$ Igs depends on the balance of antibody synthesis and renal clearance. This balance can be affected by many factors such as diseases that target the production or the clearance of these SFLC Igs. To this end, a wide variety of diseases show increased sFLC Ig levels in biological fluids. These include multiple myeloma (MM), chronic kidney disease (CKD), idiopathic pulmonary fibrosis, COPD, asthma, Sjögren's syndrome, rheumatoid arthritis, food allergy, systemic lupus erythematosus, and multiple sclerosis ${ }^{6-15}$. We previously demonstrated that CKD stage 5 (CKD5) patients on dialysis had increased SFLC Ig levels that normalized to reference levels within the first week after kidney transplantation (submitted results). Furthermore, such patients respond insufficient to e.g. hepatitis $B$ vaccination, indicating that the immune system is compromised ${ }^{16,17}$. Regarding $M M$, patients display often infectious diseases and their antibody repertoire is relatively limited. To date, the question remains whether elevated SFLC Ig levels in CKD and MM patients play a role in the modulation of immune responses in these disorders.

Currently, there is limited knowledge about the biological properties of sFLC Igs. In a study of Hutchinson et al. it was shown that FLC Igs were able to bind to the cell membranes of B cells, T cells, NK cells, and monocytes ${ }^{18}$. In addition, Thio et al. showed that FLC Igs are also able to bind directly to antigens in allergic inflammation ${ }^{19}$. These data triggered our hypothesis that FLC Igs may have an immunomodulatory role. In this light, Cohen et al. showed that polyclonal FLC Igs, which were isolated from patients on hemodialysis inhibited neutrophil apoptosis in vitro ${ }^{20}$. In addition, Braber et al. found that neutrophils showed 
Chapter 7

increased IL-8 production in vitro after the binding of FLC Igs ${ }^{10}$. Furthermore, Redegeld et al. demonstrated that FLC Igs were able to elicit hapten-specific hypersensitivity reactions in mice. The FLC Igs bound to mast cells resulting in activation and degranulation of these mast cells. Notably, these effects on the mast cells were inhibited by the FLC Ig antagonist F991, which is part of the Tamm-Horsfall protein and FLC Igs are able to bind with high affinity to this protein ${ }^{21}$. To date, the effect of SFLC Igs on other immune cells such as B cells and T cells remains elusive.

Since MM and CKD patients show increased SFLC Ig levels and often have infectious diseases or an insufficient vaccination efficacy respectively, we examined whether sera from these patients modulate the activation and proliferation of B cells and T cells. Furthermore, we studied whether purified sFLC Igs have an immunomodulatory role on the activation and proliferation of $B$ cells and $T$ cells.

\section{MATERIALS AND METHODS}

\section{Serum from transplantation and multiple myeloma patients}

The sera used in this study are defined as left-over from clinical purposes and further use for research aims is in accordance to Dutch ethical regulations. Participants who provided heparin treated blood received written informed consent, which is in accordance to Maastricht UMC ethical regulations.

Kidney transplantation. We selected serum samples (that were routinely taken for antibody assessment purposes) of 4 kidney patients (CKD5) who received kidney transplantation at the transplant center of Maastricht (MUMC). The kidney patients showed elevated K SFLC Ig levels before transplantation (120 [114-124] mg/L) that rapidly normalized to the reference level of $36 \mathrm{mg} / \mathrm{L}$ (12 controls who did not have kidney problems) within the first week after transplantation (26 [22-30] mg/L) (Table 1).

Multiple myeloma. We selected serum samples (routine diagnostics) of 4 patients with MM at MUMC. These patients were selected based on a very high SFLC Ig level before treatment (2225 [977-10040] mg/L) that normalized after treatment to the reference level (15 [11-19] $\mathrm{mg} / \mathrm{L}$ ). The sera (after treatment) were obtained 3 months after the last therapy to prevent treatment-induced effects. We used one serum sample before and after the intervention of the same patient (Table 1). 
Table 1: The kappa ( $\mathrm{k}$ ) or lambda ( $\lambda$ ) sFLC Ig levels measured in CKD and MM patients.

Tx, transplantation. MM, multiple myeloma.

\begin{tabular}{lll}
\hline Patients & \multicolumn{1}{c}{ sFLC Igs (mg/L) } \\
\hline Transplantation & Pre (high) & Post (low) \\
Tx 1 (k) & 117 & 25 \\
Tx 2 (k) & 126 & 33 \\
Tx 3 (k) & 110 & 27 \\
Tx 4 (k) & 122 & 19 \\
\hline Median [Q1-Q3] & $\mathbf{1 2 0 ~ [ 1 1 4 - 1 2 4 ] ~}$ & $\mathbf{2 6}$ [22-30] \\
& & \\
Multiple Myeloma & Pre (high) & Post (low) \\
MM 1 (K) & 16700 & 14 \\
MM 2 (K) & 1070 & 16 \\
MM 3 ( $\lambda$ ) & 884 & 21 \\
MM 4 ( $\lambda$ ) & 3380 & 7 \\
\hline Median [Q1-Q3] & $\mathbf{2 2 2 5 ~ [ 9 7 7 - 1 0 0 4 0 ] ~}$ & $\mathbf{1 5}$ [11-19] \\
\hline
\end{tabular}

\section{Quantification of serum free light chain immunoglobulins (sFLC Igs)}

Transplantation. The sFLC Ig levels were measured using an optimized ELISA-based protocol as described previously ${ }^{13}$.

Multiple myeloma. The SFLC Ig levels were measured during routine diagnostics using the commercial Freelite (The Binding Site, Birmingham, UK) kit according to the manufacturers' protocol. The sFLC Ig values were determined using nephelometry.

\section{Proliferation assay of B cells and T cells}

Peripheral blood mononuclear cells (PBMCs) were isolated from $100 \mathrm{~mL}$ heparin treated blood by Lymphoprep density gradient centrifugation (Axis-Shield, Oslo, Norway). Then, $B$ cells were isolated by negative selection using the human B cell isolation kit II (Miltenyi Biotec, Leiden, The Netherlands), according to the manufacturers' protocol. To ensure a high purification of $B$ cells, the negative isolation was performed twice. The T cells were isolated from PBMCs using sheep red blood cells and were frozen in freezing medium comprising of 40\% AIM-V medium (Gibco, Thermo Scientific, Wilmington, USA), 10\% DMSO (WAK-Chemie, 


\section{Chapter 7}

Steinbach, Germany), and 50\% human serum (Sanquin, Amsterdam, The Netherlands). The isolations resulted in a B cell and T cell purity of $>99 \%$, as determined with CD19 (BD, Breda, The Netherlands) and CD3 (BD) positivity measured with flow cytometry (FC). After isolation or thawing, the cells were labelled with $1 \mu \mathrm{M}$ proliferation marker CFSE (BD). A total of 1 $* 10^{5}$ cells per condition were seeded in 96-well U-bottom plates (Corning, New York, USA) and cultured in AIM-V medium (Gibco). In case of B cells, AIM-V medium was supplemented with $500 \mathrm{ng} / \mathrm{mL}$ anti-CD40 (R\&D Systems, Oxon, UK), 5 mg/mL CpG ODN-2006 (InvivoGen, San Diego, USA), $100 \mathrm{ng} / \mathrm{mL}$ IL-21 (Gibco), and 10\% human serum. In case of T cells, AIM-V medium was supplemented with $1 \mu \mathrm{g} / \mathrm{mL}$ anti-CD3 (BioLegend, San Diego, USA) and 10\% human serum. The purified kappa ( $k$ ) and lambda ( $\lambda$ ) sFLC Igs (AbD Serotec, Biorad, Hercules, USA) were added in the concentrations 5, 50, and $250 \mu \mathrm{g} / \mathrm{mL}$, that correspond to reference levels and elevated levels that were observed in transplant and MM patients. The cells were incubated for 4 days (B cells) and 6 days ( $T$ cells) at $37^{\circ} \mathrm{C}$ in a $5 \% \mathrm{CO}_{2}$ humidified incubator.

\section{Flow cytometry}

The B cells and T cells were analysed for activation markers CD69 and CD25 after stimulation at day 4 (B cells) or day 6 (T cells) using the following antibodies: CD69 APC (FN50, BD) and CD25 PE-Cy7 (M-A251, BD). The cell proliferation was assessed by CFSE detected in the FITC channel (BD). The cells were measured on the FACSCanto II flow cytometer and analysed using FACSDiva v.6.0 (BD) and FlowJo software v.10 (FlowJo, Ashland, USA). Living cells were gated by 7-AAD PerCp (BD) exclusion.

\section{Figures and statistics}

The statistical analyses were performed in GraphPad Prism Pro v.6.01 (GraphPad Software, La Jolla, CA, USA). The GraphPad Prism graphs and FlowJo histograms were combined in Adobe Illustrator (Adobe Systems, San Jose, CA, USA). The Mann-Whitney t-test was used to determine a statistical significance between the controls and all conditions. The values are displayed as median and range [quartile 1 - quartile 3]. For all data, a P value of $<0.05(*)$ was considered to be significant. The P-values $<0.01$ were graphically presented as $\left({ }^{* *}\right)$. 
sFLC Igs do not modulate the activation and proliferation of $B$ cells and $T$ cells

\section{RESULTS AND DISCUSSION}

\section{The effect of sera from CKD and MM patients with increased sFLC Ig levels on the activation and proliferation of $B$ cells and $T$ cells.}

In order to examine whether increased SFLC Ig levels in CKD and MM patients play a role in the modulation of immune responses, we incubated $B$ cells and $T$ cells with sera from these patients having increased and normal sFLC Ig levels. The cells were polyclonally stimulated, and the proliferation (CFSE) and activation (markers CD25 and CD69) were determined using flow cytometry. The values are shown as median and range [quartile 1 to quartile 3].

As shown in Figure 1a, the percentage proliferating B cells declined upon incubation with sera from patients after kidney transplantation (26 [16-38]) and after treatment of MM (35 [19-53]) as compared to the control (57 [48-66]). These sera contained normal levels of sFLC Igs. In contrast, there was no difference in the percentage proliferating B cells upon incubation with sera from patients before and after kidney transplantation (26 [19-56]; 26 [16-38]) or before and after treatment of MM (41 [28-58]; 35 [19-53]). With regard to T cells (Figure 1d), the percentage of proliferating $T$ cells declined upon incubation with sera from patients after kidney transplantation (28 [10-53]) as compared to the control (63 [5883]). Likewise, the percentage of proliferating $T$ cells declined upon incubation with sera from patients after transplantation (28 [10-53]) as compared to before transplantation (63 [38-78]). As shown in Figure $\mathbf{1 b}$, $\mathbf{c}$, the $B$ cell activation indicated by the expression of CD25 and CD69 was not affected upon incubation with sera from patients before (15981 [1417223629]; 366 [301-476]) and after (15047 [13230-17155]; 339 [272-474]) transplantation or before (13233 [11972-18001]; 336 [284-490]) and after (14215 [11031-18306]; 407 [295-493]) MM treatment. Regarding T cells (Figure 1e, f), the expression of CD25 was not different as compared to the control upon incubation with sera from patients. Nevertheless, we observed a decreased CD25 expression of T cells incubated with sera from patients after kidney transplantation (33589 [11868-40634]) as compared to before kidney transplantation (62397 [46916-75817]). Although the CD69 expression was increased upon incubation with sera from patients before (891 [441-1053]) and after (616 [138-1021]) transplantation as compared to the control (165 [0-550]), there was no difference between the transplant sera.

Taken together, we observed that sera from transplant and MM patients with either high and normal sFLC Ig levels did not affect the activation and proliferation of B cells. Only T cells incubated with sera from transplant patients displayed a decreased proliferation and 
a

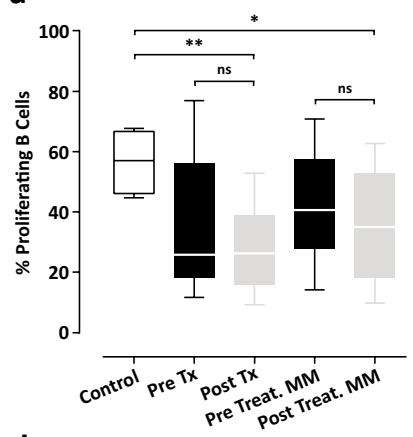

d

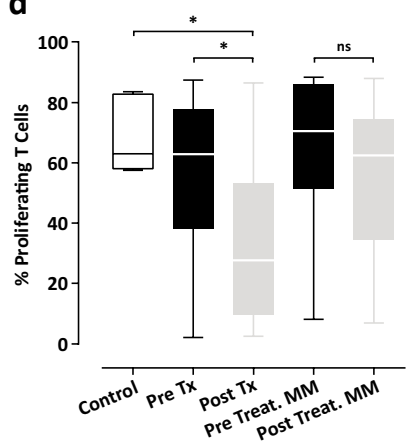

b

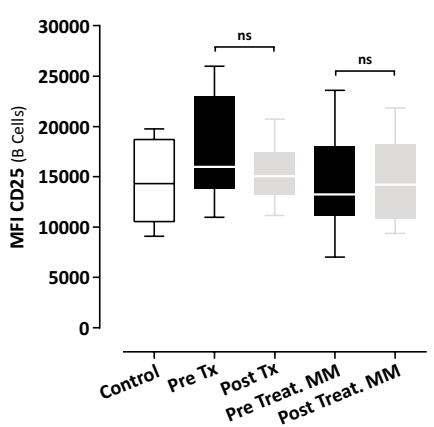

e

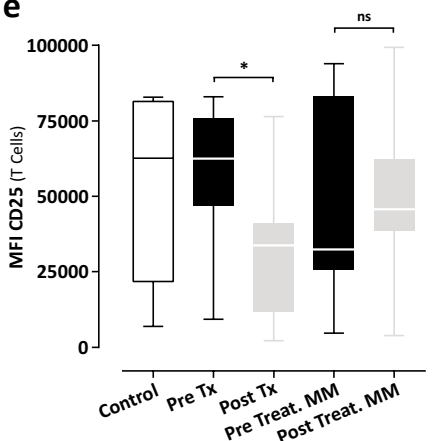

c

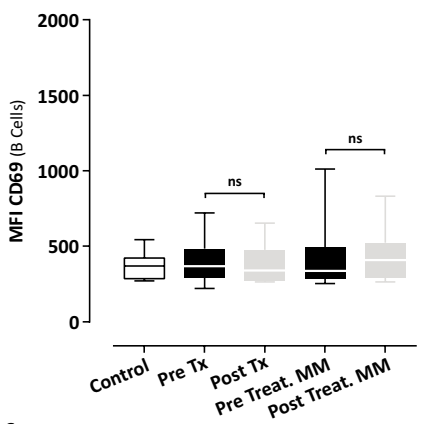

f

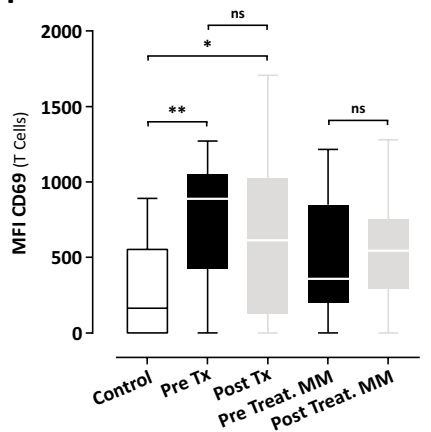

Figure 1: The effect of serum from transplant and MM patients with elevated and normal sFLC Ig levels on the activation and proliferation of peripheral B cells and T cells. B and T cells from 4 healthy donors were incubated for 4 and 6 days respectively with serum only or serum from transplant or MM patients. One sample represents elevated sFLC Ig levels (Pre) and one sample represents normal sFLC Ig levels (Post). a. The fraction proliferating B cells displayed as percentage (CFSE). b, c. The mean fluorescent intensity (MFI) values of B cell activation markers CD25 and CD69. d. The fraction proliferating T cells displayed as percentage (CFSE). e, f. The mean fluorescent intensity (MFI) values of T cell activation markers CD25 and CD69. All data are shown as boxplots (median and range) and are from one experiment representative for two independent experiments. Mann-Whitney t-test. $P<0.05$ *, $\mathrm{P}<0.01^{* *}$. ns, not significant. pre, before. post, after. treat, treatment.

CD25 expression after transplantation as compared to before transplantation. Nevertheless, these transplant patients received immunosuppressive drugs such as mycophenolate mofetil (MMF), tacrolimus, and corticosteroids that inhibit the activation and proliferation of $\mathrm{T}$ cells to prevent acute graft rejection ${ }^{22}$.

Furthermore, stimulated B cells and T cells incubated with sera from patients after kidney transplantation or treatment for MM (normal sFLC Ig levels) displayed a decreased activation (CD69 of T cells) and proliferation as compared to the control. This suggests that SFLC Igs are most likely not responsible for the declined activation and proliferation of $B$ cells and T cells. Likewise, the elevated SFLC Ig levels in sera from kidney and MM patients 
are probably not modulating the activation and proliferation of B cells and T cells. Although, these observations suggest that SFLC Igs in sera from patients do not have an effect on the activation and proliferation of B cells and T cells, we incubated stimulated B cells and $T$ cells with purified (unconjugated) $\mathrm{k}$ and $\lambda \mathrm{sFLC}$ Igs.

\section{Purified sFLC Igs did not affect the activation and proliferation of B cells and T cells.}

In order to investigate whether kappa $(\kappa)$ and lambda $(\lambda)$ sFLC Igs have immunomodulatory effects on the activation and proliferation of B cells and T cells, we incubated these cells with purified kappa ( $\mathrm{k}$ ) and lambda ( $\lambda$ ) sFLC Igs in our proliferation assay. The values are shown as median and range [quartile 1 to quartile 3].

As shown in Figure $\mathbf{2} \mathbf{a}$ and $\mathbf{3 a}$, the proliferation (as assessed by the dividing peaks of CFSE) showed no difference between the concentrations 5, 50, and $250 \mu \mathrm{g} / \mathrm{mL}$ purified sFLC Igs as compared to the control for B cells and T cells. Likewise, the percentage proliferating B cells incubated with 5 (68 [58-76]), 50 (66 [54-75]), and 250 (65 [34-75]) $\mu \mathrm{g} / \mathrm{mL}$ purified sFLC Igs was not affected as compared to the control (57 [48-66]) (Figure 2b). The proliferation was also not affected for T cells that were incubated with 5 (65 [46-78]), 50 (73 [57-84]), and 250 (76 [58-88]) $\mu \mathrm{g} / \mathrm{mL}$ purified sFLC Igs (control 63 [58-83]) (Figure 3b). To study the B cell and T cell activation, we evaluated activation markers CD25 and CD69. The mean fluorescent intensity (MFI) values of CD25 and CD69 were not different in the conditions with 5 (15483 [13731-19010]; 266 [240-339]), 50 (16115 [13450-19674]; 319 [273-442]), and 250 (13754 [12122-17889]; 342 [270-422]) $\mu \mathrm{g} / \mathrm{mL}$ purified sFLC Igs as compared to the control (14329 [11229-18685]; 368 [288-412]) for B cells (Figure 2c, d). Regarding T cells, the MFI values of CD25 and CD69 were not different in the conditions with 5 (42434 [21598-75034]; 98 [0272]), 50 (58450 [30118-77072]; 293 [17-366]), and 250 (82759 [48517-89982]; 649 [2201150]) $\mu \mathrm{g} / \mathrm{mL}$ purified sFLC Igs as compared to the control (62530 [23500-79918]; 165 [0550]) (Figure 3c, d).

Taken together, we show that purified (unconjugated) $\mathrm{k}$ and $\lambda$ sFLC Igs did not affect the activation and proliferation of polyclonally stimulated B cells and T cells. Although other studies suggested that SFLC Igs may have an immunomodulatory role ${ }^{18,19}$, we observed that the addition of these purified SFLC Igs did not affect the activation and proliferation at different physiologically relevant doses. In this study, we focussed only on the capacity of B cells and $T$ cells to become activated and start proliferation, therefore other properties of these purified SFLC Igs on B cells and T cells cannot be excluded. The group of Hutchinson 


\section{Chapter 7}

a

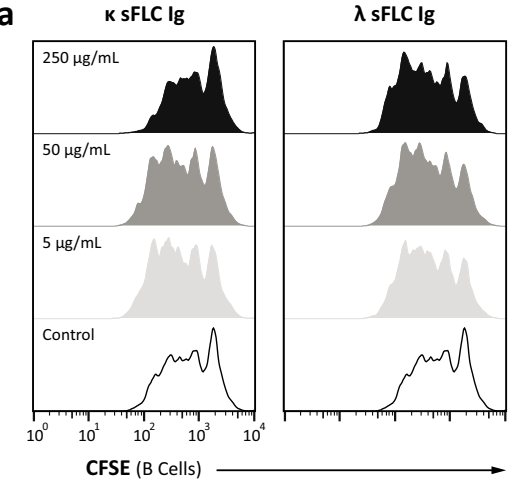

C

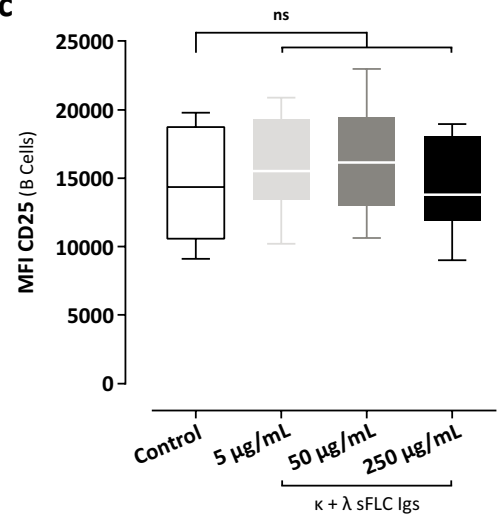

b

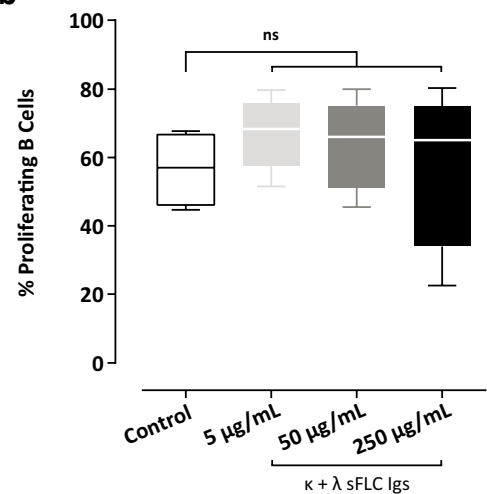

d

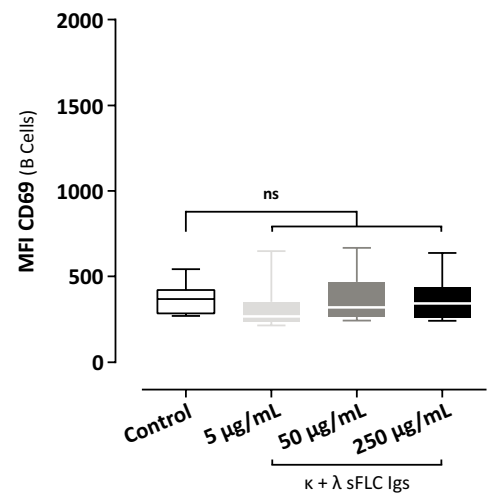

Figure 2: The effect of $\mathrm{k}$ and $\lambda \mathrm{sFLC}$ Igs on the activation and proliferation of polyclonally stimulated peripheral B cells. B cells from 4 healthy donors were incubated for 4 days with serum only or serum supplemented with 5,50 , and $250 \mu \mathrm{g} / \mathrm{mL}$ purified kappa ( $\mathrm{k}$ ) or lambda ( $\lambda$ ) sFLC Igs. a. The proliferation of B cells by means of CFSE intensity (representative for 4 donors). b. The fraction proliferating B cells displayed as percentage (CFSE). c, d. The mean fluorescent intensity (MFI) values of B cell activation markers CD25 and CD69. All data are shown as boxplots (median and range) and are from one experiment representative for two independent experiments. Mann-Whitney t-test. ns, not significant.

et al. reported that SFLC Igs were able to interact with saturated phosphocholine lipids such as sphingomyelin, which are abundant on eukaryotic membranes ${ }^{23}$. In subsequent research, they demonstrated that SFLC Igs are able to bind to B cells and T cells, nevertheless, the biological function(s) and the receptor where these sFLC Igs bind too remain elusive ${ }^{18,19}$. In this latter study, they also demonstrated that sFLC Igs bound more to monocytes, which may have a role in uptake and presentation of antigens by these professional antigen presenting cells (APCs). With respect to this, Thio et al. showed that sFLC Igs were able to bind antigenspecific, supporting the hypothesis that monocytes loaded with SFLC Igs are more prone to 

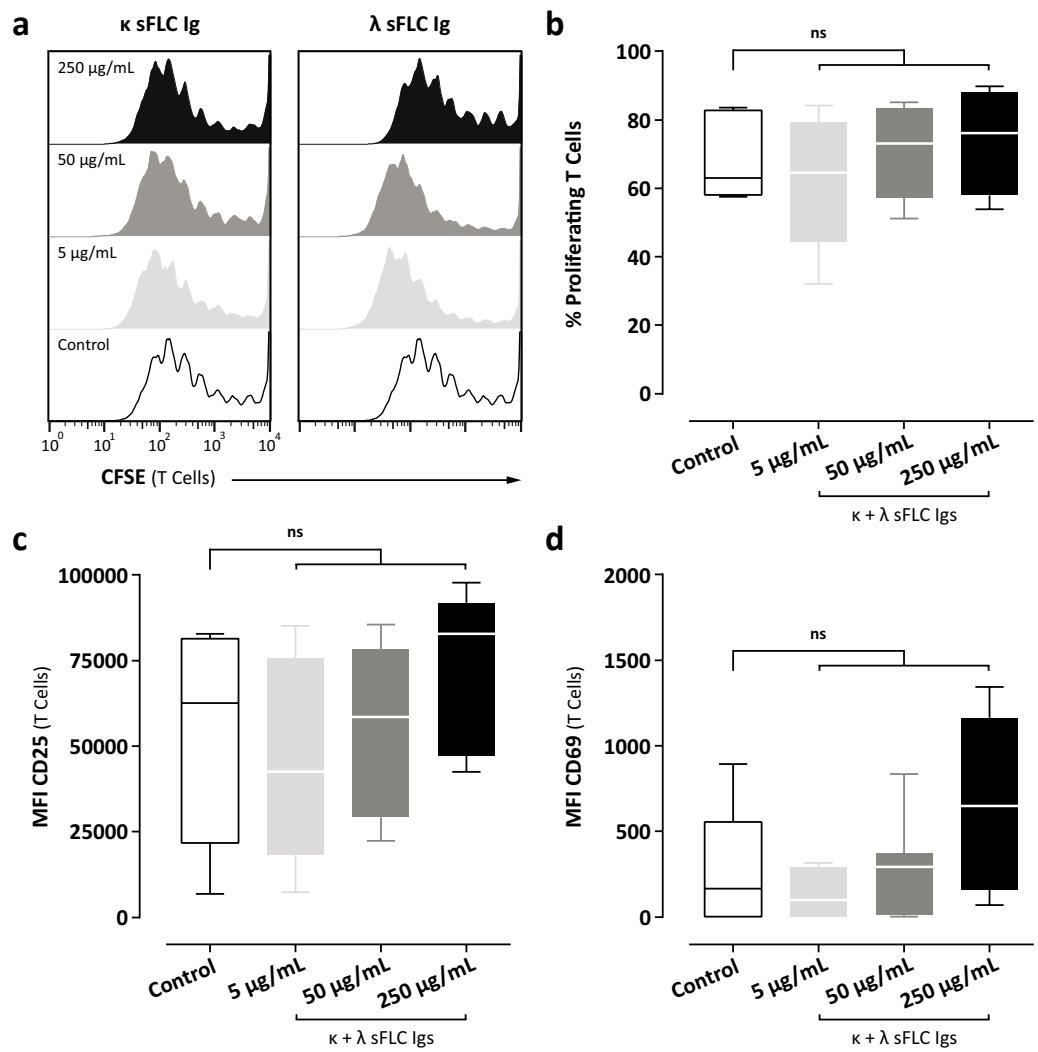

Figure 3: The effect of $\mathrm{k}$ and $\boldsymbol{\lambda}$ sFLC Igs on the activation and proliferation of polyclonally stimulated peripheral T cells. T cells from 4 healthy donors were incubated for 6 days with serum only or serum supplemented with 5,50 , and $250 \mu \mathrm{g} / \mathrm{mL}$ purified kappa ( $\mathrm{k}$ ) or lambda ( $\lambda$ ) sFLC Igs. a. The proliferation of T cells by means of CFSE intensity (representative for 4 donors). b. The fraction proliferating $T$ cells displayed as percentage (CFSE). c, d. The mean fluorescent intensity (MFI) values of T cell activation markers CD25 and CD69. All data are shown as boxplots (median and range) and are from one experiment representative for two independent experiments. Mann-Whitney t-test. ns, not significant.

capture, internalize, and ultimately present antigens ${ }^{19}$. Although SFLC Igs are able to bind to $\mathrm{B}$ cells, only the $\mathrm{k}$ SFLC Igs showed similar binding levels as compared to monocytes. The increased binding of these $\mathrm{k}$ SFLC Igs may be a result of their monomeric conformation, as $\lambda$ sFLC Igs are dimeric. Interestingly, B cells are also APCs and are able to present their antigens to $T$ cells. These data hint on a role in the initiation of immune responses by the means of antigen uptake and presentation, rather than interfering with an ongoing response. Furthermore, we polyclonally stimulated B cells and T cells with cocktails containing antiCD40, CpG ODNs, and IL-21 or anti-CD3 respectively, which may interfere with relevant sFLC 


\section{Chapter 7}

Ig-related pathways. Therefore, possible immunomodulatory effects may not be observed. In addition, the protein conformation of the purified $\mathrm{k}$ and $\lambda \mathrm{sFLC}$ Igs may be of influence to elicit a downstream effect in B cells and T cells. In future, to understand the biological role of SFLC Igs, we may focus on the antigen uptake and presentation capacity of in particular $B$ cells.

In conclusion, we showed that purified $\mathrm{k}$ and $\lambda$ sFLC Igs did not influence the activation and proliferation of polyclonally stimulated $B$ cells and $T$ cells at different physiologically relevant doses. Additionally, the sFLC Igs present in sera from kidney and MM patients are most likely not responsible for the effects on the activation and proliferation of $B$ cells and $T$ cells.

\section{ACKNOWLEDGEMENTS}

The authors would like to thank Stefan Molenbroeck and Annelie Stoop for their technical assistance.

\section{REFERENCES}

1. Edelman GM, Gall WE, Waxdal MJ, Konigsberg WH. The covalent structure of a human gamma G-immunoglobulin. I. Isolation and characterization of the whole molecule, the polypeptide chains, and the tryptic fragments. Biochemistry. 1968;7(5):1950-1958.

2. Bradwell AR. Serum Free Light Chain Analysis. Birmingham: The Binding Site Ltd.; 2010.

3. Basnayake K, Stringer SJ, Hutchison CA, Cockwell P. The biology of immunoglobulin free light chains and kidney injury. Kidney Int. 2011;79(12):1289-1301.

4. Christensen EI, Birn H. Megalin and cubilin: multifunctional endocytic receptors. Nat Rev Mol Cell Biol. 2002;3(4):256-266.

5. Katzmann JA, Clark RJ, Abraham RS, et al. Serum reference intervals and diagnostic ranges for free kappa and free lambda immunoglobulin light chains: relative sensitivity for detection of monoclonal light chains. Clin Chem. 2002;48(9):1437-1444.

6. Gottenberg JE, Aucouturier F, Goetz J, et al. Serum immunoglobulin free light chain assessment in rheumatoid arthritis and primary Sjogren's syndrome. Ann Rheum Dis. 2007;66(1):23-27.

7. Dispenzieri A, Kyle R, Merlini G, et al. International Myeloma Working Group guidelines for serum-free light chain analysis in multiple myeloma and related disorders. Leukemia. 2009;23(2):215-224.

8. Desjardins L, Liabeuf $\mathrm{S}$, Lenglet $\mathrm{A}$, et al. Association between free light chain levels, and disease progression and mortality in chronic kidney disease. Toxins (Basel). 2013;5(11):2058-2073.

9. Groot Kormelink T, Pardo A, Knipping K, et al. Immunoglobulin free light chains are increased in hypersensitivity pneumonitis and idiopathic pulmonary fibrosis. PLoS One. 2011;6(9):e25392.

10. Braber S, Thio M, Blokhuis BR, et al. An association between neutrophils and immunoglobulin free light chains in the pathogenesis of chronic obstructive pulmonary disease. Am J Respir Crit Med. 2012;185(8):817-824.

11. Kraneveld $A D$, Kool $M$, van Houwelingen $A H$, et al. Elicitation of allergic asthma by immunoglobulin free light 
chains. Proc Natl Acad Sci U S A. 2005;102(5):1578-1583.

12. Schouten $B$, van Esch BC, van Thuijl AO, et al. Contribution of IgE and immunoglobulin free light chain in the allergic reaction to cow's milk proteins. J Allergy Clin Immunol. 2010;125(6):1308-1314.

13. Kormelink TG, Tekstra J, Thurlings RM, et al. Decrease in immunoglobulin free light chains in patients with rheumatoid arthritis upon rituximab (anti-CD20) treatment correlates with decrease in disease activity. Ann Rheum Dis. 2010;69(12):2137-2144.

14. Hopper JE, Golbus J, Meyer C, Ferrer GA. Urine free light chains in SLE: clonal markers of B-cell activity and potential link to in vivo secreted Ig. J Clin Immunol. 2000;20(2):123-137.

15. Dobson R, Miller RF, Palmer HE, et al. Increased urinary free immunoglobulin light chain excretion in patients with multiple sclerosis. J Neuroimmunol. 2010;220(1-2):99-103.

16. Wong PN, Fung TT, Mak SK, et al. Hepatitis B virus infection in dialysis patients. J Gastroenterol Hepatol. 2005;20(11):1641-1651.

17. Stevens CE, Alter HJ, Taylor PE, Zang EA, Harley EJ, Szmuness W. Hepatitis B vaccine in patients receiving hemodialysis. Immunogenicity and efficacy. N Engl J Med. 1984;311(8):496-501.

18. Hutchinson AT, Jones DR, Raison RL. The ability to interact with cell membranes suggests possible biological roles for free light chain. Immunol Lett. 2012;142(1-2):75-77.

19. Thio M, Groot Kormelink T, Fischer MJ, Blokhuis BR, Nijkamp FP, Redegeld FA. Antigen binding characteristics of immunoglobulin free light chains: crosslinking by antigen is essential to induce allergic inflammation. PLoS One. 2012;7(7):e40986.

20. Cohen G, Rudnicki M, Deicher R, Horl WH. Immunoglobulin light chains modulate polymorphonuclear leucocyte apoptosis. Eur J Clin Invest. 2003;33(8):669-676.

21. Redegeld FA, van der Heijden MW, Kool M, et al. Immunoglobulin-free light chains elicit immediate hypersensitivity-like responses. Nat Med. 2002;8(7):694-701.

22. Meier-Kriesche HU, Li S, Gruessner RW, et al. Immunosuppression: evolution in practice and trends, $1994-$ 2004. Am J Transplant. 2006;6(5 Pt 2):1111-1131.

23. Hutchinson AT, Ramsland PA, Jones DR, et al. Free lg light chains interact with sphingomyelin and are found on the surface of myeloma plasma cells in an aggregated form. J Immunol. 2010;185(7):4179-4188. 


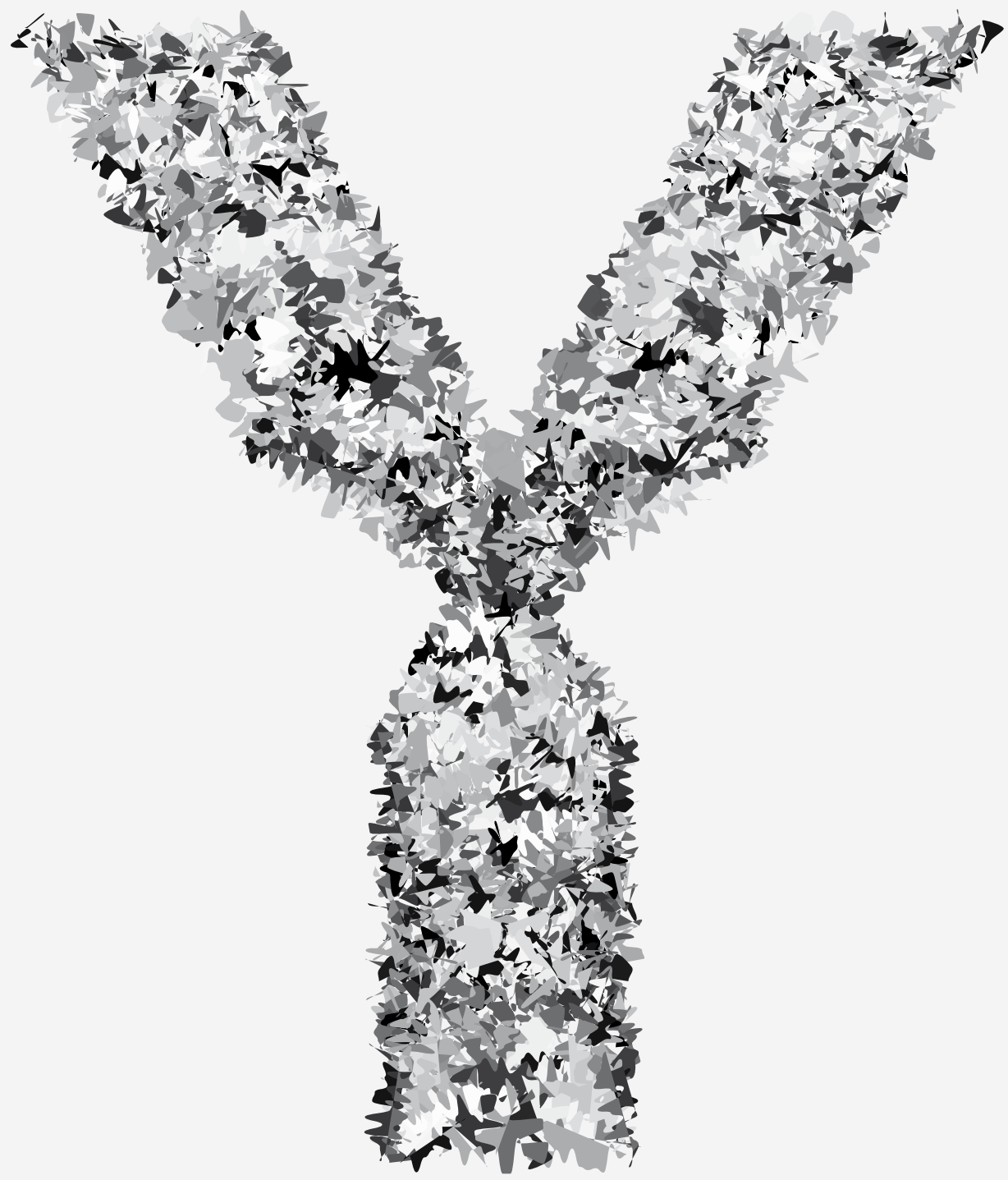




\section{CHAPTER

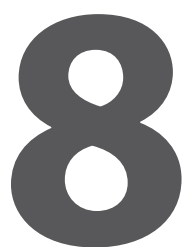

\section{General discussion}

The exposure to foreign antigens activates $B$ cells

The usage of B cells and their secreted antibodies as biomarker

The stimulation or inhibition of B cells and their effector functions

Conclusions 



\section{INTRODUCTION}

The main aim of this thesis was to investigate to what extent B cells are activated to produce antibodies after exposure to foreign antigens during (kidney) transplantation, whether their secreted antibodies can be used as marker after (kidney) transplantation or cancer treatment, and whether $B$ cells and their functions can be influenced in the context of cancer.

The exposure to foreign antigens activates $B$ cells

\section{Chapter 2}

Does RhD incompatible kidney transplantation result in the development of RhD antibodies in a setting of reduced immunosuppression and in absence of anti-RhD prophylaxis?

\section{Chapter 3}

Is HLA-DRB3 and its' allelic diversity immunogenic after kidney transplantation and does this correlate with HLA expression and graft outcome?

The usage of B cells and their secreted antibodies as biomarker

\section{Chapter 4}

Do the dynamics of sFLC Ig normalization after kidney transplantation correlate with markers for kidney function (SCr, MDRD, and $\beta 2-\mathrm{M}$ ) and HLA antibodies?

\section{Chapter 5}

Does fractionated RT in combination with DC stimulation affects a pre-existing humoral anti-tumour response in an animal model to study the abscopal effect?

The stimulation or inhibition of $B$ cells and their effector functions

\section{Chapter 6}

Does JAK1/2 inhibitor ruxolitinib affects the activation and proliferation of B cells?

\section{Chapter 7}

Do unconjugated sFLC Igs or high sFLC Ig levels in sera from CKD and MM patients influence the activation and proliferation of $B$ cells and T cells? 
Chapter 8

\section{The exposure to foreign antigens activates B cells}

Several studies have demonstrated that the graft survival is significantly increased when the recipients and graft donors are matched for HLA and ABO blood group antigens, besides the administration of reduced immunosuppression to the recipients ${ }^{1,2}$.

The polymorphic nature of HLA molecules and blood group antigens creates a major problem when organs are transplanted from donors to recipients. The recognition of foreign antigens by the recipient's immune system generates a barrier for successful graft outcome. After contact with foreign antigens, activated B cells can produce antibodies against minor and major histocompatibility antigens and antibodies against blood group antigens such as RhD. We examined whether HLA-DRB3 is immunogenic, and we assessed the prevalence of RhD antibodies after RhD incompatible kidney transplantation.

To date, there is limited insight in the immunogenicity of the associated HLA-DRB genes such as HLA-DRB3 and their allelic diversity in kidney transplantation. Some studies have proven that HLA-DRB3 is involved in antigen presentation and association studies indicated that these molecules are associated with autoimmune disease ${ }^{3-6}$. In case of neonatal alloimmune thrombocytopenia (NAIT), HLA-DRB3*01:01 is a prerequisite to develop the susceptibility ${ }^{7}$. Although HLA-DRB3 antibodies are frequently detected in patients awaiting transplantation, their clinical relevance in transplantation remains elusive. In chapter $\mathbf{3}$, we determined the prevalence and reactivity of HLA-DRB3 antibodies in kidney patients based on retrospective analysis of a caucasian patient cohort. Additionally, we studied whether these antibodies are correlated with HLA expression and graft outcome.

We estimated that $\pm 7 \%$ of patients on the waiting list develop antibodies against HLA-DRB3. It remains to be established whether this percentage is a good measure in other populations. The antibodies developed as a consequence of kidney transplantation, pregnancy, and transfusion. We identified that $79 \%$ of these patients did not carry the HLA-DRB3 gene and displayed allo-antibodies, whereas $21 \%$ of these patients were HLA-DRB3 gene carriers and displayed intra-allele antibodies against HLA-DRB3. This finding indicated that not only the presence of HLA-DRB3, but also its' allelic diversity is immunogenic.

Kidney transplant recipients with HLA-DRB3 antibodies presented an inferior graft outcome after transplantation than recipients without these antibodies. Though, the clinical relevance should be further evaluated, because most of the recipients developed HLA-DRB3 
antibodies after transplantation. Additionally, $\pm 50 \%$ of these recipients showed HLA-DRB3 antibodies after failure or transplantectomy. Therefore, these antibodies are most likely not involved in graft loss. Likewise, the recipients displayed a high PRA index indicating that HLADRB3 antibodies develop when a broad antibody response is seen. All recipients received a post-mortem donor graft, which is associated with an inferior graft outcome as compared to living donor grafts ${ }^{10}$. A large multi-center study may elucidate the overall prevalence and clinical relevance of these antibodies in (kidney) transplantation.

Moreover, the seven antibody reactivity patterns in the solid phase assays indicated that HLA-DRB3 has multiple epitopes. Most HLA-DRB3 negative patients showed antibody reactivity against all three LSA microbeads, whereas HLA-DRB3 positive patients displayed antibody reactivity against only one or two microbeads. The difference in antibody reactivity suggests that distinctive epitopes are recognized in these groups. Since the proposal that investigating 'immunogenic' epitopes rather than the presence or absence of HLA alleles may be important for proper HLA matching, we provide evidence that HLA-DRB3 has several epitopes that have to be taken into account for epitope matching strategies ${ }^{8}$. A major pitfall for epitope discovery is the limitation of only three LSA microbeads covering the major allele groups of HLA-DRB3. The variability of the amino acid sequence of HLA-DRB3 alleles hints that more positions may determine the immunogenicity of HLA-DRB3. To identify all these immunogenic epitopes, microbeads may be developed that are coated with different HLADRB3 alleles. In this way, epitope matching might be an option to define minimal matching criteria in transplantation ${ }^{8,9}$. The recipients and donors are matched based on the strength of the immunogenic epitopes instead of the presence of HLA alleles.

HLA expression levels might be an important factor underlying antibody formation against HLA-DRB3. We confirmed that the relative mRNA expression of HLA-DRB1 is always higher than HLA-DRB3 ${ }^{11,12}$. However, we showed that the protein expression of HLA-DRB3 differs in individuals, which is dependent on the HLA-DRB1 typing. For example, donors with HLA-DRB1*11 demonstrated a reduced HLA-DRB3 protein expression. Although we made use of frozen splenocytes, which may influence the stability of mRNA and proteins, fresh samples showed similar results. Our observations suggest that an antibody response against a mismatch HLA-DRB3 protein may be dependent on the expression level of the molecule. When we compared the distribution of HLA-DRB3 alleles in the immunizing events, we noted an increased frequency of HLA-DRB3*01 as compared to HLA-DRB3*02 and HLA-DRB3*03 indicating that $H L A-D R B 3^{*} 01$ may be more immunogenic than the other groups. There was 


\section{Chapter 8}

a difference in relative mRNA expression of $H L A-D R B 3^{*} 01$, but this was not reflected in the protein expression of HLA-DRB3. It remains to be established whether a promoter difference or post-transcriptional regulation is involved in the expression (mRNA, protein) of HLA-DRB3.

In (kidney) transplantation, the recipient's immune system is exposed to foreign antigens of the donor graft. To this end, the transplant recipient can be exposed for an extensive time to foreign antigens such as HLA class I antigens that are expressed on all nucleated cells of the graft, and HLA class II antigens that are only present on passenger APCs. In contrast, certain foreign antigens can be present for a short time such as RhD antigens that are expressed on RBCs. We examined whether these antigens can give rise to an antibody response, since RhD antigens are not considered for organ allocation in kidney transplantation. In previous studies, it has been shown that RhD incompatible kidney transplantation leads to the development of RhD antibodies ${ }^{13-15}$. These antibodies can persist for many years in the blood circulation 16. Therefore, transplant recipients who produce these RhD antibodies are at risk to develop hemolytic disease of the fetus and newborn (HDFN) in pregnancies. In chapter $\mathbf{2}$, we studied how frequent $\mathrm{RhD}$ antibodies develop in recipients who received RhD incompatible kidney transplantation in a transplant setting of reduced immunosuppression and in absence of antiRhD prophylaxis.

Our study showed that the development of RhD antibodies after RhD incompatible kidney transplantation is infrequent. The exposure to passenger RBCs in the graft is probably too short and low to induce a robust RhD antibody response in the RhD- kidney recipients. In addition, it has been shown that RhD antibodies are not detrimental for graft outcome ${ }^{19}$. However, since the number of pregnancies is increasing among transplant recipients, it may be advisable to provide anti-RhD prophylaxis to female transplant recipients who want to have a future pregnancy.

We showed that 156 out of 1355 transplant recipients had RhD incompatible kidney transplantation in the time-period 1993-2015. In these 156 recipients, we identified 1 out of 156 (0.6\%) RhD- recipients who developed RhD antibodies after kidney transplantation with a $\mathrm{RhD}+$ graft. This female RhD- transplant recipient had no history of RhD+ blood transfusion or pregnancies, therefore it is most likely that the antibody response against RhD developed as a result of the $\mathrm{RhD}+$ graft. Although this graft was of $\mathrm{DCD}$ origin, probably residual RBCs that were not washed out during machine perfusion were responsible for the generation of RhD antibodies. 
Even in a transplant setting of reduced immunosuppression, we did not observe an increase in RhD antibody formation after RhD incompatible transplantation as compared to existing literature. A previous study showed that 2 out of 42 (5\%) displayed RhD antibodies after RhD incompatible kidney transplantation in the presence of immunosuppressive drugs cyclosporine, prednisolone, and azathioprine ${ }^{13}$. In our study, we only observed 1 out of 156 $(0.6 \%)$ in a transplant setting of reduced immunosuppression.

Furthermore, we observed a high incidence of RhD antibodies (3.2\%) as compared to women who had RhD incompatible pregnancies in the presence of anti-RhD prophylaxis $(0.1-0.3 \%)^{17,18}$. We found that these 5 recipients were all female and had pregnancies, which may be the reason for the presence of RhD antibodies before transplantation. Although RhD antibody formation after RhD incompatible transplantation is infrequent, it is advisable to provide anti-RhD prophylaxis. To this end, it has been suggested that a dose of 500 IU anti$\mathrm{RhD}$ prophylaxis may be sufficient to neutralize $10 \mathrm{~mL}$ of blood, since it is unlikely that more than $10 \mathrm{~mL}$ is present in the graft after (machine) perfusion ${ }^{13}$. In addition, we may include a cost-effectiveness analysis in which we compare the costs of anti-RhD prophylaxis with the treatment of HDFN.

\section{The usage of B cells and their secreted antibodies as biomarker}

There remains a need for superior markers to accurately assess organ function and immune activation status in transplant recipients. Currently, $\mathrm{SCr}$ is used as standard to assess kidney function although its pitfalls as a relatively late marker for kidney damage ${ }^{20}$. We examined whether secreted antibody fragments (sFLC Igs) of B cells can be used as marker for kidney function early after kidney transplantation. Furthermore, markers that provide information on the treatment efficacy in patients with cancer are also required. We studied to what extent anti-tumour antibody levels are invariably associated with abscopal tumour regression, and are modulated by immunotherapy.

We questioned whether secreted antibody fragments of B cells can be used as biomarker for kidney function early after kidney transplantation. In normal antibody synthesis, $\mathrm{k}$ and $\lambda \mathrm{FLC}$ Igs are always overproduced (10 to $40 \%$ ) by B cells and plasma cells ${ }^{21}$. The kidneys reabsorb the secreted serum FLC (sFLC) Igs from the blood. In contrast, patients with kidney failure or on dialysis are not able to maintain normal SFLC Ig levels. After kidney transplantation, it is 


\section{Chapter 8}

crucial to distinguish early rejections and DGF by assessing kidney function. Although some new kidney function markers are proposed, a fast marker to assess kidney function directly after transplantation remains a desired tool to improve transplant outcome. In chapter 4, we studied the dynamics and normalization of $\mathrm{k}$ and $\lambda$ SFLC Igs after kidney transplantation and we determined whether these correlated with SCr, MDRD, $\beta 2-\mathrm{M}$, and HLA antibodies.

The ESRD patients on dialysis maintained elevated $\mathrm{k}$ and $\lambda \mathrm{sFLC}$ Igs, which is in line with literature ${ }^{22,23}$. Conventional dialysis membranes were not able to remove sFLC Igs from the circulation, since the pore size of 10 to $15 \mathrm{kDa}$ is smaller as compared to sFLC Igs $( \pm 25$ to $50 \mathrm{kDa})^{24}$. It has been shown that high cut-off membranes with a pore size of $65 \mathrm{kDa}$ are able to remove sFLC Igs from the blood, however these are not used in conventional dialysis, only in case of MM patients (monoclonal sFLC Igs) ${ }^{25}$. The SFLC Ig levels rapidly normalized after kidney transplantation, which indicated that a functioning kidney is required to retain normal sFLC Ig levels. This also means that the reticulo-endothelial system in the liver is not capable of maintaining normal SFLC Ig levels. Our data on the increased SFLC Ig levels after transplantectomy most likely reflects a sink function of the transplanted graft.

Graft failure can be a consequence of antibody responses against HLA molecules of the donor. Therefore, HLA-specific sFLC Igs may contribute to the total amount of sFLC Igs. Nevertheless, we did not observe a correlation between HLA class I and II antibodies and the total sFLC Ig levels after transplantation. This implies that most of the detected SFLC Igs were not a result of the HLA antibody response against the graft. However, the fact that SFLC Igs are able to bind specific to antigens ${ }^{26}$, it is possible that HLA-specific SFLC Igs contribute to AMR. The SFLC Igs in patients on dialysis are probably polyclonal and therefore not restricted to HLA antibody responses.

We showed that the $\mathrm{K}$ SFLC Ig levels in kidney transplant recipients declined faster as compared to the SCr, MDRD, and $\beta 2-M$ levels after transplantation. In addition, the $\mathrm{K} \mathrm{SFLC} \mathrm{Ig}$ levels even normalized within the first week after transplantation. This observation is further supported by the fact that the $\mathrm{k}$ SFLC Igs displayed moderate correlations with SCr, MDRD, and $\beta 2-\mathrm{M}$. Importantly, complete K SFLC Ig normalization was a hallmark for recipients with IGF, whereas recipients with DGF showed incomplete $\mathrm{k}$ SFLC Ig normalization. It remains to be established in a large prospective study whether $\mathrm{k}$ and $\lambda \mathrm{sFLC}$ Igs are a predictive marker for complete kidney function or graft rejection. Although we showed that $\mathrm{k}$ and $\lambda \mathrm{sFLC}$ Igs normalized within 1 to 3 months (15 recipients), it is unknown whether $\lambda$ sFLC Igs (dimeric conformation) display a similar normalization within the first week after transplantation (48 
recipients). Notably, these recipients received immunosuppression with the aim to inhibit T cells and B cells. However, these drugs may also hamper the antibody synthesis (sFLC Igs) by $B$ cells and plasma cells, which may contribute to the rapid decline and normalization of $k$ sFLC Ig levels after transplantation. Although the serum $\beta 2-\mathrm{M}$ levels may be influenced by the immunosuppressive drugs, there was no normalization and correlation with $\mathrm{k}$ sFLC Igs after transplantation.

We compared the clearance mechanisms of SCr, sFLC Igs, and $\beta 2-\mathrm{M}$ in the nephrons of the kidneys. $\mathrm{SCr}$ is completely excreted in the urine ${ }^{27}$. In contrast, SFLC Igs and $\beta 2-\mathrm{M}$ are for $>99 \%$ reabsorbed by PTECs ${ }^{28}$. In case this system is saturated, the SFLC Igs bind to TammHorsfall proteins and form casts in the distal tubules of the nephrons ${ }^{29}$. These casts lead to injury of the nephrons and subsequently the failed clearance of sFLC Igs results in enhanced nephropathy. After kidney transplantation, the sFLC Ig levels rapidly normalized most likely due to efficient receptor-mediated uptake in the proximal tubules. In case the sFLC Ig levels do not normalize after kidney transplantation, this may reflect kidney damage. However, the correlation of sFLC Igs and kidney damage is unknown. In this light, we may analyse the sFLC Ig levels in the urine, as we cannot exclude that the receptor-mediated uptake (by PTECS) is oversaturated and this results in elevated SFLC Igs in the urine. Importantly, we showed that the dynamics of sFLC Ig normalization is dependent on recipients with IGF or DGF. Although the serum $\beta 2-M$ levels rapidly declined, there was no normalization after transplantation. The different dynamics of sFLC Igs and $\beta 2-\mathrm{M}$ may be explained by the fact that $\mathrm{K}$ and $\lambda \mathrm{sFLC}$ Igs are reabsorbed via two receptors (megalin and cubilin), whether $\beta 2-\mathrm{M}$ is only reabsorbed via one receptor (megalin) ${ }^{30}$.

Although $\mathrm{SCr}$ is measured as 'golden' standard to assess kidney function, it has been shown that $\mathrm{SCr}$ is a late marker for kidney damage and is dependent on different factors ${ }^{20}$. We displayed weak-moderate correlations of SFLC Igs with SCr, MDRD, and $\beta 2-\mathrm{M}$, suggesting that sFLC Igs have limited applicability. However, since sFLC Igs and $\beta 2-\mathrm{M}$ (similar clearance mechanism) showed a rapid decline after kidney transplantation, these proteins may reflect immediate and effective proximal tubular function.

Although abscopal responses are infrequently observed in patients with cancer, it has been shown that this effect is immune-mediated and that T cells play a crucial role in abscopal tumour regression ${ }^{31,32}$. Certain studies implied that additional immune effector mechanisms may contribute to abscopal responses such as humoral immune responses ${ }^{33}$. This response 


\section{Chapter 8}

may be involved in tumour regression and/or may serve as marker to examine whether the applied treatment is effective in a subset of patients. In chapter $\mathbf{5}$, we determined whether fractionated RT alone or combined with Flt3-L administration (DC stimulation) boosts a preexisting humoral anti-tumour response in a mouse model to investigate the abscopal effect. Furthermore, we investigated to what extent humoral anti-tumour responses are invariably associated with abscopal tumour regression.

We showed that fractionated RT (3 x 8Gy) alone or combined with Flt3-L stimulates abscopal responses in the 67NR mouse model. In this animal model, both the irradiated and non-irradiated tumours demonstrated tumour growth inhibition. In our setting, we observed abscopal responses after fractionated RT ( $3 \times 8 \mathrm{~Gy})$, which was not observed after single RT (2 Gy) ${ }^{31}$. Although some studies demonstrated that fractionated RT is more beneficial than single $\mathrm{RT}^{32}$, all depends on the trigger dose of the irradiation. When this irradiation dose is large enough, single RT may also result in abscopal responses. To this end, we may focus on improving the precise RT regime (single or fractionated) to augment the overall occurrence of abscopal responses in patients with cancer.

All mice that were inoculated with the 67NR tumour showed an antibody response against the tumour. This finding was in line with a study showing that a pre-existing antibody response was observed in a patient with abscopal responses ${ }^{33}$. Although it is undetermined whether such antibody response is crucial for abscopal responses in patients with metastatic disease, their presence reveals that the tumour has not escaped immune recognition. The antibodies bind to epitopes shared between different tumours, which indicates that these antibodies recognize tumour-associated antigens ${ }^{34}$. Furthermore, we observed long-lasting antibody responses that were not limited to IgM antibodies, but were a diverse repertoire of Ig isotypes, indicating that multiple antigens are recognized during 67NR tumour progression 35. The presence of IgG antibodies directly proofs that CD4+ T cell-dependent responses are initiated after tumour inoculation, because CD4+ T cells are necessary for the initiation of Ig class switch recombination in B cells ${ }^{36}$. However, it remains to be established whether these antibodies directly contribute to abscopal tumour inhibition or whether they serve as marker for novel immune responses in a subset of patients.

Importantly, fractionated RT alone or combined with Flt3-L administration did not augment the pre-existing antibody response. The treatments did neither influence the total quantity of antibodies nor the Ig isotype composition. Likewise, there was no dissimilarity in immune infiltrate and Ig isotypes in all tumours that were suggestive for local Ig production. 
Notably, our study design was optimized to monitor the survival of treated mice, which is a limitation regarding the identification of mechanisms leading to abscopal tumour inhibition. In this 67NR mouse model, we did not observe a modulation of the antibody response after treatments suggesting that antibodies do not play an essential role in abscopal responses. Currently, it remains unknown whether the humoral anti-tumour response is a marker that is associated with the induction of systemic immune responses. It should be noted that our animal study is quite limited by the means of one mouse strain (Balb/C) and one tumour type (67NR). To explore the effect of other immune mechanisms responsible for abscopal responses, several mouse models and tumours may be considered. In addition, to identify immune responses at the time of abscopal tumour regression, a setting may be developed that evaluates the immune infiltrate at fixed time points. In these preclinical tumour models, the humoral anti-tumour response may be correlated with abscopal responders.

Abscopal responses are only occasionally observed after RT in patients with cancer. To stimulate the occurrence of abscopal responses, future treatment strategies should focus on RT in combination with immunotherapy. To this end, it has been shown that fractionated RT and CTLA-4 blockade (pre-clinical) or GM-CSF administration (clinical trial) augmented the percentage of patients with abscopal responses up to $20 \%{ }^{32,37}$. At present, it is well-known that combination therapy shows an increased efficacy as compared to when one treatment strategy is applied. The combination of RT (single or fractionated) with immune checkpoint inhibitors such as CTLA-4, the PD-1/PD-L1 axis, and CD40 may boost the immune system to overcome the immunosuppressive environment of the tumour ${ }^{38,39}$. In addition, TLR agonists (TLR-2, TLR-3, TLR-7, and TLR-9), neutralization of the immunosuppressive environment of the tumour (inhibition Tregs, MDSCs), and adoptive immune cell therapy (e.g. T cells and NK cells) may be treatment options to combine with $\mathrm{RT}^{40-43}$.

At present, only a small subset of patients show abscopal responses after RT. In our animal study, we also presented abscopal effects in a subset of animals without modulating the magnitude and antibody isotype composition of the humoral immune response. Though, it remains to be determined whether tumour-associated antibodies in mice and humans do contribute to abscopal tumour inhibition or may serve as marker for new immune responses or treatment efficacy in abscopal responders. Furthermore, when these antibody and B cell responses do not correlate with abscopal responses, there is need for new makers. Notably, we may increase the number of abscopal responders via new combination treatments such as fractionated RT and various kinds of immunotherapy. In these approaches, the humoral 
Chapter 8

anti-tumour response may be of interest to assess as marker for abscopal responders.

\section{The stimulation or inhibition of B cells and their effector functions}

Currently, B cells contribute to the pathophysiology of many inflammatory and autoimmune diseases, and malignancies. Therefore, it is important to investigate the precise role of these $B$ cells and their secreted products to unravel new treatment options. We studied the effect of JAK1/2 inhibitor ruxolitinib on B cells, and we assessed whether antibody fragments (sFLC Igs) have an immunomodulatory role on $B$ cells and T cells.

Chronic GVHD (cGVHD) is the major cause of morbidity and mortality after HSCT ${ }^{44}$. Although the pathophysiology of cGVHD is dominated by T cells, some lines of evidence showed that $B$ cells also play a role in $\mathrm{CGVHD}^{45,46}$. Additionally, the JAK inhibitor ruxolitinib has been shown to be effective in the treatment of acute and CGVHD in patients after HSCT ${ }^{47}$. Because $B$ cells contribute to the pathophysiology of cGVHD, we examined in chapter 6 whether ruxolitinib affects human $\mathrm{B}$ cell activation and proliferation.

We showed a dose-dependent inhibition of human B cell activation and proliferation after administration of JAK1/2 inhibitor ruxolitinib. This observation was confirmed with the more selective JAK2 inhibitor fedratinib. These findings indicate that JAK inhibitors have also a profound inhibitory effect on the $B$ cell response and may reflect a mechanism how these JAK inhibitors interfere with (acute) and cGVHD. Although these observations are promising, it should be noted that the experimental design has some pitfalls. In general, human B cells are not activated in vitro, therefore we stimulated the isolated human B cells with a cocktail containing anti-CD40, CpG ODNs, and IL-21. Since the cytokine IL-21 signals via the JAK-STAT pathway, this may interfere with the inhibitory effect that is observed. To clarify this pitfall, future experiments should focus on several manners (cocktails) to activate isolated human $B$ cells, at least without cytokine IL-21. Ideally, the precise effect of these JAK inhibitors may be evaluated in vivo. Furthermore, we observed increased cell death at the concentration of 10 $\mu \mathrm{M}$ (drug toxicity), however the type of cell death remains elusive. To this end, it should be noted that a dose up to $10 \mu \mathrm{M}$ is safe to administer (to healthy individuals) ${ }^{48,49}$.

Although our findings point towards a successful inhibitory effect of ruxolitinib and fedratinib, we merely investigated 'healthy' human B cells and it remains unknown whether these pathways are also effective in patients with cGVHD. To further elucidate the effect of 
these JAK inhibitors in patients with cGVHD, clinical trials are planned to determine whether it is attractive to measure $B$ cell activation and proliferation in these patients. Based on our results it is tempting to speculate whether these JAK inhibitors may also be effective in the treatment of different autoimmune diseases (e.g. RA, SLE) and other B cell-related diseases. These JAK inhibitors may be a drug that interfere with all the fundamental pathways known in $\mathrm{CGVHD}$, however this has to be further investigated in clinical trials.

Until now, the pathophysiology of cGVHD remains very complex and the precise role of B cells in this disorder are unknown. Some studies showed that ruxolitinib is effective in the treatment of GVHD and it is suggested that mainly $T$ cells are inhibited. However, we provide evidence that ruxolitinib inhibits also the activation and proliferation of healthy $B$ cells. Although we discussed our pitfalls in this preliminary result, ruxolitinib may also inhibit $B$ cells in case of GVHD. Large clinical trials may provide important information about the mechanism of ruxolitinib on B cells.

It has been shown that MM and CKD patients display elevated SFLC Ig levels and often have infectious diseases or insufficient vaccination efficacy respectively ${ }^{53}$. Although these sFLC Igs are always overproduced, their exact biological properties remain elusive. Only a few studies suggested that sFLC Igs may exhibit an immunomodulatory role ${ }^{26,28,50-52}$. In chapter $\mathbf{7}$, we studied whether purified (unconjugated) SFLC Igs or high sFLC Ig levels in sera from MM and CKD patients affect the activation and proliferation of $B$ cells and T cells.

We showed that the activation and proliferation of stimulated $B$ cells and $T$ cells was not affected after incubation with sera from MM and transplant patients with elevated sFLC Ig levels. The declined activation and proliferation of T cells upon incubation with sera from kidney patients after transplantation most likely reflects the effect of immunosuppressive drugs (corticosteroids, MMF, tacrolimus). This cocktail is administered after transplantation with the aim to inhibit $T$ cells, thereby preventing acute graft rejection ${ }^{54}$. Notably, the fact that we observed reduced activation and proliferation of B cells and T cells after incubation with sera from patients who had MM treatment or transplantation as compared to control sera indicated that sFLC Igs are most likely not responsible for this effect. Likewise, the sera with elevated SFLC Igs are probably not modulating the activation and proliferation of B cells and T cells.

To further investigate the biological role of sFLC Igs, we showed that purified $\mathrm{k}$ and $\lambda$ sFLC Igs did neither affect the activation nor the proliferation of stimulated B cells and T cells 


\section{Chapter 8}

at different physiologically relevant doses. In our study, we only focussed on the activation and proliferation of these cells, therefore other effector mechanisms cannot be excluded. In addition, we stimulated B cells with a cocktail of anti-CD40, CpG ODNs, and cytokine IL-21 or we stimulated $T$ cells with anti-CD3, which may influence a possible effect of the purified sFLC Igs. Therefore, the usage of different models and cocktails to stimulate these cells may provide extra information about the relevant sFLC Ig-related pathways and their effects. In previous studies, it has been shown that sFLC Igs are able to interact with sphingomyelin, and bind to $B$ cells and T cells, however their exact role and a potential SFLC Ig receptor remains unknown ${ }^{55}$. Furthermore, the binding of purified $\mathrm{k}$ and $\lambda \mathrm{sFLC}$ Igs to $\mathrm{B}$ cells and $\mathrm{T}$ cells may be affected by their monomeric ( $k$ ) or dimeric $(\lambda)$ protein conformation. In this light, it has been shown that $\mathrm{k}$ and $\lambda$ sFLC Igs exhibit an increased binding to monocytes and in case of $B$ cells only $\mathrm{K}$ SFLC Igs. These findings and the ability of SFLC Igs to bind antigen-specific may support the idea that professional APCs coated with sFLC Igs are more prone to capture and present antigens to T cells. Therefore, it is possible that SFLC Igs interfere with the initiation of an immune response rather than an ongoing response. Future efforts may emphasize on the effect of SFLC Igs on the ability of B cells to capture and present antigens.

In the search for a biological role of sFLC Igs, we demonstrated that purified sFLC Igs and high sFLC Ig levels in sera from CKD and MM patients did not affect the activation and proliferation of polyclonally stimulated B cells and T cells. Although it is unknown whether the sFLC Igs influence B cells and T cells via another mechanism, these findings indicate that the elevated SFLC Ig levels are most likely not involved in infectious diseases and vaccination efficacy problems in these patients. To further evaluate the possible functions of sFLC Igs, we may focus on the capacity to interfere with the initiation of immune responses. 


\section{CONCLUSIONS}

Taken together, the results presented in this thesis contribute to the current understanding of $B$ cell biology in transplantation and cancer. In this section we present our main findings.

\section{Chapter 2}

Does RhD incompatible kidney transplantation result in the development of RhD antibodies in a setting of reduced immunosuppression and in absence of anti-RhD prophylaxis?

Although very infrequent, our findings showed that RhD antibodies can develop after RhD incompatible kidney transplantation in our transplant setting and anti-RhD prophylaxis may be advisable for female transplant recipients who want to have a future pregnancy.

\section{Chapter 3}

Is HLA-DRB3 and its' allelic diversity immunogenic after kidney transplantation and does this correlate with HLA expression and graft outcome?

The different HLA-DRB3 proteins are immunogenic and our data indicated that an antibody response against HLA-DRB3 may be correlated with HLA expression.

\section{Chapter 4}

Do the dynamics of sFLC Ig normalization after kidney transplantation correlate with markers for kidney function (SCr, MDRD, and B2-M) and HLA antibodies?

Although the SFLC Ig normalization after kidney transplantation is weakly correlated with $\mathrm{SCr}$ and MDRD, the rapid decline and complete normalization of $\mathrm{K}$ SFLC Igs in recipients with IGF may reflect immediate and effective proximal tubular function.

\section{Chapter 5}

Does fractionated RT in combination with DC stimulation affects a pre-existing humoral anti-tumour response in an animal model to study the abscopal effect?

Fractionated RT with $3 \times 8 \mathrm{G}$ y alone or combined with Flt3-L administration showed abscopal effects without modulating the magnitude and antibody isotype composition of the humoral anti-tumour immune response. 
Chapter 8

\section{Chapter 6}

Does JAK1/2 inhibitor ruxolitinib affects the activation and proliferation of $B$ cells?

The JAK1/2 inhibitor ruxolitinib and the more selective JAK2 inhibitor fedratinib inhibited the activation and proliferation of polyclonally stimulated $B$ cells in a dose-dependent manner.

\section{Chapter 7}

Do unconjugated SFLC Igs or high sFLC Ig levels in sera from CKD and MM patients influence the activation and proliferation of $B$ cells and $T$ cells?

Purified (unconjugated) $\mathrm{k}$ and $\lambda \mathrm{sFLC}$ Igs and high sFLC Ig levels in sera from CKD and MM did not affect the activation and proliferation of polyclonally stimulated $B$ cells and $T$ cells. 


\section{REFERENCES}

1. Susal C, Opelz G. Current role of human leukocyte antigen matching in kidney transplantation. Curr Opin Organ Transplant. 2013;18(4):438-444.

2. Rydberg L. ABO-incompatibility in solid organ transplantation. Transfus Med. 2001;11(4):325-342.

3. Tighe MR, Hall MA, Barbado M, Cardi E, Welsh KI, Ciclitira PJ. HLA class II alleles associated with celiac disease susceptibility in a southern European population. Tissue Antigens. 1992;40(2):90-97.

4. Ishihara M, Ishida T, Mizuki N, Inoko H, Ando H, Ohno S. Clinical features of sarcoidosis in relation to HLA distribution and HLA-DRB3 genotyping by PCR-RFLP. Br J Ophthalmol. 1995;79(4):322-325.

5. Chen QY, Huang W, Baxter F, Volpe R, Maclaren NK. HLA-DRB1*08, DRB1*03/DRB3*0101, and DRB3*0202 are susceptibility genes for Graves' disease in North American Caucasians, whereas DRB1*07 is protective. J Clin Endocrinol Metab. 1999;84(9):3182-3186.

6. Hill M, Beeson D, Moss $\mathrm{P}$, et al. Early-onset myasthenia gravis: a recurring T-cell epitope in the adult-specific acetylcholine receptor epsilon subunit presented by the susceptibility allele HLA-DR52a. Ann Neurol. 1999;45(2):224-231.

7. Decary F, L'Abbe D, Tremblay L, Chartrand P. The immune response to the HPA-1a antigen: association with HLA-DRw52a. Transfus Med. 1991;1(1):55-62.

8. Duquesnoy RJ. Antibody-reactive epitope determination with HLAMatchmaker and its clinical applications. Tissue Antigens. 2011;77(6):525-534.

9. Duquesnoy RJ. Human leukocyte antigen epitope antigenicity and immunogenicity. Curr Opin Organ Transplant. 2014;19(4):428-435.

10. Bos EM, Leuvenink HG, van Goor H, Ploeg RJ. Kidney grafts from brain dead donors: Inferior quality or opportunity for improvement? Kidney Int. 2007;72(7):797-805.

11. Cotner T, Charbonneau H, Pious D. mRNA abundance, rather than differences in subunit assembly, determine differential expression of HLA-DR beta 1 and -DR beta 3 molecules. J Biol Chem. 1989;264(19):11107-11111.

12. Berdoz J, Gorski J, Termijtelen AM, et al. Constitutive and induced expression of the individual HLA-DR beta and alpha chain loci in different cell types. J Immunol. 1987;139(4):1336-1341.

13. Quan VA, Kemp LJ, Andrews PA, Sacks SH. Rhesus immunization after renal transplantation. Transplantation. 1996;61(1):149-150.

14. Murray S, Dewar PJ, Dinning G. Development of RhD antibodies after kidney transplantation. Br Med J. 1976;2(6035):585-586.

15. Kenwright MG, Sangster JM, Sachs JA. Development of RhD antibodies after kidney transplantation. Br Med J. 1976;2(6028):151-152.

16. Reverberi R. The persistence of red cell alloantibodies. Blood Transfus. 2008;6(4):225-234.

17. Engelfriet CP, Reesink HW, Judd WJ, et al. Current status of immunoprophylaxis with anti-D immunoglobin. Vox Sang. 2003;85(4):328-337.

18. Koelewijn JM, de Haas M, Bonsel GJ, van der Schoot CE. One single dose of 200 microg of antenatal RhIG halves the risk of anti-D immunization and hemolytic disease of the fetus and newborn in the next pregnancy. Transfusion. 2008;48(8):1721-1729.

19. Gluckman JC, Foucault C, Beaufils H, Luciani J, Cartron J, Frantz PF. Rh antibodies after kidney transplantation. Transplantation. 1981;32(3):260-262.

20. Bonventre JV, Vaidya VS, Schmouder R, Feig P, Dieterle F. Next-generation biomarkers for detecting kidney toxicity. Nat Biotechnol. 2010;28(5):436-440.

21. Bradwell AR. Serum Free Light Chain Analysis. Birmingham: The Binding Site Ltd.; 2010.

22. Jacobs JF, Hoedemakers RM, Teunissen E, Te Velthuis H. N Latex FLC serum free light-chain assays in patients with renal impairment. Clin Chem Lab Med. 2014;52(6):853-859.

23. Desjardins $L$, Liabeuf $S$, Lenglet $A$, et al. Association between free light chain levels, and disease progression and mortality in chronic kidney disease. Toxins (Basel). 2013;5(11):2058-2073.

24. Waldmann TA, Strober W, Mogielnicki RP. The renal handling of low molecular weight proteins. II. Disorders 


\section{Chapter 8}

of serum protein catabolism in patients with tubular proteinuria, the nephrotic syndrome, or uremia. J Clin Invest. 1972;51(8):2162-2174.

25. Gondouin B, Hutchison CA. High cut-off dialysis membranes: current uses and future potential. Adv Chronic Kidney Dis. 2011;18(3):180-187.

26. Thio M, Groot Kormelink T, Fischer MJ, Blokhuis BR, Nijkamp FP, Redegeld FA. Antigen binding characteristics of immunoglobulin free light chains: crosslinking by antigen is essential to induce allergic inflammation. PLoS One. 2012;7(7):e40986.

27. Stevens LA, Coresh J, Greene T, Levey AS. Assessing kidney function--measured and estimated glomerular filtration rate. N Engl J Med. 2006;354(23):2473-2483.

28. Hutchinson AT, Jones DR, Raison RL. The ability to interact with cell membranes suggests possible biological roles for free light chain. Immunol Lett. 2012;142(1-2):75-77.

29. Basnayake K, Stringer SJ, Hutchison CA, Cockwell P. The biology of immunoglobulin free light chains and kidney injury. Kidney Int. 2011;79(12):1289-1301.

30. Nielsen R, Christensen E, Birn H. Megalin and cubilin in proximal tubule protein reabsorption: from experimental models to human disease. Kidney Int. 2016;89(1):58-67.

31. Demaria $\mathrm{S}, \mathrm{Ng} \mathrm{B}$, Devitt $\mathrm{ML}$, et al. Ionizing radiation inhibition of distant untreated tumors (abscopal effect) is immune mediated. Int J Radiat Oncol Biol Phys. 2004;58(3):862-870.

32. Dewan $\mathrm{MZ}$, Kawashima $\mathrm{N}$, et al. Fractionated but not single-dose radiotherapy induces an immune-mediated abscopal effect when combined with anti-CTLA-4 antibody. Clin Cancer Res. 2009;15(17):5379-5388.

33. Postow MA, Callahan MK, Barker CA, et al. Immunologic correlates of the abscopal effect in a patient with melanoma. N Engl J Med. 2012;366(10):925-931.

34. Kowanetz $\mathrm{M}, \mathrm{Wu} X$, Lee J, et al. Granulocyte-colony stimulating factor promotes lung metastasis through mobilization of Ly6G+Ly6C+ granulocytes. Proc Natl Acad Sci U S A. 2010;107(50):21248-21255.

35. Aslakson CJ, Miller FR. Selective events in the metastatic process defined by analysis of the sequential dissemination of subpopulations of a mouse mammary tumor. Cancer Res. 1992;52(6):1399-1405.

36. Smith KM, Pottage L, Thomas ER, et al. Th1 and Th2 CD4+ T cells provide help for B cell clonal expansion and antibody synthesis in a similar manner in vivo. J Immunol. 2000;165(6):3136-3144.

37. Golden EB, Chhabra A, Chachoua A, et al. Local radiotherapy and granulocyte-macrophage colony-stimulating factor to generate abscopal responses in patients with metastatic solid tumours: a proof-of-principle trial. Lancet Oncol. 2015;16(7):795-803.

38. Melero I, Berman DM, Aznar MA, Korman AJ, Perez Gracia JL, Haanen J. Evolving synergistic combinations of targeted immunotherapies to combat cancer. Nat Rev Cancer. 2015;15(8):457-472.

39. Honeychurch J, Cheadle EJ, Dovedi SJ, Illidge TM. Immuno-regulatory antibodies for the treatment of cancer. Expert Opin Biol Ther. 2015;15(6):787-801.

40. Hodge JW, Ardiani A, Kwilas AR, Gameiro SR. The tipping point for combination therapy: cancer vaccines with radiation, chemotherapy, or targeted small molecule inhibitors. Semin Oncol. 2012;39(3):323-339.

41. Palucka K, Banchereau J. Cancer immunotherapy via dendritic cells. Nat Rev Cancer. 2012;12(4):265-277.

42. Restifo NP, Dudley ME, Rosenberg SA. Adoptive immunotherapy for cancer: harnessing the T cell response. Nat Rev Immunol. 2012;12(4):269-281.

43. Khalil DN, Smith EL, Brentjens RJ, Wolchok JD. The future of cancer treatment: immunomodulation, CARs and combination immunotherapy. Nat Rev Clin Oncol. 2016;13(5):273-290.

44. Socie G, Stone JV, Wingard JR, et al. Long-term survival and late deaths after allogeneic bone marrow transplantation. Late Effects Working Committee of the International Bone Marrow Transplant Registry. N Engl J Med. 1999;341(1):14-21.

45. Sarantopoulos S, Ritz J. Aberrant B-cell homeostasis in chronic GVHD. Blood. 2015;125(11):1703-1707.

46. Miklos DB, Kim HT, Miller $\mathrm{KH}$, et al. Antibody responses to $\mathrm{H}-\mathrm{Y}$ minor histocompatibility antigens correlate with chronic graft-versus-host disease and disease remission. Blood. 2005;105(7):2973-2978.

47. Spoerl S, Mathew NR, Bscheider M, et al. Activity of therapeutic JAK $1 / 2$ blockade in graft-versus-host disease. Blood. 2014;123(24):3832-3842.

48. Shi JG, Chen X, McGee RF, et al. The pharmacokinetics, pharmacodynamics, and safety of orally dosed 


\section{General discussion}

INCB018424 phosphate in healthy volunteers. J Clin Pharmacol. 2011;51(12):1644-1654.

49. Zhang $M, X u C R$, Shamiyeh $E$, et al. A randomized, placebo-controlled study of the pharmacokinetics, pharmacodynamics, and tolerability of the oral JAK2 inhibitor fedratinib (SAR302503) in healthy volunteers. J Clin Pharmacol. 2014;54(4):415-421.

50. Braber S, Thio M, Blokhuis BR, et al. An association between neutrophils and immunoglobulin free light chains in the pathogenesis of chronic obstructive pulmonary disease. Am J Respir Care Med. 2012;185(8):817-824.

51. Cohen G, Rudnicki M, Deicher R, Horl WH. Immunoglobulin light chains modulate polymorphonuclear leucocyte apoptosis. Eur J Clin Invest. 2003;33(8):669-676.

52. Redegeld FA, van der Heijden MW, Kool M. Immunoglobulin-free light chains elicit immediate hypersensitivitylike responses. Nat Med. 2002;8(7):694-701.

53. Wong PN, Fung TT, Mak SK, et al. Hepatitis B virus infection in dialysis patients. J Gastroenterol Hepatol. 2005;20(11):1641-1651.

54. Meier-Kriesche HU, Li S, Gruessner RW, et al. Immunosuppression: evolution in practice and trends, 1994 2004. Am J Transplant. 2006;6(5 Pt 2):1111-1131.

55. Hutchinson AT, Ramsland PA, Jones DR, et al. Free Ig light chains interact with sphingomyelin and are found on the surface of myeloma plasma cells in an aggregated form. J Immunol. 2010;185(7):4179-4188. 


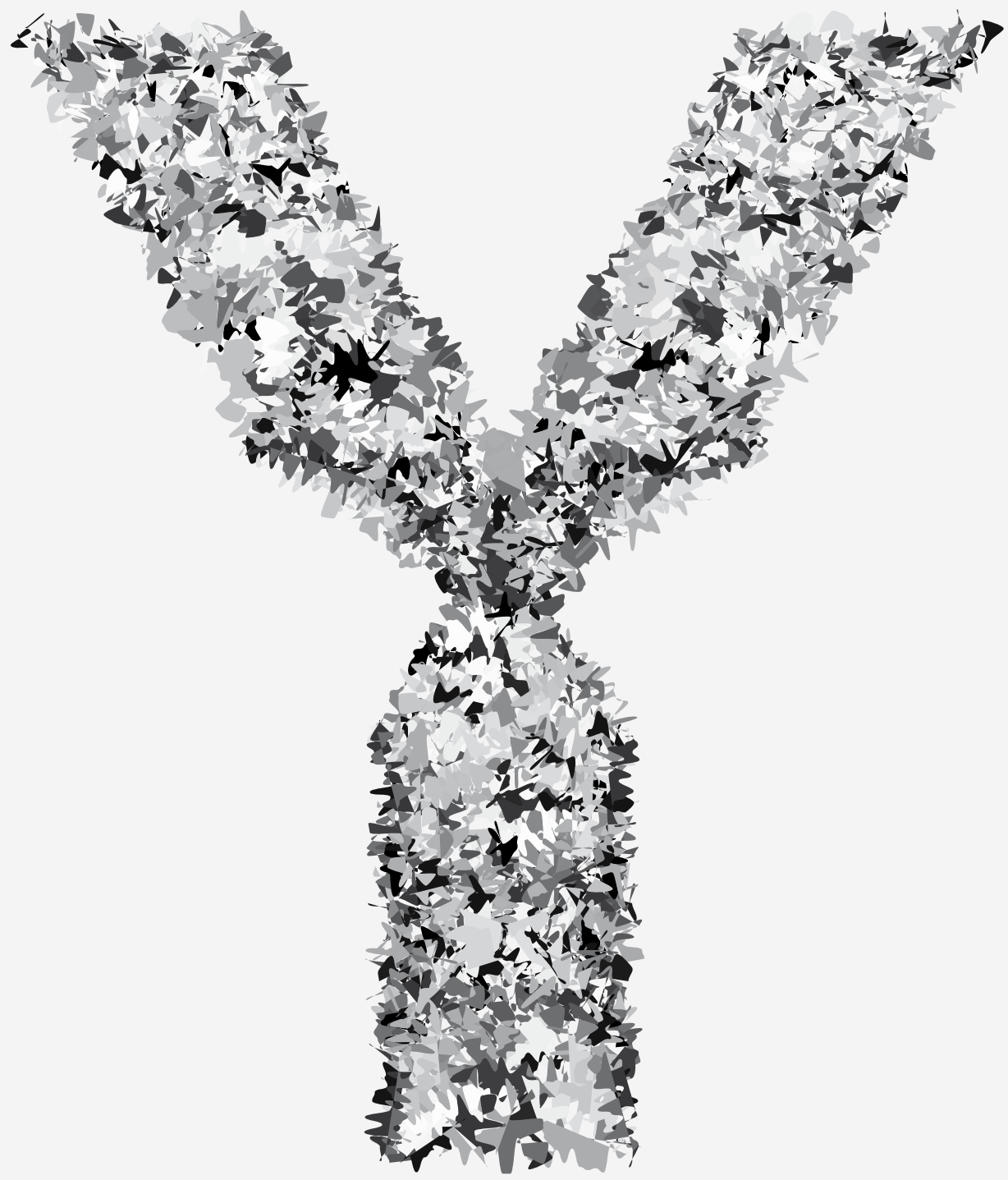




\section{CHAPTER}

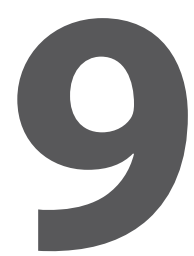

Summary

Samenvatting 



\section{SUMMARY}

The main aim of this thesis was to investigate the functional role of B cells and their secreted antibodies in transplantation and cancer. We explored to what extent B cells are activated to produce antibodies after exposure to foreign antigens in (kidney) transplantation, whether their secreted antibodies can be used as biomarker after (kidney) transplantation or cancer treatment, and whether B cells and their effector functions can be influenced in the context of cancer.

In (e.g. kidney) transplantation, the recognition of foreign antigens by the recipient's immune system generates a barrier for successful graft outcome. After contact with foreign antigens, activated $B$ cells can produce antibodies against minor and major histocompatibility antigens (such as HLA molecules) and antibodies against blood group antigens such as RhD.

HLA-DRB3 is a functional HLA class II gene, which has a limited allelic diversity in the human population. Since its presence is tightly associated with certain HLA-DRB1 allele groups, the HLA-DRB3 gene is only present in a subset of individuals. Therefore, in organ (e.g. kidney) transplantation this HLA molecule is regularly mismatched between patient and donor, and antibodies against this mismatched HLA molecule can develop. Currently, there is a limited insight in the immunogenicity of HLA-DRB3 in kidney transplantation. In chapter $\mathbf{3}$, we evaluated the prevalence and reactivity of HLA-DRB3 antibodies in kidney patients based on retrospective analysis of a caucasian patient cohort. Moreover, we studied whether these antibodies are correlated with HLA expression and graft outcome. We presented that HLADRB3 antibodies are frequently detected in kidney patients (7\%) after different immunologic events including transplantation, pregnancy, and transfusion. Interestingly, we showed that not only the presence or absence of HLA-DRB3 is immunogenic, but also the allelic variation of the HLA-DRB3 gene. Furthermore, we indicated using solid phase assays that the HLADRB3 protein has multiple epitopes. Importantly, we questioned whether these HLA-DRB3 antibodies are clinically relevant. We found that kidney transplant recipients with HLA-DRB3 antibodies showed an inferior graft outcome after transplantation as compared to recipients without these HLA-DRB3 antibodies. However, the induction of these antibodies after kidney transplantation or graft failure was associated with a wide allosensitization. At present, the exact clinical relevance of these antibodies remains unclear and needs further investigation. 
We also questioned whether the surface expression of HLA-DRB3 was relevant for antibody responses. To this end, our data indicated that the risk of developing antibodies against HLADRB3 is to a certain extent dependent on HLA expression (e.g. HLA-DRB1*11 individuals). In addition, it appears that HLA-DRB3*01 is more immunogenic than HLA-DRB3*02 and *03.

Our study provides new insights on the immunogenicity and reactivity of antibodies against HLA-DRB3 in kidney transplantation, and that HLA expression may be an important factor underlying antibody formation. These findings can be taken into account for accurate HLA and epitope matching strategies in (kidney) transplantation.

In (kidney) transplantation, the recipient's immune system can be exposed to RhD antigens, which may be present on residual RBCs in the donor graft. RhD antigens are not expressed on endothelium of the kidneys and therefore these antigens are not taken into account in the allocation of solid organs (kidneys). Nevertheless, female recipients with RhD antibodies as a consequence of RhD incompatible kidney transplantation may develop HDFN in a future pregnancy. In chapter 2, we examined how frequent RhD antibodies develop in transplant recipients who received $\mathrm{RhD}$ incompatible kidney transplantation in a transplant setting of reduced immunosuppression and in absence of anti-RhD prophylaxis. We observed only 1 out of 156 (0.6\%) RhD- recipients who developed RhD antibodies after a RhD incompatible kidney transplantation. Although this is very infrequent, RhD incompatible kidney transplantation in a setting of reduced immunosuppression and in absence of anti-RhD prophylaxis can lead to the development of these antibodies. This also indicated that even with existing perfusion media not all RBCs are washed from the kidney graft.

Since the number of pregnancies is increasing among kidney transplant recipients, it may be advisable to provide anti-RhD prophylaxis to female transplant recipients under the age of 45 who want to have a future pregnancy.

To date, there remains a need for superior markers to accurately assess organ function and immune activation status in (kidney) transplant recipients. Additionally, markers that provide information on the treatment efficacy in patients with cancer are also required.

A kidney transplantation with positive outcome depends mainly on the ability to distinguish early rejection, infectious problems, or DGF. In general, SCr levels are measured to evaluate kidney function, however $\mathrm{SCr}$ is also a relatively late marker for kidney damage. In the search 
for an advanced marker, we studied the $\mathrm{k}$ and $\lambda$ sFLC Ig levels in kidney transplantation. In normal antibody synthesis, sFLC Igs are always overproduced and efficiently reabsorbed in the kidneys. However, patients with kidney failure lose their ability to maintain normal sFLC Ig levels and also during dialysis sFLC Igs are not removed from the circulation. In chapter 4, we studied the dynamics and normalization of $\mathrm{k}$ and $\lambda$ sFLC Igs after kidney transplantation and we determined whether these correlated with SCr, MDRD, $\beta 2-M$, and HLA antibodies. We demonstrated that ESRD patients on dialysis maintained elevated $\mathrm{k}$ and $\lambda$ SFLC Ig levels. These elevated sFLC Ig levels rapidly normalized after kidney transplantation demonstrating that a functioning kidney is necessary to keep normal sFLC Ig levels. In the search for a new marker to assess kidney function immediately after transplantation, we revealed that the $\mathrm{k}$ SFLC Ig normalization was faster than SCr, MDRD, and $\beta 2-\mathrm{M}$ after kidney transplantation with a graft from either a living donor, DBD, or DCD. Importantly, we did not observe a correlation of the sFLC Ig levels with HLA antibody responses against the transplanted kidney graft. To validate our (marker) findings, we compared the sFLC Ig levels with current markers for kidney function. Our data showed that SFLC Igs do not completely reflect these markers, as transplant recipients who demonstrated complete $\mathrm{k}$ sFLC Ig normalization did not display complete SCr and MDRD normalization. Interestingly, however, we showed that complete K SFLC Ig normalization was a hallmark for recipients displaying IGF, whereas incomplete $\mathrm{K}$ sFLC Ig normalization was only observed in recipients with DGF (within the first week after transplantation). It remains to be established in a large prospective study whether $\mathrm{k}$ and $\lambda$ sFLC Igs are a predictive marker for complete kidney function or graft rejection.

Although we demonstrated that the SFLC Ig levels did not completely correlate with $\mathrm{SCr}$ and MDRD, the rapid decline of both the $\mathrm{K}$ SFLC Ig and $\beta 2-\mathrm{M}$ levels after transplantation implied that these proteins reflect efficient and immediate proximal tubular function. These findings may be essential to discriminate early graft rejections and DGF by assessing kidney function immediately after transplantation to improve transplant outcome.

Accumulating evidence reveals that fractionated radiotherapy (RT) can result in distant nonirradiated (abscopal) tumour regression or disappearance. Although some preclinical studies demonstrated the importance of T cells in this sporadic phenomenon, these studies do not preclude that other immune mechanisms such as antibody responses have an additional role in the abscopal effect. In chapter 5, we examined whether fractionated RT (3 x 8Gy) alone or combined with Flt3-L administration (DC stimulation) enhances a pre-existing humoral anti- 
tumour response in a mouse model to examine the abscopal effect. In addition, we assessed to what extent humoral anti-tumour responses are invariably associated with abscopal tumour regression. We demonstrated that fractionated RT ( $3 \times 8 \mathrm{~Gy}$ ) alone or combined with Flt3-L stimulates abscopal responses in the 67NR mouse model. Likewise, fractionated RT to the primary tumour was associated with a survival advantage and a delayed growth of the non-irradiated secondary tumour. We questioned whether these mice developed antibody responses against the inoculated tumour. To this end, we showed that the 67NR carcinoma in Balb/C mice was associated with a pre-existing antibody response, which is also observed in human studies. Nevertheless, such humoral anti-tumour immune response in terms of total quantity of plasma antibodies or the Ig isotype composition was not altered after fractionated RT and/or DC stimulation with Flt3-L in this model. Likewise, we did not observe a difference in immune infiltrate and Ig isotype content in between all tumour tissues that was suggestive for local Ig production.

Our data showed that monitoring antibodies in the setting of RT-induced abscopal tumour regression is not invariably associated with therapeutic effects. Furthermore, these findings might be of value to study the relevance of antibodies in novel cancer treatments.

\section{B cells contribute to the pathophysiology of various inflammatory and autoimmune diseases,} and malignancies. Therefore, it is important to investigate the exact role of these $B$ cells and their secreted products to unravel novel treatment options.

CGVHD is the major cause of morbidity and mortality after HSCT. Existing immunosuppressive drugs are frequently ineffective, and new therapeutic approaches are necessary. Although donor $T$ cells play a fundamental role in the pathophysiology of CGVHD, it has been shown that B cells also contribute to CGVHD. In chapter $\mathbf{6}$, we examined whether JAK1/2 inhibitor ruxolitinib affects human $B$ cell activation and proliferation. In our B cell proliferation assay, we demonstrated a dose-dependent inhibition of human $B$ cell activation and proliferation after the administration of JAK1/2 inhibitor ruxolitinib and the more selective JAK2 inhibitor fedratinib. These results indicated that JAK inhibitors have a profound inhibitory effect on the $B$ cell response, which may reflect a mechanism how these JAK inhibitors interfere with all the essential pathways known in cGVHD. Nevertheless, this has to be further investigated in clinical trials. Furthermore, these JAK inhibitors may be effective in the treatment of various autoimmune diseases and other B cell-related diseases. 
Patients with CKD and MM show high SFLC Ig levels and often have insufficient vaccination efficacy or infectious disease respectively. The question remains whether high SFLC Ig levels in these patients play a vital role in the modulation of immune responses in these disorders, since the exact biological functions of sFLC Igs are unknown. In chapter 7, we determined whether purified SFLC Igs or high SFLC Ig levels in sera from CKD and MM patients affect the activation and proliferation of polyclonally stimulated $B$ cells and T cells. We showed that the activation and proliferation of B cells and T cells was not affected after incubation with sera from CKD and MM patients with high sFLC Ig levels. Moreover, we showed that purified $\mathrm{k}$ and $\lambda$ sFLC Igs did not affect the activation and the proliferation of stimulated B cells and T cells at different physiologically relevant doses in our experimental design. Our results imply that the sFLC Igs present in sera from CKD and MM patients are most likely not involved in vaccination efficacy problems or infectious disease in these patients.

In chapter 8, we critically discuss our results presented in this thesis and point out potential limitations and future perspectives concerning antibody responses after exposure to foreign antigens in (kidney) transplantation, using antibodies as marker after (kidney) transplantation or cancer treatment, and influencing B cell function in the context of cancer.

To conclude, the outcomes described in this thesis contribute to the understanding of B cell biology and especially their secreted antibodies in transplantation and cancer. Furthermore, our findings contribute to the development and realization of enhanced patient monitoring tools and novel treatment strategies in transplantation and cancer. 
Chapter 9

\section{SAMENVATTING}

Het hoofdzakelijke doel van dit proefschrift was om de functionele rol van B cellen en hun uitgescheiden antilichamen te onderzoeken in het kader van transplantatie en kanker. Ten eerste hebben we gekeken naar de mate van antilichaam productie na de blootstelling aan lichaamsvreemde antigenen tijdens (nier)transplantatie. Ten tweede hebben we onderzocht of de uitgescheiden antilichamen kunnen worden ingezet als marker na (nier)transplantatie of kankerbehandeling. Ten derde hebben we gekeken of het mogelijk was B cellen met hun effector functies te beïnvloeden in het kader van kanker.

De herkenning van lichaamsvreemde antigenen door het immuunsysteem van de ontvanger kan een belemmering zijn voor een succesvolle (nier)transplantatie. B cellen kunnen worden geactiveerd na het contact met deze antigenen dat opeenvolgend kan leiden tot de productie van antilichamen tegen 'minor en major' histocompatibiliteit antigenen, zoals HLA moleculen en antilichamen tegen bloedgroep antigenen, zoals RhD.

$H L A-D R B 3$ is een functioneel HLA-klasse II gen, dat een gelimiteerde allel diversiteit vertoont in the humane populatie. Omdat HLA-DRB3 sterk geassocieerd is met bepaalde HLA-DRB1 allel groepen, komt het HLA-DRB3 gen alleen voor in een bepaald deel van de populatie. Dit heeft als gevolg dat dit molecuul regelmatig wordt gemismatched (niet overeenkomt) tussen patiënt en donor bij (nier)transplantaties. Door deze mismatch kunnen antilichamen worden gevormd tegen dit HLA molecuul. Op dit moment is er weinig inzicht in de immunogeniciteit van HLA-DRB3 na niertransplantaties. In hoofdstuk $\mathbf{3}$ hebben we het voorkomen en de reactiviteit van HLA-DRB3 antilichamen bij niertransplantatie vastgesteld, gebruikmakend van een retrospectieve analyse van een Kaukasisch (ras) patiënten cohort. Verder hebben we bestudeerd of deze antilichamen gecorreleerd zijn met de expressie van HLA moleculen en de overleving van het transplantaat. We hebben laten zien dat antilichamen tegen HLADRB3 regelmatig werden gedetecteerd bij nierpatiënten (7\%) nadat zij werden blootgesteld aan diverse immunologische prikkels zoals transplantatie, zwangerschap en transfusie. Een interessante bevinding van onze studie was dat niet alleen de aan- of afwezigheid van HLADRB3 immunogeen is, maar ook de allel diversiteit van het HLA-DRB3 gen. Tevens duidden we aan dat het HLA-DRB3 eiwit meerdere epitopen heeft. De belangrijkste vraag was of de HLA-DRB3 antilichamen klinisch relevant zijn. We vonden dat de transplantaat-ontvangers 
met HLA-DRB3 antilichamen een slechtere transplantaat overleving hadden vergeleken met transplantaat-ontvangers zonder HLA-DRB3 antilichamen. Echter waren deze antilichamen tegen HLA-DRB3 na de niertransplantatie of transplantaat falen geassocieerd met een brede allosensitisatie. Tot op heden blijft de precieze klinische relevantie onbekend en is er meer onderzoek nodig. We stelden ook de vraag of de expressie van HLA-DRB3 moleculen op het celoppervlak relevant was voor deze antilichaam responsen. Met betrekking tot deze vraag liet onze data zien dat het risico om antilichamen tegen HLA-DRB3 te ontwikkelen tot een zekere hoogte afhankelijk is van de expressie van HLA moleculen (HLA-DRB1*11 individuen). Het lijkt er ook op dat HLA-DRB3*01 meer immunogeen is dan HLA-DRB3*02 en *03.

Onze studie levert nieuwe inzichten over de immunogeniciteit en reactiviteit van antilichamen tegen HLA-DRB3 bij niertransplantatie en dat de expressie van HLA moleculen mogelijk een vooraanstaande factor is voor het vormen van antilichamen. Deze bevindingen kunnen worden toegepast bij HLA en epitoop matching strategieën bij (nier)transplantatie.

In het geval van bijvoorbeeld een niertransplantatie kan het immuunsysteem van de ontvanger worden blootgesteld aan RhD antigenen, die aanwezig kunnen zijn op achtergebleven rode bloedcellen in het transplantaat. RhD antigenen worden niet tot expressie gebracht op het endotheel van de nieren waardoor men geen rekening houdt met deze antigenen tijdens de toewijzing van solide organen zoals nieren. Echter kunnen vrouwen die een niertransplantaat ontvangen antilichamen tegen RhD antigenen maken als gevolg van een RhD incompatibele niertransplantatie. Dit zou kunnen leiden tot de ontwikkeling van de hemolytische ziekte bij de foetus of pasgeborene (HZFP) in toekomstige zwangerschappen. In hoofdstuk 2 hebben we gekeken naar het voorkomen van RhD antilichamen in niertransplantaat ontvangers die een RhD incompatibele niertransplantatie hebben gehad in een opstelling van verminderde immunosuppressieve medicatie en in de afwezigheid van anti-RhD profylaxis. We vonden dat slechts 1 van de 156 (0.6\%) RhD- ontvangers antilichamen tegen RhD ontwikkelde na een RhD incompatibele niertransplantatie. Ondanks het lage aantal kan RhD incompatibele niertransplantatie in een opstelling van verminderde immunosuppressieve medicatie en in de afwezigheid van anti-RhD profylaxis leiden tot de ontwikkeling van deze antilichamen. Deze bevinding geeft ook aan dat met huidige perfusie media niet alle rode bloedcellen uit het niertransplantaat worden gewassen.

Omdat het aantal zwangerschappen onder niertransplantatie ontvangers toeneemt, adviseren we om anti-RhD profylaxis te geven aan vrouwen ( $<45$ jaar) die een RhD incompatibel 
Chapter 9

niertransplantaat ontvangen en een zwangerschapswens hebben.

Tot de dag van vandaag blijft er een vraag naar superieure markers om de orgaanfunctie en de immuun activatie status nauwkeurig te bepalen bij patiënten met een niertransplantatie. Tevens zijn er nieuwe markers nodig om meer informatie te vergaren over de effectiviteit van behandelingen bij patiënten met kanker.

Bij een niertransplantatie is het belangrijk zo snel mogelijk vast te stellen of er sprake is van transplantaat rejectie, infectie problemen of een vertraagde functie van het transplantaat. In het algemeen worden de $\mathrm{SCr}$ (serum creatinine) waarden gemeten om de nierfunctie vast te stellen, maar SCr is ook een relatieve late marker voor eventuele schade aan de nier. Bij de zoektocht naar een betere marker hebben we de $\mathrm{k}$ en $\lambda$ vrij lichte ketens (VLKs) in het serum bestudeerd voor en na niertransplantatie. Tijdens de gewone antilichaam productie worden VLKs altijd overgeproduceerd en hierna efficiënt geabsorbeerd in de proximale tubuli van de nieren. Echter, patiënten die leiden aan nierfalen verliezen de mogelijkheid om normale VLK waarden te behouden. Zelfs nierpatiënten met dialyse kunnen deze VLKs niet verwijderen uit de bloedcirculatie. In hoofdstuk 4 hebben we de dynamiek en de normalisatie van $\mathrm{k}$ en $\lambda$ VLKs onderzocht na niertransplantatie. Verder hebben we gekeken of de VLKs correleren met SCr, MDRD (formule), $\beta 2-M$ ( $\beta 2$-microglobuline) en HLA antilichamen. We hebben laten zien dat nierpatiënten (ESRD) met dialyse verhoogde VLKs toonden. Deze hoge VLK waarden normaliseerde zeer snel na een niertransplantatie. Dit toonde aan dat een functionele nier noodzakelijk is om normale VLK waarden te behouden. Bij de zoektocht naar een superieure marker om de nierfunctie na niertransplantatie te bepalen, hebben we waargenomen dat de K VLK normalisatie sneller was dan SCr, MDRD en $\beta 2-\mathrm{M}$ na een niertransplantatie met een transplantaat van zowel een levende, of een hersendode, of een overleden donor. Hierbij was er geen correlatie van de VLK waarden met de HLA antilichamen die waren gericht tegen het transplantaat. Om deze bevindingen te valideren hebben we de VLKs vergeleken met huidige markers voor nierfunctie. Onze resultaten lieten zien dat er geen volledige reflectie was tussen de VLKs en deze markers. De transplantaat-ontvangers lieten namelijk een complete $\mathrm{K}$ VLK normalisatie zien, terwijl er geen complete SCr en MDRD normalisatie was. Een belangrijke bevinding van onze studie was dat complete $\mathrm{k}$ VLK normalisatie een kenmerk was voor ontvangers met een snelwerkend transplantaat, terwijl incomplete $\mathrm{k}$ VLK normalisatie alleen werd waargenomen bij ontvangers met een vertraagde functie van het transplantaat (binnen 
de eerste week na de niertransplantatie). Het moet echter verder worden onderzocht of de VLKs een voorspellende marker zijn voor complete nierfunctie of transplantaat rejectie.

Alhoewel we lieten zien dat de $\mathrm{k}$ VLKs niet volledig correleerde met SCr en MDRD, impliceerde onze bevindingen dat de zeer snelle afname van de $\mathrm{k}$ VLK en $\beta 2-\mathrm{M}$ waarden na niertransplantatie een efficiënte en snelle proximale tubulaire functie weerspiegelen. Deze resultaten kunnen cruciaal zijn voor het bepalen van een rejectie en het vaststellen van een vertraagde functie van het transplantaat door de nierfunctie meteen na de transplantatie te beoordelen. Dit zal uiteindelijk leiden tot een verbeterde transplantaat overleving.

Verschillende studies hebben aangetoond dat gefractioneerde RT (radiotherapie) kan leiden tot afgelegen niet-bestraalde (abscopal) tumor afname of zelfs complete tumor verdwijning. Alhoewel sommige preklinische studies lieten zien dat T cellen belangrijk zijn in dit zeldzaam fenomeen, werden andere soorten immuun mechanismen niet uitgesloten zoals antilichaam responsen. In hoofdstuk 5 hebben we onderzocht of gefractioneerde RT ( $3 \times 8 \mathrm{~Gy}$ ) alleen of gecombineerd met Flt3-L (stimulatie van dendritische cellen) een bestaande humorale antitumor respons kan vergroten in een apart muismodel om het abscopal effect te bestuderen. We hebben tevens vastgesteld in welke mate de humorale anti-tumor responsen invariabel geassocieerd zijn met een abscopal tumor afname. We lieten zien dat gefractioneerde RT alleen en/of gecombineerd met Flt3-L de abscopal responsen bevorderde in het 67NR tumor muismodel. Tevens was het bestralen van de primaire tumor geassocieerd met een voordeel in overleving en was er een vertraagde groei van de niet-bestraalde secondaire tumor. Later stelden we de belangrijke vraag of deze muizen een antilichaam respons ontwikkelde tegen de 67NR tumor. We hebben vervolgens waargenomen dat de 67NR tumor in Balb/C muizen geassocieerd was met een bestaande antilichaam respons. In humane studies werd dit ook gevonden. Desalniettemin werd zo een humorale anti-tumor immuun respons (hoeveelheid plasma antilichamen en de antilichaam isotype proportie) niet beïnvloed na gefractioneerde RT en Flt3-L toediening in dit muismodel. Verder werd er ook geen verschil waargenomen in het immuun infiltraat en de antilichaam isotype compositie in alle tumoren die eventueel konden wijzen op lokale antilichaam productie.

Onze resultaten lieten zien dat het monitoren van antilichamen in een opstelling van RT-geïnduceerde abscopal tumor afname niet invariabel geassocieerd is met therapeutische effecten. Deze bevindingen zijn potentieel van waarde in het bestuderen van antilichamen in nieuwe behandelingen voor kanker. 
Chapter 9

$B$ cellen participeren in de pathofysiologie van verschillende inflammatoire en auto-immuun ziekten, evenals maligniteiten. Daarom is het van belang om de exacte rol van deze B cellen en hun uitgescheiden producten te bestuderen om nieuwe behandel opties te ontwikkelen.

Chronische GVHD (cGVHD) is de belangrijkste oorzaak van morbiditeit en mortaliteit na een hematopoëtische stamceltransplantatie. De huidige immunosuppressieve medicatie is vaak ineffectief en daarom zijn nieuwe behandelmethoden hard nodig. Alhoewel donor T cellen een fundamentele rol spelen in de pathofysiologie van CGVHD, is het ook aangetoond dat $B$ cellen participeren in het ziekteprofiel van cGVHD. In hoofdstuk 6 hebben we gekeken of de JAK1 en 2 remmer ruxolitinib de B cel activatie en proliferatie kan beïnvloeden. In onze B cel proliferatie assay hebben we laten zien dat de JAK1 en 2 remmer ruxolitinib en de selectieve JAK2 remmer fedratinib de humane B cel activatie en proliferatie dosis afhankelijk remden. Deze resultaten impliceerde dat JAK remmers een grondig remmend effect hebben op de $B$ cel respons. Dit zou een mechanisme kunnen reflecteren hoe deze JAK remmers interfereren met essentiële punten in het ziekteprofiel van cGVHD. Desalniettemin zal dit verder moeten worden bestudeerd in klinische studies. Tevens zouden deze JAK remmers effectief kunnen zijn in de behandeling van verschillende auto-immuun ziekten en andere B cell gerelateerde ziekten.

Patiënten met chronische nierziekten (CKD) en multipel myeloom (MM) hebben verhoogde VLK waarden (serum). Tevens hebben deze CKD en MM patiënten vaccinatie problemen en infecties respectievelijk. De vraag blijft echter of de verhoogde VLK waarden een belangrijke rol spelen in de modulatie van immuun responsen in deze ziekteprofielen. Alsmede omdat de precieze biologische functies van $\mathrm{k}$ en $\lambda$ VLKs onbekend zijn. In hoofdstuk 7 hebben we bepaald of gezuiverde VLKs of verhoogde VLK waarden in sera van CKD en MM patiënten de activatie en proliferatie van polyklonaal gestimuleerde B cellen en T cellen beïnvloeden. We lieten zien dat de activatie en proliferatie van B cellen en T cellen niet werd beïnvloed nadat deze cellen werden geïncubeerd met sera van CKD en MM patiënten (hoge VLK waarden). Verder lieten we zien dat ook de gezuiverde $\mathrm{k}$ en $\lambda$ VLKs met diverse fysiologisch relevante doses de activatie en proliferatie van B cellen en T cellen niet beïnvloedde (in onze assay). Deze bevindingen impliceren dat de VLKs in de sera van CKD en MM patiënten waarschijnlijk niet betrokken zijn bij de vaccinatie problemen of infecties in deze patiënten. 
In hoofdstuk 8 hebben we de resultaten in dit proefschrift kritisch bediscussieerd en hebben we potentiële limitaties en toekomstperspectieven gegeven $m$.b.t. antilichaam responsen na blootstelling aan lichaamsvreemde antigenen bij (nier)transplantatie, het gebruik maken van antilichamen als marker na (nier)transplantatie of kankerbehandeling, en het beïnvloeden van de $\mathrm{B}$ cel functie in het kader van kanker.

De resultaten die beschreven zijn in dit proefschrift dragen bij aan de algemene kennis over de $B$ cel biologie en met name de rol van hun uitgescheiden antilichamen in transplantatie en kanker. Deze bevindingen kunnen worden toegepast bij de ontwikkeling en realisatie van verbeterde en nieuwe hulpmiddelen om patiënten te monitoren en behandelstrategieën in transplantatie en kanker. 


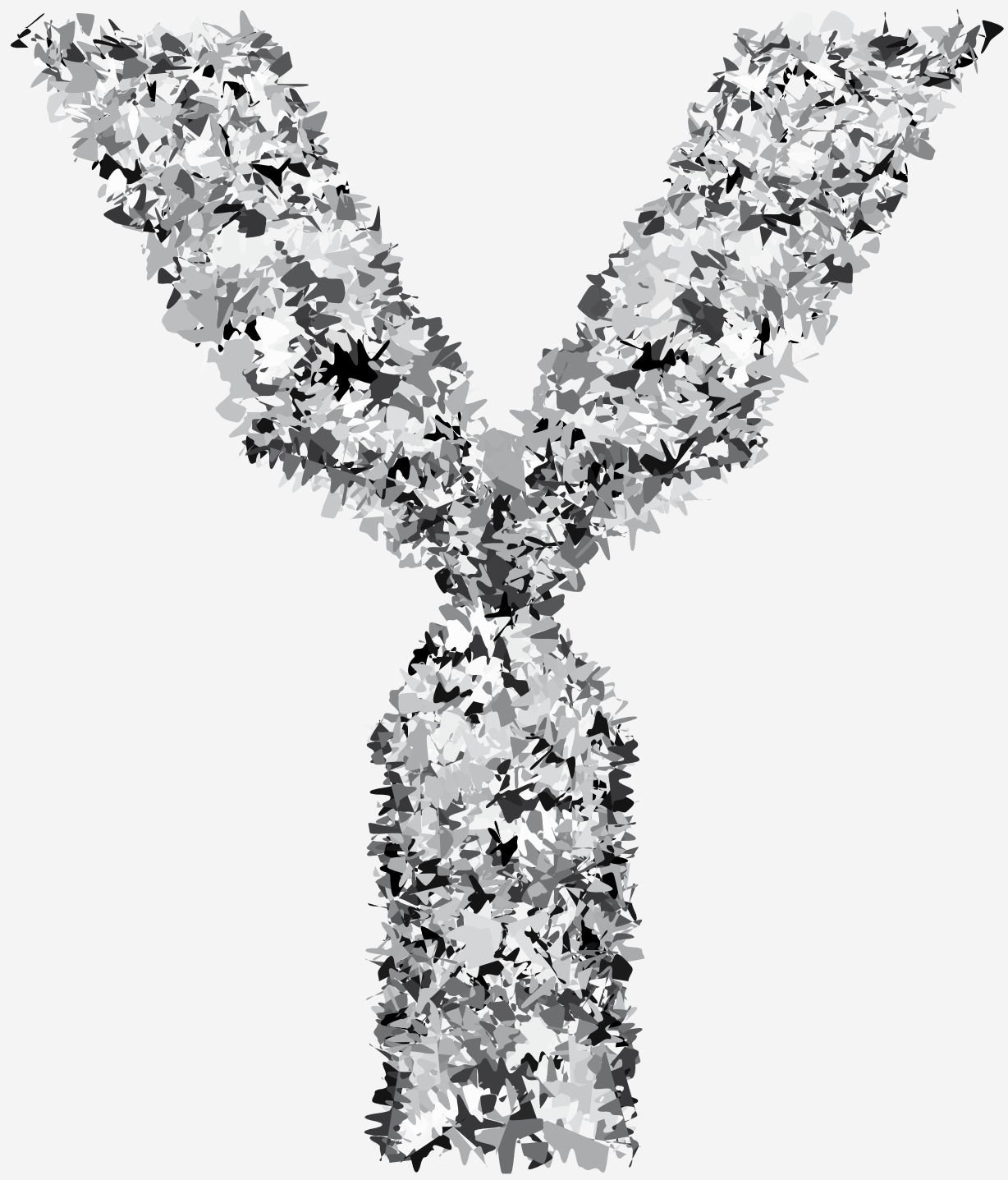




\section{CHAPTER}

Valorisation 

Although (organ) transplantation is currently mostly successful, there are still complications such as transplant rejection, where the recipient's immune system targets the graft, which can lead to graft failure and removal of the organ ${ }^{1,2}$. Matching for HLA and ABO blood group antigens in combination with the administration of immunosuppressive drugs has drastically improved graft outcome after transplantation ${ }^{3,4}$. Nevertheless, there is a subset of patients who experience difficulties after (kidney) transplantation. Therefore, enhanced treatments and monitoring tools are necessary to improve graft outcome in those patients.

Cancer (or termed malignant tumour) represents a large cluster of diseases that are capable of affecting any part of the human body and is one of the leading causes of death worldwide 5,6. Early detection of malignant tumours and the use of enhanced conventional treatments such as surgery, RT, and chemotherapy resulted in an improved patient survival. Though, not all patients with cancer benefit from existing detection and treatment strategies. Therefore, novel treatment approaches (such as immunotherapy) and assessment tools are required.

In this thesis, we aimed to improve the understanding of the functional role of B cells and their secreted antibodies in (kidney) transplantation and cancer. We focused to what extent $B$ cells are activated to produce antibodies after exposure to foreign antigens during (kidney) transplantation, whether we can use their secreted antibodies as biomarker after treatment or transplantation, and whether we are able to influence B cells and their effector functions in the field of cancer.

\section{The exposure to foreign antigens activates $B$ cells}

In (kidney) transplantation, the detection of foreign (donor) HLA molecules by the recipient's immune system can trigger powerful allograft responses, which may ultimately lead to graft rejection. To prevent these allograft responses, we match HLA molecules from the recipient and donor ${ }^{7}$. Many studies showed the importance of HLA-DRB1 matching. However, there is limited information on the immunogenicity of the HLA-DRB1 associated HLA-DRB3 protein.

In chapter 3, we examined whether HLA-DRB3 antibodies are clinically relevant. We showed that kidney transplant recipients with HLA-DRB3 antibodies displayed an inferior graft outcome as compared to recipients without these antibodies. Although our data imply that HLA-DRB3 antibodies are detrimental for kidney graft outcome, these antibodies were 


\section{Chapter 10}

accompanied with a wide-ranging alloimmunization. To further investigate the exact clinical relevance of these antibodies, large multicenter studies should be performed in future.

Importantly, we demonstrated that not only the presence or absence of HLA-DRB3 is immunogenic, but also its' allelic diversity. Furthermore, we showed using solid phase assays that HLA-DRB3 has multiple epitopes on the surface. To date, only the presence or absence of HLA alleles are taken into account for HLA matching purposes. Nevertheless, investigating 'immunogenic' epitopes (which can give rise to alloreactivity responses) rather than existing criteria may be important for accurate HLA matching ${ }^{8}$. At present, the antibody reactivity epitope determination can be assessed using a computer algorithm called HLA Matchmaker. This tool consists of a database with many polymorphic residues (eplets) that are important components of immunogenic HLA epitopes. Using this tool, HLA mismatch acceptability can be assessed based on an epitope based approach and consequently suitable donors can be selected ${ }^{9}$. A different computer algorithm called PIRCHE (predicted indirectly recognizable HLA epitopes) predicts for example the binding of processed donor-derived HLA peptides to the recipient's HLA molecules. This tool indirectly calculates the risk via the T cell response whether specific peptides potentially derived from immunogenic epitopes on the surface of HLA molecules are more prone to induce robust antibody responses ${ }^{10,11}$. Our data may be of value in such computer algorithms to expand the understanding of immunogenic epitopes.

In future, matching immunogenic epitopes may be a different approach to define minimal matching criteria in transplantation. The recipient and donor are matched based on the strength of the immunogenic epitopes instead of the presence of HLA alleles. Moreover, HLA-DRB1 associated molecules such as HLA-DRB3, HLA-DRB4, and HLA-DRB5 may provide added value for such matching approach.

To date, RhD antigens are not taken into account for the allocation of solid organs (kidneys). However, female kidney transplant recipients with $\mathrm{RhD}$ antibodies as a consequence of RhD incompatible kidney transplantation may develop HDFN in a future pregnancy.

In chapter 2, we observed only 1 out of 156 (0.6\%) RhD- kidney transplant recipients who developed RhD antibodies after a RhD incompatible kidney transplantation. Although this is very irregular, we showed that RhD incompatible kidney transplantation can give rise to RhD antibodies. Importantly, despite the low percentage, it may be advisable to provide anti-RhD prophylaxis to female kidney transplant recipients ( $<45$ years) who want to have a future pregnancy. The recommendation to administer anti-RhD prophylaxis is clinically very 
relevant, since it has been widely acknowledged that RhD antibodies can cause HDFN during pregnancy ${ }^{12}$. In case no anti-RhD prophylaxis is given to female kidney transplant recipients and they develop HDFN, various 'expensive' treatment strategies (e.g. exchange transfusion) must be applied directly. Besides the costs, these treatments are invasive for the fetus and newborn infant. In contrast, to prevent the development of HDFN in these kidney transplant recipients, the administration of anti-RhD prophylaxis is a relatively 'inexpensive' choice (e.g. $€ 60$ per $1000 \mathrm{IU}$, RheDQuin, Sanquin).

\section{The usage of B cells and their secreted antibodies as biomarker}

CKD is a significant health problem in various Western countries. For many ESRD patients, a kidney transplantation is the treatment of choice based on the gain in life expectancy and an increased quality of life ${ }^{13}$. A successful kidney transplantation depends mainly on the ability to discriminate between early rejection, infectious problems, or DGF. The 'golden' standard to assess kidney function is $\mathrm{SCr}$, however $\mathrm{SCr}$ is a relatively late marker for kidney damage ${ }^{14}$. Currently, a fast marker to assess kidney function directly after transplantation is absent and is crucial to improve transplant outcome in case of recipients with DGF. In the search for an advanced marker, we examined the SFLC Ig normalization after kidney transplantation.

In chapter 4, we showed that the K SFLC Ig normalization was faster than SCr, MDRD, and $\beta 2-\mathrm{M}$ after kidney transplantation with a graft from either a living donor, DBD, or DCD. The SFLC Ig levels were not correlated with HLA antibody responses against the transplanted graft. The most important finding was that all recipients with IGF showed complete $\mathrm{K}$ sFLC Ig normalization, whereas all recipients with DGF displayed incomplete $\mathrm{k}$ SFLC Ig normalization within the first week after transplantation. This 'hallmark' is clinically very relevant, since we are searching for a marker to evaluate kidney function directly after transplantation. To this end, SFLC Igs may be a new marker, however it should be noted that it remains to be proven in a multicenter study whether sFLC Igs are a predictive marker for complete kidney function or graft rejection.

Although there was a moderate correlation of SFLC Igs with SCr and MDRD, the rapid decline of both the $\mathrm{K}$ SFLC Ig and $\beta 2-\mathrm{M}$ levels after kidney transplantation implied that these proteins reflect efficient and immediate proximal tubular function. These findings might be of value to define graft function immediately after kidney transplantation to improve overall transplant outcome. 
Several (pre)clinical studies showed that fractionated RT can result in distant non-irradiated (abscopal) tumour regression. Although it has been shown that T cells are important in this sporadic radiation-induced phenomenon, these authors do not preclude that other immune mechanisms exhibit an additional role in the abscopal effect ${ }^{15-18}$.

In chapter 5, we showed that fractionated RT only or combined with DC stimulation (Flt3-L administration) stimulates abscopal responses in the 67NR mouse model. Moreover, irradiation of the primary tumour resulted in a survival benefit and a delayed growth of the non-irradiated (distant) tumour. These findings have a substantial relevance for the clinic, as it is of major importance to enhance beneficial RT-induced phenomena such as the abscopal effect. Some clinical case reports have been published about abscopal responses in patients with various types of cancer. In 2015, Golden et al. described a clinical trial in which patients with cancer were treated with fractionated RT in combination with GM-CSF (growth factor) administration ${ }^{15}$. This multimodal approach resulted in more abscopal responses and an improved patient survival. These clinical studies hint towards the application of fractionated RT combined with novel immunotherapies to boost the occurrence of abscopal responses ${ }^{19}$.

In our study, we mainly studied the humoral anti-tumour immune response against 67NR tumour cells in Balb/C mice. We demonstrated that the 67NR tumour in these mice was associated with a pre-existing antibody response. However, the total quantity of plasma antibodies and the Ig isotype composition were not affected after fractionated RT and/or DC stimulation with Flt3-L in this model. The monitoring of anti-tumour antibodies may be used as marker for (in this case) abscopal responses. Although we showed an evident anti-tumour antibody response, assessing these antibodies in the setting of RT-induced abscopal tumour regression was not invariably associated with therapeutic effects. Nevertheless, it has to be further studied whether anti-tumour antibody responses are of value to define the efficacy of novel treatment strategies to eradicate cancer.

\section{The stimulation or inhibition of B cells and their effector functions}

The main cause of morbidity and mortality after HSCT is CGVHD. Existing immunosuppressive drugs are frequently ineffective, and novel therapeutic strategies are necessary. Although $T$ cells (donor) play a predominant role in CGVHD pathophysiology, it has been shown that B cells also contribute to $\mathrm{CGVHD}^{20}$.

In chapter 6, we demonstrated that the activation and proliferation of polyclonally 
stimulated human B cells was inhibited in a dose-dependent manner after administration of JAK inhibitors ruxolitinib and fedratinib. Our findings are clinically very relevant, since these results indicated that JAK inhibitors have a profound inhibitory effect on the B cell response, which may reflect a mechanism how JAK inhibitors interfere with all fundamental pathways known in cGVHD. Importantly, the treatment efficacy in patients has to be further examined in clinical trials. To this end, several multicenter phase II/III clinical trials are validating JAK inhibitor ruxolitinib in patients receiving HSCT and suffering from GVHD (official trial number NCT02396628, NCT02913261, NCT02953678).

In addition, ruxolitinib and fedratinib or other JAK inhibitors may open new ways for the treatment of various autoimmune diseases and other B cell-related diseases.

Patients suffering from CKD and MM show elevated SFLC Ig levels and often have insufficient vaccination efficacy or infectious disease respectively. We examined whether these elevated sFLC Ig levels in CKD and MM patients play a fundamental role in the modulation of immune responses in these disorders, since the precise biological functions of sFLC Igs are unknown.

In chapter 7, we demonstrated that the activation and proliferation of polyclonally stimulated $B$ cells and T cells was not affected after incubation with sera from CKD and MM patients with elevated sFLC Ig levels. Similarly, purified (unconjugated) $\mathrm{k}$ and $\lambda$ sFLC Igs did not influence the activation and the proliferation of stimulated $B$ cells and $T$ cells at different physiologically relevant doses. The clinical relevance is rather limited, because we indicated that elevated SFLC Ig levels in sera from CKD and MM patients are most likely not involved in vaccination efficacy problems or infectious disease in these patients.

In conclusion, the findings described in this thesis contribute to the general understanding of $B$ cells are their secreted antibodies in kidney transplantation and cancer. The obtained data of this thesis may improve monitoring tools, HLA matching criteria, and provide additional rationale for anti-RhD prophylaxis in kidney transplantation. Furthermore, our findings may support the realization of novel treatments for cancer and for B cell-related diseases.

\section{REFERENCES}

1. Kim IK, Bedi DS, Denecke C, Ge X, Tullius SG. Impact of innate and adaptive immunity on rejection and tolerance. Transplantation. 2008;86(7):889-894.

2. LaRosa DF, Rahman AH, Turka LA. The innate immune system in allograft rejection and tolerance. J Immunol. 


\section{Chapter 10}

2007;178(12):7503-7509.

3. Susal C, Opelz G. Current role of human leukocyte antigen matching in kidney transplantation. Curr Opin Organ Transplant. 2013;18(4):438-444.

4. Rydberg L. ABO-incompatibility in solid organ transplantation. Transfus Med. 2001;11(4):325-342.

5. Global Burden of Disease Cancer C, Fitzmaurice C, et al. Global, Regional, and National Cancer Incidence, Mortality, Years of Life Lost, Years Lived With Disability, and Disability-Adjusted Life-years for 32 Cancer Groups, 1990 to 2015: A Systematic Analysis for the Global Burden of Disease Study. JAMA Oncol. 2016.

6. Hanahan D, Weinberg RA. Hallmarks of cancer: the next generation. Cell. 2011;144(5):646-674.

7. Opelz G, Dohler B. Effect of human leukocyte antigen compatibility on kidney graft survival: comparative analysis of two decades. Transplantation. 2007;84(2):137-143.

8. Duquesnoy RJ. Antibody-reactive epitope determination with HLAMatchmaker and its clinical applications. Tissue Antigens. 2011;77(6):525-534.

9. Duquesnoy RJ. Human leukocyte antigen epitope antigenicity and immunogenicity. Curr Opin Organ Transplant. 2014;19(4):428-435.

10. Geneugelijk K, Spierings E. Predicting alloreactivity in transplantation. J Immunol Res. 2014;2014:159479.

11. Otten HG, Calis JJ, Kesmir C, van Zuilen AD, Spierings E. Predicted indirectly recognizable HLA epitopes presented by HLA-DR correlate with the de novo development of donor-specific HLA IgG antibodies after kidney transplantation. Hum Immunol. 2013;74(3):290-296.

12. Bowman JM. RhD hemolytic disease of the newborn. N Engl J Med. 1998;339(24):1775-1777.

13. Stevens LA, Coresh J, Greene T, Levey AS. Assessing kidney function--measured and estimated glomerular filtration rate. N Engl J Med. 2006;354(23):2473-2483.

14. Bonventre JV, Vaidya VS, Schmouder R, Feig P, Dieterle F. Next-generation biomarkers for detecting kidney toxicity. Nat Biotechnol. 2010;28(5):436-440.

15. Golden EB, Chhabra A, Chachoua A, et al. Local radiotherapy and granulocyte-macrophage colony-stimulating factor to generate abscopal responses in patients with metastatic solid tumours: a proof-of-principle trial. Lancet Oncol. 2015;16(7):795-803.

16. Postow MA, Callahan MK, Barker CA, et al. Immunologic correlates of the abscopal effect in a patient with melanoma. N Engl J Med. 2012;366(10):925-931.

17. Demaria S, Ng B, Devitt ML, et al. lonizing radiation inhibition of distant untreated tumors (abscopal effect) is immune mediated. Int J Radiat Oncol Biol Phys. 2004;58(3):862-870.

18. Dewan $\mathrm{MZ}$, Kawashima $\mathrm{N}$, et al. Fractionated but not single-dose radiotherapy induces an immune-mediated abscopal effect when combined with anti-CTLA-4 antibody. Clin Cancer Res. 2009;15(17):5379-5388.

19. Melero I, Berman DM, Aznar MA, Korman AJ, Perez Gracia JL, Haanen J. Evolving synergistic combinations of targeted immunotherapies to combat cancer. Nat Rev Cancer. 2015;15(8):457-472.

20. Sarantopoulos S, Ritz J. Aberrant B-cell homeostasis in chronic GVHD. Blood. 2015;125(11):1703-1707. 



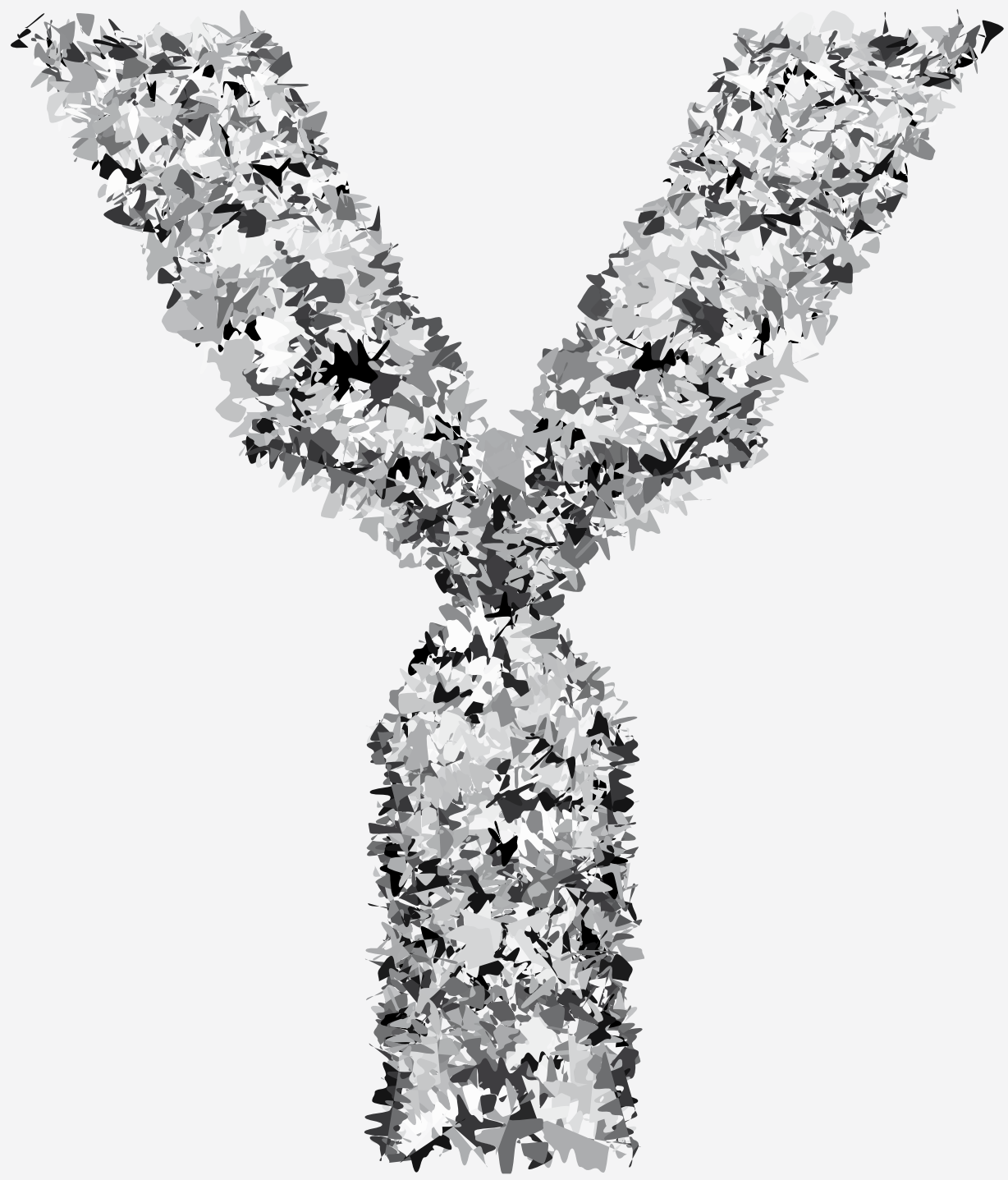




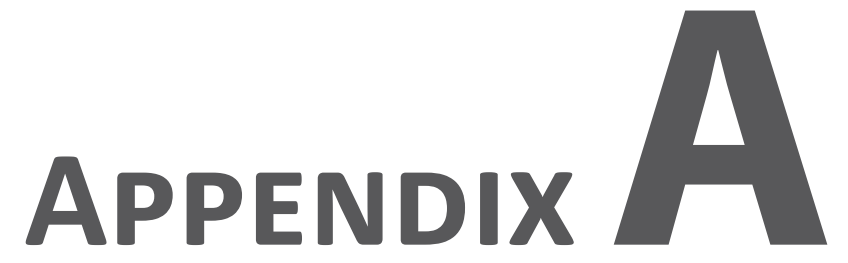

List of abbreviations 


\section{Appendix A}

7-AAD

$\alpha$

ADCC

AID

AMR

APC

APC

ATG

B2-M

BCR

Breg

BSA

$C$

CBA

CD

CDC

CDC

CDR

CFSE

cGVHD

CKD

COPD

CpG ODN

CRP

CSR

CTL

CTLA-4

DAMP

DBD

$\mathrm{DC}$

DCD

DGF

DMSO 7-aminoactinomycin D

anti

antibody-dependent cell-mediated cytotoxicity

activation-induced cytidine deaminase

antibody-mediated rejection

allophycocyanin

antigen-presenting cell

anti-thymocyte globulin

beta2-microglobulin

$B$ cell receptor

regulatory $B$ cell

bovine serum albumin

constant (domain)

cytometric bead assay

cluster of differentiation

complement-dependent cytotoxicity

conventional DC

complementarity-determining regions

carboxyfluorescein succinimidyl ester

chronic graft-versus-host disease

chronic kidney disease

chronic obstructive pulmonary disease

CpG oligodeoxynucleotides

C-reactive protein

class switch recombination

cytotoxic T Iymphocyte

cytotoxic T lymphocyte-associated protein 4

damage-associated molecular pattern

donation after brain death

dendritic cell

donation after cardiac death

delayed graft function

dimethyl sulfoxide 


\begin{tabular}{|c|c|}
\hline DSA & donor HLA-specific antibodies \\
\hline eGFR & estimated glomerular filtration rate \\
\hline ELISA & enzyme-linked immunosorbent assay \\
\hline ESRD & end-stage renal disease \\
\hline FC & flow cytometry \\
\hline FcR & Fc receptor \\
\hline FCS & fetal calf serum \\
\hline FITC & fluorescein isothiocyanate \\
\hline Flt3-L & FMS-like tyrosine kinase 3 ligand \\
\hline FMAIT & fetal-maternal alloimmune thrombocytopenia \\
\hline FSC & forward scatter \\
\hline GAPDH & glyceraldehyde 3-phosphate dehydrogenase \\
\hline GC & germinal center \\
\hline GFR & glomerular filtration rate \\
\hline GM-CSF & granulocyte-macrophage colony-stimulating factor \\
\hline GVHD & graft-versus-host disease \\
\hline Gy & gray \\
\hline $\mathrm{H}$ & heavy (chain) \\
\hline HDFN & hemolytic disease of the fetus and newborn \\
\hline HLA & human leukocyte antigen \\
\hline HPA & human platelet antigen \\
\hline HRP & horseradish peroxidase \\
\hline HSC & hematopoietic stem cell \\
\hline $\mathrm{HSCT}$ & hematopoietic stem cell transplantation \\
\hline HuPo & human acidic ribosomal protein \\
\hline ICD & immunogenic cell death \\
\hline iDC & immature DC \\
\hline IFN & interferon \\
\hline $\lg$ & immunoglobulin \\
\hline IGF & immediate graft function \\
\hline $\mathrm{IHC}$ & immunohistochemistry \\
\hline IL & interleukin \\
\hline IT & immunotherapy \\
\hline
\end{tabular}




\section{Appendix A}

\begin{tabular}{|c|c|}
\hline JAK & Janus kinase \\
\hline K & kappa \\
\hline kDa & kilodalton \\
\hline$\lambda$ & lambda \\
\hline $\mathrm{L}$ & light (chain) \\
\hline LSA & Luminex single antigen \\
\hline $\mathrm{mAB}$ & monoclonal antibody \\
\hline $\mathrm{mDC}$ & mature DC \\
\hline MDRD & modification of diet in renal disease \\
\hline MDSC & myeloid-derived suppressor cell \\
\hline MESF & molecules of equivalent soluble fluorochromes \\
\hline $\mathrm{MFI}$ & mean fluorescent intensity \\
\hline $\mathrm{MHC}$ & major histocompatibility complex \\
\hline MM & multiple myeloma \\
\hline MMF & mycophenolic acid \\
\hline mRNA & messenger RNA \\
\hline NAIT & neonatal alloimmune thrombocytopenia \\
\hline NK & natural killer \\
\hline OR & odds ratio \\
\hline PBMC & peripheral blood mononuclear cell \\
\hline PBS & phosphate buffered saline \\
\hline PCR & polymerase chain reaction \\
\hline PD-1 & programmed cell death protein 1 \\
\hline PD-L1 & programmed death-ligand 1 \\
\hline $\mathrm{pDC}$ & plasmacytoid DC \\
\hline$P E$ & phycoerythrin \\
\hline PerCp & peridinin chlorophyll protein complex \\
\hline post & after \\
\hline PRA & panel reactive antibodies \\
\hline pre & before \\
\hline PTEC & proximal tubular epithelial cell \\
\hline Q-PCR & quantitative PCR \\
\hline & rheumatic arthritis \\
\hline
\end{tabular}


RAG

$\mathrm{RBC}$

RhD

RNA

RT

SBT

$\mathrm{SCr}$

SD

SEM

sFLC Ig

SHM

SLE

SPA

SSC

STAT

TAA

TAM

TBA

TCR

TD

Th

TI

TIB

TIL

TLR

TNF

TR

Treg

Tx

$\mathrm{V}$

VDJ recombination-activating gene

red blood cell

Rhesus D-antigen

ribonucleic acid

radiotherapy

sequence based typing

serum creatinine

standard deviation

standard error of the mean

serum free light chain immunoglobulin

somatic hypermutation

systemic lupus erythematous

solid phase assay

sideward scatter

signal transducer and activator of transcription

tumour-associated antigens

tumour-associated macrophage

tumour binding antibody

T cell receptor

thymus-dependent

Thelper

thymus-independent

tumour-infiltrating B cell

tumour-infiltrating lymphocyte

toll-like receptor

tumour necrosis factor

transitional

regulatory $T$ cell

transplantation

variable (domain)

V (variable) D (diversity) J (joining) 


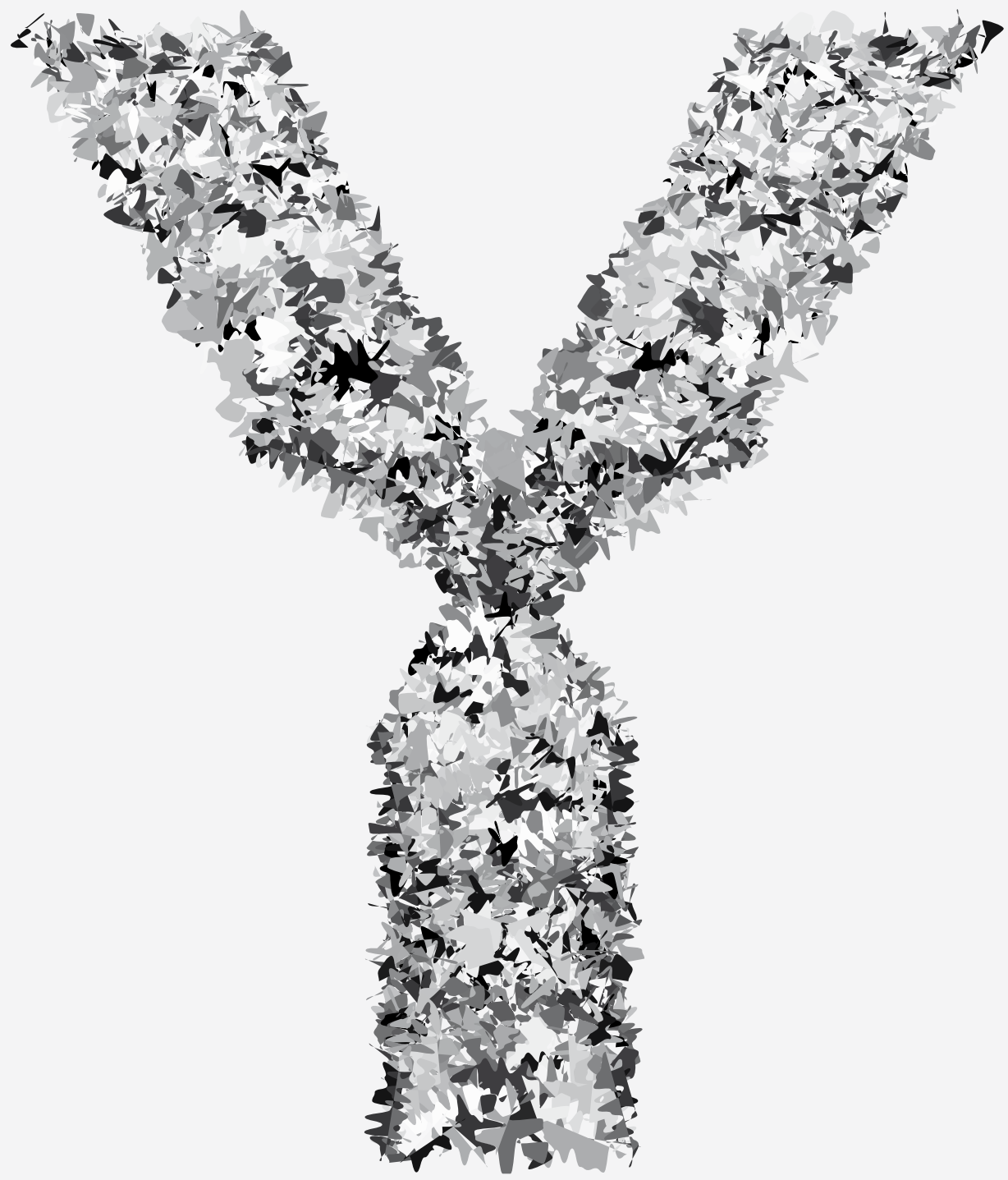




\section{APPENDIX}

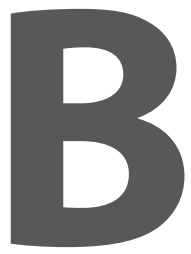

Acknowledgements

Dankwoord 

'Vele wegen leiden naar Rome' in combinatie met steile bergen en diepe dalen, die elkaar per maand, minuut of seconde volgen, hebben dit proefschrift tot stand gebracht. Ik wil alle collega's, vrienden en familie ontzettend bedanken voor alle hulp tijdens dit promotietraject.

Eerst wil ik het promotieteam bestaande uit Prof. dr. Gerard M.J. Bos, Prof. dr. Marcel G.J. Tilanus en dr. Joris Vanderlocht warmhartig bedanken. Gerard, je had altijd een zeer goed overzicht (de rode lijn) over alle projecten. Vooral het fundament van elk onderzoek: probleem, vraag, methode, resultaat, en conclusie zorgde voor een duidelijk doel en voorkwam te veel 'bijzaken'. De mogelijkheid om mijn promotietraject bij jullie te mogen uitvoeren, je gerichte kritische blik, alsmede het gelijk trekken van de projecten over de twee afdelingen heb ik zeer gewaardeerd. Marcel, ik wil je bedanken dat ik ook bij jullie op het laboratorium mijn promotietraject mocht uitvoeren. Vooral het aanmoedigen van het presenteren van mijn onderzoek op veel congressen in Nederland, maar ook in Stockholm (Zweden) en Denver (Colorado, USA) heb ik zeer gewaardeerd. Je interessante wijze van het letten op 'een te hoge borst opzetten', alsmede 'het niet te veel gebruik maken van animaties' heeft mijn scherpheid op hoger pijl gebracht.

Beste Joris, ten eerste heb je de uitzonderlijke gave om iemand in een miniem moment maximaal te motiveren. Dat heeft mij altijd moed gegeven om verschillende 'moeilijke' kwesties te overwinnen. Ik leerde je kennen als mede-supervisor tijdens mijn senior stage (master) waarbij je mij de kernwaarden van fundamenteel onderzoek hebt bijgeleerd. We hebben hier een heel mooi resultaat bewerkstelligd met behulp van een 'zeer' uitgebreide optimalisatie van onze onderzoeksmethodes. Hierbij aansluitend, de kracht van je begeleiding was 'optimalisatie' van alle assays, immers 'de sterkte van de ketting wordt bepaald door de zwakste schakel'. In de maanden na mijn master stage heb ik de mogelijkheid gekregen met jou aan het HLA-DRB3 en het vrij lichte keten (sFLC Ig) project te werken als pre-PhD student. Het 'daadwerkelijke' promoveren begon vanaf april 2013, waarbij we verder gingen met de 'grotere' projecten omtrent het abscopal effect, de rol van HLA-DRB3 antilichamen en de vrij lichte ketens. Zoals ik dit dankwoord begin, hebben we mogen ervaren dat we pieken en dalen hebben gehad tijdens deze uitdagende projecten. Tijdens het promotietraject hebben we lange meetings gehad, maar ook onze bekende 'micro-meetings' van 5 tot 10 minuten, waarbij we altijd snel eens waren over de koers. Ik heb al deze meetings als zeer plezierig en productief ervaren. Tijdens je opleiding tot medisch immunoloog in combinatie met stages 


\section{Appendix B}

in binnenland en buitenland, alsmede je resterende werkzaamheden bij weefseltypering, hebben we ook minder contact gehad. Ik wil hierbij vermelden dat ik het altijd zeer op prijs heb gesteld en het ook bewonderingwaardig vind dat je tijdens al deze werkzaamheden, en natuurlijk niet te vergeten je gezin, toch nog tijd had mij te begeleiden. Ik wil je ontzettend bedanken voor al je hulp, steun, waardevolle inbreng, enthousiasme, veel kennis en motivatie tijdens mijn gehele promotieonderzoek. Tenslotte wens ik je een geweldige tijd met je vrouw en jullie drie dochters.

Ik wil de leden van de beoordelingscommissie bestaande uit Prof. dr. Marc H.V. de Baets (voorzitter), Prof. dr. Karel M.L. Leunissen, Prof. dr. Boris W.W. Kramer, Prof. dr. Niels Hellings, en dr. Henny Otten alsmede de leden van de corona hartelijk danken voor het lezen, beoordelen en het positieve oordeel van dit proefschrift.

Vanzelfsprekend wil ik alle collega's van het hematologie laboratorium (UM) bedanken: Wilfred, Birgit, Ans, Tammy, Mirelle, Subhashis, Melanie, Niken, Silvie, Michel, Monique, Ariane, Mateusz en Prof. dr. H. Schouten. Wilfred, ik wil jou bedanken dat jij mij de mogelijkheid hebt gegeven mijn senior stage (master) in jullie laboratorium uit te voeren. Verder had je altijd tijd en inbreng voor de projecten, met name het abscopal effect. Ik heb ook altijd genoten van onze gesprekken over mijn passie fotografie. Birgit, het abscopal effect project was een uitdaging voor ons. Wij zijn begonnen met het onderzoeken van de antilichaam respons gericht tegen tumorcellen in een muis model. Ik wil je bedanken voor de begeleiding, tips en al je kennis van de FACS. Tammy, thanks for all your novel ideas, troubleshooting, helping me in various projects, reordering my desk, and especially your sociability! Mirelle, je had altijd een scherpe inbreng in projecten en ik wil je bedanken voor je gezelligheid op het laboratorium. Subhashis, I was really honored to be your paranimph, it was always exciting at our room and I liked your explicit choice of music. Furthermore, I really enjoyed the time at your wedding in Kolkata, India. Maybe we will meet again in the Netherlands! Niken, you were always enthusiastic and helpful during many micro-meetings at our room, I wish you good luck to finish your PhD! Ans, ik wil je bedanken voor je hulp met het abscopal effect project. Melanie (PCR-expert), we hebben gelachen over allerlei zaken, maar ik wil je vooral bedanken voor je technische bijdrage in diverse projecten. Verder wil ik Silvie, Ariane en Mateusz bedanken voor jullie inbreng en discussies in het laboratorium. Tenslotte wil ik Michel en Monique bedanken voor jullie inzichten tijdens de werkbesprekingen. 
Alsmede wil ik alle collega's van het weefseltypering laboratorium (azM) bedanken en in het bijzonder: Kevin, Stefan, Jacqueline, Nina, Esther, Simone, Fabienne, Annette, Coline, Maud, Els, Timo, Mathijs, Christien, Lotte, Diana en Audrey. De 'andere kant' werd het genoemd bij hematologie. Ik heb dan ook de nodige kilometers afgelegd om van mijn kamer op de UM naar het weefseltypering laboratorium te lopen, maar altijd met groot genoegen! Kevin, als mede PhD student weet je als geen ander hoe de baan 'promoveren' eruitziet. Ik heb het altijd uitzonderlijk prettig gevonden veel kwesties te delen en te bediscussiëren tijdens onze 'vaste' $\left(-5^{\circ} \mathrm{C}\right.$ tot $\left.35^{\circ} \mathrm{C}\right)$ wandeling in de lunchpauze. Tevens waren onze reizen naar Denver (Colorado, USA) en India een mooie ervaring. Ik wens je veel succes met je huidige baan bij Immucor! Stefan, je enthousiasme voor het sFLC Ig project was voor mij altijd een grote steun in het afronden van dit hoofdstuk (4). Je was zeer gedreven, had veel interesse en kundigheid, en hielp mij met het uitvoeren van de experimenten. Hier wil ik je enorm voor bedanken! Jacqueline, ik wil je bedanken voor de assistentie bij het HLA-DRB3 project, alsmede je inzet bij verzoeken gedurende mijn promotietraject. Nina, ik wil je bedanken voor je hulp, inzichten en gezelligheid. Natuurlijk wil ik de 'prikdienst' bestaande uit Annette, Coline, Jeroen en Fabienne bedanken voor jullie snelle inzet om aanmerkelijke hoeveelheden bloed af te nemen bij alle vrijwillige donoren. Zonder de assistentie van Esther, Maud, Simone, Els, Filiz, Christel, Ilse, Fausto, Sandra, Marjolijn en alle andere analisten had ik alle gegevens en monsters nooit zo snel en vlekkeloos bij elkaar kunnen krijgen. Verder wil ik alle stafleden en leden van het wetenschappelijk 'TIM' team Mathijs, Timo, Christien, Lotte en Jennifer bedanken voor jullie inbreng in mijn projecten. Tenslotte wil ik Diana, Audrey en Mieke bedanken voor jullie medewerking op het secretariaat.

Ik wil tevens alle donoren die zich vrijwilliger hebben aangemeld hartelijk bedanken voor het geven van bloed, zodat veel van de hoofdstukken in dit proefschrift tot stand zijn gekomen.

Niet te vergeten, mijn paranimfen Mark en Marijn. Mark, recentelijk PhD, kameraad van het leven, ik ken je al vanaf de bassischool. Ons pad naar de 'benaming' PhD heeft elkaar gevolgd vanaf de basisschool, middelbare school en bachelor MLW, maar hierna scheidde onze wegen in oncologie voor mij en neurowetenschappen voor jou. Tijdens ons promotietraject hebben we veel kennis over onze vakgebieden uitgewisseld. Het bespreken van allerlei zaken heeft mij altijd goed gedaan en ik wil je hierom heel erg bedanken. Deze periode kunnen we samen afsluiten als paranimf van elkaar te zijn en ik wil je heel veel succes wensen met je nieuwe 


\section{Appendix B}

baan in Adelaide, Australië. Marijn, roommate, met jou heb ik vooral in de laatste 'hevige' maanden van mijn promotie de voortgang kunnen relativeren. Je gaf me motivatie door over experimenten te praten, maar we hebben ook vaak in een deuk gelegen om de meest 'melige' onderwerpen. Immers 'lachen maakt je gelukkig en zelfverzekerd'! Bedankt voor je steun en de mogelijkheid om paranimf bij mijn promotie te zijn. Ik wil je succes wensen met je baan bij CiMaas BV en ik hoop je nog vaak te mogen treffen.

Verder wil ik alle coauteurs bedanken die hebben bijgedragen bij de verschillende artikels. Met name Maarten, Tim, Yvonne, Ron, Bouke, Laura, Niels, Jan en Frank. Maarten, bedankt voor je scherpe blik en de kritische besprekingen over de presentaties en hoofdstukken. Tim, je was altijd enthousiast over de resultaten en bedankt voor je hulp en inbreng. Yvonne en Ron, bedankt voor jullie bijdrage aan het RhD hoofdstuk (2). Het team uit Groningen bestaande uit Bouke, Laura en Niels wil ik bedanken voor hun gastvrij ontvangst in het laboratorium en jullie bijdrage aan het HLA-DRB3 hoofdstuk (3). Tenslotte Jan en Frank bedankt voor jullie goede blik en inbreng in de sFLC Ig artikels (hoofdstuk 4 en 7).

En vanzelfsprekend wil ik ook mijn familie en vrienden bedanken. Wouter, bedankt voor het helpen met het ontwerpen en inrichten van dit proefschrift. Ik wil Leon en Marlou bedanken, omdat jullie mij altijd hebben aangemoedigd om mijn doelen te bereiken. Alhoewel het een hele uitdaging was mijn exacte onderzoeken over te brengen, heeft dit mij ook geleerd mijn onderzoek in een breder perspectief te plaatsen. Verder wil ik Jos, Marion en Thomas bedanken voor jullie steun tijdens mijn promotietraject. Tenslotte wil ik mijn vriendengroep van de middelbare school en studievrienden van de universiteit bedanken voor hun support.

Sanne, je liefde, je optimisme en je steun heeft mij de afgelopen jaren ontzettend veel kracht gegeven om dit proefschrift af te maken. De laatste loodjes van mij waren 'bloed, zweet en tranen' en hierbij heb jij mij ongelooflijk goed bijgestaan. Ik wil je enorm bedanken voor je geduld, steun, interesse en vooral de ongekende motivatie die je mij telkens gaf tijdens mijn promotietraject. Ik hou van jou!

Ik sluit mijn dankwoord af met mijn twee oma's. Ik vind het een eer dat jullie, zijnde 92 en 93, aanwezig kunnen zijn bij het verdedigen van mijn promotieonderzoek en het behalen van de titel $\mathbf{D r}$ (PhD). 
‘Onmogelijke opdrachten voeren we direct uit, wonderen duren iets langer' 


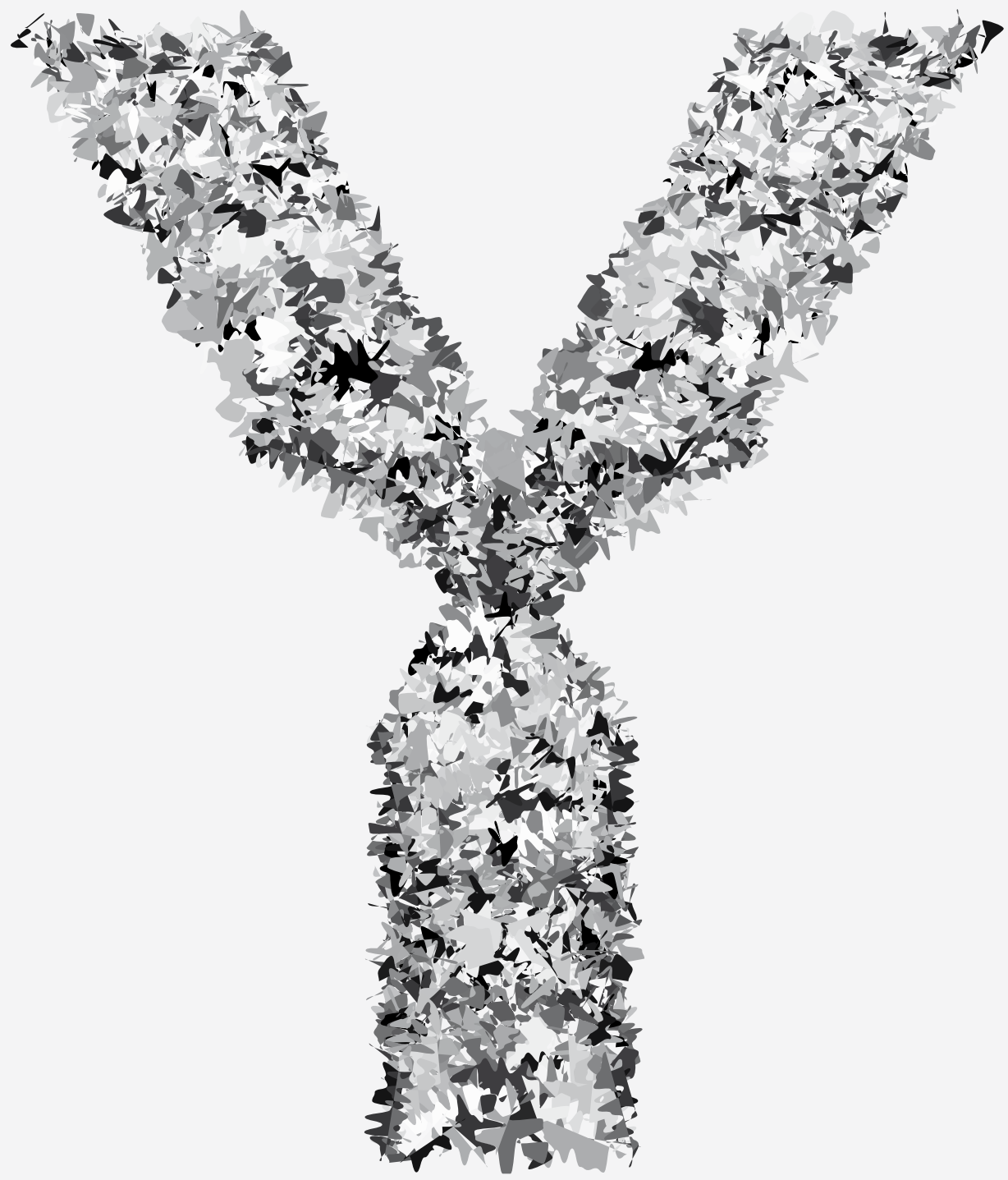




\section{APPENDIX}

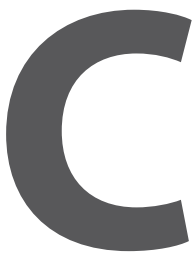

List of publications 



\section{PUBLICATIONS}

Fractionated radiotherapy with $\mathbf{3} \times \mathbf{8}$ Gy induces systemic anti-tumour responses and abscopal tumour inhibition without modulating the humoral anti-tumour response Thomas H.P.M. Habets, Tammy Oth, Ans W. Houben, Mirelle J.A.J. Huijskens, Birgit L.M.G. Senden-Gijsbers, Melanie C.A. Schnijderberg, Boudewijn Brans, Ludwig J. Dubois, Philippe Lambin, Marijke De Saint-Hubert, Wilfred T.V. Germeraad, Marcel G.J. Tilanus, Felix M. Mottaghy, Gerard M.J. Bos, Joris Vanderlocht

PLOS ONE. 2016 July 18; 11(7): e0159515

The development of Rhesus-D (RhD) antibodies after RhD incompatible kidney transplantation in a setting of reduced immunosuppression

Thomas H.P.M. Habets, Joris Vanderlocht, Ron J.M.H.E. Straat, Tim C. van Smaalen, Gerard M.J. Bos, Erik A. Beckers, Maarten H.L. Christiaans, Yvonne M.C. Henskens

Under revision

The JAK1 and JAK2 inhibitor ruxolitinib inhibits the activation and proliferation of polyclonally stimulated peripheral B cells

Thomas H.P.M. Habets, Melanie C.A. Schnijderberg, Michel van Gelder, Joris Vanderlocht, Gerard M.J. Bos

Submitted for publication

The dynamics of serum free light chain (sFLC) immunoglobulin (Ig) normalization after kidney transplantation

Thomas H.P.M. Habets, Stefan J.J. Molenbroeck, Tim C. van Smaalen, Christina E.M. Voorter, Jan Damoiseaux, Gerard M.J. Bos, Frank A. Redegeld, Maarten H.L. Christiaans, Marcel G.J. Tilanus, Joris Vanderlocht

Submitted for publication

Serum free light chain immunoglobulins ( $\mathrm{FFLC} \mathrm{Igs)} \mathrm{do} \mathrm{not} \mathrm{modulate} \mathrm{the} \mathrm{activation} \mathrm{and}$ proliferation of polyclonally stimulated $B$ cells and T cells

Thomas H.P.M. Habets, Melanie C.A. Schnijderberg, Jan Damoiseaux, Frank A. Redegeld, Marcel G.J. Tilanus, Joris Vanderlocht, Gerard M.J. Bos

Submitted for publication 
Appendix C

Pathogen recognition by NK cells amplifies the pro-inflammatory cytokine production of monocyte-derived DC via IFN- $\gamma$ but not TNF- $\alpha$

Tammy Oth, Thomas H.P.M. Habets, Wilfred T.V. Germeraad, Marijke I. Zonneveld, Gerard M.J. Bos, Joris Vanderlocht

Submitted for publication

The prevalence of antibodies against the HLA-DRB3 protein in kidney transplantation and the correlation with HLA expression

Thomas H.P.M. Habets, Bouke G. Hepkema, Niels Koupri, Melanie C.A. Schnijderberg, Tim C. van Smaalen, Laura B. Bungener, Maarten H.L. Christiaans, Christina E.M. Voorter, Gerard M.J. Bos, Marcel G.J. Tilanus, Joris Vanderlocht

In preparation

\section{CONFERENCES}

The prevalence of antibodies against the HLA-DRB3 protein in kidney transplantation and the correlation with HLA expression

Thomas H.P.M. Habets, Bouke G. Hepkema, Niels Koupri, Melanie C.A. Schnijderberg, Tim C. van Smaalen, Laura B. Bungener, Maarten H.L. Christiaans, Christina E.M. Voorter, Gerard M.J. Bos, Marcel G.J. Tilanus, Joris Vanderlocht

Oral: 2014, ASHI Conference, Denver, Colorado, USA

Oral: 2013, EFI Summer School, Best Presentation Award, Joris Vanderlocht, Sardinia, Italy Oral: 2013, EFI Conference, Maastricht, the Netherlands

Oral: 2013, NTV Bootcongres, Duiven, the Netherlands

Fractionated radiotherapy with $3 \times 8$ Gy induces systemic anti-tumour responses and abscopal tumour inhibition without modulating the humoral anti-tumour response

Thomas H.P.M. Habets, Tammy Oth, Ans W. Houben, Mirelle J.A.J. Huijskens, Birgit L.M.G. Senden-Gijsbers, Melanie C.A. Schnijderberg, Boudewijn Brans, Ludwig J. Dubois, Philippe Lambin, Marijke De Saint-Hubert, Wilfred T.V. Germeraad, Marcel G.J. Tilanus, Felix M. Mottaghy, Gerard M.J. Bos, Joris Vanderlocht

Oral: 2013, EFI Conference, Maastricht, the Netherlands

Poster: 2013, NVVI Conference, Noordwijkerhout, the Netherlands 
The dynamics of serum free light chain (sFLC) immunoglobulin (Ig) normalization after kidney transplantation

Thomas H.P.M. Habets, Stefan J.J. Molenbroeck, Tim C. van Smaalen, Christina E.M. Voorter, Jan Damoiseaux, Gerard M.J. Bos, Frank A. Redegeld, Maarten H.L. Christiaans, Marcel G.J. Tilanus, Joris Vanderlocht

Oral: 2014, ASHI Conference, Denver, Colorado, USA

Poster: 2014, EFI Conference, Stockholm, Sweden

Identification of a link between the immunodominance of different HLA class II epitopes and their structural location in the molecule

Thomas H.P.M. Habets, Joris Vanderlocht, Mathijs Groeneweg, Christina E.M. Voorter, Gerard M.J. Bos, Maarten H.L. Christiaans, Marcel G.J. Tilanus

Poster: 2013, NTV Bootcongres, Leiden, the Netherlands

The influence of immune suppressive medication on human DC-induced CD4+ T cell polarization in an autologous setting

Tammy Oth, Thomas H.P.M. Habets, Melanie C.A. Schnijderberg, Birgit L.M.G. SendenGijsbers, Maarten H.L. Christiaans, Wilfred T.V. Germeraad, Marcel G.J. Tilanus, Gerard M.J. Bos, Joris Vanderlocht

Poster: 2013, EFI Conference, Best Poster Award, Maastricht, the Netherlands

Poster: 2013, NVVI Conference, Noordwijkerhout, the Netherlands 


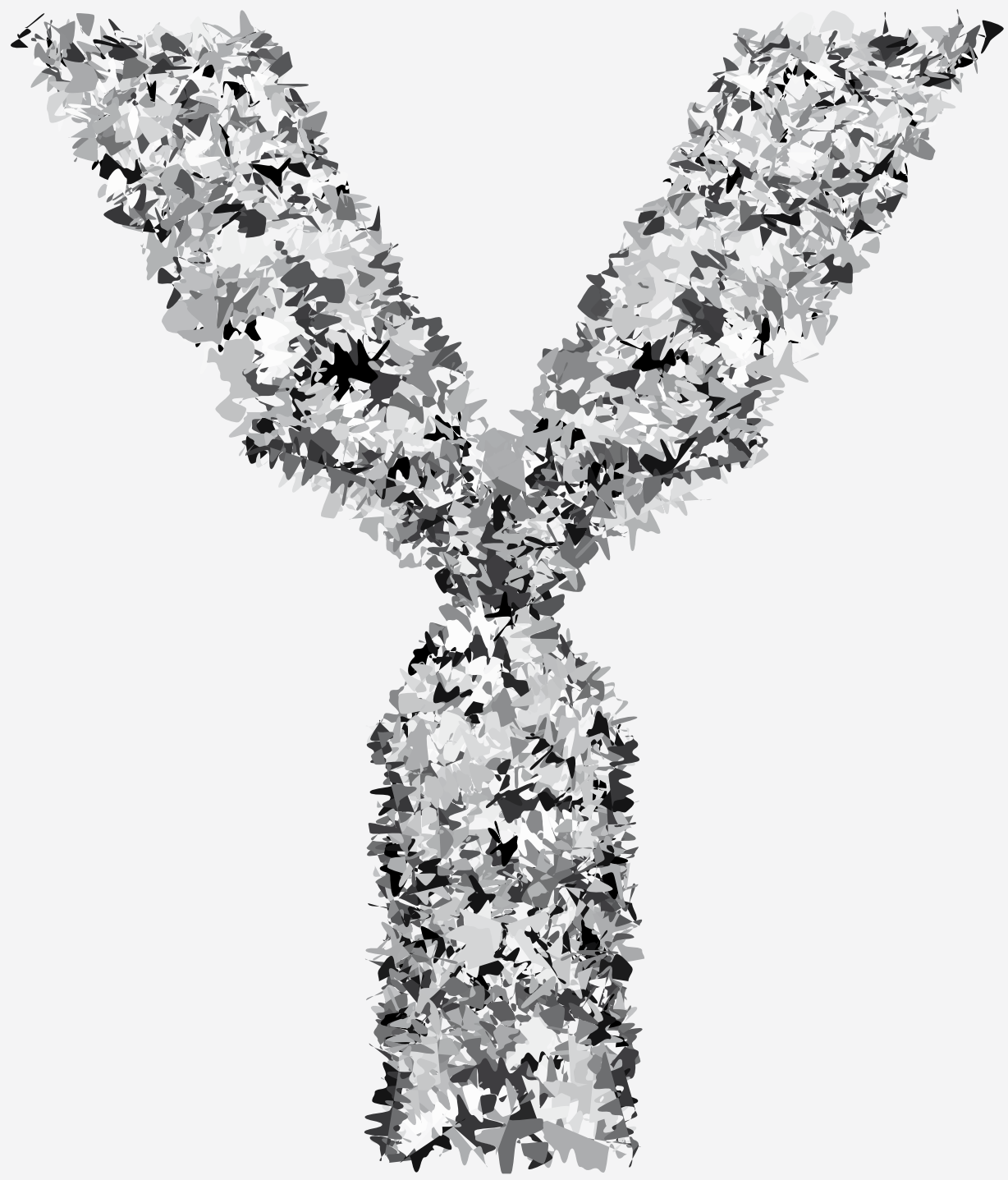




\section{APPENDIX}

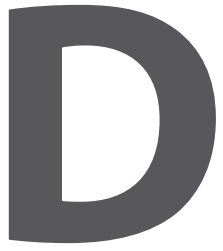

Curriculum vitae 

Thomas Henricus Petrus Maria (T.H.P.M.) Habets was born on September $11^{\text {th }}, 1988$ in Maastricht, the Netherlands. He grew up in Maastricht and went to the elementary school in Scharn. After finishing his secondary school in 2007 at Sint-Maartens College in Maastricht, he continued his education at Maastricht University obtaining Bachelor of Science in Molecular Life Sciences. Subsequently, Thomas studied the master Molecular Life Sciences (Specialization in Oncology and Developmental Biology) at Maastricht University. He performed his senior internship at the department of Hematology (Internal Medicine) of Prof. dr. Gerard Bos at the MUMC+ in Maastricht. After obtaining his master degree in 2012, Thomas performed several research projects at the department of Tissue Typing (Transplantation Immunology) of Prof. dr. Marcel Tilanus at the MUMC+. Afterwards, he started his doctoral research within GROW, School for Oncology and Developmental Biology, at the departments of Hematology (Internal Medicine) and Tissue Typing Laboratory (Transplantation Immunology) at the MUMC+ under the supervision of Prof. dr. Gerard Bos, Prof. dr. Marcel Tilanus, and Dr. Joris Vanderlocht. The results of this research period are described in this thesis.

Thomas Henricus Petrus Maria (T.H.P.M.) Habets werd geboren op 11 september 1988 te Maastricht. Hij bracht zijn gehele jeugd door in Maastricht en ging naar de basisschool in Scharn. Na het behalen van zijn VWO diploma in 2007 aan het Sint-Maartens College te Maastricht, vervolgde hij zijn opleiding met de bachelor Moleculaire Levenswetenschappen aan de Universiteit van Maastricht. Aansluitend is hij de master Molecular Life Sciences richting Oncology and Developmental Biology gaan studeren aan de Universiteit van Maastricht. Tijdens zijn afstudeerstage heeft hij zijn onderzoek uitgevoerd in het laboratorium van Hematologie (Interne Geneeskunde) van Prof. dr. Gerard Bos aan het MUMC+ in Maastricht. $\mathrm{Na}$ het behalen van zijn master in 2012 is Thomas gestart als onderzoeksmedewerker bij het laboratorium van Weefseltypering (Transplantatie Immunologie) van Prof. dr. Marcel Tilanus aan het MUMC+. Hierna is hij begonnen met zijn promotieonderzoek bij GROW, School for Oncology and Developmental Biology, op de afdelingen Hematologie (Interne Geneeskunde) en Weefseltypering (Transplantatie Immunologie) aan het MUMC+ onder begeleiding van Prof. dr. Gerard Bos, Prof. dr. Marcel Tilanus en Dr. Joris Vanderlocht. De resultaten van dit promotieonderzoek zijn beschreven in dit proefschrift. 


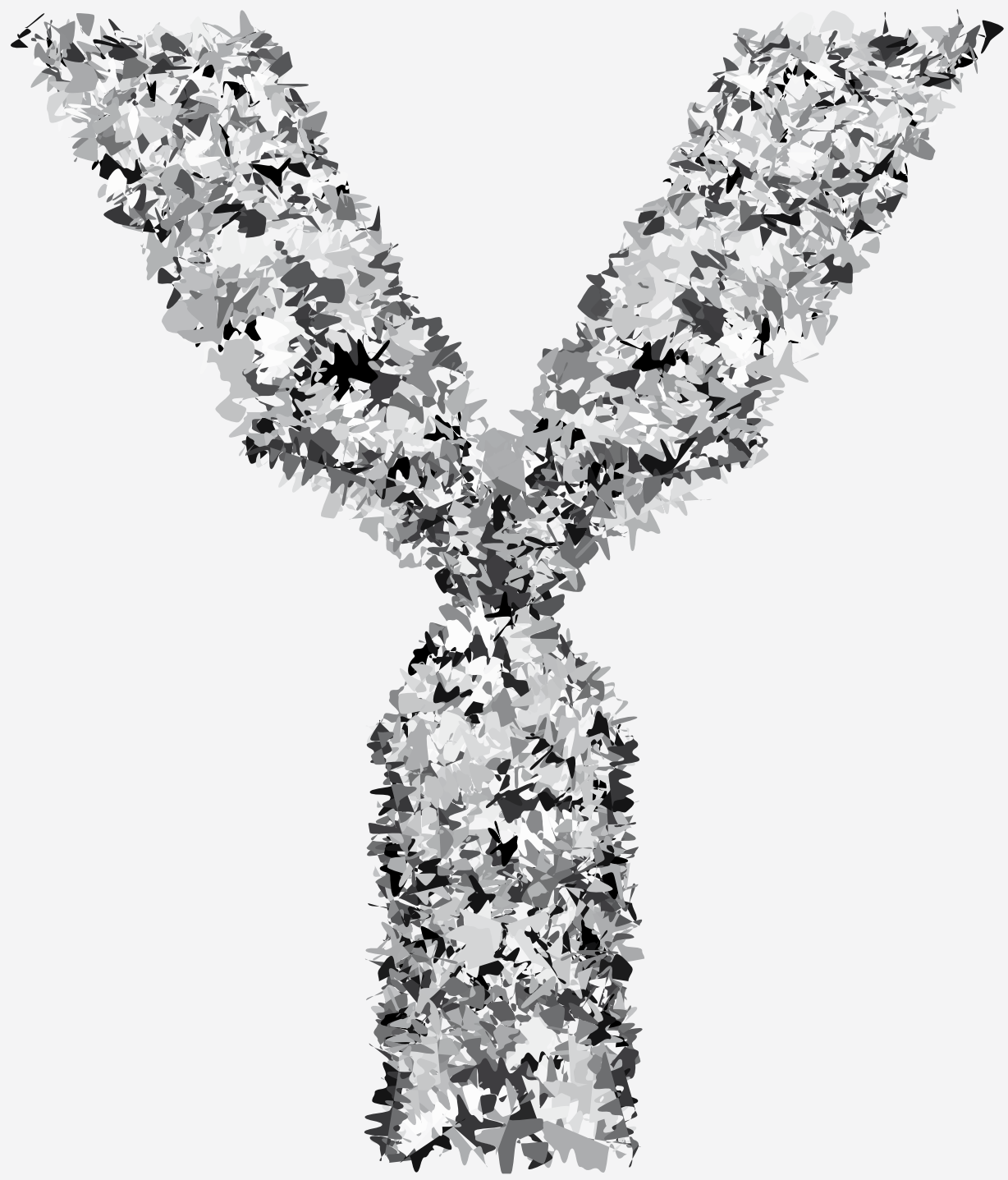




\section{APPENDIX}

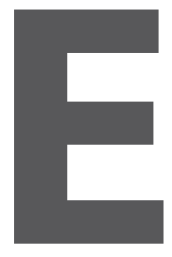

Notes 

